The International Journal of Screendance FALL 2013 - VOlume three
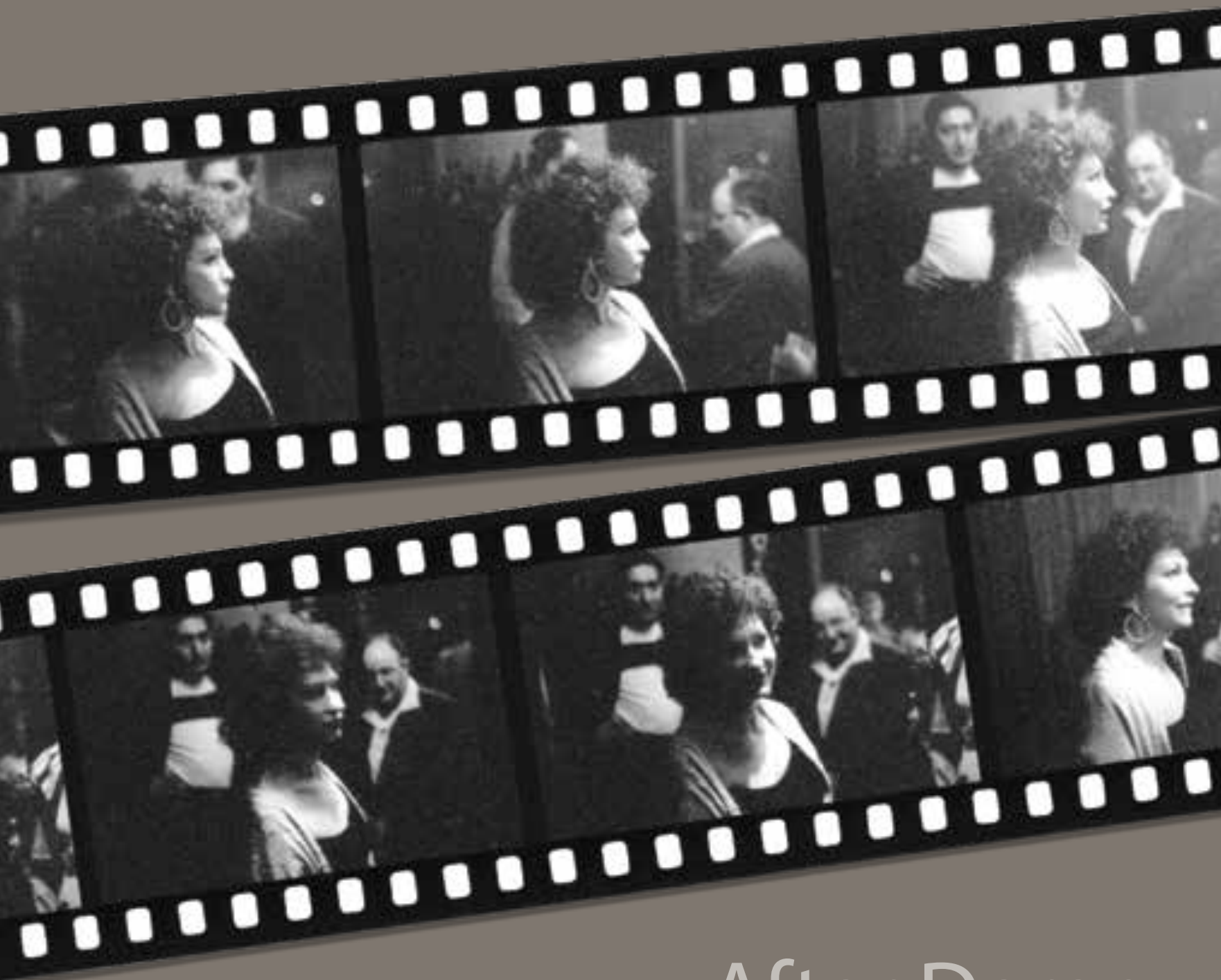

After Deren 


\section{The International Journal of Screendance}

FALL 2013 • VOLUME 3

ISSN 2154-6878

\section{EDITORS}

Douglas Rosenberg and Claudia Kappenberg

\section{GUEST EDITOR}

Elinor Cleghorn

\section{EDITORIAL ASSISTANT}

Nathan Jandl 



\section{THE INTERNATIONAL JOURNAL OF SCREENDANCE EDITORIAL BOARD}

\section{DR. ANN COOPER ALBRIGHT}

Professor of Theater and Dance

Oberlin College

\section{ELLEN BROMBERG}

Associate Professor, Department of Modern Dance

University of Utah

\section{DR. HARMONY BENCH}

Assistant Professor, Dance Department

Ohio State University

\section{DR. SIMON ELLIS}

Reader (Practice-based)

Roehampton University

\section{DR. FRANK GRAY}

Director of Screen Archive South East (SASE)

University of Brighton

\section{CLAUDIA KAPPENBERG}

Principal Lecturer, Performance and Visual Art;

School of Arts and Media

University of Brighton

\section{MIRANDA PENNELL}

Independent film and video artist

London, UK

\section{DOUGLAS ROSENBERG}

Professor of Art, Department of Art

University of Wisconsin-Madison

\section{DR. THERON SCHMIDT}

Lecturer in Theatre and Liberal Arts

King's College London

\section{SILVINA SZPERLING}

Director, Internacional Festival de Videodanza

Buenos Aires, Argentina

\section{DR. SARAH WHATLEY}

Professor of Dance

Coventry School of Art and Design

Coventry University

\section{MARISA ZANOTTI}

Senior Lecturer Dance

University of Chichester 


\section{Cover and Publication Design}

Barry Roal Carlsen, University Marketing, University of Wisconsin-Madison

\section{Cover Image}

Maya Deren Collection at the Howard Gotlieb Archival Research Centre, Boston University

\section{The International Journal of Screedance}

ISSN 2154-6878

Parallel Press

University of Wisconsin-Madison Libraries

Madison, Wisconsin

http://parallelpress.library.wisc.edu

Website: journals.library.wisc.edu/screendance

Email: screendance@gmail.com 


\section{Table of Contents}

1 Editorial: After Deren

Claudia Kappenberg and Douglas Rosenberg

6 Maya Deren: A Prologue

Harmony Bench

12 Thresholds to the Imaginary

Lucy Reynolds

22 If I can't dance, it's not my revolution!: Tracing the Revolutions of Maya Deren's Dance in Jane Campion's In the Cut

Sophia Mayer

38 On Collaboration and Interdisciplinarity: Meshes of the Afternoon

Andrew James

53 Pas de deux for Dancer and Camera in Maya Deren's Films

Sarah Keller

61 Art is Energy: Barbara Hammer Speaks with Sarah Keller about the State of Experimental Cinema after Maya Deren

Barbara Hammer

72 Ritual in Transfigured Time: Narcisa Hirsch, Sufi Poetry, Ecstatic Dances, and the Female Gaze

Silvina Szperling

85 Seeing (Oneself) Looking Into the Camera: An Interview with Narcisa Hirsch Alejandra Torres

101 Film as Poetry

Claudia Kappenberg

120 Touching Sound: An Interview with Jayne Parker

Aura Satz

128 Review Essay: About Maya Deren's Sink

Eleni Tranouli

133 Review Essay: Writing on the What Matters Festival, 11-15 April 2012

Fiona Wright

140 Review Essay: Beach Party Animal

Marisa Zanotti

144 Review Essay: Dancing Bodies, Moving Images: An Exhibition of Installed Works at Summer Dancing, Coventry, UK, June 2012

Andrea Barzey and Polly Hudson

151 Review Essay: Screendance: Yes, And...

Karen Pearlman

159 Epilogue: After Deren

ElinorCleghorn

163 Contributors 



\section{EDITORIAL}

\section{After Deren}

\section{by Claudia Kappenberg and Douglas Rosenberg}

$\mathrm{T}$

here have been numerous books and articles written on Maya Deren, and of course Deren herself left us with an abundance of writing that serves as a metric for scholarship based on her film practice. Deren has been the object of much scrutiny and occupies a rarified position in the narrative of experimental film, though less has been written explicitly addressing her contributions to screendance. This issue is devoted to Maya Deren, which means that for the first time, Deren is viewed within the context of screendance as a genre, a methodology, and a practice. Indeed, this issue explores Deren in the context of Deren.

Maya Deren's orbit encompasses multiple spheres of influence and Deren herself often seems to appear in different guises or manifestations. There is the actual, historical Maya Deren, but also the utopian, perfected image of Maya Deren and the mythological Deren encouraged by both temporal distance and the re-imagining of her via digital culture itself. One sphere of influence derives from thinking about Deren as contemporary — the projection of Deren filtered through the lenses of feminist theory, film theory, Freudian analysis, and a host of other literary and cinematic tropes and devices, each of which contribute something to the multi-faceted crystalline figure we call Deren. The other is the lingering shadow of Deren as both a maker of films rich with visual references, and also as a passionate writer of lectures, essays, and diaries that offer clues about her process and the origins of her particular species of filmmaking.

Maya Deren (née Eleanora Derenkowskaia) is an uncontested pioneer of the American Avant-Garde, if not its "mother"; but how American was this avant-garde, and should we insert an "s" to signal multiple avant-gardes? Bill Nichols's introduction to Maya Deren and the American Avant-Garde (2001) begins with a biographical account of Deren's origins in Kiev (where she was born in 1917), and describes her emigration with her parents to the US in 1922 as they fled anti-Semitic pogroms. Deren become a naturalized citizen in 1928 and later immersed herself in a European émigré scene in Greenwich Village. Eventually she was joined by Czech photographer and filmmaker Alexander Hammid (Alexandr Hackenschmied) who came to the United States in 1942, twenty years after Deren. Just one year later they would make their first collaboration, Meshes of the Afternoon (1943).

Another figure in the New York émigré scene was Lithuanian poet, filmmaker, and art activist, Jonas Mekas. Mekas arrived in New York in 1950 from Germany, where he had lived for six years following his escape from his native Lithuania in 1944. In an interview for his 2012 exhibition in Cologne and London, he recalls that he could read English when he arrived in New York — he had read Hemingway_-but that he kept all his notes in Lithuanian until the mid-fifties, eventually writing his diaries in English by 1957. Publishing regularly 
on the new American experimental film, he quickly became a spokesperson, although his early writings vehemently criticized the American "film-poems" for being feeble, unintelligible, and lacking in meaning and moral stance.' In this early writing he particularly accuses Deren of intellectual formalism, revealing not only a patriarchal attitude but advocating a very different, improvisational approach to filmmaking. ${ }^{2}$

Radically changing his position, he began to advocate the new film and formulated, in 1960, the first manifesto of the New American Cinema Group, a public statement serving in part to identify the new group of filmmakers as American. ${ }^{3}$ However, this was no homogenous group and Maya Deren was conspicuously absent from his reviews - such as the extensive "Notes to the New American Cinema" from 1962. ${ }^{4}$ Discussing categories such as spontaneous street films, social engagement films, cinematic improvisation and the new documentary frontier, he praised above all "The Pure Poets of Cinema": Brakhage, Breer, and Marie Menken, the latter also a Lithuanian. ${ }^{5}$ Another significant figure of the experimental film scene, who, like Deren, didn't make it into the "Notes" from 1962, was Kenneth Anger, an American who was strongly influenced by the European avant-garde and in particular by the French filmmaker, artist, and poet, Jean Cocteau. Anger shot his seminal film Rabbit Moon in Paris in 1950 thanks to the support of the Cinémateque Française, which furnished him with $35 \mathrm{~mm}$ film stock. ${ }^{6}$ Anger identified strongly with the European tradition; in an interview for the Guardian newspaper in 2010, he was asked if he knew what he was doing back in 1947 in Hollywood when he made the film Fireworks. He replied: "Well, I knew all about French Avant-garde, so I was the American Avantgarde."7 By contrast, Deren, whose work is so often associated with and read through a European lens of Surrealism and Freudian analysis, vehemently rejected these as points of reference for her films. Eventually, in 1963, Mekas published Imagism in four Avant-Garde Films, discussing both Deren's Choreography for Camera as well as Anger's Eaux d'Artifice. ${ }^{8}$ For the essay Mekas took inspiration from a reference that filmmaker Stan Brakhage had made to the Imagists's concept of the image as central motivation for poetry, which Mekas thought to apply to avant-garde film in general. Deren had of course written her MA thesis on the Imagists back in 1939 and their ideas had been key to the theorization of avant-garde film which she developed in the 40s and 50s. ${ }^{9}$ Mekas' essay of 1963 could therefore be considered as an example of the slow, deferred and oblique uptake of Deren's critical oeuvre.

Given the ambivalence of the American filmmakers with regards to the earlier European films, the naming of the New American Cinema Group can be seen both as a reference to and a distinction from the European avant-garde. The latter was known, above all, as the French avant-garde, a name that was just as generalizing as it in turn had been led by a peripatetic group of artists such as the Romanian Tristan Tzara and the American immigrant Man Ray, the émigré Marcel Duchamp and the German Walter Benjamin.

The New American Cinema Group may well have been called the émigré Cinema Group, but its identification as an American film movement made strategic sense in allowing artists to signal differences and new beginnings. In reality, the group represented the continuity of a wide-ranging network full of intersecting lines that connected an international field of artists and practices that collectively demonstrated a desire to forge an identity as an autonomous cultural force. Still, at the same time, these filmmakers aspired to share European provenance with their counterparts. This is not dissimilar to, and perhaps 
reinforced by, the complexity of cinema as an art form, which was from the very outset a cross-disciplinary project, advanced by diverse disciplines and artists spread across different international locations.

This scenario of an internationally connected, multinational group of filmmakers who were exploring a medium that was not yet established as a medium for art constitutes the backdrop for this issue on Maya Deren and her legacy. A range of international voices have therefore been brought together to demonstrate the wide impact of Deren's work and the extensive migration of her ideas. The writers featured in this issue articulate questions from within a muddy yet vital zone of inter-, trans- and cross-disciplinary debates, offering readings of Deren's work while further opening up the field of possible references. Much like Nichols's Maya Deren and the American Avant-garde, which grew out of a conference at San Francisco State University in 1996, this issue of The International Journal of Screendance builds on a Deren season at the British Film Institute in London in 2011. Curated by Elinor Cleghorn as part of her PhD research into the relation between the body and technologies in early film practices, the conference demonstrated a significant interest in Deren's work from UK-based filmmakers and scholars. This was complemented by Claudia Kappenberg's visit to Buenos Aires and discussions on Maya Deren's influence in South America at the Festival Internacional de Videodanza, which suggested that an issue of the International Journal of Screendance devoted to Deren would be very relevant for the international readership. Finally, a retrospective in 2012 of the American filmmaker Barbara Hammer at Tate Modern (London, UK) and at the Jeu de Pomme (Paris, France) with a screening of Maya Deren's Sink suggested a further expansion of contemporary perspectives on Deren.

Besides inviting scholars from the global community to contribute to the issue, we also chose to profile three filmmakers - Jayne Parker from the UK, Narcisa Hirsch from Argentina, and Barbara Hammer from the US-in order to explore Deren's legacy in contemporary film practices. This focus on contemporary filmmakers was a deliberate choice in that film studies and histories are somewhat underrepresented in current discourses on screendance. On the other hand, and despite this focus on Deren's films as films, the essays in this issue speak across art forms and seek to articulate the hybrid nature of Deren's practice and its many different roots. As the debates at the British Film Institute provided the starting point for this issue, we invited the curator of the Deren season, Elinor Cleghorn, to be guest editor and to work with us on bringing together scholarly research and artists' points of view, historical perspectives, and contemporary voices.

In this issue there are recurring references to such thinkers and theorists as Laura Mulvey, Walter Benjamin, Georges Méliès, Judith Butler, and Renata Jackson, as well as to conceptual frameworks surrounding proto-feminism, the body, Surrealism, and temporal phenomenology, among many others. As Harmony Bench points out in the following prologue, the diversity of Deren's legacy is evident throughout the issue; indeed, in "Thresholds to the Imaginary," Lucy Reynolds notes that, "Despite some compelling arguments, it may therefore be more productive to see Deren's practice in relation to the wider discussions of pre-war thinkers contemporary to the Surrealists, who were also engaged in debating the potential, and social impact, of the new medium." Reynolds goes on to position Deren as a product of a fertile surrealist/fin de siècle culture whose work flirts with the uncanny. Sarah Keller interviews legendary filmmaker Barbara Hammer, who cites the synergy of practice and theory in Maya Deren's approach to her life/work as instrumental 
in her own artistic development. Hammer also notes the specificity of Deren's medium and the spaces in which it was situated:

If Maya Deren lived in the woods as a wild child with a video camera, with multiple hours of recording devices, I think we'd have a different kind of film. And I think that Meshes and Ritual are really home-based works. Meshes was all shot in her home. A lot of Ritual in Transfigured Time was shot in her Morton Street home and some of Study for Choreography for Camera was too. The interior structure of the home means the artifacts in the home are visible as images on the screen for us to see, even if we can't handle them. If an artist is working in space-time relationships, the space that she lived in and worked in seems to me a very interesting primary focus of what occurs in the filming itself.

As Hammer reminiscences abut her own films, it becomes clear that she has often appropriated Deren's fantasies, reanimating the kinetic, dancerly exuberance of Deren in the process.

Sophie Mayer finds traces of Deren in Jane Campion's films and identifies Deren's relationship to the "narrative, pleasurable and political."Separating from the Surrealist tether that most often is used to situate Deren's cinematic visuality, Mayer notes that Deren's Meshes of the Afternoon "is an uncanny prefiguration of many of the preoccupations of film noir; indeed, it fuses suggestively three popular American genres of the 1940s: noir, the musical, and melodrama." She locates Deren's anxious Jewishness, pointing out that, "The film's labile atmosphere and intensely private domestic language, at once intimate and violent, can be read as suffused with specific anxieties about being a leftist Jewish immigrant in the US in 1942," an important observation and analytical point of view. Finally, Mayer tracks the logical extension of Deren's film architecture to Jane Campion's In the Cut. And Andrew James notes the influence of Annette Michelson's On Reading Deren's Notebooks in mining Deren's own writing and film work for traces of interdisciplinarity. James treads into potentially fraught territory by drawing out Alexander Hammid's contributions to Deren's work, thus raising issues of authorship, genius, and embedded narratives and mythologies that are oft-quoted tropes of modernism.

With After Deren, the journal launches headlong into current, lively debates on a filmmaker who, for some, is the representative of screendance as such. However, Deren's systematic grounding of her practice in theory and her ongoing concerns with the ethical dimension of technologies and artistic practices is not as widely known. The aims of this issue are therefore to honor Maya Deren as artist and theorist; to examine current research on Deren; and to do so in the context of contemporary screen-based practices that bear traces of Deren's work.

In The Essential Deren (2005), Bruce McPherson gives a brief and humorous account of Deren that offers insight into her free spirit and passionately inquisitive nature. Arguing with a Central Park officer over a permit for filming in the park, Deren gets into trouble when she cannot describe the film, identify its content or its purpose, or indicate why in fact she is making it. Afterwards, reflecting on the situation, Deren writes:

... after three years and five films I had no succinct term or formula to describe their nature. My work has constituted an exploration of the medium of film rather than the fulfillment of a precise goal. I am fascinated precisely by those aspects and methods of cinema which are as yet undefined and rarely exploited. ${ }^{10}$ 
Even though Deren was a prolific writer and speaker, continuously advancing the theorization of her practice, any writing on Deren must be mindful of her persistent quest to develop and refine her ideas and her artform.

A journal is a form of curation that sits between the determined form of books and other more temporary structures; it functions both as a response to a field and as a provocation or call. The dedication of a whole issue to one single artist/theorist is a curatorial invitation, or provocation, to the dominant mode of screendance festivals and screenings, which seldom commit the whole of their resources to a single artist and the in-depth focus that such a commitment entails. All of the authors in this issue approach Deren not as an untouchable icon, but rather as a filmmaker who left behind a treasure trove of researchable and readable material, both on film and on paper. We hope that readers will find this focus and detailed scholarship inspiring and rewarding.

\section{Notes}

1. Mekas, "The Experimental Film in America."

2. Ibid. 23, 24.

3. "Shoot Shoot Shoot," in Jonas Mekas, 181.

4. Mekas, "Notes to the New American Cinema."

5. Ibid. 98-101. For a discussion of his friendship with Marie Menken see "Jonas Mekas on His Films: Interview with Scott MacDonald," 148.

6. "Rabbit's Moon + Kenneth Anger in Conversation," n.p.

7. Hattenstone, n.p.

8. Mekas, "Imagism in four Avant-Garde Films."

9. Deren, "The Influence of the French Symbolist School on the Anglo-American Poetry."

10. McPherson, Essential Deren, 199.

\section{References}

Deren, Maya. "The Influence of the French Symbolist School on the Anglo-American Poetry." M.A. Thesis, Smith College, 1939. Maya Deren Collection, Boston University Mugar Library Special Collection.

Hattenstone, Simon. "Kenneth Anger: 'No, I am not a Satanist."' The Guardian, March 10, 2010. http://www. guardian.co.uk/film/2010/mar/10/kenneth-anger-interview.

"Jonas Mekas on His Films: Interview with Scott MacDonald." Jonas Mekas. London: Koenig Books, 2008. Published in conjunction with the exhibition by the same name, shown at the Museum Ludwig, Cologne, 2008. In English and German.

Nichols, Bill, ed. Maya Deren and the American Avant-garde. Los Angeles: University of California Press, 2001.

McPherson, Bruce R., ed. Essential Deren: Collected Writings on Film. Kingston, New York: Documentext, 2005.

Mekas, Jonas. "The Experimental Film in America." In Film Culture Reader, edited by P. Adams Sitney, 21-26. London: Secker and Warburg, 1971.

. "Notes to the New American Cinema." In Film Culture Reader, edited by P. Adams Sitney, 87-107. London: Secker and Warburg, 1971.

."Imagism in Four Avant-Garde Films." In Film Culture Reader, edited by P. Adams Sitney, 187- 200. London: Secker and Warburg, 1971.

"Rabbit's Moon + Kenneth Anger in Conversation." BFI London. October 15, 2009. www.bfi.org.uk/live/video/20.

"Shoot Shoot Shoot: Interview with Hans Ulrich Obrist." In Jonas Mekas, 181. London: Koenig Books, 2008.

Published in conjunction with the exhibition by the same name, shown at the Museum Ludwig, Cologne, 2008.

In English and German. 


\title{
Maya Deren: A Prologue
}

\author{
Harmony Bench
}

E

qual parts artist, theorist, entrepreneur, and evangelist, it is difficult to measure Maya Deren's lingering, pervasive, and sometimes forgotten influence on experimental cinema, but this issue of The International Journal of Screendance tries to do just that. With more film projects abandoned than completed, however, it would be incorrect to assume that Deren's impact was exclusively or even primarily an aesthetic one. Deren was a game-changer, to be sure, but her impact on filmmaking was felt as much through her actions and words, which legitimated experimental cinema in an American context, as it was felt through her films. Deren biographer Catrina Neiman notes that Deren "put as much effort into cultivating the audience for cinema as an art form as she did into film-making itself." It seems that no one ever told Deren that there were things she couldn't do, that there were rules and protocols to be followed. Or if they did, she paid no attention. In this way, Deren paved the way for artists coming after her, forging an American avant-garde cinema. She gained recognition from institutions that had not previously acknowledged film as an artistic medium: she was the first to receive a fellowship from the Guggenheim Foundation for "Creative Work in the Field of Motion Pictures" in 1947. She lectured widely on her films and on her theories about film. She screened and distributed her own work. Just as she repeatedly used the techniques of filmmaking to open up new and unexpected terrains for movement, splicing and juxtaposing environments across which a performer could navigate (for example, in At Land and A Study in Choreography for Camera) in her life, Deren made space for experimentalism in an era that favored films of an educational, documentary, or commercial entertainment variety.

Chastising filmmakers for what she termed their "criminal negligence" of cinema's magical and transformative properties, ${ }^{2}$ Deren argued that the only authentic use of film was one that "creates a reality and itself constitutes an experience." ${ }^{3}$ Though Deren's imagery seems influenced by the visual arts world —-then, as now, the field most proximate to experimental cinema-Deren's aesthetic structures are undoubtedly grounded in the poetic logics of the performing arts. Of course Deren's films frequently featured dancers as well as other artists. As a result of Deren's dance background and study of performance, she developed a cinema that was more magical than surreal (she took great care to distinguish her work from surrealists), more dream than unconscious, more ritual than intellectual. But when Deren realized that she could not creatively reinterpret the danced rituals of Haitian Voudoun (Deren's spelling) in film as choreographer Katherine Dunham (with whom Deren worked in 1941) had done for the stage, Deren became an anthropologist, writing the definitive Divine Horsemen: The Living Gods of Haiti in 1953.

In her films, Deren emphasized a choreographic aesthetic, regardless of whether or not onscreen movement could be classified as "dancing," and she denounced what she saw as the typical Hollywood style of treating film as though it were simply another stage: "In most 
dance films the dancer, knowing little of the possibilities of camera and cutting, works in terms of theatrical choreographic integrity...The usual unsatisfactory result is neither... good film nor good dance."4 Choreographers, assuming a fixed-front audience, imported proscenium framing and spacing into the film medium, while cameramen distorted choreography by moving through dance ensembles. The more successful a dance was for presentation onstage the less successful it was onscreen, resulting, Deren intimates, in a misshapen, incoherent entity. Indeed, both Busby Berkeley and Fred Astaire, who had clearly-articulated visions of how to present dance onscreen, sustained the integrity of one art form-either cinema or dance-at the expense of the other. Berkeley, for example, intended for his choreographies to be seen from 360 degrees, eschewing any notion of a fixed-front viewer. Adapting his theatrical style to the screen, Berkeley had his dancers create short bits of dance material, which he then arranged according to his shooting needs. He peered down on the dancing women in his signature overhead shots or traveled across arrays of spread-eagle legs, indifferent to choreography as such. Astaire, in contrast, limited camera movement and duplicated theatrical perspective. He choreographed lengthy sequences, which were generally filmed as full-body shots with few changes in camera angle and with very minimal editing. In an interview, John Winge quotes Astaire as saying, "Either the camera will dance or I will. But both of us at the same time-that won't work. A moving camera will make the dancer look like [he is] standing still."5 Both men rejected the hybridity that Deren sought in her own films.

In contrast to the popular dance styles represented in Hollywood movies, Deren turned to American modern dance, and later to contemporary ballet, when she incorporated dance in her films. Given Deren's insistence upon the specificity of the film medium, it is somewhat curious that she should welcome dance and develop an explicitly choreographic, and not merely a kinetic, approach to cinema. But she found in dance a "magical" way of moving that interested her as a filmmaker, ${ }^{6}$ and she advocated the development of choreographed motion specific to the film medium: "If film is to make any contribution to the realm of movement, if it is to stake out a claim in an immeasurably rich territory, then it must be in the province of film-motion, as a new dimension altogether of movement."7 Deren's fusion of dance and film resulted in a form she called "film-dance," which, she asserted, is "so related to camera and cutting that it cannot be 'performed' as a unit anywhere but in this particular film" — — an idea that is practically gospel in many corners of the screendance community. Employing the filming and editing techniques available to her, Deren interrogated the spatio-temporality of a screenic body. She reimagined the space of dance and the time of movement, replacing choreographic repetitions with cinematic ones, experimenting with slow motion and reverse action, and exploring the psycho-visual import of photographic negative. She choreographed space as well as the bodies and objects in it. She pushed the aesthetic and ontological elasticity of both dance and cinema, encouraging if not forcing their recreation, redefinition, and reevaluation. Deren discovered a unique way to film movement and opened up choreography as a concept to be explored cinematically.

The choreographic register is not the register that resounds most strongly in this issue of The International Journal of Screendance. This collection of essays was inspired by the presentations and discussions that took place at the Maya Deren: 50 Years On retrospective and symposium held at the British Film Institute in October of 2011. Focusing on how 
Deren's work continues to reverberate some 50 years after her death, the authors in these pages emphasize continuities and residual effects observable in contemporary experimental cinema and the continued usefulness of Deren's film theory and practice. In the six essays that make up the bulk of this special issue on Maya Deren, three main themes emerge: Deren's own first principles of filmmaking and the centrality of the poetic and magical in the structure and effect/affect of her films; comparative analyses of Deren's films and those of contemporary filmmakers; and finally, Deren's unique modes of working and theorizing that have been rearticulated in more recent scholarship.

Sophie Mayer discovers residual elements of Deren's aesthetic in Jane Campion's 2003 film In the Cut, particularly in the "vertical" structuring of both films and the doubling of their protagonists. Crucially, Mayer locates Deren's Ritual in Transfigured Time historically at the conclusion of WWII, and Campion's In the Cut in the aftermath of September 11, 2001. Read in the context of global violence, Mayer argues that Deren and Campion share what film theorist Elena del Rio calls a "micropolitics of the powers of affection" that allows them to comment on "grief and vulnerability." With Deren as a consistent touch-point, Mayer attends to the use of dance in Campion's film, which, like Ritual, "unites dance and death," and in so doing, "grieves the geopolitical conflict... and counters it." Silvina Szperling similarly discusses Deren's influence among South American artists as seen especially through the work of German-born Argentinean experimental artist and filmmaker Narcisa Hirsch, who was also interviewed for this issue of The International Journal of Screendance. Paying particular attention to Hirsch's 1999 film Rumi, Szperling emphasizes the quest of each filmmaker to render poetic and emotional states in visual form. Each filmmaker, Szperling notes, believed that "experimental films with their non-linear structure and dream-like transitions could visually transpose the experiential qualities of lyric poems."

The poetic remains at the fore for Sarah Keller as well, who supplements poetry with rhythm in her account, and for Lucy Reynolds, who emphasizes the magic embedded in Deren's poetic onscreen transformations. Keller specifically places Deren within a dance context, noting that Deren's exposure to dance and her work with notable dancers and choreographers infused her films with a sense of rhythm not native to the medium of film, but rather created where dance and film mutually intersect with motion. Indeed, Keller argues, rhythm can be viewed as a signal principle underlying Deren's interests across poetry, cinema, dance, and anthropology. But it is ultimately poetry that gives Deren's films their shape, in Keller's analysis, for it is the poetic form, which dance shares, that eschews linear and narrative causality in favor of felt impressions linking images together in otherworldly rhythmic ecologies. Such alternate rhythms lend themselves to explorations of the marvelous, and Reynolds encourages readers to attend to the spaces of imagination Deren's films open up in their relationship to film magic. Reynolds emphasizes that Deren creates strange new worlds, which, though magical, maintain their own internal logic. Reading Deren's film theories alongside those of Jean Epstein, Reynolds suggests that Deren's relationship to myth, ritual, and magic situates her more closely to what Laura Mulvey calls the technological uncanny than the psycho-sexual "shocks" of Surrealists, whom Deren rejected.

Claudia Kappenberg similarly plumbs the poetic in Deren's films as logical visual structure commensurate with written forms of poetry, but crucially different from language as such. Kappenberg particularly examines Deren's theorization of verticality and horizontality in films as they relate to time, emotion, and action. Here, horizontality refers to causality, the 
teleology of dramatic action, and the progression of a narrative. Verticality, in contrast, refers to the suspension of action and slowing of time that enables a filmmaker to drill down into different layers of emotion, coloration, technique, reflection, or other considerations that recede into the background when attention is primarily focused on an unfolding plot. These Kappenberg likens to French philosopher Gilles Deleuze's articulation of the movement-image and the time-image, arguing that despite the negative reception of Deren's theory of form, Deleuze legitimates the structures Deren describes.

But as Andrew James notes, it was not only Deren's film theories that are in need of recuperation. James suggests that Deren's interdisciplinarity and her emphasis on collaboration has rendered her less visible to film scholarship, including feminist critics engaged in writing women back into the history of filmmaking. When scholars do consider Deren's work, Alexander Hammid's central role in Deren's most influential film Meshes of the Afternoon, and collaborators on other films become obscured in favor of Deren-as-auteur. To better understand Deren's work and contributions to filmmaking, scholars must apply the seemingly recent notions of interdisciplinary and collaboration to her artistic process.

Together, these essays go a long way to invite Maya Deren's work to the table of contemporary cinematic experimentation and scholarship, but they also collectively focus on the films with which audiences and readers are most familiar, namely Meshes of the Afternoon, Ritual in Transfigured Time, and, to a lesser extent, A Study in Choreography for Camera and At Land. The authors gathered here remain mostly silent on the films Meditation on Violence, made with Chao-Li Chi, and The Very Eye of Night, made with Antony Tudor. Much remains to be gleaned from her unfinished and/or unreleased films as well: The Witch's Cradle, made with Marcel Duchamp; Medusa, made with Jean Erdman; Ensemble for Somnambulists; and Seasons of Strangers. Divine Horsemen: The Living Gods of Haiti, posthumously edited on Deren's behalf by Cherel and Teiji Ito and an important work in visual anthropology, is a notable absence in these discussions. In the second issue of The International Journal of Screendance, Elinor Cleghorn picked up a few of these threads and added a few others in her article "Manus Operandi: Film, Sculpture, Choreography." There, she analyzed The Witch's Cradle alongside Richard Serra's experimental film Hand Catching Lead. Both films focus intimately on the movement vocabulary of hands and fingers - catching, or attempting to catch, in Serra's film, and entangling and disentangling a disconcertingly agential string in Deren's. Both films are also principally informed by sculpture: Serra's own practice as a sculptor, and the surrealist sculptures amongst which Witch's Cradle was filmed. Though unintentional, dividing Deren across issues in this way is quite apropos for a filmmaker who was a specialist in discovering ways to use bodies, motion, and cinematic magic to create a bridge between shots. Cleghorn's essay functions similarly, connecting this issue with the previous one.

Yet, our interest in Deren is by no means exhausted by including Cleghorn with the six other essayists. Rather, we see more conversations opening in front of us-and, of course, to the sides and behind, above and below. No book, journal issue, or collection can hope to tackle all of an artist's work. To Andrew James's point, however, the fact that Deren moved from poetry to film, incorporated dancers and a choreographic sensibility into her work, collaborated with many artists, wrote prolifically, and pursued her fascination with ritual and magic into the field of anthropology, means that no single biographical narrative or skillful film interpretation will grasp the complexity of Deren's life, aesthetics, or ideas. No 
life or body of work can ever be packaged neatly, but Deren in particular was simply too interdisciplinary to be reduced to a few films and a couple of theories, as any attempt to understand Deren's lingering influence must inevitably do. In a way, Deren's corpus reflects the poetic realities she created in individual films. There is no logical connection that leads from one film to the next, no life story that reaches its inevitable conclusion with Deren's premature death —only a felt connection that carries us from one to another like Deren's sandaled feet swinging from landscape to landscape in Meshes of the Afternoon. Deren isolates and explores gaps in space, time, and consciousness that she straddles cinematically. But in bridging here and there, now and then, observer and participant, self and loss of self, Deren always points to the gulf between them. It is there that Deren's significance will continue to be sought out and discovered: in the in-between-frames.

\section{Notes}

1. Clark, et al., Legend Vol. 1 Part 2, 4.

2. Deren, "Cinema as an Independent Art Form," 345.

3. Deren, "Cinema as an Art Form," 22 (emphasis in original).

4. Deren, "Choreography for the Camera," 220-221.

5. Winge 8 .

6. Deren, "Creating Movies," 132.

7. Deren, Anagram, 48.

8. Deren, "Choreography for the Camera," 222.

9. The International Journal of Screendance 2 (Spring 2012): 129-139.

\section{References}

Clark, VèVè, Millicent Hodson, and Catrina Neiman. The Legend of Maya Deren: A Documentary Biography and Collected Works. Vol. 1, Part 2: Chambers (1942-47). New York: Anthology Film Archives/Film Culture, 1988.

Cleghorn, Elinor. "Manus Operandi: Film, Sculpture, Choreography." The International Journal of Screendance 2 (Spring 2012): 129-139.

Deren, Maya. An Anagram of Ideas on Art, Form, and Film. In Maya Deren and the American Avant-Garde, edited by Bill Nichols, 267-322. Berkeley: Univ. of California Press, 2001.

. "Choreography for the Camera." In Essential Deren: Collected Writings on Film by Maya Deren, edited by Bruce McPherson, 220-224. Kingston: Documentext, 2005.

. "Cinema as an Art Form." In Collected Writings on Film by Maya Deren, edited by Bruce McPherson, 19-33.

Kingston: Documentext, 2005.

. "Cinema as an Independent Art Form." In The Legend of Maya Deren: A Documentary Biography and Collected Works. Vol. 1, Part 2: Chambers (1942-47), edited by VèVè Clark, Millicent Hodson, and Catrina Neiman, 345-349. New York: Anthology Film Archives/Film Culture, 1988.

. "Creating Movies with a New Dimension: Time." In Essential Deren: Collected Writings on Film by Maya Deren, edited by Bruce McPherson, 131-138. Kingston: Documentext, 2005.

Winge, John. "How Astaire Works." Theater Today (1950): 7-9. 


\section{Media}

At Land (1944). Dir. Maya Deren, with Hella Heyman and Alexander Hammid. 16mm, 15:00 min., b\&w, silent. Meditation on Violence (1948). Dir. Maya Deren, with Chao-li Chi. 16mm, 13:00 min., b\&w, sound.

Meshes of the Afternoon (1943). Dir. Maya Deren and Alexander Hammid. 16mm, 14:00 min., b\&w, silent. Music by Teiji Ito added in 1959.

Ritual in Transfigured Time (1945-1946). Dir. Maya Deren and Frank Westbrook, with Hella Heyman and Rita Christiani. 16mm, approx. 15:00 min., b\&w, silent.

A Study in Choreography for Camera (1945). Dir. Maya Deren, with Talley Beatty. 16mm, approx. 3:00 min., b\&w, silent.

The Very Eye of Night (1952-1955). Dir. Maya Deren and Antony Tudor, with the Metropolitan Opera Ballet School. $16 \mathrm{~mm}, 15: 00 \mathrm{~min} ., \mathrm{b} \& \mathrm{w}$, sound. Music by Teiji Ito.

\section{Unfinished Films}

Ensemble for Somnambulists (1951). Dir. Maya Deren, with Cynthia Barrett and Brian Macdonald. 16mm, approx. 7:00 mins, b\&w, silent.

Haitian Film Footage (1947-1955). Released as Divine Horsemen: The Living Gods of Haiti (1985). Dir. Maya Deren, with Haitian Voudoun practitioners. Edited by Teiji and Cherel Ito. $16 \mathrm{~mm}$, approx. 4 hours, b\&w, silent and sound recordings.

Medusa (1949). Dir. Maya Deren, with Jean Erdman. 16mm, approx. 10:00 min., b\&w, silent.

Season of Strangers (a.k.a. Haiku Film Project) (1959). 16mm, approx. 58:00 min., b\&w, silent.

The Witch's Cradle (1943). Dir. Maya Deren, with Marcel Duchamp and Pajorita Matta. 16mm, fragments approx. 13:00 min., b\&w, silent.

\section{Further Reading and Viewing}

Clark, VèVè, Millicent Hodson, and Catrina Neiman. The Legend of Maya Deren: A Documentary Biography and Collected Works. Vol. 1, Part 1: Signatures (1917-42). New York: Anthology Film Archives/Film Culture, 1984.

The Legend of Maya Deren: A Documentary Biography and Collected Works. Vol. 1, Part 2: Chambers (1942-47). New York: Anthology Film Archives/Film Culture, 1988.

Essential Deren: Collected Writings on Film by Maya Deren. Ed. Bruce McPherson. Kingston: Documentext, 2005.

Deren, Maya. Divine Horsemen: The Living Gods of Haiti. Kingston: McPherson, 1983.

. "Film in Progress. Thematic Statement." Film Culture 39 (Winter 1965): 11-17.

."Notes on Ritual and Ordeal." Film Culture 39 (Winter 1965): 10.

"A Statement on Dance and Film." Dance Perspectives 30 (Summer 1967): 10-13.

In the Mirror of Maya Deren (2002). Dir. Martina Kudlácek. Perf. Miriam Arsham, Stan Brakhage, Chao Li Chi, Rita Christiani, Maya Deren, Katherine Dunham, and Alexander Hammid. Zeitgeist Video. DVD.

Invocation: Maya Deren (1987). Dir. Jo Ann Kaplan. Narr. Helen Mirren. Perf. Stan Brackage, Joseph Campbell, Maya Deren, Alexander Hammid, Hella Heyman, Teiji Ito, Jonas Mekas, Jana Sheldon, Amos Vogel, and Marcia Vogel. Jackson, Renata. The Modernist Poetics and Experimental Film Practice of Maya Deren (1917-1961). Edwin Mellen Press: Lewiston, 2002.

Maya Deren and the American Avant-Garde. Nichols, Bill, ed. Berkeley: University of California Press, 2001. 


\title{
Thresholds to the Imaginary
}

\author{
Lucy Reynolds
}

mongst the many texts and articles that Maya Deren produced concerning the
processes and properties of film, it is notable that she writes enthusiastically of the
suggestive potential of cinema technology to create effects that could suspend
belief. She even entitled a 1946 magazine article "Magic is New," demonstrating that
she was not shy of using the term "magic" in relation to her practice and proclaiming:
"[W]hat particularly excited me about film was its magic ability to make even the most
imaginative concept seem real."' Surprisingly little has been written about Deren's interest
in film's magical potential. Nor has the natural magic that she conjures been subject to close
critical analysis, either for its formal methods or its effects on the viewer. With the excep-
tion of Lucy Fisher's insightful 2001 comparison to the French filmmaker magician George
Méliès, ${ }^{2}$ Deren's appreciation of film magic has more often been alluded to than explicitly
addressed in film scholarship. Emphasis has tended to be placed on her use of ritual in film
and writing, as the analyses of writers from Annette Michelson to Renata Jackson have
shown. ${ }^{3}$ In what follows here, I argue for the significance that magic plays within Deren's
practice, both as a filmmaker and an advocate-as her early article shows- for the potency
of the cinematic medium as a space for magic.

For me, Deren's creative displacements of time and space share the properties of the "natural magic" first articulated by the sixteenth-century scientist Giovanni Battista della Porta. In his book Magiae Naturalis he describes how, in a portent of cinema, the mechanics of early optical technology associated with the camera obscura and parabolic mirrors could conjure the presence of illusions both terrifying and marvelous from the environment around them. Thus was opened up the potential for optical technology as a tool for suggestive spectacle as well as scientific study, through what Tom Gunning has referred to as the "creation of new relations between the perceiving eye and the power of light."4 If della Porta relied on the technological refraction and distortion of the world around him to create monsters, so Deren took the viewer's belief in the truth of the filmstrip's photographic inscription as a starting point from which belief might be suspended. Through the camera mechanics of slow motion, reverse, and stop-frame, and her precise use of montage, photographic certainties thus coalesce with her deft manipulation of cinematic time and space to create bodies and places that appear to transcend the laws of natural gravity-whether to multiply oneself in Meshes of the Afternoon, to take flight across space in A Study in Choreography for Camera, freeze statue-still in Ritual in Transfigured Time or become a celestial body moving stately among the stars in her last film, The Very Eye of Night. For Deren's enthusiastic writings on the attributes of cinema technology could be seen to share something of della Porta's desire to communicate the unparalleled properties that his optical devices offered, and the illusions they could effect. Her suggestions for how the amateur filmmaker might manipulate filmic time and space employ the simple 
sleights of hand familiar from the films of early cinema masters such as Georges Méliès or Mack Sennett. She explains, for instance, the temporal interpositions of the stop-frame technique with the example of the running figure across the sand dunes in her film At Land: "that the running can be interrupted at any moment, and resumed on the same frame... [A]nd so the girl, who started out so near us, has, in a magic way, become rapidly distant." This is not to suggest that she courted the knowing thrill and delight in illusion which the magician hopes to draw from his audience, and which relies as much on the revelation, and appreciation, of his trickery as it does upon the incredulity it first engendered. As Lucy Fisher rightly asserts when she compares Deren and the film magician George Méliès: "for Méliès, magic is fundamentally a 'trick', for Deren it constitutes access to the 'marvelous."' Thus Deren might be understood as a different kind of showman from either Méliès or forbears like della Porta and the magic lanternist Athanasius Kircher. The key to her difference lies in Fisher's emphasis on the term "access." For the mode of perception which Deren sought from film was not a trick of the eye, but the means to create a threshold to an inner space, where the realms of the imaginary might be shaped into material form. As she put it: "The creative effort should be directed not at making a thing look like itself, but at using the capacity of the camera to make it look like what the audience should feel about it."7

Deren's intent that a thing should "look like what the audience should feel about it" implies a desire for the camera to act as a device for psychic projection, where once familiar objects and situations - a telephone off the hook, a cocktail party-take on strange, often uneasy, dimensions, which prompt associations in the mind of the viewer. Deren's games of defamiliarization can be traced back to the Surrealist's earlier acknowledgement of cinema's inherently transformative "modern magic." For them, as Paul Hammond describes it, film had the power to "confer a dignity and poetic value on common objects, to render them into what Freud called 'thing-representations,' indices of the unconscious." As Hammond suggests, the new significances that cinema afforded to the banal was conferred by its power of focus: "In isolating objects, magnifying them and recombining them in new ways, things were revealed-and reveiled, as [André] Breton demanded-in all their fulsome, hieratic mystery." ${ }^{8}$ Thus, as Louis Aragon would have it: "a bottle that on occasion becomes a weapon, a handkerchief that reveals a crime, a typewriter that's the horizon of a desk."

Deren's own writings also share this recognition of film technology's power of metamorphosis, and appreciation of the unique potential of the medium. Yet, at the same time, she was categorical in distancing her practice from that of the Surrealists. Indeed, as the programme notes that prefaced her early screenings declared:

Under no conditions are these films to be announced or publicized as surrealist or Freaudian [sic ]. This is not only a serious misrepresentation of the films, but also confuses the audience by inspiring a false interpretation of the films according to sustems [sic] to which they bear no relation. The preoccupation with conscious control of form which is involved ... is obviously at variance with the Sur-realist esthetic of spontaneity. ${ }^{10}$

Deren's emphatic disavowal suggests that she perceived a fundamental difference between herself and the Surrealists at the level of control asserted over the construction of the film form, setting her own careful orchestrations of filming and editing in contrast to the chance operations seen to be practised by the latter. However, a shared methodology, and desire to 
access the subconscious, has certainly been identified between Deren and the practices of the Surrealists. Ute Holl observes that: "Deren's cinematic tricks that associate, condense, and displace the visual material actually correspond to what Freud described as the processes of dream work and to what the Surrealists called expressions of the subconscious."11 For Holl, the difference between Deren and the approach of the Surrealists-already hinted at in Deren's programme note refutals - was their belief that these cinematic effects were inherent to the workings of the subconscious, whereas Deren understood them as the result of the artist's own subjective vision and technological manipulations, or as Holl puts it, "consciously applied effort."12

George Amberg's contemporaneous comments illuminate an additional difference of emphasis which might enlighten us further about Deren's view of Surrealism in relation to her practice. For him, the undermining tactics of the Surrealist "shock effect" were designed to "destroy confidence in the validity of the world which they create and frustrate the potential participation of the spectator in it." In contrast, Amberg perceives in Deren's films a "powerfully convincing reality" of overarching and cohesive logic where the images are "chained to each other on the level of emotional, visual and logical implication."13 It is telling that Deren places Amberg's text within her first serious essay on her film method, "Cinema as an Independent Art Form" (1945), for it presages a subject she returned to throughout her writing..$^{14}$ In agreement with Amberg, she saw her films as evincing what she often referred to as a "classical structure," where the disjunctures of time and space explored were less concerned with eliciting visceral reactions in her audiences through a series of shock images, than building a persuasive and all-encompassing world, however strange, into which the viewer is slowly initiated.

Deren may have been understandably defensive that her films were judged in relation to an earlier European avant-garde rather than on their own merit as contemporary works. However, her unfinished first film, Witch's Cradle, further complicates the question by implying an alignment to the very art worlds she dismisses. Set in the Museum of Modern Art's "Art of This Century" galleries, her camera pans over the sculptural works of artists associated with Surrealism, such as Hans Arp and Magritte, as well as other pre-war European artists such as that most iconic figure of the pre-war avant-garde, Marcel Duchamp, depicted tangled within his own string sculpture..$^{15}$ On the other hand, this first foray into film also provides glimpses of the interests in game-play and ritual that would come to inform Deren's later work: for instance, the arcane symbols painted upon the central figure of a young woman, whilst the title of the film alludes to Deren's burgeoning interest in the occult and the supernatural, as well as positing the first of the female protagonists who would dominate her films.

Despite some compelling arguments, it may therefore be more productive to see Deren's practice in relation to the wider discussions of pre-war thinkers contemporary to the Surrealists, who were also engaged in debating the potential, and social, impact of the new medium. For example, in his famous 1936 essay, "The Work of Art in the Age of Mechanical Reproduction,"Walter Benjamin uses the concept of the unconscious to delineate the unique and intrinsically modern mode of perception that cinema opens up to the viewer. Although there is no evidence from Deren's writings that she knew of Benjamin's discussions of cinema, his description of an "optical unconscious" bears relation to Deren's belief that cinema was "the most propitious and appropriate art form for expressing, in 
terms of its own paradoxically intangible reality, the moral and metaphysical concepts of the citizen of the new age." ${ }^{\prime 16}$ Deren's observations, for example, about "The ideas of condensation and of extension, of separateness and of continuity, in which it [film] deals,"17 might also be seen to echo Benjamin's own observations that the "resources of the camera" such as slow motion, close-up and other mechanistic operations opened up in familiar actions and objects an "unconsciously penetrated space" and "different nature."18 Indeed, Benjamin's descriptions bring to mind the opening sequence of Meshes in which the door key that falls from Deren's hand is caught in ominous slow motion and close focus as it bounces down the steps, assuming a significance disproportionate to its size and mundane function.

Deren was certainly aware of other pre-war theories of cinematic perception, and in An Anagram of Ideas on Art, Form and Film, her ambitious 1946 treatise on film theory and aesthetics, she mentions how she had just received the French filmmaker and poet Jean Epstein's book I'Intelligence d'une Machine. Deren clearly felt him a kindred spirit, writing of how the implication of the title, and his "poetic, inspired tone" led her to believe that they shared "a profound respect for the magical complexities of the film instrument."19 No further references to Epstein exist in Deren's writings, but a comparative reading of their theories on cinema reveals a shared recognition of film technology's extra-ordinary abilities, which for Epstein was the "cinematic property of things, a new and exciting form of potential."20 Like Deren, Epstein privileged the potential of time relations in cinema, writing of how the camera was capable of "making immensely more supple the play of temporal perspective."21 However, it is Epstein's notion of photogénie which seems particularly significant to Deren's understanding of cinema technology's power of evocation, or "magical complexities," for he suggests that the camera might open up, not only a new mode of perception to the viewer, but might also expose the very soul, and "inner nature of things." 21 The much debated difference between the Surrealist understanding of cinema and Deren's gains a further difference of emphasis beyond that of Amberg's professed distinctions, when read in relation to Epstein. For the latter argued for the profound potential of cinema to expose the essence of an object or person, rather than simply allow for the surfacing of the subconscious. This comes much closer, I would argue, to Deren's understanding of the alternate, interior worlds which cinema technology could unlock; perceived by Epstein as "untrue to everyday reality just as everyday reality is untrue to the heightened awareness of poetry."22 Deren also writes with admiration in Anagram of the "economy of statement" to be found in Jean Cocteau's film The Blood of a Poet (1930), and later cites his effective use of reverse motion and negative image in Orphée. ${ }^{23}$ Like Deren, Cocteau also conjured spaces of bewitchment by utilizing the simple cinematic trickery beloved by Méliès or Sennet, such as the use of slow, reverse and stop-frame motion to suggest different registers of gravity within a space, or as a means of investing the protagonist with magic powers. These effects often occur once a threshold has been crossed, or a portal opened, such as when Orphée passes through the mirror into Cocteau's shattered underworld, or Deren crawls from beach to rowdy dining table in At Land. Often misleadingly associated with the Surrealists, ${ }^{24}$ Cocteau's interest in the supernatural worlds and beings associated with mythology are well documented in his poetry, artwork and his films. These might be compared with Deren's own fascination with the structures of myth and fable, which was to find its most overt expression in her final film, The Very Eye of Night, in which dancers assume the identity of the mythological figures who populate the night sky as the stars of the 
zodiac. Furthermore, as the occult symbolism in Witch's Cradle already suggests, the notion of myth in Deren's work cannot be disconnected from her understanding of ritual. A dominant theme of her films and wider philosophy, she takes care to explain her understanding of ritual in Anagram, after establishing that her definition looks beyond, yet encompasses, the specific rites and ceremonies with which anthropology associates the term, including "a specific magical purpose." ${ }^{\prime 25}$ Rather, ritual for Deren posits a morally-inflected and collective sense of consciousness, which acknowledges the authority of myth and "man's relationship with deity."26 Much analyzed in relation to her ethnographic practices in Haiti, and in the examination of theoretical texts such as Anagram, as well as through close readings of the film themselves, her notion of ritual remains compelling, yet often elusive-determined by the changing concerns of Deren's art and her interests. ${ }^{27}$ It is as if each of her films explores different ritualized forms: the occult of Witch's Cradle; the game of chess so central to the protagonist's journey in At Land; the social rituals of marriage in Ritual in Transfigured Time; or the trance possessions within which she participated in Haiti. Like Cocteau, several of her films overtly depict a ritualized threshold space requiring certain actions for access: a repeated unlocking of the door to the house in Meshes, a chess piece as a guide in At Land, or the doorways from one dominion into another depicted at the beginning of Ritual in Transfigured Time, with Anaiis Nin as their imposing sentinel. Deren's experiences in Haiti brought into another register her belief in the ritual power of rhythm and movement, which signals less a subjective state of being than a form of collective embodiment, characterized by Moira Sullivan as "the element of a depersonalized individual within the dramatic whole."28 For Deren, this allowed the dancer, or initiate, to become "part of a dynamic whole which, like all such creative relationships, in turn, endows its parts with a measure of its larger meaning." 29

However, it is important to stress that Deren's understanding of ritualized form was intimately connected to film form. For she believed it was through the unique "creative time-space relationships" of cinema technology, that she could most effectively create a sense of the dynamic whole which she sought. Indeed, as Holl argues: "her understanding of'ritualistic'is not a (pseudo) primitive one but refers to the media aspect of art: artforms, as she will further elaborate in Anagram, are historical techniques of transmission that produce reality. ${ }^{\prime \prime 0}$ The social and religious ceremonies which she presents in Ritual in Transfigured Time, for example, reach a level of ritual signification only possible through her manipulations of film technology. Here, film's printing processes effect a transformation at once scientific and alchemical, when Rita Christiani's widow's weeds becomes a bridal gown through the simple action of silver nitrate chemicals reversing positive to negative image. Deren's use of slow-motion and freeze-frame throughout the film brings an intensity to the interactions between the protagonists, exposing the nuances of their encounters as they are frozen into a series of attitudes and postures, as if, in mythological allusion, turned to stone. In the film's most notable use of slow-motion, Deren herself acquires a psychotic, even malevolent, aspect as the muscles of her smiling countenance, filmed in close-up, appear to perceptibly flap and stretch into grotesque form as she turns her head. This unnerving close-up shows the enchantment that she weaves with her film camera is not necessarily of a benign nature, being deeply connected to the rituals and myths of life and death. Holl surmises, Deren's "dangerous yet promising adventures" investigate "archaic and modern ritualistic forms" in order to "extend the visual horizon of perceivable selves." ${ }^{\text {"11 }}$ 
And what better medium to choose for her explorations than a technology that holds the power to breathe life into the inanimate and resurrect what is past? For despite Deren's insistence that the effect of her films springs from her "conscious control" of film form, I would argue that her careful temporal spatial manipulations shape an evocative power already latent in film, the profound role of cinematic time as an agent of resurrection, to summon the once dead into spectral on-screen form. Prefaced by its mirror-faced harbinger, film's powers over life and death resonate in the ambiguous interplay of waking, dreaming and death that repeat themselves throughout Meshes of the Afternoon, and become almost literalized in Rita Christiani's ghostly white form as she appears to rise up through the negative film image at the end of Ritual in Transfigured Time.

Cinema's technological power to raise apparitions returns us firstly to della Porta's natural magic, where incredulity at the effects of his optical devices encouraged people to believe that they saw visions, eliciting a return to the superstitions and irrational beliefs of more archaic times. Laura Mulvey terms this uneasy mixture of wonder, fear and disbelief, where science and superstition collide, "a technological uncanny," where "the most rational mind experiences uncertainty when faced with an illusion that is, if only momentarily, inexplicable."32 Mulvey cites Freud and Wilhem Jentsch's famous texts on the uncanny to make a case for the innately uncanny qualities of film, which, like della Porta's parabolic mirrors, might produce what Freud referred to as "that species of the frightening which goes back to what is once well known and had long been familiar."33 Mulvey suggests that this confusion of technology and science with the supernatural arises in cinema from the "indexical uncanny" of the photographic inscription at the heart of the filmstrip, which carries its own imprint of technologically induced reality and of time arrested. The particular presentiment of death — a sensation which André Bazin referred to as photography's "embalmed" timeis brought into a register of further uncanny dimensions when movement is returned to it by the agency of the film projector, bringing an unnatural veracity to the images on screen. Here, Mulvey notes an enchantment in cinema which goes more profoundly into questions of perception than a sleight of hand, when she writes that: "This is not the mystery of the magic trick but the more disturbing, uncanny sensation of seeing movement fossilized for the first time." ${ }^{\prime 3}$

Cinema's acute sensitivity to the power of passing time, which enables it to conjure life, or imprint death, in the frame, produces a sense of the uncanny that emanates strongly from Deren's films. It is apparent, for instance, in the unheimlich spaces of the house to which she repeatedly returns in Meshes of the Afternoon, their familiar dimensions inexplicably made strange. It also manifests in the deathly significance of the double in her films, most vividly as she multiplies her own self in Meshes to become a coven of four, playing a ritual game with knife and key-familiar objects which themselves assume a talismanic power. Deren conjures these "familiars" (to evoke the word's ritual context) through an experimental application of techniques similar to those used to establish narrative continuities in fiction cinema. Here the eyeline match is applied, not to delineate the space of narrative diegesis, but as a mode of multiplication across spaces, as one Maya turns to look across the sand dunes in At Land to another, who occupies the edge of the table, or struggles through a thicket of leaves. In Ritual this exercise of suture extends to an uncanny shift of identities, where by cutting on the movement of a turn of the head, or the gesture of an outstretched arm, Christiani metamorphoses into Deren. 
Citing Otto Rank's definitive study on the subject, Freud connects the form of the double with: "mirror-images, shadows, guardian spirits, the doctrine of the soul and the fear of death."35 As he asserts, the double was once seen as a magic insurance against death, evident in the effigies and paintings in the tombs of Egyptian kings, the first expression of the "immortal soul." But in another example of the familiar becoming the demonic other, its role is now reversed to signify instead "the uncanny harbinger of death." ${ }^{16}$ In Meshes, the double assumes its most ominous shape, going beyond the role of harbinger to become the instigator of death as she grasps the knife, flinging it through the mirror. However, amongst the many selves pictured, who is guilty of the crime? And who is dead? The double becomes here a means through which an additional layer of ambiguity is added to this already beguiling film. Maureen Turim perceives these multiplications as reflections of the woman's relationship to "the other, to her various selves." This "splitting of the subject" implies the fragmentation of female identity, as well as "a multiplicity of positions, fragmentations, and transformations that appear to be seeking a location in domestic violence. ${ }^{137}$ As a reflection of the trauma of patriarchy, it is a compelling reading, offering the same interpretative power as Lauren Rabinovitz's assertion that Meshes resembles the structure and iconography of film noir, with its portrayals of the powerful and ultimately dangerous female. The materialization of Deren's four counter-selves could be seen to represent the different aspects of her psyche, taking us back to Freud's reading of the uncanny double as a disturbance or disassociative disorder of the ego. Deren's own programme notes for Meshes appear to affirm this reading, when they speak of the film's concern with "the inner realities of an individual and the way in which the sub-conscious will develop, interpret and elaborate an apparently simple and causal occurrence into a critical emotional experience." ${ }^{\prime 38}$

Freud recognizes that, whatever the cause, the pervasive sense of ill ease and foreboding attached to the appearance of the double remains powerful and rooted in very ancient urges, both culturally and in the psychological development of the individual, belonging, as he puts it, to "a primitive phase in our mental development, a phase that we have surmounted."399 Through her elegant sutures on the turn of the eye, Deren is thus able to materialize multiple selves that articulate not only the fragmentation of the female body and identity, nor the workings of the subconscious, but also the more profound and inexplicable fear associated with the "terror" of the double with its uncanny portent of death. ${ }^{40}$

Furthermore, as Freud has pointed out, the sensation of the uncanny hinges on the conflict between belief and doubt, where an object, person or place appears simultaneously familiar and yet somehow awry. He gives special attention to the uneasy perceptual slippage which occurs "when the boundary between fantasy and reality is blurred, when we are faced with the reality of something that we have until now considered imaginary, or when a symbol takes on the full function and significance of what it symbolizes, and so forth." ${ }^{\prime 11}$ Applied to cinema, this effacement occurs when, through the agency of photographic inscription onto celluloid, the imaginary worlds caught in movement on screen appear to take on the guise of the real. Deren would refer to this uncanny dialogue between the real and the illusory as the "controlled accident" when the "innocent arrogance of an objective fact"42 presented by the photographic image might be held in "delicate balance between what is there spontaneously and naturally as evidence of the independent life of actuality, and the persons and activities which are deliberately introduced into the scene."43 
Deren achieves this uncanny through a careful edit on the movement and gesture of the body, which finds its most elegant resolution in A Study for Choreography in Camera. In this short film, the limbs of the dancer Talley Beatty become unnaturally elongated, vaulting impossible distances, through the appearance of a continuous pan on movement which leads the eye seamlessly from forest to mountain, interior to exterior, on the tip of a toe. At the same time, emanating from the body in motion on the film screen-even when it is subordinated to the logical flow of narrative-there is always a whisper of the mechanical presence of the apparatus which is its progenitor, such as the camera and projector which bring animation to what Mulvey terms "an inorganic trace of life." ${ }^{\text {"44 }}$ As Mulvey's contradiction implies, cinematic movement produces a doubled and paradoxical experience of the uncanny, where the spectral inscription of the body that was once alive in front of the camera merges with the technological bodies of the machines that capture and regenerate it as a projected cinematic illusion. Mulvey relates this uncanny motion to "the uncanny of mechanized human movement" ${ }^{\prime 45}$ and the automata that both Freud and Jentsch refer to in their studies of the uncanny, whose jerky movements approximate life, whilst also betraying their mechanical origins. She cites Benjamin's eloquent observation of Chaplin, the avant-garde's epitome of cinema's mechanical modernity, producing "the same jerky succession of tiny movements, which applies the law of filmic sequence to that of human motorics."46

Whereas Chaplin's exaggerated jerky movements might be seen as an overdetermined embodiment of cinematic technology, the fluid gestures of Beatty, Christiani, or Deren herself, as I have already argued, function to suture disparate spaces, creating the logic of a "relativistic universe" through a "purely cinematic coherence and integrity." ${ }^{\text {"77 }}$ This is the uncanny propagated by the unique conditions that Deren recognized in the film medium, where the body moves to the technological rhythms of temporal spatial manipulation, not the syncopations of the cinematic apparatus. If Benjamin recognized in Chaplin's step the sequential movements of the film strip through the projector, so we might recognize in Deren's moving bodies the rhythms of her edit and her manipulations of cinematic time and space. Therefore, rather than Chaplin's comic echo of automation, the movements of Deren's protagonists reveal their technological origins through the "cinematic coherence" of slow motion, the freeze-frame and the body sent in motion backwards as well as forward. Their movements describe worlds working to a stranger gravity than the machine: a somnambulist rhythm that evokes the spectral and explains why the notion of trance has so often been attached to Deren's films.

Yet whilst the movements of Beatty, Christiani and others act as points of juncture across filmic space, at the same time their bodies bear the scar of this celluloid severancean injury of the cut sustained beneath their seamless act of suture across space, which accentuates the inhuman uncanny of the filmic body that animates, while it destroys, their on-screen semblance. In this sense, Deren's films resonate with an uncanny consciously conjured as a ritual magic from the agencies of the film form. Writing in 1946 about making At Land, she describes how she was "anxious to develop the idea of cinematic magic in terms of space and time."48 This magic is at work throughout her films, and the beguiling worlds that she creates. As I have argued, more sorcerer than showman, Deren summons magic that does not intend to delight through illusion, nor to deploy the Surrealist tactics of humor and shock, but to offer a darker and often difficult passage into the more profound questions of the rituals of life and death. 


\section{References}

Aragon, Louis. "On Décor" (1917). In The Shadow and Its Shadow: Surrealist Writing on the Cinema, edited by Paul Hammond, 55-59. Polygon: Edinburgh, 1991.

Benjamin, Walter. "The Work of Art in the Age of Mechanical Reproduction" (1936). In Walter Benjamin: Illuminations, edited by Hannah Arendt, 217-251. New York: Schocken Books, 1969.

Deren, Maya. An Anagram of Ideas on Art, Form and Film. In Essential Deren: Collected Writings on Film by Maya Deren, edited by Bruce R. McPherson, 35-109. Kingston, New York: Documentext, 2005.

. "Cinema as an Independent Art Form." In Essential Deren: Collected Writings on Film by Maya Deren, edited by Bruce R. McPherson, 245-247. Kingston, New York: Documentext, 2005.

."Magic is New." In Essential Deren: Collected Writings on Film by Maya Deren, edited by Bruce R. McPherson, 197-206. Kingston, New York: Documentext, 2005.

Epstein, Jean. "On Certain Characteristics of Photogénie" (1923). In "Bonjour cinéma and Other Writings," translated by Tom Milne, 23. Afterimage 10 (1981).

."Magnification and Other Writings."Translated by Stuart Liebman. October 3 (Spring, 1977): 9-25.

Fisher, Lucy. "The Eye for Magic." In Maya Deren and the American Avant-Garde, edited by Bill Nicols, 185-204.

Berkeley: University of California Press, 2001.

Freud, Sigmund. The Uncanny (1919). Translated by David McLintock. London: Penguin Books, 2003.

Hammond, Paul, ed. The Shadow and Its Shadow: Surrealist Writing on the Cinema. Polygon: Edinburgh, 1991.

Holl, Ute. "Moving the Dancers'Souls." In Maya Deren and the American Avant-Garde, edited by Bill Nicols, 151-177.

Berkeley: University of California Press, 2001.

Mannoni, Laurent. The Great Art of Light and Shadow: Archaeology of the Cinema. Exeter: University of Exeter, 2000.

Michelson, Annette. "Poetic and Savage Thought: About Anagram," In Maya Deren and the American Avant-Garde, edited by Bill Nicols, 21-45. Berkeley: University of California Press, 2001.

Mulvey, Laura. Death 24 X a Second. London: Reaktion Books, 2006.

Rees, A.L. A History of Experimental Film and Video. London: BFI, 1999.

Soussloff, Catherine. In Maya Deren and the American Avant-Garde, edited by Bill Nicols, 105-129. Berkeley:

University of California Press, 2001.

Sullivan, Moira. "Deren's Ethnographic Representation of Haiti." In Maya Deren and the American Avant-Garde, edited by Bill Nicols, 207-234. Berkeley: University of California Press, 2001.

Turim, Maureen. "The Ethics of Form." In Maya Deren and the American Avant-Garde, edited by Bill Nicols, 77-102. Berkeley: University of California Press, 2001.

\section{Notes}

1. Deren, "Magic is New," 202.

2. Fisher, "The Eye for Magic."

3. See, for example, Ute Holl, "Moving the Dancers'Souls"; Annette Michelson, "Poetics and Savage Thought"; Renata Jackson, "The Modernist Poetics of Maya Deren"; and Annette Michelson, "On Reading Deren's Notebook."

4. Mannoni, The Great Art, xxii.

5. Deren, "Creating Movies," 137.

6. Fisher," The Eye for Magic," 187.

7. Deren, "Magic is New," 202.

8. Hammond, The Shadow and Its Shadow, 8.

9. Aragon, "On Décor," 57.

10. Deren, qtd. in Rabinovitz, Points of Resistance, 68.

11. Holl, "Moving the Dancers'Souls," 163.

12. Ibid.

13. Qtd. in Soussloff,"Maya Deren Herself," 118.

14. See, for instance, "Creating Movies in a New Dimension: Time" (1946), which she ends with the advice: "But remember - whatever the technique, it must serve the form as a whole, it must be appropriate to the theme 
and to the logic of its development, rather than a display of method designed to impress other movie makers." In Bruce R. McPherson (ed), Essential Deren, 138.

15. Deren wrote of her admiration for Duchamp's film Anemic Cinema in An Anagram of Ideas on Art, Form and Film. See McPherson, 98-99.

16. Deren, "Cinematography: The Creative Use of Reality," 127.

17. Ibid., 126.

18. Benjamin, "The Work of Art," 237.

19. Deren, An Anagram, 102.

20. Epstein, "On Certain Characteristics of Photogénie," in Bonjour Cinema and Other Writings, trans. Tom Milne, 21.

21. Epstein, "Magnification and Other Writings," 9

22. Epstein, "On Certain Characteristics of Photogénie," 23.

23. Ibid.

24. Cocteau and the Surrealists were contemporaries in Paris in the pre-war period but perceived their practices as very different. As A.L Rees asserts, Cocteau was "scathingly attacked by the 'official surrealists in his own time."' Rees goes on to assert that his form of "classicist'return to order"' could be more firmly linked to the work of Georges Franju and post-war French Art Cinema, and credits Cocteau with inaugurating the avant-garde film genre of the psychodrama with which Deren is so often associated. See A History of Experimental Film and Video, 47.

25. See Deren's "Cinematography: The Creative Use of Reality, in McPherson, 121.

26. Deren, An Anagram, 57.

27. Ibid., 58.

28. For more in-depth discussions of Deren's use of ritual see Moira Sullivan, "Deren's Ethnographic Representation of Haiti," 207-234; and Annette Michelson, "Poetic and Savage Thought: About Anagram," 21-45. Both in Nicols, Bill (ed), Maya Deren and the American Avant-Garde.

29. Sullivan, "'Deren's Ethnographic Representation,"' 209.

30. Maya Deren, An Anagram, 58-9.

31. Holl, "Moving the Dancers'Souls," 167-168.

32. Ibid, 171

33. Mulvey, Death $24 x$ a Second, 42.

34. Freud, The Uncanny, 124.

35. Mulvey, Death $24 x$ a Second, 36.

36. Freud, The Uncanny, 142.

37. Ibid.

38. Turim, "The Ethics of Form," 90.

39. Deren, "Cinema as an Independent Art Form," 246.

40. Freud, The Uncanny, 143.

41. It could also be argued that Freud's implication of the double as a folk memory, or product of a cultural consciousness, could also be seen as the point at which the notion of the uncanny touches on Deren's articulation of ritual. She writes in Anagram of how the "deep recesses of our cultural memory release a procession of indistinct figures wearing the masks of Africa, or the Orient, the hoods of the chorus, or the innocence of the child-virgin ... the faces always concealed, or veiled by stylization-moving in formal patterns of ritual and destiny" (55). For Deren, the ritualistic form revealed in these patterns of societal initiation-from song to procession, which "exist simultaneously in unrelated cultures" — were of great importance, revealing "the moral problems which have been the concern of man's relationship with deity, and the evidence of that privileged communication" (58).

42. Freud, The Uncanny, 150.

43. Deren, "Cinematography: The Creative Use of Reality," 117.

44. Ibid., 118.

45. Mulvey, Death 24X a Second, 175.

46. Ibid.

47. Ibid., 178.

48. Deren, "Magic is New," 205. 


\title{
If I can't dance, it's not my revolution!: Tracing the Revolutions of Maya Deren's Dance in Jane Campion's In the Cut
}

\author{
Sophia Mayer
}

Movement is the qualitative multiplicity that folds, bends, extends the bodybecoming towards a potential future that will always remain not-yet. This body-becoming (connecting, always) becomes-towards, always with. I move not you but the interval out of which our movement emerges. We move time relationally as we create space: we move space as we create time.

- Erin Manning, Relationscapes ${ }^{1}$

\section{If I can't dance, it's not my revolution!}

In 1990, radical feminist writer and performer Kathy Acker called for the development, in critical theory, of "the language of the body" to shift "[t]he Anglo-Saxon adoption and adaption of deconstruction [which] had depoliticised its theories." ${ }^{2}$ Writing as the subject of censorship for obscenity for her full-on representations of both female sexuality and feminist rage, Acker insists that the language of the body be recognised as political because it includes "flux ... wonder ... contradict[ion] ... scatology ... languages of play [through which] the life of the body exists as pure intensity."3 Acker's insight prefigured by three years feminist critic Susan Bordo's Unbearable Weight, a book that crucially drew attention to the disappearance of the body as both material and political field in psychoanalytic feminist theory. Since Bordo, feminist and queer cultural theorists have emphasised performance and embodiment in live performance and cinema. In doing so, both theorists and artmakers have revisited an earlier utopian imaginary, that of the American Jewish anarchist feminist Emma Goldman, who in her 1931 autobiography, Living My Life, recounts the anecdote that gave rise to the paraphrased quotation attributed to her: "If I can't dance, it's not my revolution!"4

Goldman, who emigrated from what is now Lithuania to the United States in 1885, was deported to Russia for political reasons in 1917, the year that dance filmmaker Maya Deren was born in Kiev. Deren(kowskaya, as was her birth name) and Goldman never met, as, after her deportation, Goldman was unable to return to the US, where Deren's family emigrated in 1922. While their paths did not cross physically, it is both possible and productive to imagine that Deren discovered Goldman's writing during her literary studies and political activism at Syracuse University in the early 1930s. As Renata Jackson argues, Deren's direct political activism ceased after her divorce from Gregory Bardacke in 1939; or rather, it was transfigured by dance. Goldman's insistence on the dance of revolution, and revolutionary possibility of dance, echoes in Deren's post-graduate employment with African-American dancer Katharine Dunham. In dance, Deren appears to have located a model of affinity, 
collaboration, and transformation that both drew on Trotskyite socialism - to which she had been committed as a student - and also took further Trotsky's arguments for the revolutionary potential of the arts. Deren's casting of dancers of colour from Dunham's company, including Trinidad-born dancer Rita Christiani, in leading roles in her films, demands to be read politically_ and in doing so expands political readings of dance and film to include, and indeed be predicated on, "the language of the body."Thus, Deren's films offer a model for reading the implicit, and often-ignored, politics of embodiment in feminist filmmaking, on which her influence is pervasive.

Dance theorist Erin Manning, who inventively entwines the language of the body with the language of deconstruction in her writing, stands as epigraph to this essay for her idea that the reciprocal movement of dance "extends the body-becoming towards a potential future that will always remain not yet." This extension and potentiality is evident in Deren's dance films, and particularly in Ritual in Transfigured Time (1946). Made the year after the United States ended the Second World War by dropping nuclear bombs on Hiroshima and Nagasaki, Ritual in Transfigured Time is not a capital-P political film. It focuses on the internal and affective drama of womanhood through five danced acts: a stylised exchange in which Christiani helps Deren wind wool, watched by a cicerone played by erotic writer Anaïs Nin; a social dance party that becomes nightmarish through repetition, as Christiani attempts to move through the party; an outdoor ballet in which a statue (Frank Westbrook) comes to life and dances with Christiani and Deren; and a sequence of stylised movement in which Deren and Christiani run into the sea, and then appear to be drowning, surfacing and flying all at once.

In each danced scene, Deren employs a specific cinematicity to translate the movement: slow motion for the wool-winding encounter between Deren and Christiani; graphic matches and loops in the social dance; jump cuts for the modernist pas-de-trois; and finally negativisation. Christiani-who is veiled-and Deren appear as white figures against a black background. Fusing the nun, the mourner and the bride, Christiani is at once a figure of life and death, of mourning and marriage. The coda expands through "the language of the body," connecting the domestic (melo)drama of becoming-female and its rituals and contortions, via the trope of the "angel in the house" to the role of women in war, as mourners on the home front, victims on the battlefront, and - as in the Angel of Verdunmuses of militarism. Falling/rising as a cloud of white, Christiani registers as a visual echo of the atomic cloud. The violence of domestic politics and enforced feminisation is imagistically connected to the violence of international politics through the dancing body, in a way that Goldman would have understood.

Combining rigorous choreo-cinema with a ritualized narrative structure, Ritual forms a mirror to Deren's most celebrated film Meshes of the Afternoon (1942); read together, they book-end American involvement in WWII. A dark fantasia on a sunny afternoon in Hollywood, Meshes is an uncanny prefiguration of many of the preoccupations of film noir; indeed, it suggestively fuses three popular American genres of the 1940s: noir, the musical, and melodrama. Murderous actions and impulses pulse through the short film, embodied in key gestures with a knife, a key, and a kiss. Deren appears in the film as a woman returning home, repeatedly and with some anxiety. Her then-husband, and the film's co-director Alexander Hammid, plays the woman's partner, who returns at the end of the film to find her asleep-and then returns again, to find her dead. Anxiety focuses 
on the shifting, risky boundaries between outside and inside, as the window, the door, and the internal stairs are repeatedly traversed and dislocated. ${ }^{6}$ The film's labile atmosphere and intensely private domestic language, at once intimate and violent, can be read as suffused with specific anxieties about being a leftist Jewish immigrant in the US in 1942 .

Deren's oblique politics are what dance-film theorist Elena del Rio calls a micropolitics of the powers of affection: that is, a body politics that suffuses the body politic. ${ }^{8}$ Del Rio's argument reframes Michel Foucault's idea of a biopolitics (political effects at the level of embodied experience, and even genetic life itself) to suggest that "powers of affection"-a phrase she takes from Gilles Deleuze to describe the complex intertwining of sensory data and emotional response-could be politically efficacious because they act on the body at the cellular, neuronal and haptic levels. This is particularly important as an intervention into large scale (or capital-P) Politics: a recognition that what queer theorist and philosopher of the body Judith Butler names "frames of war" act not just at the level of the nation-state, but body-to-body. ${ }^{9}$ Like Meshes and Ritual, Jane Campion's In the Cut (2003) is a film made within a "frame of war," as the first film to be granted an official permit for shooting in Manhattan after the destruction of the World Trade Center on September 11, 2001. Campion's study of individual grief, centred on Franny, a female professor of literature, at the epicenter of the ever-Decreasing circles made by a femicidal serial-killer, is — like Ritual —an oblique but powerful comment on national and transnational grief and vulnerability. While powerful readings of the film by Sue Gillett and Lucy Bolton have identified many critical ways in which Campion brings together verbal, visual and gestural languages, ${ }^{10}$ no attention has been given to the film's use of dance-nor how its insistence on everyday embodiment, of moving sensually through the world, both grieves the geopolitical conflict in which it is located, and counters it.

Both Ritual and In the Cut speak in "the language of the body" - which unites dance and death-at similar socio-political moments in US history, described by feminist sociologist Susan Faludi in The Terror Dream. After national traumas, argues Faludi, the US mainstream recapitulates the myth of the frontier, with its archetypal figures of the powerful, isolationist, and violent male protecting the vulnerable, domesticated female. Westbrook's spinning throws of his two female partners in Ritual imply the coercive violence towards women that (re)surfaces in the body politic at such historical junctures, while both films explore women's possibilities of escape." Deren's female protagonists choose death over domesticity every time; by Ritual, that death has become richly symbolic of flight to another mode of being within ecstatic religious ritual. Campion's protagonists often pass through a death-like experience-such as Ada's near-drowning in The Piano or Ruth's hallucinatory experience in the desert in Holy Smoke - before choosing a transformed life; In the Cut's Frannie is no different. In In the Cut, as in Ritual, the possibility is extended through relationality: specifically, a relationship with another woman who is both herself and the protagonist's double. In Ritual, as described, this doubling which is not one takes place between and across the figures performed by Deren, the white Russian Jewish immigrant, and Christiani, the black Trinidadian immigrant. In In the Cut, the physical identification is closer, but the union still occurs through dance, as Frannie and her half-sister Pauline compare their separate (and separated, by their mutual father's infidelities) adolescences while dancing in Pauline's apartment.

This echo of foundational feminist theorist Luce Irigaray's This Sex Which Is Not One is deliberate: questions of binaries and dualities are crucial in feminist theory, and perhaps 
crucial too with regards to dance. In Darren Aronofsky's film Black Swan (2010), to take a high-profile example, schematic misogynist dualities between masculine and feminine and within femininity are troped through associations with (feminised) dance and performance, despite forty years of feminist dance and dance film. Irigaray's generative language of doubleness and repetition-with-a-difference offers a potent framework for reading both Deren's and Campion's films as they mimic, but alter, the misogynist noir genre, and as their protagonists try to break out of the spiral of repetition of gendered violence. This is the primary political work of the dance in both films: asserting the biopolitical power of the active, affective body as, in Manning's words, dance "folds, bends, extends the bodybecoming."12 It is this becoming - this extension to a potential future that refuses the femicidal narrative logic of the genre-that unites Ritual and In the Cut, and is unfolded through this essay.

\section{Moving and Moving}

Compositionally, albeit not traditionally choreographically, Campion's film clearly signals its inheritance from Deren, and in particular Deren's theory of poetic film's "verticality."Whereas Deren used dance to thread the stacks of her vertical, associative montage, Campion makes dance scenes one of the associative tracks or stacks through In the Cut. Each danced scene is constructed with both explicit and implicit references to Deren's associative and rhythmic editing, her juxtaposition of real and imagined spaces, and her non-linear temporal signature. But it is their associative repetition-with-a-difference across the film that creates a structural verticality that strings the film together, like the bridges across which Frannie travels to reach Pauline's apartment, which connect Manhattan to its outer boroughs, and to the rest of the U.S.

As Frannie travels home from the George Washington Bridge in the very north of Manhattan (where her quest to discover the serial killer ends), to her apartment in Washington Square in the south (following the track of Broadway), a series of associative edits moving her across the city suggests the famous sequence in Meshes, in which Deren steps from beach to garden to interior across straight cuts. As Manning comments, "when I take a step, how the step moves me is key to where I can go."13 The step is the key signature of Campion's film, as it is of Meshes. Frannie, too, is frequently shown walking up (and down) stairs, often with the use of expressionistic camera angles and slow motion. Like Meshes, In the Cut is a daylight anti-noir that uses the tropes of the genre (including the knife and the key) to critique femicide, to tell, in Yeats's words, the dancer from the dance-that is, to take the femme fatale, whom Janey Place reads as an intelligent, forceful female protagonist able to articulate her own desire, and separate the femme from her fatality. ${ }^{14}$

Famously, Laura Mulvey's "Visual Pleasure and Narrative Cinema" proposed an anti-narrative counter-cinema to do that work. Yet Deren's films, which influenced countercinema dancer-filmmakers such as Yvonne Rainer and Sally Potter as well as Campion, are not anti-narrative, but rather foreground dance as a counter-strategy that, like narrative, moves through time and moves the body. They use dance to foreground the female body not as an object of the gaze, but in the manner argued by feminist performance art theorist Jill Dolan, as a subject "know[ing], intellectually and psychophysically ... how to control the seductions inherent in the frame, and how to speak the language so that authority, 
seduction and language mean something different about the status of women in culture."15 Similarly, Deren's films use dance in the same way that Mulvey suggests that conventional Hollywood narrative cinema uses the close-up of the female face: to delay, disperse and defer the narrative thrust.

Like Deren, Campion uses dance to disrupt narrative logic without recourse to the reifying force of the close-up. Instead, she offers medium long shots of bodies in movement; as Lucy Bolton notes, Frannie is rarely still. ${ }^{16}$ She walks incessantly around New York; even standing on the subway, she moves and is moved, both by the forward motion of the subway car, repeated by the handheld camera, and by the Poetry in Transit placards that cause her to move her mouth, reading to herself. This repeated scene of Frannie engaging, bodily, with an artwork in a rectangular frame, repeats and draws attention to Campion's imagining of the viewer's experience of cinema. Film theorist Noël Carroll described dancefilmmaker and choreographer Yvonne Rainer's work as "moving and moving."17 That is, screen movement (co-composed of gesture and cinematography) engages the viewer affectively because the viewing body responds to movement.

Campion's earlier film, The Piano, was crucial to the development of feminist film phenomenology, a theory that extended Carroll's insight to explore exactly how screen media affect the viewing body. Its pioneer, Vivian Sobchack, devotes a chapter in Carnal Knowledge to reading the opening moments of The Piano, in which the viewer appears to be looking through Ada, the protagonist's, fingers. In In the Cut, Campion experiments with other images of women's self-touch in relation to the female gaze, including a scene in which Frannie masturbates. Yet she is unable to climax because her foot cramps. Later in the film, after Pauline's death, this bare foot becomes a sign of vulnerability and mourning: she loses her shoe in the police station; then on the stairs of her apartment building when she goes to welcome a student who subsequently attacks her; after the attack, her loverthe detective investigating the murders, Giovanni Malloy—bathes her and washes her feet. When she finds a clue that suggests he is the murderer, she flees down the stairs and into Washington Square barefoot, returning the same way the following morning.

Sally Banes titles her book on post-modern dance Terpsichore in Sneakers to suggest the contrast between the traditionally feminine, atemporal, fleet-foot image of the dancer, and the multiplicity, dynamism, athleticism, and creative juxtapositions of the form's reinvention. Yet Frannie's barefoot movements are far from indicative of a nostalgic return to Mount Helicon. Instead, as viewers, we become aware of the sole of the foot as a sensitive, even erotic, surface of touch, like Ada's (piano-playing) fingers in The Piano, so that what Laura U. Marks calls our "haptic visuality" is solicited. ${ }^{18}$ The vulnerability of Frannie's feet makes us feel (texture) and feel (emotion). Feet yoke agential forward motion and the dilatory effects of dance. They also draw attention to the ground Frannie stands on: New York, whose traumatic recent history is the counterpart to many other historical strands, including immigration via Ellis Island (Giovanni Malloy's name suggests his heritage from both Irish and Italian immigrants), as well as counter-cultural practices from Deren's days in Greenwich Village to the radical dance innovations of Judson Church described by Banes. Like the sneaker-clad dancers of Yvonne Rainer's Trio A, Frannie's barefoot flights blur the boundaries between dance and the everyday, drawing attention to all of the gestural language in (the) film as choreographic. Although there are only a handful of brief scenes that could formally be designated as dance in In the Cut, Frannie's feet moving and 
moving - nevertheless mark Campion's inheritance from Deren, not least her repetitionwith-a-difference of Deren's danced intervention into film noir.

\section{Dance of the Seven Veils}

Femmes fatales don't dance. As Richard Z. Santos notes, despite its nocturnal urbanity and erotic overtones, noir rarely employs dance, with only mannerist, pastiche noirs Bande à Part and Pulp Fiction containing notable dance scenes. ${ }^{19}$ Richard Dyer suggests that dance would allow the viewer to know the femme fatale on her own terms, and that this would undermine the conceit of the genre, in which the male protagonist is knowable, stable and thus our point-of-view character, while the femme fatale is mysterious to both the (anti) hero and the viewer. He notes of Gilda:

No other femme fatale dances ... The use of dance as "self-expression" as instanced by Fred Astaire was also available to and used by [Rita] Hayworth (though always in a less developed form than Astaire's). Although "self-expression" is a problematic concept in relation to the arts, as a notion informing artistic practices, and especially dance, it is extremely important, and especially in the context of a character who is generically constructed as having no knowable self. ${ }^{20}$

Santos points to the contrasting example of David Lynch and Mark Frost's television series Twin Peaks, which features dance as a polyvalent expression, oscillating between a potent symbol of female sexuality (culminating in the ridiculous Miss Twin Peaks pageant choreography) and a dangerous expression of male madness (the Man from Another Place's shoe shuffle, Leland Palmer's dancing); either way, it marks alterity and the disruptive power of sexual desire.

Santos does not include In the Cut in his article, and critics have failed to note the way in which dances similarly pervade In the Cut, focusing instead on the film's engagement with literature and verbal language. Frannie teaches creative writing at a community college, and is writing a book about street slang. Yet there is a verbal connection between these two cerebral activities that also connects them intimately to her body. She is teaching Virginia Woolf's To the Lighthouse, and among the first lines of dialogue in the film is an exchange about one of the slang words she has pinned to her wall, when she explains to Pauline that "virginia" means "vagina, as in 'he penetrated her virginia with a hammer."'The coolly-delivered grotesque violence, emerging as it does from a dreamy credit sequence in which Pauline walks through early morning Manhattan, is startling. Campion's film is insistent on both the grace and the vulnerability of embodiment, on how being open to the sensual world also leaves one open to the invidious violence of those who are threatened by openness.

As in Ritual and Meshes, a woman's entry into the world risks the equal and opposite entry of the world into the woman: this can be consensual or violating. The interchange in In the Cut between verbal language, visual language, and gestural language is highlighted by Frannie's absorption in the Poems in Transit on the subway. When Malloy is similarly stimulated to read aloud a quotation from Pablo Neruda that Frannie has pinned to the wall in her home office, we are alerted to their simpatico and his feminine openness. "I want to do with you / What spring does with cherry trees," he reads, wiping his hand across his moustache, as Gillett observes. ${ }^{21}$ When a white blossom pastes itself to Frannie's leg as she 
climbs the stairs barefoot and grieving, this quotation returns to mind, again connecting poetic language to physical movement, and particularly the Terpsichorean figure. It is by harmonizing her poetic insights and her kinetic embodiment that Frannie is "[anti ] generically constructed as having [a] knowable self."

Barbara Kennedy, reading the feminist potential of neo-noir, argues that "the erotogenics of the filmic experience ... articulates more than just the pleasures of scopophilia and voyeurism. Identities and subjectivities are experienced, created or negated through wider affective or sensual frameworks outside the notions of vision and the gaze."22 It is through the mediation of dance that Frannie's poetics of the body becomes actualised, and/as it is her poetics that lifts the film's dance. As in Meshes, the use of eccentric framing, slow motion, extreme close-up, canted angles, and the contrast between exterior and interior light adds to the film's expressionistic dreaminess, and its insistence on femmeinity as a challenge to the hard-boiled, hard-bitten noir genre encoded. It is this reframing, which reinforces the dilatory temporality of danced movement, that in both films not only troubles but completely reappropriates the voyeuristic scopic regime apparently incited by the focus on the female protagonist as erotogenic subject. Through choreo-cinema, they articulate an answer to Clare Whatling's question: "Can the femme lesbian articulate, just by looking, that she is both object and subject of that look?"23 Both films suggest that looking needs to be embedded in movement and the haptic to achieve that articulation.

Both Frannie and her half-sister Pauline are decidedly femme in their self-presentation: both have, as various men in the film note, long hair, and they exchange dresses and jewellery. Unlike the hard-bodied heroines of post-feminist films such as Thelma and Louise (1991) or Blue Steel (1989), which rewrite the narrative of the thriller by making the female protagonist(s) physically aligned with the action hero, Frannie is an accidental hero, embroiled in a murder mystery by chance when a woman's body parts are found in the garden beneath her window. Frannie finds herself a key witness, complicated by having seen the woman alive shortly before her murder, and further complicated by becoming sexually involved with the investigating detective, Malloy, whom she suspects of being the killer. Although Frannie's relationship with Malloy unfolds across the course of the film, Pauline is Frannie's primary relational figure. Campion and co-screenwriter Susanna Moore, adapting her own novel, transposed Frannie and Pauline from best friends to halfsisters. This adds both biopolitics, through their genetic connection, and, as Bolton argues, an Irigarayan female genealogy. She notes "a tender, gentle scene in which the intimacy between the women is portrayed by their clothing, their gestures, and their palpable affection ... [which frames] the discussion of their mothers as women."24

The palpability of their affection is presented through dance. They are in Pauline's apartment, which is a mass of sensory stimuli that blurs the auditory, visual and tactile: beaded curtains, textured fabrics, and the women's own bodies in conversation. The use of close-ups, attention to small sounds, muted colours combined with sparkle, and natural light, all leading into the dance, combine to

make experiential musicality felt as a sound-moving-with and a moving-withsound. This creates an amodal relay that distributes sound throughout the sensing body in movement as both the effect of movement and the instigator of 
experiential space-time. We experience this sound-movement tonally, affectively, through a rhythmic re-invention of the environment's sensory dimensions. ${ }^{25}$

When Frannie and Pauline dance, it is as if they have been led into the dance not only by the song on the radio and the intimacy of their conversation, but by the sonorous, reflective, tactile kinesis of the apartment and the cinematography.

Their dance is tactile, languorous, unforced, suggestive of a shared adolescence-the shared adolescence that their conversation reveals they didn't have, as Frannie's father left her mother for Pauline's mother, whom he didn't marry, but also abandoned. "In the Cut has been read as a Freudian essay on the feminine Oedipus complex-both Pauline and Frannie, deprived of paternal love and familial security, are driven to 'Wait in Vain' for their phallus." ${ }^{26}$ As they talk, Annie Lennox's cover of Bob Marley's "I Don't Wanna Wait in Vain for Your Love" plays on Pauline's radio, suggesting a typical chick flick, in which women talk only about men, and perform only for men-specifically, for a man who will probably come between them, causing jealousy and separation. Ritual dramatizes this separation in the violence of Westbrook's partnering and the impossibility of an equal pas-de-trois, as his appearance separates Deren and Christiani even as, and because, he dances similar sequences with each of them.

Yet Frannie denies that chick flick trope. Instead of arguing about men, she quotes poet Samuel Taylor Coleridge to the effect that she is "of this human heart a-weary." When the song changes, she jumps up and pulls Pauline into a dance, saying of "Just My Imagination," "This is my song," a phrase that is suggestive both of romantic relationships culminating in marriage ("They're playing our song"), and the strip bar downstairs from Pauline's flat, where the workers may lay claim to, or be scheduled by, particular songs. Yet, as Frannie would know, the phrase could also be Coleridge's, and thus stand outside these gendered forms, as he theorised "imagination" as the generative power of creativity, which could be read as an abrogation of female reproductive capacity. ${ }^{27}$ Thus Frannie lays claim—my song, my imagination-just after Pauline has told her she thinks she should have a baby, for their mothers' sakes. Pauline later gives her a charm bracelet with a baby-in-a-carriage charm that becomes a clue in her identification of the killer. Dance, with its affective knowing, will end up saving Frannie's life-as it re-unites (or merges) and saves Deren's and Christiani's in Ritual, as they are transfigured from drowning to flying. The final union makes good on the initial encounter between Deren and Christiani within the house, winding wool, and repairs the damage done by the pas-de-trois. Frannie and Pauline's dance resonates far beyond its brief length because of the discussion of their mothers - which extends the film's duration back in time beyond its first scene to Frannie's mother's engagement to her father - and because Frannie claims "her song," her knowable self expressed through music and movement.

\section{Dancing in Circles}

Frannie's claim to her song layers the affect of this scene across the film, almost as a manifesto, so that both previous scenes - specifically, her interactions with Malloy (which are the subject of discussion before she and Pauline dance-and future scenes-specifically, the encroachment of the serial killer, who acts on/out his warped "imagination"-are embedded in this casual dance. Both the use of dance and its centering of a spiral that 
exists in productive tension with the linear drive of the thriller point to the influence of Deren's work on the film, and particularly to Ritual. Whereas Deren worked with the lyric intensity of short films, Campion uses Deren's strategies to structure a narrative feature that takes on the fatalistic (il)logic of noir, using dance both to delay noir's tight temporality, and to illustrate, for both the viewer and Frannie, the ways in which embodied repetition can become a difference, preventing fatality.

Dismantling the romantic narrative often associated with the dance film (although Sue Thornham argues otherwise ${ }^{28}$ ), and of which noir is the cynical obverse, In the Cut counterposes the intimacy of the sisters. It does so through a series of resonating danced scenes, centred on Frannie and Pauline's dance, whose spiralling interconnection echoes the multiple modes of social dance that are Deren's rituals to transfigure time. As in Deren's film, the dances span from quasi-adolescent homosocial "bedroom dancing" to the highly public and coercive rituals of heteronormativity, when Frannie enters the classic neo-noir scene of the (Looking for Mr. Good) bar on a date with Malloy. This association is made explicit in the climactic scene, when the serial killer who has been stalking Frannie asks her, at knifepoint, to dance. This confrontation echoes both Rituals and Meshes: the violent pas de trois of the former, with Pauline, the killer's previous victim, as an absent presence between the dancing pair of Frannie and Rodriguez; and the alternating homicidal encounters of the latter, as we think Frannie has been murdered, then - after a reverie - we learn she has killed the killer. Deren, making films in the 1940s as both feminism and socialism were curtailed by the war and then by post-war normativisation, can find only ambiguous solutions; Campion, making films after post-feminism and 9/11, returns to those solutions but allies them to feminist experiments in narrative, particularly the retelling of myths and fairy tales.

This is most apparent in a second associative cascade, also connecting Frannie and Pauline: an imagined dance, shown in sepia vignettes, whose coloration and costuming link In the Cut to Campion's costume dramas The Piano (1993), The Portrait of a Lady (1996), and Bright Star (2009), which investigate women's resistance to the coercive gendered asymmetry replicated by canonical literature..$^{29}$ The first vignette appears in the opening sequence, and shows a beautiful young woman whose ice-dance on a frozen pond solicits the gaze of a handsome older man, who skates up and proposes to her. Frannie is awakened from this dream by Pauline arriving to describe the petal shower she had danced in, which Frannie had thought was the snow seen in her dream. This vignette repeats as Frannie dances languidly with Pauline, and retells this story of her mother's engagement to their father. It recurs again, changing its details towards a horrific realisation, after Frannie's dance with the killer: it is what interrupts, and then restarts, the scene of the murder in its doubling. The reconfiguration shows Frannie's mother's legs being severed by the show-off skater when she refuses his offer of an engagement ring (as Frannie has refused the killer's offer of a ring); grotesque and grand guignol, red blood spurts into the sepia tint. Campion uses this violence, as Deren does in Meshes, to uncover the violent premise of submission secreted at the heart of the costume drama and of the heteronormative partner dance.

\section{Dancing in the Ashes}

Both Meshes and In the Cut engage, via danced embodiment, with noir 's deathliness as both an analogy for, and a paradigm of, the fatalistic national American myth of male violence 
in defense of the victimised female/feminised victim described so precisely by Faludi. Noir is particularly powerful as an analogy that problematises this model because, as Rebecca Stott argues, the femme fatale is not the simplistic figure of the feminised victim, but "a sign, a figure who crosses discourse boundaries, who is to be found at the intersection of Western racial, sexual and imperial anxieties." ${ }^{\prime 30}$ Like Meshes, In the Cut uses the home as a site of dangerously porous boundaries to posit a dual meaning of "domestic" that conflates living space and nation-state at moments of crisis. Within that domestic space, the crisis of invasive violence disrupts the cohesive self, so that experimental techniques, including embodiment as danced, become psychically and empirically "realist," moving us into what Gilles Deleuze would describe as the molecular experience of a particular (and particulate) subjectivity. Deren, prefiguring Julia Kristeva and influenced by Henri Bergson, describes her films as "the films of a woman... Time is built into her body in the sense of becomingness.... I think that my film is putting the constant stress on metamorphosis ... this is a woman's time sense."131 This emerges signally in dance, as suggested by Manning. The repeated, hieratic movements of dance also introduce ritual or festival time; as described by Mikhail Bakhtin, this resonates with Deren's idea of the vertical film, in that ritual time, through repeated performances linked to the cyclical calendar of the seasons, lifts the festival out of historical horizontal time, stacking it vertically with all other occurrences of that festival. Thus dance is again figured as a disruption of the linearity that produces the violent vengeance of cause/effect narratives, as they structure US foreign policy as well as noir.

It is thus suggestive of the origins of theatrical performance in the Greek mysteries, which involved ritual dances by women, to be performed away from the male gaze. Mystery comes from the Greek root muein, meaning "to close one's eyes." In the Cut uses the close-up to stage a micro-dance of the eyelids, opening and closing: the film opens with Frannie drifting in and out of sleep while dreaming of her parents' meeting, and ends with her awakening fully from the nightmare of the ice-dance that is her primal mystery. As Sue Gillett notes, the film is replete with references to Medusa, and thus to the Freudian primal mystery of the mother's (castrated) genitals. ${ }^{32}$ Countering this, however, the disarticulated heads left by the killer could be read as evoking the myth of Orpheus and Eurydice, with Frannie gender-transposing the role of the grieving poet as she ascends and descends stairs. The Orphic mysteries borrowed from those of Demeter, whose search for her daughter Persephone in the Underworld was commemorated at Eleusis, outside Athens. It was one of the few occasions when women were allowed to leave the classical city-state without chaperones, providing an all-female space that was also public and political. In the context of post-9/11 America, this is deeply suggestive, as the Eleusinian mysteries were rituals of civic mourning performed only by women, grieving for the dead and reincorporating them into civic life as beloved memory. They allowed the city to mourn: that is, to move on, to accept the reality of death, to accept that, as Butler argues in Precarious Life, even the most powerful city-state can be undone, and is always vulnerable.

The film positions Frannie as Korē, the figure of the Girl as always being abducted by Death, as three women, including Pauline, are in the film; it also, however, suggests her as an inverse-Demeter, searching for her mother, and later for Pauline. On one of her subway journeys, she sees a bride on the platform, a vision that will recur to her when she is in the car with the killer towards the end of the film. Both Eurydice and Persephone, and also Alcestis who died on her wedding day to save her husband's life and was returned to 
life by the hero Theseus, the bride encodes marriage as murder and mourning, reflecting the serial killer's modus operandi of proposing engagement to his victims. She is also an ambiguous but utopian sign to Frannie: as well as warning her of the serial killer's MO, she invokes Alcestis' and Persephone's possibility of return from the underworld - not erasing it, but surviving it. Reading the end of In the Cut, Elisabeth Bronfen argues that "waking up and walking into the dawn of morning might just as well mean preserving the dialectic between night/day rather than insisting on a violent repression of the nocturnal side of the psyche. It might well mean focusing on the partial darkness inevitably accompany all hopes and anticipations connected to love, on the partial light illuminating all sense of vulnerability and anxiety."33

Such a reading could also be applied to Meshes and Ritual. Deren wrote to James Card in 1955, "What I meant when I planned that four stride sequence [at the end of Meshes] was that you have to come a long way-from the very beginning of time-to kill yourself." ${ }^{\prime \prime 4}$ Frannie's repetition of Deren's stride in her dawn walk suggests such a death as both a figure of transformation, and "a preservation of the dialectic between night/day." Deren sought and found such a dialectic outside mainstream American culture: first in Dunham's dance, and then later_following Dunham's own work as an anthropologist_-in her anthropological work in Haiti. In Divine Horsemen: The Living Gods of Haiti, Deren writes of her identification with, and possession by, Voudoun goddess Erzulie, the goddess of love (and its shadow side, jealousy) and imagination: the arts, and especially dance, fall under her sway. Erzulie, as an archetype, is absent, suppressed or distorted in Graeco-Roman and Judaeo-Christian mythology, hence Bronfen's reappropriation of the Queen of the Night from Mozart's opera The Magic Flute and Campion's of Demeter/Persephone: at the heart of these figures, in their movement in particular, is the kernel of a pre-patriarchal feminine power that Deren found in Erzulie.

\section{The Dance of Death}

Bronfen reads the Queen of the Night as an the uncanny figuration that condenses female power and the occult, rather than emphasising "positive representation." The medieval image of the woman locked into the Dance of Death, of which the femme fatale is but the latest iteration, is predicated on female reproductive sexuality, which both by its sinfulness and its temporality entraps women in the mortality of the body. Frannie's dance with death ends with her shooting Rodriguez with Malloy's gun; she had snatched up his jacket after finding the baby-in-the-carriage charm from Pauline's gift bracelet, while looking for the handcuff key. Mistaking the charm for the key to the identity of the killer, she also finds - at exactly the moment she needs it-his gun. So the danced logic of the film, which led her through affective contact with Pauline to trust Malloy, reverses the dance of death. It is Frannie's generative immersion in the temporality and sensuality of embodiment-which first emerges in contact with Pauline-that saves her.

In In the Cut, dance marks a model of women's time whose embodied presentness insistently carries traces of the genealogical past; from that remembering, which is also grieving, there emerges a potential future. This is both personal and political, as in the negativized coda at the close of Rituals, where Christiani's survival by merging with Deren is a riposte to racism and warmongering. Similarly, Frannie's dance with Pauline forms the 
fulcrum of two vertical series that draw on her lived experience with Pauline in order to initiate her survival of Pauline's fate. It's part of the sisters' physical and affective closeness in urban movement, walking around lower Manhattan near Frannie's apartment holding hands and talking, and also of their intimacy in domestic space: moving and moving. They also move between, and thus link, spaces: they spend time in Frannie's apartment at the start of the film, and then-after Frannie's apartment is tainted by Angela Sands' murder, and then by a mugger who takes her keys-Pauline's. Pauline's apartment is above a strip club, where both Frannie and Pauline hang out, chatting with the staff. On one occasion, Frannie watches part of a dance, whose exaggerated eroticism and muscular virtuosity is in contrast with her dance with Pauline, and yet whose vigorous female embodiment (and loud music) connects the dancefloor to the apartment vertically above it. Troubled by the loud music in a later scene, Pauline comments to Frannie, "I need to move." It's her last line in the film.

Even after Pauline's apartment is desecrated by her murder-and Frannie finds her sister's head in exactly the location that Pauline uttered this line-the interpersonal bond between them shapes the film. Del Rio argues for

the irreducibly affirmative signatures of the body, which only the onset of death can fully erase, for it is precisely at that moment that the body's powers to affect, and to be affected by, other bodies reach a point of exhaustion ... [Yet n]either forgetfulness of signs or traces, not the physical elimination of bodies, can truly result in a full erasure of their affects. Instead, the body subjugated cannot but continue, however stealthily, to express itself..35

Dance as propulsive movement opens the sisters' relationship towards the city (and vice versa); as affective touch, dance's traces throughout the film link all its locations as a shared intimate space. In both forms, it enables Frannie, through her relational enmeshing with Pauline, to contest the fatalistic spiral of the killer's phantasmic heteronormativity. She had been wearing Pauline's dress when she first heard about Rodriguez's demotion, and subsequently receives a startling display of Rodriguez' misogyny, even as he cruises the dancefloor at the bar where she has met Malloy. She and Malloy do not dance, and she walks home alone. She has a bruising encounter with a masked mugger, which she subsequently replays with Malloy in her kitchen. Both in its specific physicality-the mugger encircling her neck from behind, a gesture reminiscent of the starting pose of Johnny and Baby's climactic dance in Dirty Dancing (Baby's given name, uncannily, is Frances) - and this rehearsal, the mugging is transmuted into dance, as Frannie's self-awareness of desire begins to open the spiral of gendered violence into the negotiated potential of mutuality.

When she engages in a performative, hyper-femme re-embodiment of Pauline after the murder-dressing in red, Pauline's colour, and being sexually aggressive-Malloy not only accepts but enjoys it. Handcuffed to a radiator pipe, Malloy is literally trapped in Frannie's imagined spiral of repetition as she mis-takes him for the killer, fleeing into the path of Rodriguez. Although Frannie returns to Malloy, still cuffed to her pipe, at the end of the film, her Meshes-esque walk is so evocative of Pauline's journey through the city at the beginning of the film that the two relationships-heterosexual and homosocial—fuse into each other, with Malloy repeating Frannie's supine position of the opening scene. It is as if the spiral/cycle can start again —of course, it can't, and it doesn't cancel 
grief. But it is the as if, the transfiguration of time, that is part of the film's utopian project. Pauline's dance in the petal shower at the opening, which Frannie says she thought was the snow in her dreamed vignette, has been transmuted into dazzling glitter that occurs after Rodriguez appears to strangle Frannie, which transpires to be rain falling onto their bodies; the sparkling bead curtain of Pauline's apartment forms an intermediate term. This "haptic visuality," in which the screen itself appears to dance, is allusively described by Gilles Deleuze in Cinema 2, where he says that cinema "spreads an 'experimental night' ... over us; it works with 'dancing seeds' and a 'luminous dust'; it affects the visible with a fundamental disturbance, and the world with a suspension, which contradicts all natural perception."36

In the Cut meshes profilmic and cinematographic "dancing seeds" to instigate a Derenian poetic cinema that resituates the everyday as dreamy, imaginative, sensual and affective. Dance is no longer a distinct/ive mode of the performative, but integrated into feminist cinematic embodiment. This integration is what opens the film and its danced bodies beyond questions of representation and presence, into a negotiation with biopolitics at the level of 'luminous dust,' which figures both the generative imagination (Frannie's revised dream returning her to life, re-mothered by Pauline's death) and the micropolitics of the body. This in turn figures the new feminist theory argued for by Elizabeth Grosz, which "needs to welcome again what epistemologies have left out: the relentless force of the real, a new metaphysics ... we need to reconsider both representation and representational forces in their impact on the mediation of the real."37 Closing her apartment door in our faces, Frannie turns us both back to the beginning of the film with a set of tools learned from the spiral to read the spiral, and outwards towards the world. In its haptic and narrative pleasures, predicated on Derenian dance, this is Emma Goldman's longed-for revolution.

\section{Notes}

1. Manning, Relationscapes, 17.

2. Acker, "Critical," 91; 85.

3. Ibid. 91-92.

4. Goldman, Living, cap. 5.

5. Manning, Relationscapes, 17.

6. Rhodes, Meshes, 64-66.

7. Alexander Hammid, Deren's husband and the co-director of Meshes, fled to the US from fascist Czechoslovakia over fears about a critical documentary he had shot. At the moment Deren and Hammid were conceiving Meshes in Los Angeles, Japanese Americans were being interned under FDR's Internment Act of February 1942, at Pomona and Santa Anita just outside LA, as elsewhere throughout the West Coast.

8. del Rio, Deleuze, 208-16.

9. Butler, Frames, passim.

10. Bolton, Film, 60-94; Gillett, "Engaging."

11. See Geller, "'Each Film Was Built,"' on Deren's strategic response to the post-war re-domestication of women in the US.

12. Manning, Relationscapes, 17.

13. Ibid., 6.

14. Place, "Women," 37.

15. Dolan, Presence, 1. 
16. Bolton, Film, 62.

17. Carroll, "Moving."

18. Marks, Skin, 206-11

19. Santos, "Dancing."

20. Dyer, "Resistance," 96-97

21. Gillett, "Engaging."

22. Kennedy, "Post-Feminist," 126.

23. Whatling, "Femme," 80.

24. Bolton, Film, 82.

25. I'm here borrowing Manning's account of a short dance film. See Manning, Relationscapes, 214.

26. Bolton, Film, 66.

27. See Harvey, Ventriloquized.

28. Thornham, "Starting," 33-46.

29. All of Campion's costume dramas feature tangential or eccentric versions of the climactic social dance scenes that are a key trope of costume drama, while never offering pointed parody, as Sally Potter does in the ballroom scene The Gold Diggers, where the female dancers throw over their male partners and escape, leaving the men to dance together. In The Piano, for example, Ada's young daughter Flora dances uninhibitedly on the beachperforming cartwheels that reveal her knickerbockers - as Ada plays the piano, while in Bright Star, Fanny Brawne is seen at a dance at the start of the film, cuing viewer expectations of an Austen-esque romance. Fanny talks about making dresses for dances thereafter, but her expected unison with John Keats through the trope of social dance is never realised.

30. Stott, Fabrication, 30.

31. Qtd. in Kudlácek, In the Mirror.

32. Gillett, "Engaging," n.p.

33. Bronfen, "Nocturnal," n.p.

34. Qtd. in Rhodes, Meshes, 86.

35. del Rio, Deleuze, 209.

36. Deleuze, Cinema 2, 201, qtd. in Brannigan, Dance Film, 10.

37. Grosz, Becoming, 85 .

\section{References}

Acker, Kathy. "Critical Languages." In Bodies of Work, 81-92. London: Serpent's Tail, 1997.

Banes, Sally. Terpsichore in Sneakers: Post-Modern Dance. Middletown CT: Wesleyan University Press, 1987.

Bolton, Lucy, Film and Female Consciousness: Irigaray, Cinema and Thinking Women. Basingstoke: Palgrave Macmillan, 2011.

Bordo, Susan. Unbearable Weight: Feminism, Western Culture and the Body. Berkeley: University of California Press, 1993.

Brannigan, Erin. Dance Film: Choreography and the Moving Image. New York: Oxford University Press, 2011.

Bronfen, Elisabeth. "Nocturnal Embodiments: Gendering Allegories of the Night." June 10, 2004. http://www. bronfen.info/index.php/archive/47-archive2004/108-gendering-allegories.html. Accessed 30 July 2012.

Brooks, Jodi. "Rituals of the Filmic Body." Writings on Dance 17 (1998): 15-20.

Butler, Judith. Frames of War. London: Verso, 2010.

Carroll, Noël. "Moving and Moving." Millennium Film Journal 35/36 (Fall 2000). http://www.mf-online.org/ journalPages/MFJ35/MovingandMoving.htm. Accessed 30 Jul. 2012.

del Rio, Elena. Deleuze and the Cinemas of Performance: Powers of Affection. Edinburgh: Edinburgh University Press, 2008. 
Deleuze, Gilles. Cinema 2: The Time-Image. Translated by Hugh Tomlinson and Robert Galeta. London: Continuum, 2005.

Dolan, Jill. Presence and Desire: Essays on Gender, Sexuality, Performance. Ann Arbor MI: University of Michigan Press, 1993.

Dyer, Richard. "Resistance through Charisma: Rita Hayworth and Gilda." In Women in Film Noir, edited by E. Ann Kaplan, 91-99. London: BFI Publishing, 1980.

Geller, Theresa L. "'Each Film Was Built as a Chamber and Became a Corridor': Maya Deren's Film Aesthetics as Feminist Praxis." In There She Goes: Feminist Filmmaking and Beyond, edited by Corinn Columpar and Sophie Mayer, 79-92. Detroit: Wayne State University Press, 2009.

Gillett, Sue. "Engaging Medusa: Competing Myths and Fairytales in In the Cut." Senses of Cinema 31 (2004). http:// sensesofcinema.com/2004/feature-articles/in_the_cut/. Accessed 30 July 2012.

Goldman, Emma. Living My Life. New York: Alfred A. Knopf, 1931. http://theanarchistlibrary.org/library/emmagoldman-living-my-life\#toc7. Accessed 30th July 2012.

Grosz, Elizabeth. Becoming Undone: Darwinian Reflections on Life, Politics and Art. Durham NC: Duke University Press, 2011.

Harvey, Elizabeth D. Ventriloquized Voices: Feminist Theory and Renaissance Texts. London \& New York: Routledge, 1992.

Kennedy, Barbara. "Post-Feminist Futures in Film Noir." In The Body's Perilous Pleasures: Dangerous Desires and Contemporary Culture, edited by Michele Aaron, 126-142. Edinburgh: Edinburgh University Press, 1999.

Kristeva, Julia, “Women's Time."Trans. Alice Jardine and Harry Blake. Signs 7, no. 1 (Autumn, 1981): 13-35.

Manning, Erin, Relationscapes: Movement, Art, Philosophy. Cambridge: MIT Press, 2009.

Marks, Laura U. The Skin of the Film: Intercultural Film, Embodiment and the Senses. Durham: Duke University Press, 2000.

Mayer, Sophie. "Putting on the Red Shoes: A Tango with the Camera." Vertigo 3, no. 5 (Spring 2007): 17-19.

Mulvey, Laura. "Visual Pleasure and Narrative Cinema." Screen 16, no. 3 (1975): 6-18.

Nichols, Bill, ed. Maya Deren and the American Avant-Garde. Berkeley: University of California Press, 2001.

Place, Janey. "Women in Film Noir." In Women in Film Noir, edited by E. Ann Kaplan, 35-67. London: BFI Publishing, 1980.

Pramaggiore, Maria, "Seeing Double(s)." In Maya Deren and the American Avant-Garde, edited by Bill Nichols, 237-260. Berkeley: University of California Press, 2001.

Rabinovitz, Lauren. "Maya Deren and the American Avant-Garde Cinema." In Points of Resistance: Women, Power and Politics in the American Avant-Garde Cinema, 1943-71, 41-91. Champaign: University of Illinois Press, 1991.

Rhodes, John David. Meshes of the Afternoon. Basingstoke: BFI/Palgrave Macmillan, 2011.

Santos, Richard Z. "Dancing Around the Scene of the Crime." Criminal Element.Com, December 2011. http://www. criminalelement.com/blogs/2011/12/dancing-around-the-scene-of-the-crime. Accessed 30 July 2012.

Sobchack, Vivian. Carnal Thoughts: Embodiment and Moving Image Culture. Berkeley: University of California Press, 2004.

Stott, Rebecca. The Fabrication of the Late Victorian Femme Fatale: The Kiss of Death. London: Macmillan, 1992.

Thornham, Sue. "Starting to Feel Like a Chick: Re-visioning Romance in In the Cut." Feminist Media Studies 7, no. 1 (2007): 33-46.

What If I Had Been the Hero? Investigating Women's Cinema. Basingstoke: BFI/Palgrave Macmillan, 2012.

Whatling, Clare, "Femme to Femme: A Love Story." In Butch/Femme: Inside Lesbian Gender, edited by Sally Munt, 74-81. London: Cassell, 1998. 


\section{Media}

At Land (1944). Dir. Maya Deren. Experimental Films. New York: Mystic Fire Video. 2002. DVD.

Bande à Part (1964). Dir. Jean-Luc Godard. London: BFI, 2003. DVD.

Black Swan (2010). Dir. Darren Aronofsky. London: Twentieth Century Fox Home Entertainment., 2011. DVD.

Blue Steel (1989). Dir. Kathryn Bigelow. London: Lions Gate Home Ent. Ltd., 2007. DVD.

Bright Star (2009). Dir. Jane Campion. London: Twentieth Century Fox Home Entertainment, 2010. DVD.

Dirty Dancing (1987). Dir. Emile Ardolino. London: Lionsgate UK, 2009. DVD.

Gilda (1946). Dir. Charles Vidor. London: Sony Pictures Home Ent., 2000. DVD.

The Gold Diggers (1983). Dir. Sally Potter. London: BFI, 2009. DVD.

Holy Smoke (1999). Dir. Jane Campion. London: 4DVD, 2008. DVD.

In the Cut (2003). Dir. Jane Campion. Culver City CA: Columbia Tristar Home Entertainment, 2004. DVD.

In the Mirror of Maya Deren. Dir. Martina Kudlácek. New York, Zeitgeist, 2003. DVD.

Looking for Mr. Goodbar. Dir. Richard Brooks. 1977. Film.

Meditation on Violence (1948). Dir. Maya Deren. Experimental Films. New York: Mystic Fire Video. 2002. DVD.

Meshes of the Afternoon (1943). Dir. Maya Deren. Experimental Films. New York: Mystic Fire Video. 2002. DVD.

The Piano (1993). Dir. Jane Campion. London: Optimum Home Entertainment, 2003. DVD.

Portrait of a Lady (1996). Dir. Jane Campion. London: Universal Pictures UK, 2011. DVD.

Rituals in Transfigured Time (1945-6). Dir. Maya Deren. Experimental Films. New York: Mystic Fire Video. 2002. DVD.

A Study in Choreography for the Camera (1945). Dir. Maya Deren. Experimental Films. New York: Mystic Fire Video. 2002. DVD.

The Tango Lesson (1997). Dir. Sally Potter. London: Artificial Eye, 2012. DVD.

Thelma and Louise (1991). Dir. Ridley Scott. London: MGM Home Entertainment, 1998. DVD.

Thriller (1979). Dir. Sally Potter. The Gold Diggers. London: BFI, 2009. DVD.

Trio A. Chor. Yvonne Rainer. 1966. Performance.

Twin Peaks. Scr. and dir. David Lynch. Prod. Mark Frost. 1990-91. Television.

YES (2004). Dir. Sally Potter. London: Optimum Home Entertainment, 2006. DVD. 


\title{
On Collaboration and Interdisciplinarity: Meshes of the Afternoon
}

\author{
Andrew James
}

nterdisciplinarity and collaboration are prominent contemporary concerns in the arts that are evident in recent writings about Maya Deren. I will be critically engaging with

the literature on Deren in order to explore the potential of the term "interdisciplinary," with a view to opening her work further for contemporary practice. The film Meshes of the Afternoon (1943) was co-created with Alexander Hammid and offers a rich text through which to explore Deren's collaborative strategies and her approach to interdisciplinarity. This black and white, $16 \mathrm{~mm}$ film will be the central focus of the essay. I will be referring exclusively to the silent version that resulted from the original collaboration' and to the central character as "Maya."

Maya Deren's An Anagram Of Ideas On Art, Form And Film is a fifty-two page "chapbook" originally published as a limited run by the Alicat Book Shop Press, New York in 1946. This work is now recognized as an important contribution to film theory, a radical attempt to reconcile an interdisciplinary sensibility with avant-garde film practice. Yet, the academic recognition of the importance of Deren's filmmaking and theoretical work has been comparatively recent. It was not until 1980 that theoretical attention to Deren's work began to gather momentum, with Annette Michelson - at that time writing for the journal October - a key figure in Deren scholarship at this point. ${ }^{2} 1984$ and 1988 saw the release of the first two parts of The Legend of Maya Deren, an important biographical compendium. ${ }^{3}$ The next significant development in Deren scholarship came in 1991, with Lauren Rabinovitz's book Points of Resistance: Women, Power and Politics in the New York Avant-Garde Cinema. This influential text played an important role in reclaiming Deren as a key precursor of feminism. In the essays included in Maya Deren and the American Avant-Garde (2001), edited by Bill Nichols, Deren's work is framed in the wider context of avant-garde practice in America, and in recognition of her important connections to avant-garde milieus across art, film, dance and poetry. Renata Jackson's book The Modernistic Poetics and Experimental Film Practice of Maya Deren (2002) emphasises the important role that Deren's early poetic practice played in shaping her subsequent work on film. ${ }^{4}$ Also in this year an accessible online article by Wendy Haslem, entitled "Maya Deren: The High Priestess of Experimental Cinema," was published in Senses of Cinema.

Most recently there have been two key texts produced that understand Deren in relation to contemporary concerns. John David Rhodes' Meshes of the Afternoon, published in the British Film Institute's Film Classics series, was launched during Maya Deren: 50 Years On at BFI Southbank in October 2011. Rhodes emphasises the radically open form of this film; in addressing the experimentation and aesthetics, he makes available the creative discourse between its collaborators-Deren from a background in poetry and Hammid from that of film. Attention to the intensely collaborative nature of Meshes provides an important 
starting point for this study. In Dancefilm: Choreography and the Moving Image (2011), Erin Brannigan approaches Deren's films from a dance perspective, placing emphasis on their interdisciplinarity. She challenges the limitations of the prevalence of writing on "dancefilm," which she perceives as strongly biased toward the profilmic choreographic event (the live performance) and suffering from a lack of engagement with the range of relevant film theories. Brannigan defines a practice of "dancefilm" that is truly interdisciplinary in nature, focussing on "cine-choreographies" that exist only in film and because of film. Deren's work is central to this thesis, both for key films that embody this interdisciplinary approach and also for the concepts and methodologies found in her writing.

Writers on Deren have advanced different explanations for why her films and theories of film have not attracted the critical discourse and position they deserve. Jackson, for example, aims to establish the position of Deren's An Anagram of Ideas on Art, Form and Film (1946) within modernist film theory. She notes that Deren's writings do not echo the language of feminist film theory and that this may have contributed to them being overlooked. ${ }^{5}$ Nichols supports this, noting that highly influential feminist writers like Claire Johnson and Laura Mulvey "ignored Deren entirely in their search for pioneering feminist filmmakers." This is perhaps overstating the case as in her paper "Film, Feminism and the Avant-Garde"(1978), Mulvey does refer to Deren's pioneering work. While she does not choose to analyse Deren's work in relation to experience of oppression and the exploitation of the image of women, Mulvey does place Deren alongside Germaine Dulac, suggesting that "both directors' intermingling of cinematic movement and interior consciousness interested feminist and avant-gardistes alike." Brannigan suggests the interdisciplinary focus may have resulted in Deren's work falling between key theoretical frames. She also draws attention to Deren's significant contribution to the area of dancefilm and the general slow development of critical discourse within this area. ${ }^{8}$ Nichols also suggests a range of additional factors that could have contributed to the period of Deren's neglect, including the move within independent cinema toward a Beat improvisational sensibility, the ascendance of structural filmmaking in the avant-garde of the 60s, and the prominence of cinéma vérité.

Annette Michelson's On Reading Deren's Notebook provides an insightful exploration of the rigor and scope of Deren's writings, as well as an important description of the relation between theory and practice in her work.

The sense of a constant and intimate articulation of theory with practice, of a relentless concern with systematization, the determination to ground innovative practice in theory. And, of course, the manner in which both practice and theory stand in a relation of fruitful, unresolved tension, of variance with those of her time. Tracing the development of Deren's work and of her role, one discerns a particular logic evident only once before in the history of the medium. ${ }^{9}$

In her preface to An Anagram of Ideas on Art, Form and Film, Deren takes an anti-reductionist stance, drawing attention to the proliferation of statements and theories on which creative practice is based. She states with conviction that "these are, almost without exception, inferior to those works from which the principles were derived." ${ }^{\prime \prime 0}$ She proceeds to chart the evolution of her own statements, noting how each film would provoke new theories rather than illustrate previous ones, thus creating a "dynamic and volatile" relationship between theory and practice. ${ }^{11}$ 
The systematization that Michelson refers to above is of particular interest here in relation to interdisciplinarity, as is the notion of an "anagram of ideas" rather than a logical linear progression. Here we find Deren seeking innovative ways to work with the complex and interrelated nature of an interdisciplinary practice. It is perhaps this refusal to orientate her work in relation to one area of critical discourse that has resulted in the slow uptake of her contribution by theorists and critics. Deren's practice may, by its nature, be open to indeterminate readings as each discipline allows for a particular perspective to be applied, the meaning lying somewhere between these and the creative concerns of the people involved in its making. Not surprisingly, any attempt at defining the genre, meaning or plot of Meshes is problematic. These uncertainties become evident when we compare the different approaches that have been taken to framing Meshes within an historical or theoretical context. Haslem refers to Deren's work as "evasive and unclassifiable," stating that Deren "actively rejected categorization as a surrealist and refused the definition of her films as formalist or structuralist."12

Writers engage in various ways with issues surrounding authorship in textual analysis, particularly in regard to reducing the complexity of a film to a function of the biography and the presumptive psychology of an author. Rhodes highlights the dangers of this approach in regard to Meshes, referring to the details of Deren's life as being "dangerously seductive," suggesting that "Deren with her antipathy to the claim of the personal and the biographical, would herself have been the first to object to any emphasis on the facts of her life as a way into an understanding of her work."13 The biographical nature of Haslem's article does, to some extent, lead her in this direction. This approach, regardless, would need to address the histories of both authors of Meshes. Rhodes perceives the film as:

... a point of origin (that from which much later avant-garde film-making flows), a point of transition (the thing that connects the interwar avant-gardes to those of the postwar period), a point of intersection (between the lives of two artists, between male and female, film and literature), an artefact of an extremely personal-even Hermetic - modernist vision, and a document of political feminism. ${ }^{14}$

Rhodes suggests that the remarkable characteristic of Meshes is that it manages to be all these things simultaneously, and many more besides.

In addressing the interdisciplinary nature of Deren's work, notions of collaboration are of particular relevance. The question of the authorship of Meshes has always been disputed and difficult. Haslem quotes filmmaker (and friend of Deren) Stan Brakhage, as well as historian of avant-garde cinema P. Adams Sitney, as stating that authorship should be attributed solely to Hammid. On the other hand, Haslem aligns herself with the consensus of Deren's biographers in perceiving the project as a collaboration, with Hammid providing the mechanical expertise to "realize images born from Deren's imagination."15 I would argue that reducing Hammid's role to one of mechanical expertise is unfortunate as it obscures the conceptual level of a collaborative discourse that has much relevance to contemporary film practice.

One text that has become available online recently is Film and Music by Alexander Hackenschmied (Hammid). While written a decade before the making of Meshes, it does offer insight into his initiatives and strategies for experimental film. Exploring the use of 
language and concepts from one medium transposed to another, Hammid frames this line of exploration in relation to his contemporaries at the Bauhaus School in Dessau. His approach challenges the conventional relationships of collaboration as he explores the possibility of a new medium, where neither music nor film can be divided and performed separately, because one part without the other would be unintelligible. This echoes the relationship between dance and film that Brannigan promotes as "cine-choreography." It is possible that Hammid's ideas prefigured Deren's notion of film form as an anagram where the parts are inseparable from the whole. Along with his proposed title for the film Music of Architecture, this text suggests a preparedness on Hammid's part to employ inter- and transdisciplinary strategies across several disciplines for the purpose of one project.

Rhodes refers to the issue of the authorship of Meshes as vexing. He acknowledges that his writing on the film focuses on Deren far more than Hammid, and offers as an apology his conviction that Meshes "emerges from a set of concerns and passionate commitments that are native to Deren's life and her trajectory" that preceded the making of the film. ${ }^{16}$ However, Rhodes also points out that "Hammid was truly a man of cinema, whereas, in the tremendous paper trail that documents her life prior to meeting Hammid, Deren makes only the scarcest and most desultory of references to cinema."17 Rhodes draws attention to precedents in innovative film form that can be seen in Hammid's earlier work, most notably the "startling intervention in point of view editing"18 that Hammid employs towards the end of his early avant-garde film, Aimless Walk (1930). Here we see the central character exchange glances with what we can only assume to be his double. In his article for Film Culture, "Alexander Hammid: A Survey of His Film-making Career," Thomas E. Valasek interviews Hammid who describes how separating a person into multiple self-images had always fascinated him. Valasek explores the key role this concept plays in Aimless Walk both in terms of the film's structure and its integration of disparate elements:

Hammid skilfully dramatizes the idea of separation in the three climatic sequences that end the film. In the first of the three, where the protagonist walks easy from himself in the park, Hammid employs a panning technique that allows both of the protagonist's "selves" to appear in the same shot. After the camera follows the man a short distance, it pans back to his original position, during which time the actor has run behind the camera and repositioned him-self. The effect is startling. Hammid follows up with point-of-view shots from both positions. In the second sequence, where the protagonist hops a tram, Hammid cuts quickly and on action to give the illusion that the man is again splitting in two before your eyes, even though this time there is a cut. In the final sequence Hammid superimposes the water and the tram, the two unifying images of the protagonist's "aimless walk," to suggest symbolically the forces which have split him. In each of the three sequences Hammid employs carefully-implemented cinematic techniques which strikingly realize the concepts of separation. ${ }^{19}$

The three self-images of Maya in Meshes of the Afternoon, along with the innovative use of both architectural and natural environments, can be seen to extend and develop this concept and aesthetic. Hammid explains that Deren "had poetic vision and was very responsive to that kind of thing, too." 20 Deren's subsequent two films continue to explore this line of work both through multiple self-images and through different actors being 
substituted for the same character. Valasek also draws attention to structural similarities between Aimless Walk and Meshes, particularly in the use of an almost double ending where the final shot opens up new interpretations. ${ }^{21}$ In Points of Resistance (1991/2002), Lauren Rabinovitz recognises the film's stylistic and conceptual debt to Hammid's first film. She briefly draws attention to Hammid's contribution and his description of the collaboration as being "so involved between the two of us that it's hard to separate what was one person's idea and what was the other's."22 However, she suggests that the emotional intensity and overall mood of the piece is dissimilar to his work. Valasek's analysis concurs with this as he suggests that Hammid brought "a study into the visual and intellectual possibilities of a cinematic idea" while Deren involved the viewer emotionally, significantly influencing "the overall tone and mood. ${ }^{23}$ Rabinovitz suggests that the film's significance lies in its function as a "woman's discourse that rewrites Hollywood's objectification of women by addressing a female subject who must contend with her own objectification."24 Determining the significance of the film in this way establishes Deren's contribution to resisting the dominant forms and institutions in art and media, and Deren's position in relation to feminist film theory. However, opening up the film's value as a key interdisciplinary text requires an approach that is ready to explore the genesis of ideas and collaborative strategies that brought this film into being.

Both Jackson and Rhodes explore the range of archival material on Deren's life and filmmaking with regards to the issue of collaboration. ${ }^{25}$ Jackson notes that what becomes apparent is a contrast of personalities: "Hammid's quiet manner and preference for calm versus Deren's forceful presence and frenetic pace."26 Rhodes notes Hammid's tendency for self-effacement and his reluctance to be credited, in contrast to Deren who showed herself to be a great self-promoter. ${ }^{27}$ Valasek draws attention to how Hammid contributed greatly at a conceptual level to many of the projects he worked on but rarely took sole credit for a directorial role. He appears to have been most comfortable in collaborative roles and in collective ways of working.

Valasek first locates Hammid in the 1920s as one of the few rebellious "malcontents" in Prague who advocated for "nonconformist views about form and meaning in art [and] who wrote about practical applications of 'nova fotorafie' and 'novy film.' They argued for film, the 'seventh art'... and for Czechoslovakia to develop an avant-garde cinema."28 Here the commonalities with Deren's writings and her contribution to American avantgarde cinema become apparent. However, Hammid's interest went beyond developing an aesthetic avant-garde, as we see when he writes in 1930: "the social and ideological reform of the film industry is the highest goal of the independent film." ${ }^{29}$ Valasek suggests that in his extensive career Hammid would "strive to manifest 'the free spirit' in a variety of commercial, documentary and experimental films." ${ }^{\prime \prime 0}$ In the years immediately prior to the making of Meshes, Hammid concentrated on documentary filmmaking. Rhodes describes the complex circumstances that led to his emigration to the USA, where, having worked with American leftist documentary filmmaker Herbert Kline on his film Crisis (1939)—a film documenting the Nazi takeover of Czechoslovakia—Kline, fearing for Hammid's life, arranged for his immigration. ${ }^{31}$ It was only on meeting Deren that Hammid applied himself once again to experimental filmmaking. It is of note too that after their separation, Hammid pursued his career through a range of roles in independent and mainstream film projects rather than establishing himself as an avant-garde filmmaker. 
Jackson exposes some interesting contradictions in the biographical statements included in Deren's publicity material that somewhat inaccurately present her subsequent film practice as one in which she performed all the roles herself, despite the continuing involvement through to 1946 of Hammid and their photographer friend Hella Heyman. This notion of an individual "doing it all" may have been inspiring to subsequent avant-garde filmmakers but there are possible negative implications here in terms of Deren's legacy. This notion may have created a mystifying and unachievable premise for filmmakers who have attempted to make similar films on their own, with disappointing results. It continues to be the case that Deren inspires individual filmmakers, but this can easily become an obstacle to development without proper appreciation of the working processes and the creative discourse involved in her work. In addition, this misconception may also have encouraged a disregard for the range of collaborative contributions (both practical and conceptual) that occur in avant-garde filmmaking.

It is notable that following her careful examination of the available texts, Jackson, in her filmography, credits Hammid and Deren as conceptual collaborators and lists Hammid as co-editor and one of the camera operators on Deren's three subsequent films. In direct contrast, Brannigan's filmography lists Meshes as directed by Deren alone, and she makes no reference in her book to Hammid. Perhaps this is a function of her stated decision to focus on the contributions of female dancers, filmmakers and choreographers in order to redress the gender imbalance in critical discourse around film and dance..$^{32}$ If collaboration is a significant aspect of the interdisciplinary practice of "filmdance," then this omission is a limiting factor of Brannigan's book. Hammid's later film with Martha Graham may also be of interest here..$^{33}$ In Martina Kudlácek's documentary In the Mirror of Maya Deren (2002), we see Hammid holding a storyboard for Deren's later film A Study in Choreography for Camera (1945) and describing the decisions "we" made, suggesting that the creative discourse established in the making of Meshes continued through to this film. Authors have commented on the marked shift in aesthetics and form in the films Deren made after her creative association with Hammid. Haslem comments that the film Meditation on Violence (1948) "is marked by a lack of dynamism and mobility that we have come to expect from Deren's camera," ${ }^{34}$ while Rhodes notes that by comparison her subsequent films "flirt with a kind of formlessness." ${ }^{\prime 35}$

The interest in collaborative strategies has become well established in contemporary art in the past two decades. We now have the opportunity to place Meshes within a more extensive critical debate. In The Collaborative Turn, Maria Lind overviews the range of contemporary strategies for collaborative authorship in art, highlighting the often ideological and political motivations of those involved. In the pre-feminist context where a woman's contribution could more easily be subsumed, Deren's choices were limited. However, given her earlier commitments to the collective endeavour of radical socialist activism, along with her interdisciplinary strategies and concepts of ritualistic form, it is worth considering whether given today's context, Deren would define her practice in terms of collaboration rather than that of a sole agent.

At the time of the making of Meshes, Deren saw herself as a poet and had studied the ideas of T.S. Eliot and Ezra Pound. This orientation may offer us some insight into her approach to authorship. In his 2007 article, "T.S. Eliot and the Art of Collaboration," Ronald Schuchard brings a current perspective to the range of collaborative strategies employed by Eliot, and 
to the struggles he had in reconciling this with the modernist ideal of authorship. Schuchard focuses on The Waste Land and how this emblem of modernism was a suppressed collaboration formed through editing by Ezra Pound and Vivienne Eliot. The Waste Land is an interesting text because it exposes the processes of collaboration that lie behind the modernist notions of authorship that were an important part of Deren's formation as an artist. Although Deren would not have known that The Waste Land was a collaborative text, even with that knowledge it is unlikely that the questions of power involved in authorship would have allowed her to fully acknowledge her collaborative processes as a female artist. Nonetheless, this is an important context for interpreting her work.

Lind goes beyond both the ideological rationales for collaboration and the struggles that can surround notions of authorship to locate a key creative premise for collaboration. She illustrates this through a quote from the curatorial collective What, How \& for Whom, who state that their criteria for selecting collaborative practice is that "It has to result in something that would otherwise not take place; It simply has to make possible that which is otherwise impossible." ${ }^{\prime 36}$ Meshes gives evidence of this criteria and of Deren's astute choice of collaborative strategy, with the discourse between the two authors resulting in remarkable work that neither could have achieved or even imagined on their own. Rhodes explores how this was achieved, noting that Deren and Hammid innovated with the materials and environment that they had, while not letting assumptions and previous experience limit what was possible. Rhodes draws attention to how

Deren and Hammid suspended themselves between intense artists' intentionality (think of the precision of Hammid's in camera effects) and a kind of intentionless ignorance about what they were up to (think of Deren's proposal: "Why don't we make a film"). ${ }^{37}$

Meshes is interesting because of the way that the openness associated with interdisciplinarity is coded into the fabric of the film. Meshes starts with a shot of a pathway; walls and vegetation demark the space as it snakes uphill into the curved distance dissolving from sight. In the foreground, a flower (a synthetic poppy) descends into frame held by an arm, which we soon perceive to be that of a mannequin; the arm vanishes leaving the flower on the ground. The film is shot in black and white; bright sunshine casts shadows through the trees and fences on to the path, rendering the scene full of ambiguities of space and form. In a second shot from amongst the shadows cast by the trees on the path, we see another shadow of a figure, a young woman progressing towards the flower. Her shadow reaches out, its form touching the flower, before the physical hand joins it in the frame in the act of picking up the flower.

In this opening scene Deren and Hammid depart from any notion of representing or illustrating her poetic ideas. Instead we see a process of an interdisciplinary nature, where ideas, concepts and literary poetic devices are reconceived in relation to those of filmmaking. The authors took a broader approach to medium specificity than the exclusivist approach promoted by Clement Greenberg. ${ }^{38}$ Deren states that

what particularly excited me about film was its magic ability to make even the most imaginative concept seem real. For if the tree in the scene was real and true, the event which one caused to occur beneath it seemed also real and true. ${ }^{39}$ 
This indexical nature of film, its ability to be perceived as not just "representing" but somehow "being" the thing itself or at least having a causal relation to it, is described by Rhodes:

the flower is left amid the shadows cast on the pavement, their movement an index of the trees, whose movement we have already seen-movement that is itself an index of the wind that we cannot see except through the trees and their shadows. ${ }^{40}$

Rhodes suggests that the directors use this medium-specific quality of filmmaking to its fullest extent to establish with the viewers a language of how we are to engage with the work.

Nothing could be simpler than this opening sequence, and yet few opening shots of any film are so strange. What begins as cinematic realism (an image of the world, "as it is") converts, within seconds into a demonstration of cinematic artifice. ${ }^{41}$

This encourages the viewer to cease creating a real world of logical consequences and to instead "marvel at the whole nature of the art of filmmaking to produce such startling sensations." ${ }^{\text {" }}$

In contrast to Rhodes, Haslem gives less attention to the key cinematic innovations in Meshes and focuses more on narrative devices, on the circularity that results in "unnerving repetition" and on a "vision in crisis" constructed from a "myriad of eyeline matches and mismatches."43 She also draws attention to how filmic techniques such as jump cuts and montage are used to incorporate a fascination with the instability of objects that she associates with the Gothic. ${ }^{44}$ However, placing the film in relation to categories such as "experimental" or "gothic" runs the risk of concealing how the film challenges such categories and actively defies definition.

Rhodes' approach highlights how introducing the analysis of the film form and medium specificity of Meshes can liberate it from reductionist readings. For example, he points to how attempts at reading the film with an eye towards understanding how it satisfies questions of female agency "run the risk of producing answers that are too readyto-hand." ${ }^{45}$ He gives the example of the scene where, following the kiss, the poppy turns into a knife, which "Maya 3" reaches for and smashes against Hammid's face. As we discover, this "face" is but a reflection in a shattered mirror, the gaps in its broken shards revealing the ocean. In the next shot we see the shards landing on the beach only to be washed over by the sea. At first glance this could be interpreted as gender warfare. Whilst warning against over-simplistic readings, Rhodes acknowledges Lauren Rabinovitz's sophisticated interpretation of the film as signifying the destruction of "the objects governing a woman's sexual reflection, the man who is both male sexuality and a mirror for narcissistic female sexuality," Maya has "literally reached out to control the definition of herself." 46 Rhodes appreciates the way that Deren and Hammid exploit and confront the specificity of the film medium, suggesting that this scene also "constitutes a revolt against the containment of cinematic structures." ${ }^{177}$ In this sense, our engagement in the filmmaking illusion is exposed or shattered by Deren and Hammid into unresolved possibilities.

Several writers focus on the window shot, referred to by Hammid and Deren as their "Botticelli."48 This shot is the apex and point of reflection in Hammid and Deren's multiple 
self-image strategies, and can be seen to embody the complexity of meaning in the film. Having seen "Maya 2" approach the window, place her hand on the glass, and gaze down on the path, we then see a shot from her point of view as the mirror-faced figure walks past, followed by "Maya 3" in futile pursuit. It is at this point that the "Botticelli" shot occurs. It is taken from outside of the house at window level, the reflection in the glass of foliage against the sky combining with the image of Maya's hair. This shot would be impossible without the use of a crane, so we should assume that Hammid and Deren again employed their film artistry and resourcefulness in using another more accessible window selected for this combination of reflection and transparency. Haslem points out that this creates an equivalence to a filmic superimposition. As she writes, we "identify with the enigmatic expression at the window, silently observing from within. Although her eyes indicate distrust, she is not desperate to escape her domestic space, but she is not entirely comfortable immured behind the glass."49 Here we find Haslem quickly revising her interpretation of Maya's expression from one that is enigmatic to one of distrust, suggesting a more sinister and melodramatic interpretation. While Rhodes joins Haslem in interpreting the shot in relation to a woman's containment in a domestic space, he suggests that it is an image of "Inside-ness pressed up against outsideness," which condenses the film's focus on interiority and making the internal external. ${ }^{50}$ At the moment it appears in the film, this "image operates somewhat like a fulcrum of a chiasmus, with the versions of herself before and behind her."51 As Rhodes suggests, it can be seen to function as a metonymic signifier for the film project as a whole. He points to a metaphorical equivalence between the nature of the window's framing and the functioning of cinema itself. Supported by the fact that the woman in the image is identifiable both as the central character and as co-author of the film, he navigates the complexity of its meaning, suggesting that as her hands press against the membrane of glass it operates as both the boundaries of domestic containment and metaphorically as the skin of the cinematic image itself. ${ }^{52}$ In my own reading of the film I do not perceive the "distrust" in this gaze that Haslem refers to, but instead I experience a calm, allowing curiosity as she observes her own cycles, and invites us to join her in that quality of observation. Perhaps this has something in common with Haslem's suggestion that "in this still shot she establishes a silent connection with the eyes, suggesting the possibility for reverie or even hallucination." ${ }^{25}$ Haslem strangely blurs the distinction between the still image used for publicity and the moving image in the film. She also leaves us unclear to whom she is referring, whether it is the central character of the film, the filmmaker herself, or both: as she writes, "it is an image that suggests the most compelling themes of her film work: dreaming, reflection, rhythm, vision, ritual and identity."54 It is questionable how this shot suggests rhythm and ritual, and indeed identity. Perhaps Haslem is looking to attribute too much to this image. When she says "this still shot" perhaps she is referring to the moving image that has a quality of stillness. While it may be valid to critique Haslem's writing, it is however more interesting to view these possible contradictions and inconsistencies as a measure of Deren and Hammid's success in engaging the viewer. Rhodes experiences a liberation in the ways in which the film continually sets up and breaks expectations, in its plasticity and indeterminacy. ${ }^{55}$ Arguably, Haslem's metonymic consideration of the still and moving image provokes her to attempt to say too many things for the brevity of her article. However, that one image can evoke such a nexus of ideas, experiences and associations is to some extent indicative of the resonances of Deren's body of work, though it is also possible that Haslem's observations are over-determined by the form of a biographical article, 
which inevitably tends to read the work as a sign of the author and the author's oeuvre as a whole. It is of interest that this same shot provokes Rhodes to use such words as "metonym" and "fulcrum of a chiasmus," interdisciplinary applications of literary devices which echo Deren's conceptual use of the form of the "anagram."

It is in Deren's theoretical work that we can look for the key to her thinking about interdisciplinarity, though her exploration of these issues is far from straightforward. Jackson notes a tension in Deren's writing, as Deren warns against adapting other forms into film, particularly novels and theatre, and yet seeks out analogous concepts and methods in poetry in particular, and also in dance and music..$^{56}$ The essential nature of film is one of openness and interdisciplinarity. This leaves film vulnerable to becoming subservient to other forms. We can see Deren's approach as challenging the reduction of film to a form of interdisciplinarity dominated by the practices and constructs of mainstream theatre and literature. Deren is, for example, not advocating a film about poetry or about dance, but is striving instead for an innovative translation of the concepts, and creative impulses of these disciplines into the very form, construction and conception of the film itself. This innovative approach -involving a playing off of the constructs, concepts and languages of different disciplines - has similarities to that of Hammid in Film and Music 1930. This characteristic is central to Deren's work and is therefore crucial to any attempt to speak of it as interdisciplinary. In order to examine this more closely, it is useful to explore similar practices that have been identified in discourses that attempt to understand the nature of work across disciplines. In relation to health research, Aboelela et al. survey a range of definitions for interdisciplinary practice, within which the term transdisciplinary is used to define those practices, which employ translational innovations along with a high degree of synthesis of ideas and methodologies. ${ }^{57}$ It is perhaps the "translational innovations" that distinguish Deren's practice and as such it may be necessary to make this distinction in terminology.

Authors have made a range of observations about the interdisciplinary relationships between filmmaking and poetry that Deren developed and promoted. Jackson suggests the engagement with the perceiver/audience central to Deren's strategies in Meshes can be seen to stem from Ezra Pound's definition of the poetic image as "that which presents an intellectual and emotional complex in an instant of time."58 Rhodes suggests that T.S. Eliot's notions of depersonalisation informed Deren's writings and her approach to the collaboration where authenticity and expressivity come not from personality and subjective emotions but through the intensity of the artistic process.

Jackson draws attention to the equivalence in the construction of meaning in film and poetry, quoting Deren from Anagram, "the spatiotemporal manipulations made possible in filmmaking and editing allow for an economy of statement akin to poetry where a complex of meaning can be created that far transcends the few juxtaposed words."

The question of interdisciplinarity cuts across many of the analyses of Deren's work. Rhodes explores the relationship of interdisciplinarity in the nature of the collaborative process, referring to Hammid's recollection that Deren was constantly writing poetry, as this was her main focus and ambition at that time. It was this focus that provided the starting point through her poetic "images" on paper, which he would visualize in relation to his knowledge and formal experimentation with film.

Brannigan observes the relationship of the symbolist poets to modern dance, particularly in regard to Loïe Fuller, icon of the symbolist poetic imagination, who she perceives as 
a precursor to Deren in her utilisation of the technologies of her time to create new forms of choreographic art. ${ }^{60}$ However, it is interesting to note that she does not take this connection with poetry further in relation to Deren and Meshes.

Deren imports this interdisciplinarity into how she describes her films as variously "chamber films," "cine-poems," and "choreographies for camera."61 Jackson further develops this, suggesting that Deren's "adaptation of her literary mentors' aesthetics provides her with an established philosophical paradigm through which she could argue for film's legitimate status as an art form." ${ }^{\prime 62}$

A specific parallel emerges between imagist principles and Deren's strategies for performance in film. Brannigan quotes Deren: "Movements should be rather an extension and perfecting of a normal movement so that audience [sic] is kinaesthetically identified with them, under illusion [sic] that they too are capable of it."63 This approach is echoed to some extent in a principle of the imagist poets that Jackson locates in Deren's writing: "to use the language of common speech, but to employ always the exact word, not the nearlyexact, nor merely decorative word." ${ }^{44}$ Brannigan notes that the performances in Meshes do not simply present everyday utilitarian behaviour but instead have "movement trajectories and loiter along gestural routes that escape into verticality through strategies that preempt Bausch: repetition, exaggeration, abstraction, or rhythmic manipulation." ${ }^{165}$ As the film progresses we see various sequences where Maya ascends the stairs:

In one, she exaggerates her run upstairs, kicking up her heels. In another her progression is played out in slow motion and shot from several angles. In a particularly motile sequence her ascent is shot from above with a swinging camera, Deren lunging from side-to-side as if the staircase is rocking. In her final ascent she appears frozen at various positions on the stairs through a series of shots from a still camera. ${ }^{66}$

Brannigan notes that this approach to choreography has been adopted for live performance, particularly in dance theatre, and that the more successful dance films, such as those of DV8 physical theatre, owe a lot to the approach to performance that Deren and Hammid developed in Meshes of the Afternoon.

The notions of ritualistic form that Deren writes of are potentially significant in considering the success in creating "filmdance." Nichols links Deren's interest in dance, play and games with her concepts of ritual referring to her writings

The ritualistic form treats the human being not as the source of the dramatic action, but as a somewhat depersonalized element in a dramatic whole. The intent of such depersonalization is not the destruction of the individual; on the contrary, it enlarges him beyond the personal dimension and frees him from the specialization and confines of personality. He becomes part of a dynamic whole that, like all such creative relationships, in turn, endow its parts with a measure of its larger meaning. ${ }^{67}$

For Brannigan this is evident in Deren's films where "corporeal performance is one filmic movement among many"68 with the choreography spreading across people and objects. Brannigan suggest that this characteristic, along with film's inherent freedom to construct time and space, has had a significant influence on the choreographers of today ${ }^{69}$ 
This emphasis on depersonalization is supported by Rhodes' close reading of Meshes. Rhodes draws attention to the way in which Maya's image is introduced in the film and notes that given the film's focus on one woman's experience, the filmmaking withholds any vision of her body for a remarkably long time. Instead, we are introduced to her by an intricate composite of shadows and fragments in close-up, building up a complex relation to her environment and to the filmmaking artifice. It is only within the second layer of the dream or consciousness of Maya that we see her face. Rhodes suggests that due to her striking, unusual beauty "we might have been too absorbed looking at her to be able-or want to-look through her," ${ }^{\prime \prime 7}$ and that holding this moment back was important to creating the engagement of the viewer that they wanted to achieve. ${ }^{71}$

Whilst advancing cinematic devices and discourses, Deren drew extensively on dance and emphasised the proximity between the two artforms. In the discussion on Deren's films as "cine-choreographies," Brannigan refers to Deren's tribute to dance and movement as key structural elements in her filmmaking:

I feel that film is related more closely to dance than any other form because, like dance, it is conveyed in time ... [It] conveys primarily by visual projection and ... it operates on a level of stylization — it is the quality of the movement that renders the meaning. ${ }^{72}$

Brannigan examines Meshes on the basis of choreography as the "primary organising methodology," arguing how the "vertical" form of the film frees the figure from the linear cause and effect progression of the horizontal form. ${ }^{73}$ "The movement 'event' of the film passes from Deren through her fragmented and multiple selves to the inanimate objects through stylisation and filmic manipulation."74 However, an interesting question arises here as to whether Brannigan's decision to identify dance and choreography as the determining methodology and frame of reference really captures the transdisciplinarity of Meshes. There is a lot of textual evidence (from her MA thesis onwards) that supports the notion that Deren's interest in the imagist poets influenced her approach both to the performances and to the filmmaking in Meshes. It is possible that the innovative choreographic nature of Deren and Hammid's film form owes as much to Deren's use of poetic concepts and methodologies as explored by Jackson, and to the range of strategies brought by Hammid (particularly in regard to space and architecture), as it does to those of dance choreography. Deren and Hammid's agility in engaging a wider range of principals and conceptual frameworks is perhaps crucial to their success in making "dancefilm." This approach may have liberated their work from the expectations and practices surrounding live dance performance, choreography, and indeed from the conventions and assumptions surrounding the practice of filmmaking.

In conclusion, I would suggest that there is value in challenging the dominant notion of Deren as sole conceptual author of her films, a notion promoted to some extent by Deren and perpetuated by writers such as Haslem and Brannigan. Arguably, by omitting Deren's collaborative strategies in Meshes, Brannigan misses a potentially valuable aspect of this interdisciplinary practice. Looking at Deren's work as collaborative and interdisciplinary has the potential to offer contemporary artists a richer and more achievable model to draw on in their work and opens up the range of possible readings of the film. Valasek's article is of particular value in this respect. Collaboration seems to have an important relation to 
interdisciplinarity in a film like Meshes due to the different conceptual and methodological frameworks brought to the project by its co-creators. It is beyond the scope of this essay to fully examine this suggestive relationship, though it certainly warrants further investigation.

With regard to the most recent developments in research into Deren, Rhodes' close reading of Meshes is particularly valuable to interdisciplinary film practice in liberating the film from the reductionist tendencies of any one theoretical discourse. In doing so, he exposes a work, which by its intention, nature, and creative processes defies definition. Brannigan emphasises interdisciplinarity as something that Deren offers to contemporary practice. However, she limits her exploration of Deren's work to a study of the relationship between dance and film. Deren's notion of an "anagram of ideas" points to a more complex integration of strategies. While Brannigan's singular approach offers a valuable analysis from a choreographic perspective, it has limitations in regard to the range of interdisciplinary strategies employed by the authors and how these inform one another.

Jackson highlights important tensions in Deren's approach to interdisciplinarity, exposing the need for a more precise definition of her process. Deren warns against adapting or integrating the forms and accepted practices of other disciplines into film, and yet she seeks out analogous concepts, employing translational innovations in regard to poetry, dance, and music. "Transdisciplinary" may be a more appropriate term for her process and for the resulting film that characteristically resists reductive interpretations.

Michelson offers an important contribution to appreciating Deren's work from a contemporary perspective. When she writes, of the filmmaker's "sense of a constant and intimate articulation of theory with practice, of a relentless concern with systematization, the determination to ground innovative practice in theory," we can read this in terms of Deren's endeavour to discipline the shifting elements and complexity of a transdisciplinary practice. ${ }^{75}$

\section{Notes}

1. A sound score by Teiji Ito was added by Deren in 1959.

2. See Michelson, On Reading Deren's Notebook.

3. Clark et al., The Legend of Maya Deren.

4. Jackson, The Modernistic Poetics and Experimental Film Practice of Maya Deren.

5. See The Modernistic Poetics and Experimental Film Practice of Maya Deren.

6. Nichols, Maya Deren and the American Avant-Garde, 13.

7. Mulvey, 114.

8. Brannigan, Dancefilm.

9. Michelson, On Reading Deren's Notebook, 48.

10. Deren, An Anagram of /deas, 35.

11. Ibid, 35-36.

12. Haslem, Maya Deren: The High Priestess of Experimental Cinema, 5.

13. Rhodes, Meshes of the Afternoon, 13.

14. Ibid.,12.

15. Clarke, Hodson, Neiman in Haslem, The High Priestess of Experimental Cinema, 4.

16. Rhodes, Meshes of the Afternoon, 13.

17. Ibid., 50 .

18. Ibid., 41.

19. Valasek, Alexander Hammid: A Survey of His Film-Making Career, 282. 
20. Ibid.

21. Ibid.

22. Valasek quoting Hammid in Rabinovitz, Points of Resistance, 56.

23. Valasek, Alexander Hammid: A Survey of His Film-Making Career, 284.

24. Rabinovitz, Points of Resistance, 56.

25. Clark et al., The Legend of Maya Deren.

26. Jackson, The Modernistic Poetics and Experimental Film Practice of Maya Deren, 37.

27. Rhodes, Meshes of the Afternoon.

28. Valasek, Alexander Hammid: A Survey of His Film-Making Career, 251.

29. Hammid cited in Ibid, 252.

30. Ibid, 252.

31. Rhodes, Meshes of the Afternoon.

32. Brannigan, Dancefilm.

33. Hammid, Alexander, and Martha Graham, Night Journey.

34. Haslem, Maya Deren: The High Priestess of Experimental Cinema, 4.

35. Rhodes, Meshes of the Afternoon, 86.

36. Lind, The Collaborative Turn, 29.

37. Rhodes, Meshes of the Afternoon, 92.

38. See Greenberg, Modernist Painting

39. Deren cited in Rhodes, Meshes of the Afternoon, 53.

40. Rhodes, Meshes of the Afternoon, 51.

41. Ibid, 51

42. Ibid.

43. Haslem, Maya Deren: The High Priestess of Experimental Cinema.

44. Ibid.

45. Rhodes, Meshes of the Afternoon, 90.

46. Ibid, 89-91.

47. Ibid, 91

48. Hammid cited in Rhodes, Meshes of the Afternoon.

49. Haslem, Maya Deren: The High Priestess of Experimental Cinema, 12.

50. Rhodes, Meshes of the Afternoon, 76.

51. Ibid, 75

52. Ibid.

53. Haslem, Maya Deren: The High Priestess of Experimental Cinema, 2.

54. Ibid., 2 .

55. Rhodes, Meshes of the Afternoon.

56. Jackson, The Modernistic Poetics and Experimental Film Practice of Maya Deren.

57. Aboelela et al., Defining Interdisciplinary Research.

58. Jackson in Nichols, Maya Deren and the American Avant-Garde,60.

59. Deren cited by Jackson in Nichols, Maya Deren and the American Avant-Garde,63.

60. See Brannigan, Dancefilm.

61. Jackson in Nichols, Maya Deren and the American Avant-Garde, 51.

62. Jackson, The Modernistic Poetics and Experimental Film Practice of Maya Deren, 118.

63. Deren in Clark et al., 268, cited in Brannigan, Dancefilm, 120.

64. Jackson, The Modernistic Poetics and Experimental Film Practice of Maya Deren, 117.

65. Brannigan. Dancefilm, 122.

66. Ibid., 123.

67. Deren, An Anagram of ideas, 20 
68. Brannigan, Dancefilm, 113.

69. Ibid.

70. Rhodes, Meshes, 69.

71. Ibid.

72. Brannigan, Dancefilm, 120.

73. Ibid., 114.

74. Ibid., 124

75. Michelson, On Reading Deren's Notebook, 48.

\section{References}

Aboelela et al. "Defining Interdisciplinary Research." Health Services Research 42 (2007): 329-346.

Brannigan, Erin. Dancefilm: Choreography and the Moving Image. New York: Oxford University Press, 2011.

Clark, VèVè, Millicent Hodson, and Catrina Neiman. The Legend of Maya Deren: Documentary Biography and Collected Works. Vol. 2. New York: Anthology Film Archives, 1984.

Deren, Maya. An Anagram of Ideas on Art, Form and Film. In Essential Deren: Collected Writings on Film, edited by Bruce R. McPherson, 35-109. Kingston, New York: Documentext, 2005.

Haslem, Wendy. "Maya Deren: The High Priestess of Experimental Cinema." Senses of Cinema (2002). Accessed 15 Jan. 2011. http://archive.sensesofcinema.com/contents/directors/02/deren.html

Hackenschmied [Hammid], Alexander. "Film and Music." Film Quarterly 1 (1933): 152-5. Accessed 15 Oct 2012. http://www.logosjournal.com/hammid_1.htm.

Greenberg, Clement. "Modernist Painting." The Collected Essays and Criticism, Volume 4: Modernism with a Vengeance, 1957-1969. University of Chicago Press, 1995.

Jackson, Renata. The Modernistic Poetics and Experimental Film Practice of Maya Deren (1917-1961). New York: Lampeter, 2002.

Lind, Maria. "The Collaborative Turn." In Taking the Matter into Common Hands: On Contemporary Art and Collaborative Practices, edited by Maria Lind, Johanna Billing, and Lars Nilsson, 15-31. London: Black Dog Publishing Limited, 2007.

Michelson, Annette. “On Reading Deren's Notebook." October 14 (1980): 47-54. http://www.jstor.org/ stable/778530

Mulvey, Laura. "Feminism, Film and Avant-Garde." In Visual and Other Pleasures, 111-126. London: MacMillan, 1989.

Nichols, Bill. Maya Deren and the American Avant-Garde. Berkeley: University of California Press, 2001.

Rabinovitz, Lauren. Points of Resistance: Women, Power and Politics in the New York Avant-Garde Cinema, 1943-71. 2nd ed. Urbana and Chicago: University of Illinois Press, 1991/2003.

Rhodes, John David. Meshes of the Afternoon: BFI Film Classics. London: Palgrave Macmillan for British Film Institute, 2011

Schuchard, Ronald. "T.S. Eliot and the Art of Collaboration." Modernism/modernity 14, no. 4 (November 2007): 777-79.

Valasek, Thomas E. "Alexander Hammid: A Survey of His Film-Making Career." Film Culture 67-68-69 (1979): 250-322.

\section{Media}

Aimless Walk (1930). Dir. Alexander Hammid/Hackenschmied. Czechoslovakia. Accessed 15 Dec. 2011. http:// www.virtual-circuit.org/art_cinema/Hammid/Walk.html.

In the Mirror of Maya Deren (2002). Martina Kudlácek. Zeitgeist Films.

Meshes of the Afternoon (1943). Dir. Maya Deren and Alexander Hammid.

Night Journey (1960). Dir. Alexander Hammid, and Martha Graham. New York: Phoenix/BFA. Clip available: http:// www.youtube.com/watch?v=fFNsKeMbW20 


\title{
Pas de deux for Dancer and Camera in Maya Deren's Films
}

\author{
Sarah Keller
}

A n expansive interest in dance guided Maya Deren's ambitions even before she began to make films. She served as secretary for progressive choreographer and research anthropologist Katherine Dunham's dance troupe in 1942, touring with their production of the musical Cabin in the Sky. That same year, she published an article on religious possession and dance in the American journal Educational Dance. She was fond of dancing both formally and informally: friends recall her dancing at the slightest provocation. Then, in her first films, including Meshes of the Afternoon (1943) and At Land (1944), Deren embraced "dancerly" movement as one of several ways of producing meaning outside of narrative paradigms.' By the time she made A Study in Choreography for Camera (1945), her relationship to dance-film was solidified. Then and thereafter, she consistently collaborated with trained dancers and talented choreographers (Talley Beatty, Rita Christiani, Frank Westbrook, Anthony Tudor, Jean Erdman) over several film projects. Further, she participated in lectures and discussions on film and dance, and she published articles in venues such as Dance magazine, articulating her aims for using dance in her films. She began to categorize several of her films as "choreographies for camera,"2 compared their form to dance forms, and reflected at length on how the two media could be combined towards the goal of a wholly new artistic expression. Her investment in dance, as a filmmaker, was impressive and sustained across her career.

Deren invented a unique aesthetic for filmed dance that drew on her own theories of cinema; on current trends in modern dance, the art world, and anthropology; and on the example of several cinematic predecessors. In his recent book Screendance: Inscribing the Ephemeral Image (2012), Douglas Rosenberg outlines some of the artistic debts owed by Deren's expression of a relationship between camera and dancer, noting that her work belongs to a "continuum of production that flows from a rhizomatic network of sources,"3 including Eadweard Muybridge's early photographic motion studies as well as the "particular type of physicality" in performers such as Charlie Chaplin and Buster Keaton. ${ }^{4}$ Further, he notes the influence of modernist artists such as Marcel Duchamp and Man Ray, who were experimenting with the effects of movement in their work - work which came to include the cinema. ${ }^{5}$ Indeed, it is certain that a wide range of artists, including Loïe Fuller, Fernand Léger, René Clair, and Germaine Dulac, are indisputable forerunners to what Deren developed as a film-dance aesthetic, more or less directly. For instance, Dulac's abstract film Thèmes et variations (1928) combines the movements of a dancer with parallel movements in nature and machinery, predating Deren's similar use of dancers within her mise-en-scène; likewise the slow motion of the funeral procession in Clair's Entr'Acte (1924) predicts Deren's own investigations into how the manipulation of film time creates rhythms within otherwise mundane events. Deren experimented with combining cinematic movement and 
dance movement in ways that are indebted to such artists, and even as she forged her own aesthetic, it developed with strong parallels to their earlier work. ${ }^{6}$

Deren's investment in dance expanded her sense of the purview of cinema; her notion of cinematic specificity, for example, came as a result of using cinematic devices to connect with the rhythms of dance in her films. In this way, she extended the reach of modern dance's coincident trend to include natural movements (e.g., following the later developments championed by the Judson Church dancers ${ }^{7}$ ) by showing how such movements performed in compelling combination with cinematic movements might augment both media according to their special features. ${ }^{8}$ For example, in the movement of Deren's hair at the end of the first sequence in Ritual in Transfigured Time (1946), Deren manipulates temporality in a slow-motion study to make time unfold in an unfamiliar way. Correspondingly, the sequence initiates a compelling, dance-like rhythm. In Deren's longest and most complex statement of film theory, An Anagram of Ideas on Art, Form, and Film, published that same year, she describes her reasons for shooting an action (shaking one's hair) in this fashion:

When a fast turning is reduced by slow-motion, it still looks natural, and merely as if it were being performed more slowly; the hair, however, moving slowly in the lifted, horizontal shape possible only to rapid tempos, is unnatural in quality. Thus one creates a movement in one tempo which has the qualities of a movement of another tempo, and it is the dynamics of the relationship between these qualities which creates a certain special effectiveness, a reality which can only be achieved through the temporal manipulation of natural elements by the camera as an art instrument. ${ }^{9}$

Deren attempts the kind of shot she describes here first in her climb up a ladder of driftwood in At Land, ${ }^{10}$ but such an effort gains complexity as it unfolds in Ritual in Transfigured Time. In this later film, Deren appears, turning her head in slow motion while she vivaciously talks and winds yarn with the character played by Rita Christiani (one of Katherine Dunham's dancers). As Deren suggests in her writings, the slow motion of this moment affords the spectator the ability to analyze the subtlest intricacies of the figure's movement: intricacies inaccessible to the unassisted eye. The way the yarn moves, the nuances of Deren's facial expression, and the broader gestures of her bodily movement are broken down into an entirely new rhythm, which is revealed more potently in the slower motion effected by the camera. We see the fast, graceful, "dancerly" movements of the actor (as filmed) intersected by the slow motion of the camera, making a new rhythm of the two in partnership.

Moreover, the slow-motion movement underlines options available to the cinematic medium for expressing a rhythmic sense of time. The shots are cut between Rita Christiani and Deren winding the yarn into a ball together, and Anaïs Nin standing in the threshold of a doorway beyond. First, the film depicts Christiani turning her head in "real" time, at a regular, unhurried pace. In slight slow motion, Nin turns her head to look away from the women. The image of turning, shared by these three women across several shots, communicates the shifting relationships among them (at first Christiani seems to feel welcomed by Deren, then alienated as Deren disappears within the space of Christiani turning towards her). The rhythm of this simple gesture is played out in several different temporal registers: we have someone turning quickly but depicted slowly via camera time; we have someone turning slowly in both camera and real time; and we have three people turning individually 
at a normal speed in real time but slowed or extended by the way Deren draws that collective turn across several shots. By cutting to close-ups of the yarn or to a longer shot of the three women in a line, Deren further attenuates the action of turning and contextualizes it in an activity (creating the ball of yarn, women gathering in a room). The fugue of rhythms binds their activity together and underlines the feeling of how time passes via these multiple indications of cinematic temporality.

There are several ways that Ritual in Transfigured Time explores rhythm according to cinematic modes. For instance, it underlines a specifically cinematic rhythm in its sequence that takes place among statues, where it freezes certain frames to highlight cinema's dependence upon and simultaneous ability to manipulate a relationship between stasis and motion. The fact of making the dancing figures like statues also evokes a metaphorical relationship, asserting kinship between the mobile figures and the statues among which they frolic. Rhythm, deriving from alternation from stasis into motion, underlies the nature of the cinematic medium: twenty-four still frames per second allowing for the illusion of collective movement of those frames (and the images depicted in them). Such rhythmical relationships in fact drove Deren's investment in dance as cinematic subject and film-theoretical touchstone, which has corollaries in several of her passions beyond filmmaking, including fine arts, anthropology, and poetry. She was an incorrigible touch-à-tout, who tried her hand at many things, perhaps partly to find the best avenue for expressing her ideas. As a result, she refined and honed her film practice cross-medially. Deren drew important conclusions about film art based on issues she explored through dance and poetry in particular, in that both depend on a sense of rhythm that Deren derived from these models and expressed in vertiginous spatial and ideational mobility within and between the frames of her films.

Deren displayed an active interest in poetic form from an early age. This interest developed in important ways throughout her short filmmaking career, and is most resonant in her treatment of dance on film. Poetry, rhythm and dance serve as keys for understanding the primacy of temporal investigation and reinvention in her films. As her first artistic outlet, poetry exerted an especially powerful influence on both Deren's conceptual thinking and her filmic conceits. From early amateur versifying for her school journal, where she first received encouragement for her poems (she wrote home from boarding school in Switzerland, "I am hailed by all the girls as a sure poet"11), until soon after she met her second husband Alexander Hammid and began to make films, Deren identified as a poet, claiming it as her artistic calling. ${ }^{12}$ Hammid later described the genesis of Meshes, on which they collaborated in 1943, as deriving from Deren's poetic sensibility combined with his own cinematic expertise. He recalls that she was at that time "writing poetry always. It was one of her main ambitions. So she started with poetic images on paper, and I was visualizing them."13 Their work together charted a movement from imagination to image through rhythms determined both by movement within the frame and through editing, where those rhythms were dictated equally by the duration of shots, slow or fast motion, and spatial relationships among a set of images. This trajectory, from imagination to image through rhythm, shaped Deren's later work more broadly.

Poetic precedents in her films are evident in the way Deren addressed questions of temporality and rhythm. In fact, she mobilized several modes of poetic thinking in her film work: she used poetry as a metaphor for cinema itself, enlisted visual metaphors to express ideas, theorized a "poetic" temporality as preferable for cinema (the "horizontal" and 
"vertical" thesis Deren posited in greatest detail in 1953, at a symposium on poetry and film organized by Cinema 16 ${ }^{14}$ ), and described the nature of the "image" in cinema in terms that resonate with her work on Imagist poets prepared for her master's thesis at Smith College. Focused on the Symbolists and the Imagists, and exploring how each group resolved the dilemma of how images generate poetic ideas, Deren's thesis culminated in a chapter on Ezra Pound and T.S. Eliot. Pound's pronouncements about the directness of the image-e.g. "that which presents an intellectual and emotional complex in an instant of time" - were refashioned in Deren's thinking according to the technical specificities of the film camera. ${ }^{15}$

To convey her sense of the directness of expression that she posited was more readily available to the visual image (she claimed poetic ideas could not convey images so directly, in that they had to capitulate to the intermediary mechanism of language ${ }^{16}$ ), Deren found a perfect vehicle in the gestural, charged expressivity of dance. For Deren's aesthetic, cinematic dance is most immediate and capable of conveying ideas, emotions, and rhythms with directness and force. She put the resources of her background in poetry and her exposure to dance to work in the moving image, offering an artistic method in contradistinction to literary and theatrical linearity, chronology, and causality. Doing so, she importantly reconfigured the temporal relationships within the artwork: her work favors models that allow development according to recursions of time characteristic of memory, dreams, and rituals. Deren's films accrue meaning based on the non-linear juxtaposition of related actions and images, expressed both directly and indirectly through the paradigms of poetry and dance.

A Study in Choreography for Camera (1945), the third film Deren completed, succinctly illustrates these influences. A brief film of barely three minutes duration, Study was conceived by Deren as an equal partnership between the dancer and the camera: a pas de deux. It progresses over four very short sequences, and features just one dancer, Talley Beatty. He begins in a birch forest, moves to a living room and then to the Egyptian Hall at the Metropolitan Museum before returning to the out-of-doors for the last part of the piece. His body connects these disparate spaces, beginning a gesture in one setting and completing it in another, making use of a standard device in continuity editing (a match on action) for holding together a somewhat jarring discontinuity. Dance, rhythm, and poetic devices provide virtually the entirety of the form and content for this film.

The opening section of Study articulates one of several metaphorical relationships introduced by the film. It implicates man (Beatty) and nature (trees) by filming them both as part of the natural movement within the setting. In his book Film at Wit's End, filmmaker Stan Brakhage describes the cooperation between the film's mise-en-scène and Beatty's movements, which "rhyme with all the little branches of the trees around him. So that he is a rhyme with the trees. In fact, during the first pan across, he can almost be missed as being a tree."17 On the level of the mise-en-scène, Beatty's figure functions as if he were part of the background; his body generates a sense of symmetry by being a graphic match within the frame. Deren fashions the image so that Beatty mirrors his surroundings, implying a relationship between natural movement (branches in wind) and creative movement within the film (the dancer among those branches), as well as outside of the film (through the movement of the camera).

The third section more fully elaborates such relationships. It begins with another match on action, shifting the scene without warning from Beatty's spin in a living room area to a 


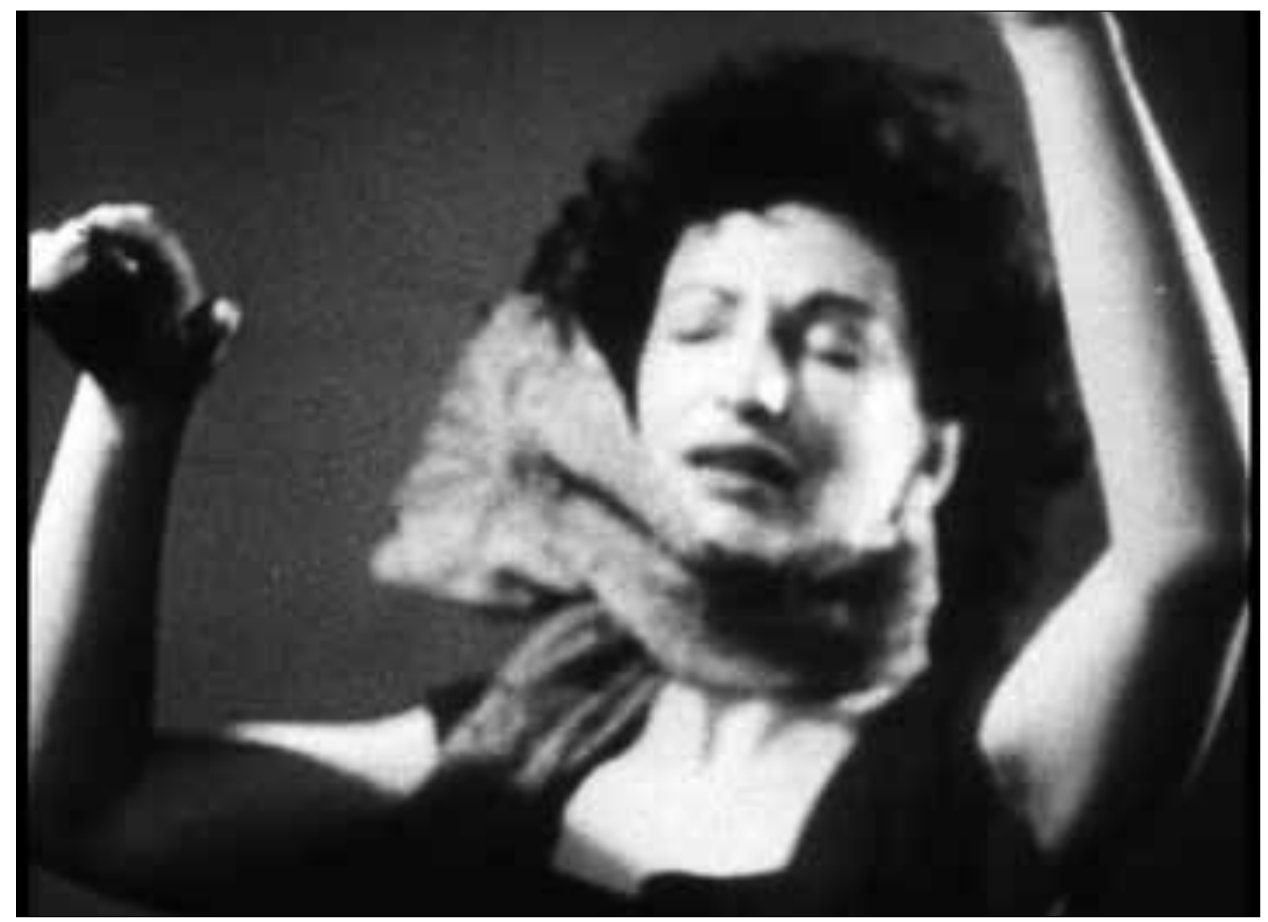

Fig. 1: A study of motion and rhythm in Ritual in Transfigured Time (Maya Deren, 1946).

shot of his legs completing that spin on a new surface. He runs gracefully away from the camera in what is revealed to be (as the camera tilts up) a long gallery. ${ }^{18}$ When he reaches the end of the room, he turns and retraces his steps, returning to a position closer to the camera and the same framing of his legs. Deren masks the spatial discontinuity by beginning with a close view without contextualizing details, so we don't immediately know he is in a place other than where he began. ${ }^{19}$ The new space is further made strange, disjunctive, by Deren's use of a wide-angle lens, making the hall appear much longer than it actually is. This exaggerated perspective, as Deren asserts, "by causing him to diminish in size very rapidly, makes it seem as if he had covered a tremendous distance in a relatively short time."20 The camera assists in conveying the rhythm of the dance, but with new parameters specific to its own devices and capacities.

The close-up of Beatty's feet used as transition enlists synecdoche as another variation on a metaphorical relationship, this one particularly apt for the fragmentation necessary to generate close-up framing. Here, the feet stand for the dancer. The next shot underscores this synecdoche by placing the dancer's body in the gallery among sculptural objects (not unlike the statuary sequence in Ritual in Transfigured Time). His depiction takes on both literal meanings (his art form mobilizes dance in an art-specific setting) and figurative ones (he serves as a figure for the art Deren is creating, metaphorically compared with the human-like art figures, and, as with the sundry states of fragmentation among the figures in the hall, he is fragmented by the camera). Multiplying the metaphorical relationships, Deren then cuts to a medium close-up of Beatty's head and shoulders, with a Bodhisattva head and shoulders also in medium close-up behind him. Beatty begins to spin, and in his spin mimics the statue behind him. Like the Bodhisattva's head, Beatty also occupies the 

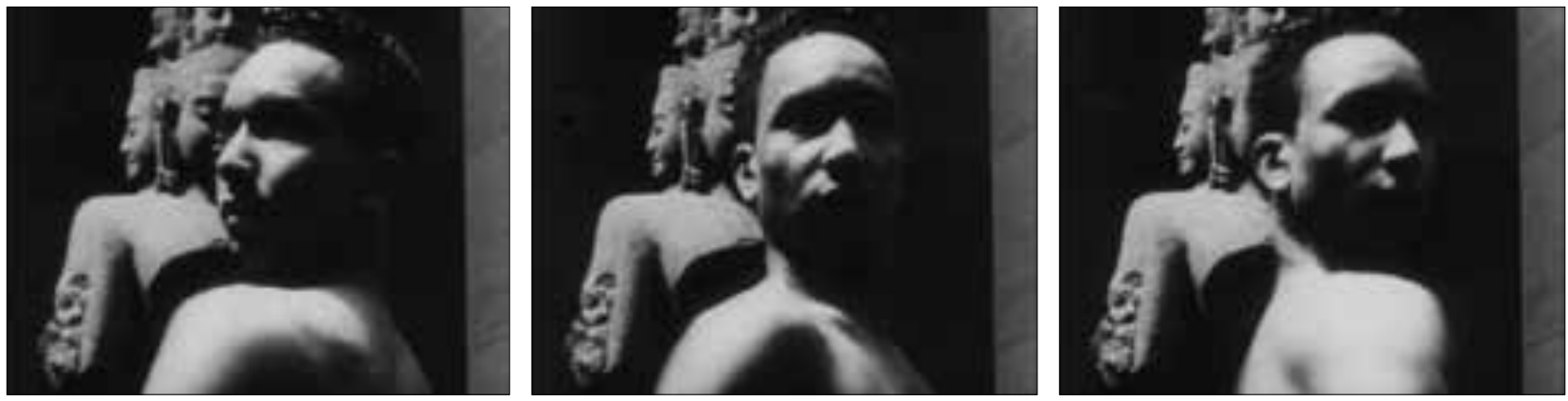

Fig. 2: The Bodhisattva Spin in A Study in Choreography for Camera (Maya Deren, 1945).

vantage point of multiple directions, especially when the spin accelerates and his head becomes blurred (Fig. 2).

P. Adams Sitney has noted that this framing brings the two figures together to evince a metaphorical relationship: "The implied metaphor identifies the dancer, whose twirling head seems to face all directions at the same time, with the statue and relates to the theme of the ambiguity of space (here, direction)." Sitney further deems the resulting metaphor a "compositional" metaphor, "one made by framing rather than by interrupting the action/ image with superimposition or intercutting."21 This type of composition is a further elaboration in Deren's multiform uses of metaphor. She doesn't underline the metaphor in the same way that cutting between the statue and Beatty's spin would: instead, the context of the shot (the museum) provides a justification for the juxtaposition; the spectator is left to piece the fragments of the shot together.

Echoing the statuary sequence in Ritual in Transfigured Time, the relative stasis of the statue-a stand-in for plastic arts more generally-draws attention to the difference cinema makes (motion), while the framing of the shot asks us to consider how the camera expresses an idea. (Deren does not intercut, but she could have: both would express something, but this is more compact.) Of course, the Bodhisattva head associates Beatty with the dancing figure Hevajra who occupies all directions and sees everywhere at once. For Beatty, too, in his spin assisted by Deren's acceleration of the motion, faces all directions at once: a modern, technologically supported, cross-medial, and artistic expression of omniscience.

The combination of Beatty's spinning movement with the camera's varying speed of movement underlines Deren's filmic practice: she employs her camera not simply to record Beatty's dance, but to expose the uniquely harmonious cinematic/terpsichorean nature of her endeavor. The way she describes this sequence in publicity materials and later articles invokes her pride in having devised the way to achieve the shot, followed by a series of metaphors that underlines how she thinks about the metaphorical qualities of this imagery more generally. Beatty is a "dervish," with the "frenzied whirling of a machine pace."22 His feet twirl him increasingly fast, "like spinning top."23 In Deren's films, the effect of the shotits overall qualities in relation to other qualities across the film, rather than its position in the linear sequence of the sections or shots_takes precedence: "... in the course of the shot, the camera speed was changed from extreme slow motion to extreme acceleration. The movement, then, begins with a dreamlike quality and ends with the blurring of a machine wheel."24 Such comparisons should remind us again of Deren's cinematic antecedents, perhaps especially Dulac's metaphors of movement in her abstract film Thèmes 
et variations, particularly in that both highlight a machine aesthetic compared metaphorically to more ancient and/or natural forms, including of course dance itself. ${ }^{25}$ The chug of machinery evoked by Deren carries Beatty over into the final section of the film, a return to the woods by way of a leap, sustained for what Deren described as "a much longer period than is humanly possible."26 In a rhythmic, four-shot sequence, it depicts dance movement complemented by cinematic movement (for example, Deren runs the leap backwards, so that Beatty appears to lift effortlessly from a pirouette into the air). This set of shots, "a pas de deux between camera and dancer,"27 as Deren put it, enables the body to surmount its usual capitulation to gravity.

Dance in Deren's films engages the unique temporal possibilities of the cinematic medium and its ability to conjure images of both an abstract and wholly realistic nature to create a new cinematic reality. It does so by engaging with Deren's thinking about poetry and rhythm on a direct level: the temporality of the film is recursive rather than linear, and the images are composed with a mind to expose how such images might come into being in the cinema. Those images are set in deliberate rhythm not only by the dancer's movements before the camera, but through the camera's engagement and interaction with those movements. By the three-way merger of her sense of poetic, terpsichorean, and cinematic devices, she prompts a cross-medial investigation of ideas elevated by connections that drive her creative practice.

\section{Notes}

1. Elinor Cleghorn has posited a connection between Deren's choreographic aesthetic and her unfinished project from the same time, Witch's Cradle, as well. "Manus Operandi: Film, Sculpture, Choreography." The International Journal of Screendance 2 (Spring 2012): 129-139.

2. Deren, "Program Notes."

3. Rosenberg, 35.

4. Ibid., 42.

5. Ibid., 42-47.

6. For an elegant, cogent, historically-invested, discussion that further situates these predecessors in relation to Deren's work, see Erin Brannigan's Dancefilm: Choreography and the Moving Image. Note, too, that Deren acknowledges her interest in her predecessors in dance film if not quite her sense of their influence in reference to the earlier cinematic avant-garde in France in her Anagram of Ideas on Film, Form, and Art.

7. The dancers affiliated with the Judson Church (in Greenwich Village, New York City), where they practiced and performed, tended to make dance out of everyday movements, so that the gesture of walking, for example, would elicit a dance-like rhythm.

8. This action places Deren in the camp of media-specific theoreticians of cinema, where the properties that are deemed unique for a particular medium are mobilized and highlighted to create art.

9. Deren, Anagram.

10. The editors of The Legend of Maya Deren, Vol. I, Part 2: Chambers draw this parallel in their section "The Making of At Land." See Clark et al., 186.

11. Quoted in The Legend of Maya Deren, Vol. I, Part 1: Signatures, 347.

12. Legend of Maya Deren, Voll, Part 2, 186-87.

13. Hammid quoted in Legend of Maya Deren, Vol I, Part 2, from interviews conducted on September 4, 1975 and August 3, 1976. Deren continued to write poetry even after she begins to identify as a filmmaker, though less often than before.

14. For a detailed account of Deren's ideas as expressed in the symposium, see the reprint of part of the transcript of that event, "Poetry and the Film," 171-186. 
15. Pound, 3.

16. Legend I.2, 57.

17. Brakhage, 13.

18. This sequence was filmed in the Egyptian wing of the Metropolitan Museum of Art, New York.

19. Deren describes the genesis of this shot in her article for Dance in 1945. Essential Deren: 222-223.

20. Ibid., 223.

21. Sitney, "Imagism," 188. Sitney takes the term "compositional" metaphor from Eisenstein; see for example "Laocoön."

22. Deren, "Original Plan for A Study in Choreography for Camera."

23. Ibid.

24. Ibid. A very similar formulation occurs in "Choreography for the Camera," op cit., 223.

25. The relationship of machinery and modernism to both mainstream and avant-garde film practices, particularly as it expresses cinematic rhythm (the cinema of course being itself a machine), has been explicated in several recent works, including Kristin Whissel's Picturing American Modernity: Traffic, Technology and the Silent Cinema, Lucy Fischer's recent work presented for the Philadelphia Cinema and Media Seminar in April, 2012, "Modernity, Machine, Movies, Mind: Abel Gance's La Roue," and Tom Gunning's essay on Chaplin, "Chaplin and the Body of Modernity," a talk given at the BFI international conference on Chaplin on 22 July 2005. The proceedings of the entire conference are available on the BFI website: http://chaplin.bfi.org.uk/programme/conference/ papers.html

26. Deren, "Choreography for the Camera," 224.

27. Deren, "Program Notes.

\section{References}

Brakhage, Stan. Film at Wit's End: Eight Avant-Garde Filmmakers. New York: McPherson \& Co., 1989.

Brannigan, Erin. Dancefilm: Choreography and the Moving Image. New York: Oxford University Press, 2011.

Clark, VèVè, Millicent Hodson, and Catrina Neiman. The Legend of Maya Deren, Vol. I, Part 1: Signatures (Legend, I.1). New York: Anthology Film Archives, 1988.

.The Legend of Maya Deren, Vol. I, Part 2: Chambers (Legend, I.2). New York: Anthology Film Archives, 1976.

Cleghorn, Elinor. "Manus Operandi: Film, Sculpture, Choreography." The International Journal of Screendance 2 (Spring 2012): 129-139.

Deren, Maya. An Anagram of Ideas on Art, Form, and Film. In Maya Deren and the American Avant-Garde, edited by Bill Nichols, 267-322. Berkeley: Univ. of California Press, 2001.

. "Original Plan for A Study in Choreography for Camera." Maya Deren Collection (MDC), Howard Gotlieb Archival Research Center, Boston University Library.

. "Program notes." February, 1946. MDC.

Eisenstein, Sergei. "Laocoön." In Selected Works, Vol. II., edited by Michael Glenny and Richard Taylor, 109-202. London: I.B. Tauris, 2010.

Fischer, Lucy. "Modernity, Machine, Movies, Mind: Abel Gance's La Roue." Lecture for the Philadelphia Cinema and Media Seminar, April, 11 2012. Fisher-Bennett Hall, University of Pennsylvania.

Gunning, Tom. "Chaplin and the Body of Modernity." Lecture for the BFI international conference on Chaplin, 22 July 2005. Available: http://chaplin.bfi.org.uk/programme/conference/papers.html

"Poetry and the Film: A Symposium with Maya Deren, Arthur Miller, Dylan Thomas, Parker Tyler. Chairman, Willard Maas. Organized by Amos Vogel." Film Culture Reader, P. Adams Sitney, editor. New York: Cooper Square Press, 2000.

Pound, Ezra. "A Retrospect." In Literary Essays of Ezra Pound, edited by T.S. Eliot, 3-14. London: Faber \& Faber, 1954. Rosenberg, Douglas. Screendance: Inscribing the Ephemeral Image. New York: Oxford University Press, 2012.

Sitney, P. Adams. "Imagism in Four Avant-Garde Films." In Film Culture Reader, 195-199. New York: Cooper Square Press, 2000.

Whissel, Kristen. Picturing American Modernity: Traffic, Technology and the Silent Cinema. Durham, NC: Duke University Press, 2008. 


\section{INTERVIEW}

\section{"Art Is Energy": Barbara Hammer Speaks with Sarah Keller about the State of Experimental Cinema after Maya Deren}

B arbara Hammer is a visual artist primarily working in film and video. She was recently honored with retrospectives at the Museum of Modern Art in New York City (2011), the Tate Modern, London (2012), and the Jeu de Paume, Paris (2012). Her work reveals and celebrates marginalized peoples whose stories have not been told, and it engages an audience viscerally and intellectually with the goal of activating them to make social change. Her trilogy of documentary film essays on lesbian and gay history has received numerous awards: Nitrate Kisses (1992), Tender Fictions (1995), History Lessons, (2000). Recent films, A Horse Is Not A Metaphor (2009), Generations (2010), and Maya Deren's Sink (2011) were awarded Teddy Awards for Best Short Film at the Berlin International Film Festival. HAMMER! Making Movies Out of Sex and Life, a book of memoirs and personal film theory, was published by The Feminist Press, City University of New York, and Fearless Frames: The Films of Barbara Hammer at The Tate Modern will be released by Mousse Publishing, Milan, Italy in 2013.

Sarah Keller first became aware of Barbara Hammer's work through her first research into Maya Deren's work, specifically from Hammer's essay in tribute to Deren in Bill Nichols' anthology Maya Deren and the American Avant-Garde (University of California Press, 2001). Since then, she has become a great fan of Hammer's work, and recently invited her to lecture at Colby College, where it has generally been affirmed that during her visit Hammer positively transformed people's lives, not at all unlike the way Deren affected her own audiences. Hammer's films draw on Deren's example in certain ways, but of course they also embrace their own rhythms, their own artistic investments and interests. Hammer and Keller spoke about these issues in New York City in July 2012, and then continued the interview over email in the months following.

Sarah Keller: We're talking about things "after Maya Deren," so I want to ask you about your sense of Deren's legacy for filmmaking. I also want to talk about how you have personally picked up the mantle of her artistic plans or her way of advocating for experimental cinema in general, through networks of distribution, awards, and the Creative Film Foundation, and then talk a little bit about how those kinds of things have influenced you. It might make sense to start with your film Maya Deren's Sink, and the ways that you've taken up some of the things that were dearest to Deren — how you've interacted with those issues recently. 
Barbara Hammer: Maya's films and writing and distribution strategies incredibly influenced me, because I saw that in making work, you could also write about your ideas about work, and then once you'd made it, you could distribute it, or exhibit it, and get it out in the world yourself. Meanwhile, you needed to gain money for your films, so you learned how to write grant applications. Deren got the first Guggenheim in film, which I think is extraordinary, and it was totally right for them to give it to her because film is a fine art the way we artists practice making it. ${ }^{2}$ Also of influence is/was Maya's complete dedication. Her life was really committed to her work, I think, before anything else. That may be the hardest thing to commit to in a world of relationships. The artist has to make the choice for the work, for writing the book, over the family. This is pretty taboo in our society.

SK: Especially for women.

BH: Especially for women, exactly. I see Maya's plans as still viable today. I try to show my work at universities, as you know. Deren's energetic self-distribution showed me a twopronged approach that's often to the artist's advantage. One can distribute her/his films as well as go through an established distribution outlet.

And Maya's many letters to the editor of The Village Voice were important. For example, the column on film she wrote when Jonas Mekas went on vacation and asked her to take over. She had other outlets too, such as magazine articles, and this meant she could write about her own work even if other people didn't (often the general public doesn't understand experimental film). But if you talk about layers of memory represented by images or in Deren's case, "vertical cinema," and explain it, and you're not on a panel with Dylan Thomas_ ${ }^{3}$

SK: Or Arthur Miller.

BH: Or Arthur Miller. Yes. You have a better chance to be understood. And you're challenging your audience, too, because you've given them word concepts as well as image concepts to work with in evaluating your work or experiencing it. Maya's vitality and energy have been remarked upon by so many people. I remember once in the late 70's I was rewinding films, a very physical activity, and I kept repeating a mantra out loud: "Art is Energy, Art is Energy." That was and is my definition of "art."

I think my work, being energetic as it is, reflects my ideas as well. I've always found that every filmmaker has her own personal, interior rhythm that she uses in the editing structure and filming structure, and Deren's was so dance-based, especially when we think of Meshes of the Afternoon.

You make your first film, and you really don't think of yourself in capital letters. You're just burning with your own energy. And then it's made, and Dyketactics becomes a film that people talk about and suddenly you're a filmmaker and you self-reflect. That self-consciousness and reflection cuts down on your spontaneity. And I think it did Deren's after Meshes of the Afternoon. I know, after my '70s films, in the '80s, when I turned to landscape, and I turned to more structural cinema, the exuberance is there but in another fashion. It's not in the freedom of expression with the camera that we find in Meshes, or maybe in Dyketactics.

SK: Well, that's an interesting point, because (as we've talked about) the energy in Meshes is part of Deren's "perfect collaboration" with her then-husband, Alexander Hammid, who used a very mobile camera. He was famous for being able to free up the camera, to walk 
it everywhere, basically doing a kind of steady cam without a steady cam. And in her films after Meshes, Deren doesn't replicate that specific sort of mobility with the camera. But it seems to me that maybe she depends on a more dynamic editing strategy at that point. Would you agree with that?

BH: Dynamic in terms of bringing diverse images together. Meshes is confined to one house and the sidewalk in front. But when she gets to At Land and she uses Buffy Johnson's studio and is out on Long Island, in different locations, both the seaside and the orchard end up butt-ended to each other, and we have a different cinema. She brings us into some kind of global editing in her verticality and geographical discontinuities that become whole through her juxtapositions. Whereas somebody first viewing those films might not feel they're as unified as Meshes. But you're right. She does step out into new editing. Rethinking my earlier statement, Deren does use creative geography in Meshes, too, and steps outside the house and its environment when she traverses diverse landscapes, as in At Land.

SK: That's right. It's there and then continues in Study in Choreography for Camera and Ritual in Transfigured Time...

BH: And Study in Choreography, yes. Talk about editing. That's a masterpiece.

SK: It really is.

BH: And to achieve that jump in air, that use of space... so she really brings in space in the same way she worked with time in Meshes. This is fun, to think about it.

SK: Continuing with these connections, could we talk just a little about homage and Maya Deren's Sink? What are some of the ways that you're paying homage to Deren-or do you feel like there's another element to it besides homage that we should be paying attention to when we're looking at that film?

BH: Maya Deren's Sink is definitely an homage, because the lowly artifact of a bathroom sink is thrown onto the New York streets where people will pick it up, and Anthology Film Archive comes and saves it, and I hear about it and suddenly-I get inspired. As a filmmaker, I never know what's going to come next. I just had this burning desire to first see the sink—and then to project her films back into it.

SK: Why was that? What was it about seeing the sink that was important?

BH: Good question. You know, I've never - there's a person who's in this building who has two artifacts from Maya Deren, she was married to one of Deren's husbands-

SK: Which one?

BH: Teiji Ito. Ilene Ito promised to show me these items, but for various reasons she never fulfilled her promise, and I was never able to see these or put my hands on them. So I think that the sink became a substitute for this desire. When I go to an archive, I want to see the ephemera. It's really interesting. For example, with the Elizabeth Bishop archive I've been visiting at Vassar College, there is her slide projector from the '50s, and I want to see it because I'm shooting a lot of her slides.

I'm not a mystic; it's not that I feel like there's an aura about these objects. I think it's about mortality - my own. I think about what objects of mine will be left. Especially when 


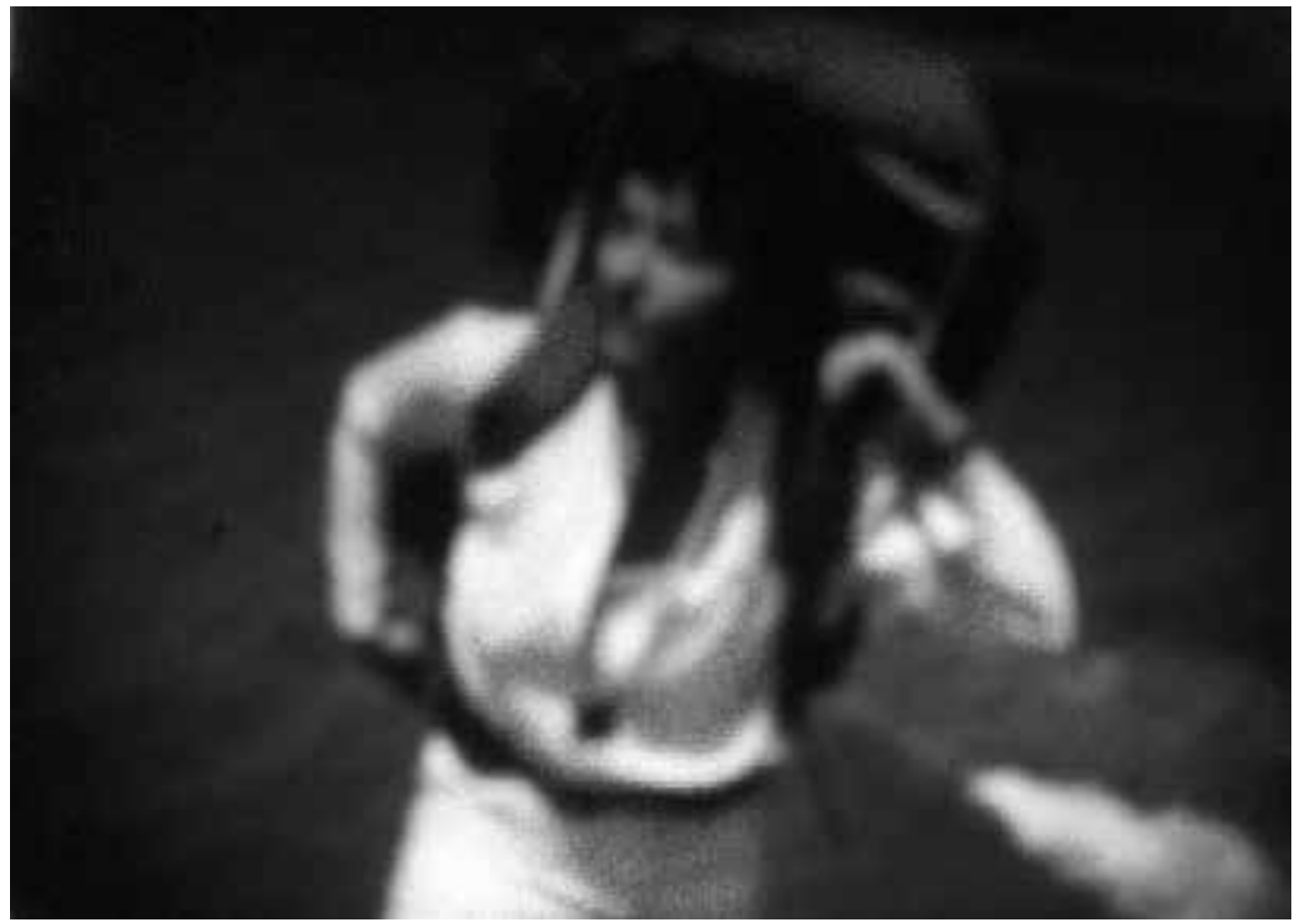

Above: Dream Age (1979), Dir. Barbara Hammer. United States, 12:00 min., 16mm film, color/sound. Courtesy of the artist.

Below: Dyketactics (1974), Dir. Barbara Hammer. United States, 4:00 min., 16mm film, color/sound. Courtesy of the artist.

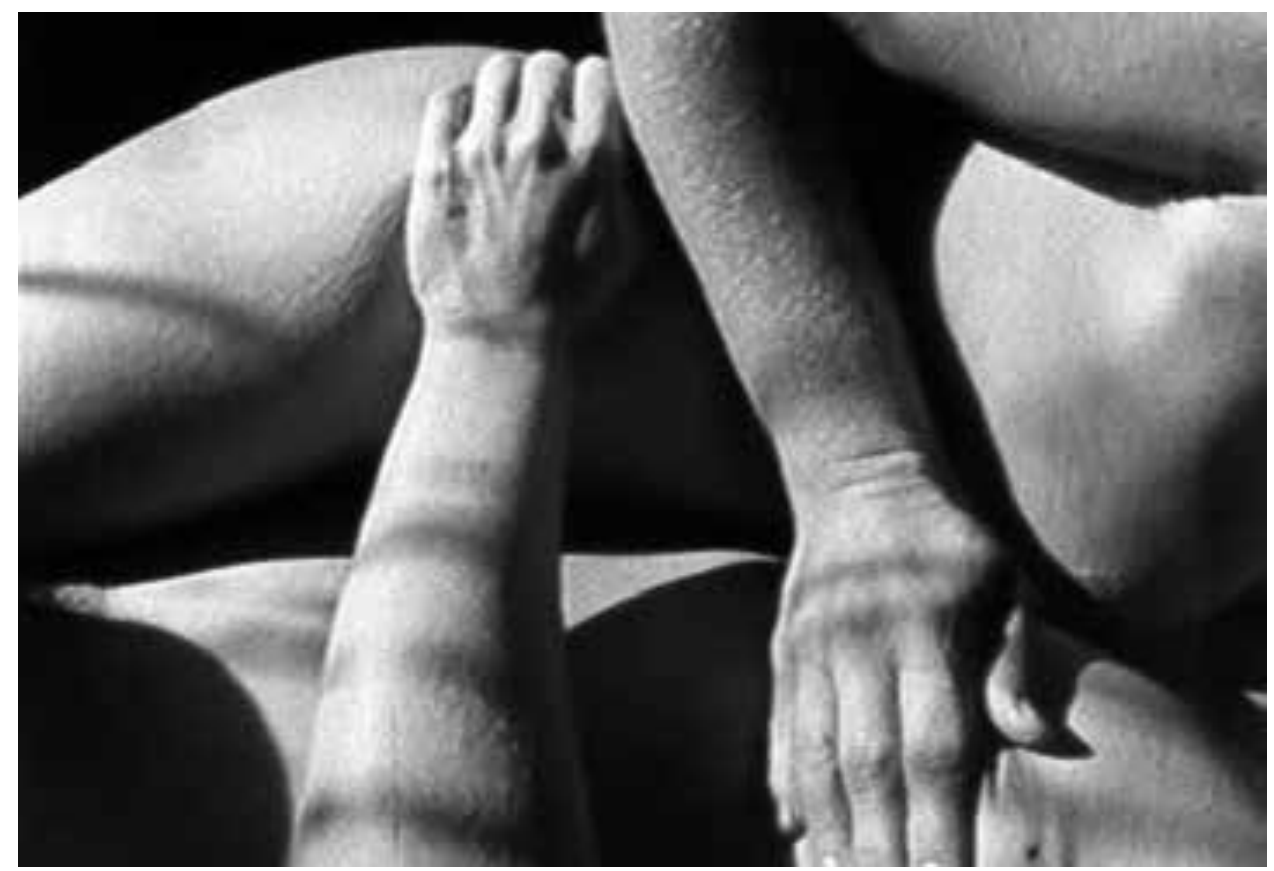




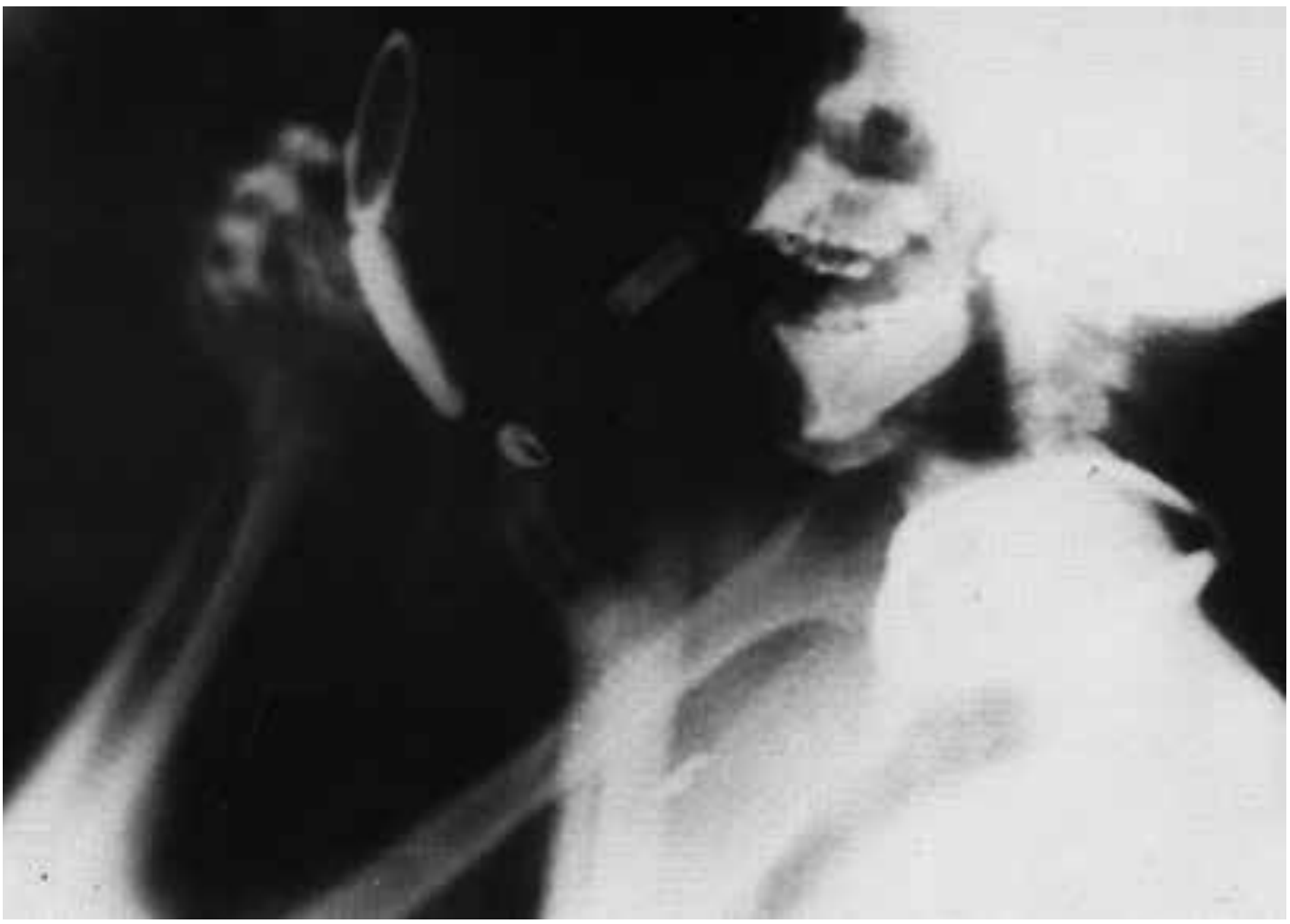

Above: Sanctus (1990), Dir. Barbara Hammer. United States, 19:00 min., 16mm film, color \& B/W, sound by Neil B. Rolnick. Courtesy of the artist.

Below: Home (1978), Dir. Barbara Hammer. United States, 12:00 min., 16mm film, color/sound. Courtesy of the artist.

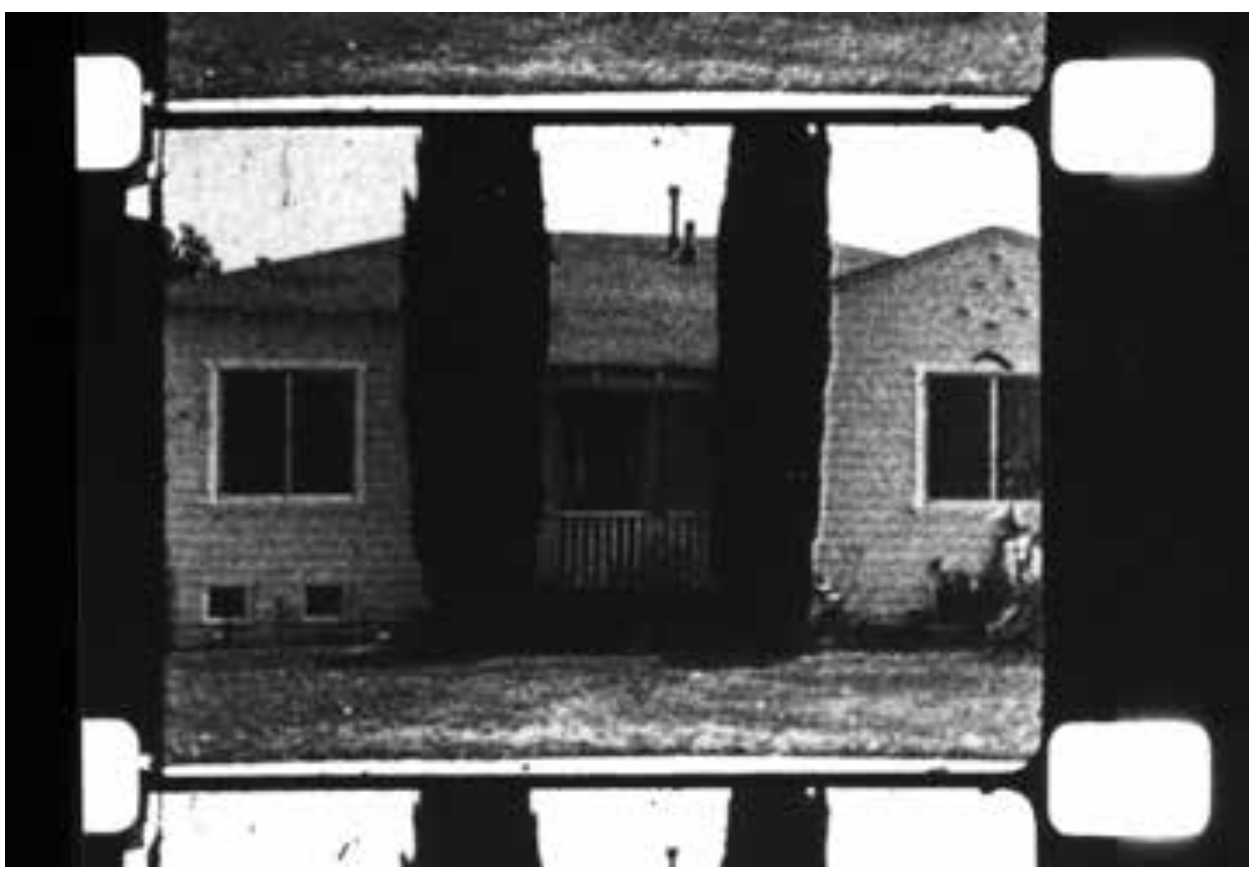


you're going to make a move, a studio move: you've got to get rid of things. And I think: what objects will be left? What should I preserve to benefit or to sell to an archive myself? I think this is one of the reasons I'm doing archive work right now: I'm thinking about my own.

SK: What do you see as the difference between the films you've made becoming artifacts of your creative process versus the other kinds of things that end up in archives?

BH: Well, one thing is: that's what the artist has held onto and passed on. In her archive, there is a nameplate for the house that was one of Elizabeth Bishop's homes: it was very important to her. So you get a sense of the interiority of the artist by looking at the ephemera of the archive. It's something else when we make a leap of judgment to think that the artist has preserved this, not the heir or the executrix of the will. You know Maya Deren's Sink in this case speaks to us of the cultural and economic geography of the time. When I filmed in her former Manhattan home, the house was quite run down. You can see some of the wallpaper that was in one of her films because the plaster has been pulled away due to age. One imagines that she probably didn't have a chance to replace this very ancient sink herself, because in the'50s, there were much better sinks available. This artifact tells you something about her: that her money was going toward films, not into the furniture in her house.

It's curious, but something compels me in my research to know something more than the artworks themselves. The artworks become artifacts, but these other items are also artifacts. Deren, who wrote so much, reminds us that letters are objects, paper sheets, and there must be a lot that was never published. It must be a very rich archive. In answering your question, I notice I've spoken about Deren's archive, not my own, because it's easier.

SK: And who knows, as you say, which of these articles Deren wanted to have preservedin some cases, she had catalogued her own things, so it seemed like it was already being archived. But other things-parking tickets, for example-probably not. So it makes me wonder about an artist's legacy and how we read that legacy according to these material traces of her presence while she was here.

BH: That's the artistic practice of being an academic or a biographer. I mean if we look at biographical and archival studies as being not about truth but about imagination, and we give the maker of that work - you, in terms of your book on Maya Deren - the embrace of being able to be creative in your work - to use your imagination, to use hypotheses - then we have a more vital production in the end. Because there's no way to know the truthabsolutely no way to do anything but regard the solid "facts," i.e., leftovers. And the truth is-we know there's no truth.

SK: Right. If we get to the truth, it's still subjective; it still is subject to change.

BH: I'd also like to say something else about her homes.

SK: Please do.

BH: The home-or the studio, if one is lucky-is where the artist works and creates. And that kind of structure, or space, most of it being rectangular and small for us artists I think, has a lot to do with the work we make. If Maya Deren lived in the woods as a wild child with 
a video camera, with multiple hours of recording devices, I think we'd have a different kind of film. And I think that Meshes and Ritual are really home-based works. Meshes was all shot in her home. A lot of Ritual in Transfigured Time was shot in her Morton Street home and some of Study for Choreography for Camera was too. The interior structure of the home means the artifacts in the home are visible as images on the screen for us to see, even if we can't handle them. If an artist is working in space-time relationships, the space that she lived in and worked in seems to me a very interesting primary focus of what occurs in the filming itself.

Then there's just the personal desire. Desire is — as it has been defined, I think —what you can't have. Who can go into the homes of Maya Deren? Well, at first I can't, but then I want to, and I find a way. I wanted to go into her homes especially after I found out that they were still here-they hadn't been destroyed. And I love challenges. Those homes should be museums. They should be preserved as part of the archive. They shouldn't be destroyed nor ignoredwe should at least have a plaque on her homes to memorialize her.

SK: I agree.

BH: But that requires the owner of the building to admire Maya Deren, which isn't the case in New York.

SK: Tell me about the kinds of traces of home in your own films.

BH: Well, I made a film called Home, of 9536 Felton Avenue in Inglewood, California, where my first memories come from. I moved, or was moved there, when I was about maybe three months of age, and I grew up through twelve in that home. I remembered the home from the size that I was. It was very interesting to me to go back and visit as an adult and notice the way the grasses grew around a particular tree and whether the tree was even still there. And the dirt, and the driveway being those two cement tracks with grass growing in between, something different than our driveways today, which are solidly paved. It was fulfilling a desire to recall, to remember, to explore that house with a moving camera, as I did, and then to abstract it through using infrared film so that the leaves are red, rather than green. Home gave me a way to re-experience my own life as a subjective process, but isn't that what we are always doing?

SK: That transformative use of infrared is really interesting. In fact, it sounds a lot like the widow-into-bride moment of Ritual in Transfigured Time. Do you think there are aspects of Deren's film style that have found their way into your own creative imagination?

BH: I immediately think of a film of mine that is very rarely viewed; it's called Dream Age. The last image of that film is me with a backpack, walking into the ocean-actually into the San Francisco Bay, submerging myself. It was my attempt to mature. The characters in the film are all women with white hair, and I don't yet have white hair. In a ritual, on a salt mound, they paint my hair white. A ritual is a repeated activity, and eventually the repeated activity is that my hair is painted completely white. I wanted to hurry along the process of aging. I wanted to know more, to be more critical and reflective-my idea of what age can bring.

SK: Deren worked on several projects that are intimately tied to rituals, too, especially her monumental project in Haiti, for which she planned to use Voudoun ritual dances as the centerpiece. Do you have thoughts on why she would have had trouble working with this 
material—ritual, sacred dances_even while she didn't have trouble filming non-sacred, camera-generated dances?

BH: The most exciting chapter of Divine Horsemen was the one where Deren is mounted by Erzulie during a Voudoun ritual. I cannot comprehend how she could make a film, or part of a film, about this experience since there is a loss of consciousness as we know it -or, so it seems to me-during possession. Perhaps this is why Deren never edited, nor even began to edit, her vast cans of footage. And when Joseph Campbell told her to write a book instead, telling her that she knew more about Voudoun than any anthropologist, she proceeded without hesitation. I wonder about that. Now I want to go back and see what she did in words that she didn't do in film.

SK: Do you think your allusions to Deren's work were conscious? Do you feel you learned some of your filmmaking from Maya Deren, or did you sort of unconsciously absorb some of her aesthetic and use it - maybe especially at the beginning of your career?

BH: I definitely used consciously Deren's line in the film where I'm talking about time being circular and not linear. ${ }^{4}$ take the key out of my mouth, and that's in direct reference to Deren's key that opens the door to her psyche, her house. My key starts my BMW motorcycle: my dyke bike. On the motorcycle is the squash, the pumpkin I've found in the field. I open the squash: what's in it, but a knife. We think of the knife on the bed in Meshes of the Afternoon and I feel that the knife for both of us was a means of protecting our burgeoning feminine, constructed, yes, but there, burgeoning feminine sensibilities. It's about women experiencing time differently.

And then there's the gun. There's no gun in Deren, but the knife has the same sense of violence about it that the gun has. They are both seen as an instrument of power. Deren had the bed, a passive place, where she lay, and even the chair, the armchair, again displays her restful passivity. If anything, I'm changing Deren into a motorcycle dyke. Or a woman of the women's movement of the 1970s, which happened at the same time I was becoming a filmmaker. Finally, after thinking through the film I believe there are both conscious and unconscious projections in the work. I don't think embracing pumpkins and running through a pumpkin field was Deren-influenced, but the projection on the body might have been because there is, in Deren, there's that-those eyes blinking. I'm not sure if that is a projection on her or literally her eyes blinking. In any case, there is the projection in the mirror, and the breaking of the mirror, of Hammid's face. And in I Was/I Am, I'm breaking a glass bell jar that was put over my head-with a hammer. There are a lot of influences including Sylvia Plath and her novel The Bell Jar.

SK: Let me ask you some more about influences, for example in collaborations with others. Deren worked with dancers, including Talley Beatty, Frank Westbrook, and Rita Christiana, and she used other people who are not dancers, including Anaïs Nin, Gore Vidal, and anyone she could find to do the party sequence in Ritual in Transfigured Time where she needed people to move in a choreographed way. But she had problems when she began to enlist the aid of thirty people because it's difficult to get thirty people to agree to meet for free at a certain time and do crazy things for twelve hours. I'm wondering about your own practice - in many of your films you're using your own figure, which Deren also did. Is 
that in part to obviate the need to depend on others, or is it more of a personal expression of your own subjectivity or something else? Or is it for other reasons entirely?

BH: I have worked in collaboration going all the way back to Dyketactics, which for that film meant gathering a group of women and taking them to the country for a weekend, along with sync sound cameras, back-up cameras, Nagra reel-to-reel tape recorders, and a full crew of women to shoot and record. I provided food for them and camping places to sleep, and spontaneously directed rituals in nature. Women are jumping through the leaves, embracing trees, maybe six or seven within the film frame at a time. My approach was to take what I could get. Give a general direction, and then as people are performing what you've asked for, you can find your way to film it. Or accept it. Some of the best images are the unpracticed, unrehearsed, undirected ones such as a little child meandering across the screen to get her hair brushed, or women sitting casually by the streamside, not in performance mode, not posing. But to think of Deren managing thirty people in the dance scene of Ritual in Transfigured Time, you know that would be very difficult, especially knowing how exact she was. It's a different aesthetic altogether having to do with control or letting the control go.

SK: I want to ask you more about your sense of choreography, dance, and rhythm.

BH: I have been thinking about Maya Deren in terms of contemporary dance today, and I've been thinking about Yvonne Rainer and the Judson school and the very minimal approach Rainer and others, but especially Rainer, took toward what dance is and the way dance was redefined. I think some of Deren's work is very early structural, minimalist work. The way one walks, the way one puts the foot down, the way one crawls through a tree trunk on the beach. You know, very planned and minimal.

The definition of dance is like the definition of art: whatever the dancer or artist says is "dance" is or "art," is. I only know Rainer's work from the Judson Dance Theater period, that minimal period where she struck a new note for dance by walking across the dance floor or by walking across the dance floor bouncing a ball. Maya Deren takes a step on the stairs of the North Hollywood cottage and freezes; then another step and position and freezes; another and another: minimal. But who is dancing? Maya or the cinematographer cameraman, her husband at the time, Alexander Hammid? Who was dancing and who was directing, and could the dancer dance without direction?

Similarly, Bekka Lindstrom, who amazingly had made her own film using Deren motifs when a student at NYU film school, was asking me while acting in Maya Deren's Sink: "What is Voudoun ritual dance?"What did I know? I had seen Divine Horsemen, I had my own idea of what the movement would look like if the person dancing lost a sense of self in merging with a stronger force-for me, that stronger force could even be gravity. I just started to shake and move, allowing my body to be pulled towards the ground, closing my eyes, and then Bekka took over and found her way, the way you see in the film.

SK: This reminds me of the way you were talking about the rhythm of natural movement... would you say that this kind of rhythm is important to your films? Do you think you use it in a similar or different way from how it is used by Deren?

BH: Rhythm is the basis of my life, the way I move, the way I edit. I believe each one of us has a different rhythm and that if we are based in a movement art form our best work can 
be done by corresponding and dialoguing with our inner rhythm. Deren had her rhythm, I have mine, you have yours. It is the rhythm of the coursing of blood through our body; the breath through our nostrils and lungs; the musculature, structure, and movement dictated by brain rhythm. Last week I took a class in the Martha Graham studio where the Merce Cunningham studio had been. Even though we were assigned contraction/expansion à la Graham, I could not help but diverge and add my own beats, twirls, skips and hops. It is very hard to follow a standard routine as my internal rhythm demands variation. I have to admit I was a little pleased with the instructor who asked if I were a choreographer. Deren was a choreographer of cinema, and although formally untrained, I would hope I may have followed a few of her leaps and bounds, aka, the Choreography of a Dancer.

SK: When you mention minimalist movement as Deren's dance aesthetic, it makes me think of one of my favorites of your films: Sanctus. I admire it so much in part because it so beautifully depicts the motion of the human body but in a completely minimalist form. Would you relate that film to the kinds of dance movement you are talking about?

BH: It's strange but Talley Beatty's ribs come to mind. The ribs, the staircase, the layers of stratification of the skeleton pushing against the skin as minimal, although we like to think of ourselves as more than minimal. The footstep geography expanded, one time on the grass, one at the seashore, followed by a footstep on concrete, and the final one on the carpet of the room in which you commit suicide. Thank you, Maya Deren, for expanding our space as well as our time with four shots. Nothing could be more minimal than that.

SK: And thank you, Barbara, for your elucidation of Maya Deren's work in relation to your own, and for carrying forward the same spirit of exuberance and panache in your creative film work!

\section{Notes}

1. Hammer's Maya Deren's Sink (2011) addresses the artifacts of Deren's life and film work through a creative documentary approach, fixating on an abandoned sink from Deren's Greenwich Village apartment as well as Deren's writings and persona.

2. Maya Deren was awarded the first Guggenheim foundation grant for "creative work in motion pictures" in 1946.

3. Deren participated in a Cinema 16 roundtable discussion: "Poetry and the Film: A Symposium," along with Arthur Miller, Dylan Thomas, Willard Maas, and Parker Tyler, in October of 1953. A transcript of the discussion is reprinted in P. Adams Sitney, ed., Film Culture Reader. Miller and Thomas disparage Deren's remarks about cinema that is "vertical" (one that "probes the ramifications of the moment, and is concerned with its quality and its depth," in Deren's words) versus "horizontal" ("one action leading to another.") See Sitney 173-174, 184.

4. See Hammer, I Was / I Am. 


\section{References}

Deren, Maya. Divine Horsemen: The Living Gods of Haiti. Kingston, NY: Documentext, 2004.

Fearless Frames: The Films of Barbara Hammer at The Tate Modern. Milan: Mousse Publishing, forthcoming 2013. Hammer, Barbara. HAMMER! Making Movies Out of Sex and Life. New York: The Feminist Press, City University of New York, 2010.

Nichols, Bill, ed. Maya Deren and the American Avant-Garde. Berkeley: University of California Press, 2001.

"Poetry and Film: A Symposium with Maya Deren, Arthur Miller, Dylan Thomas, Parker Tyler. Chairman, Willard Maas. Organized by Amos Vogel." In Film Culture Reader, edited by P. Adams Sitney, 171-186. New York: Cooper Square Press, 1970.

\section{Media}

At Land (1944). Dir. Maya Deren. 16mm film, 14:00 min., B\&W/Silent.

Dream Age (1979). Dir. Barbara Hammer. 16mm film, 12:00 min., Color/Sound.

Dyketactics (1979). Dir. Barbara Hammer. 16mm film, 4:00 min., Color/Sound.

Generations (2010). Dir. Barbara Hammer, with Gina Carducci. 16mm film, 30:00 min., Color/B\&W/Sound.

History Lessons (2000). Dir. Barbara Hammer. 16mm film, 66:00 min., color/sound.

Home (1978). Dir. Barbara Hammer. 16mm film, 12:00 min., Color/Sound.

A Horse Is Not A Metaphor (2009). Dir. Barbara Hammer. DVD, 30:00 min., Color/B\&W/Sound by Meredith Monk. I Was / I Am (1972).Dir. Barbara Hammer. 16 mm, B\&W, sound.

Maya Deren's Sink (2011). Dir. Barbara Hammer. HD, 29:00 min., Color/B\&W/Sound.

Meshes of the Afternoon (1943). Dir. Maya Deren and Alexander Hammid. 16mm film, B\&W. Sound by Teiji Ito added 1959

Nitrate Kisses (1992). Dir. Barbara Hammer. 16 mm film, 67:00 min., B\&W/sound.

Ritual in Transfigured Time (1946). Dir. Maya Deren. 16mm film, 15:00 min., B\&W/Silent.

Sanctus (1990). Dir. Barbara Hammer. 16mm film, 19:00 min. Color \& B/W, Sound by Neil B. Rolnick.

Study in Choreography for Camera (1945). Dir. Maya Deren. 16mm film, 3:00 min., B\&W/Silent

Tender Fictions (1995). Dir. Barbara Hammer. 16mm film, 58:00 min., color/sound. 


\title{
Ritual in Transfigured Time: Narcisa Hirsch, Sufi Poetry, Ecstatic Dances, and the Female Gaze ${ }^{1}$
}

\author{
Silvina Szperling
}

I say:

I burn like a moth in the candle of your face.

You say:

Die.

— Jelaluddin Rumi (1207-1273)

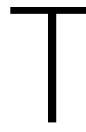

his essay intends to shed some light on the work of the artist Narcisa Hirsch, an Argentinean experimental filmmaker born in Berlin in 1928. It also discusses the influences of Maya Deren's films on the artistic work of Hirsch, exploring the legacy of Maya Deren in South America.

Narcisa belongs to roughly the same generation as Maya Deren—she was born eleven years after Deren - and their lives show some similarities: they were both infant immigrants (one in the USA, the other in Argentina) who escaped death and misery, and who found new communities that offered the possibility to realize their ideas on art and film. They were strong women at a time when Feminism was rather new, and they both practised an artform (Cinema) when women were not generally holding the role of director. Narcisa Hirsch continues to be, at the age of 85, an active artist.

Narcisa Hirsch's film Rumi (1999) is the focus of this paper, since it uses dance as one of its main elements. Other films of Hirsch's, such as Testamento y vida interior (1976), A-dios (1982), Comeout (1971), and Ana, ¿dónde estás? (1987) will be referred to as experimental films that, although they would not be considered as screendance, are connected to the experimental cinema of Maya Deren.

\section{The Myth of Narcisa}

Following the example of a painter father whom she barely knew, Narcisa attended a number of painting workshops as a teenager in Buenos Aires, where she had arrived from Austria in 1937, at the age of nine. The emigration happened just in time to escape the Second World War.

Born in Berlin as the only child of an Argentinean-German mother and a German father who abandoned them when she was five years old, Narcisa grew up in rural Tyrol and was sent to a Viennese school at the age of eight with no previous formal education. The move to Vienna cut her off from the Tyrolean childhood of cows, daisies, snow, and lakesimages which turn up over and over again in her films. She then went to Argentina at age 
nine, when her mother took her for a sabbatical year to her grandmother's house in order to recover from the experience of the Viennese school.

Argentina became her adoptive country, although she was always seen as an outsider: a German to the Argentineans, an Argentinean to the Germans. Eventually Narcisa Heuser married and adopted the surname of her husband, Paul Hirsch. After a decade of raising four children she joined the avant-garde movement of the 1960s that circled around the Di Tella Institute. This movement proclaimed the death of easel painting and introduced her to a local scene of happenings, where she performed street actions in collaboration with her friends, the photographer Marie Louise Alemann and the actor Walter Mejía. They distributed apples to pedestrians in the busy city centre with the intention of taking Art to common people. Explaining her motivation for this event, Narcisa refers to the comment of a pedestrian and participant: "This is the first time that I ever got anything for free. In this country, you never get anything for free." ${ }^{2}$ Later on, they performed another street action, distributing baby dolls to passersby. This was in 1972, after Hirsch had performed the event in London and New York with the intention of creating a three-city-happening. The performance of this action coincided with the arrival in Buenos Aires of the corpses of sixteen people who had been shot in a multiple execution in Trelov, Patagonia. Hirsch remembers that at the time a friend had asked her if she was going to do the performance anyhow, to which she replied: "Of course I am going to do it. There's nothing extraordinary about today; they are killing people every day." During the street action the performers were surrounded by policemen who tried to stop the performance, while angry crowds stomped on the dolls and tried to crush them.

In 1967 the group performed Marabunta, the biggest of their happenings, at the foyer of the Coliseo theatre on the night of the premiere of Antonioni's Blow Up. Marabunta consisted of a giant female skeleton covered with food, which fell prey to the greed of spectators who casually passed by. When one of them took a pineapple that was strategically placed at the skeleton's sex, three or four birds painted in fluorescent colors that had been hidden inside the body flew away, as if flying free from a cage. In order to record this action, Hirsch got in touch with the camera operator, filmmaker and political activist, Raymundo Gleyzer, who was later "disappeared by"the military dictatorship. Whilst editing the material with Gleyzer, Hirsch became interested in filmmaking and joined the world of underground cinema. She flew to New York, where she attended film sessions at MOMA, met Jonas Mekas, and got to know the New American Cinema, the formation with which Deren had been involved.

Primarily a visual artist with a background in Action Art, Hirsch included, from the very first moment, human movement and the body itself as a primordial axis in her cinema. Wanting to experiment above all else, she surmises her filmmaking as follows:

I think that the twentieth century, to which I belong, has a lot to do with movement and I still feel that I need to achieve a certain mobility, I need to unleash certain things... the fall of fixed values, truth, reality, all that we have been carrying since Modernity in philosophical and metaphysical terms, all this is in ruins at this moment. ${ }^{3}$

Her early pieces reveal a strong boldness and an interest in transcendental themes such as death, love, sex, and time. She was one of two women in a group comprised of Claudio Caldini, Juan José Mugni, Juan Villola, Horacio Valleregio and Marie Louise Alemann, and Hirsch and Alemann shared the role of leadership. The group gathered under a kind of 
artistic activism; what brought them together was not a common aesthetic but the idea of sharing a total freedom of expression and the possibility of collaboration in terms of equipment, technical ability, and efforts to summon a reluctant audience, who usually added up to a mere dozen people. Extensive debates were facilitated in the face of the resistance of an audience that was not used to experimental art, and in the face of the total ignorance on the part of local critics. In situations when they shared a screening with other groups of emerging filmmakers who made narrative or "commercial" films (for example, at a UNCIPAR festival / Unión de Cineastas de Paso Reducido / Short Filmmakers Union), large riots would take place between both groups. The screaming arguments would eventually become another form of Happening.

In 1976, at a UNCIPAR contest, Hirsch's Comeout, with music by Steve Reich, won the first prize in the "Fantasy" category, and Film Gaudíby Caldini won the second prize of the "Documentary" category. Comeout consists of a single shot that starts with an out-of-focus image and gradually reveals, after about ten minutes, a record player with the revolving record of the soundtrack. The critics, who rarely paid any attention to experimental film, responded very negatively to the prizes obtained by Hirsch and Caldini. ${ }^{4}$ With regards to Comeout by Narcisa Hirst [sic ], erroneously translated as "Salir y mostrar" in the programme notes, ${ }^{5}$ a critic wrote:

We elude all comment about this film, since we could not attend the last screening on the Fantasy category for special reasons. Thus, we'll limit ourselves to inform the reader about its theme, referred to us by third parties. The film is conformed by only one shot that shows the needle of a record player, which appears to play a broken record. After approximately 15 minutes [sic] the arm of the record player lifts automatically, showing that (against expectation) the record was not broken. ${ }^{6}$

With regards to Film Gaudí by Claudio Caldini, the critic stated:

Regrettably it is not possible to make a comment on this film without feeling the obligation of taking as reference the films made (on this very subject) by professionals and in superior formats. Maybe that's the worst mistake of this film, despite the fact that it has nothing to do with it. Nevertheless the concrete and real is that anybody who had seen any of the previous films tends to establish comparisons, most often hideous ones, but which are valid from the point of view of the spectator, and also the critic's.?

The comments suggest that the critic took minimalism for a mistake (comparing it to a broken record), while he did not even mention the cinematography with the long out-offocus shots, probably because he hadn't actually attended the screening.

A certain amount of scandal regularly surrounded the public presentations of the group around Hirsch and Alemann. In the same way that their sixties happenings attracted the presence of police who often tried to interrupt the events, the seventies screenings transcended the usual audience of friends and acquaintances, and caught the protest of an angry audience, who, according to Hirsch, tended to make familiar accusations such as: "This film could have been done by my five year old daughter". More recently, in April 2012 in Buenos Aires, members of the audience booed during a screening of Comeout. The film was recently chosen for a Blow-up to $35 \mathrm{~mm}$ Award at the Viennale 2012, but still manages to discomfort some audiences in Buenos Aires. 
The year 1976 proved to be a turning point when the Goethe Institute of Buenos Aires, who used to tour German films throughout Argentina, hosted the group of experimental filmmakers via a connection with Marie-Louise Alemann. The Institute provided them with a room for exhibitions and workshops with well-known filmmakers including the Lithuanian, New York-based artist Werner Nekes. During Nekes' visit the artists lived together for two weeks in a suburb of Buenos Aires, each producing their own $16 \mathrm{~mm}$ film. By then, Hirsch had already joined the majority of the group in filming on Super 8. This format turned out to be economically viable, and therefore capable of sustaining the complete artistic freedom of the group. During the late seventies Argentina suffered its bloodiest military dictatorship, but the group of experimental filmmakers did not attract too much attention. It was labelled elitist and bourgeois by activists of political cinema, like the Grupo Cine Liberación (Liberation Film Group) founded by Fernando Solanas, Octavio Getino, and Gerardo Vallejo, and at the same time was considered repugnant and senseless by mainstream filmmakers. Hirsch, although politically minded, was therefore again marginalized between two positions, but it was this marginality that allowed her to survive: "Because things happened," she says, quoting her mentor, Werner Nekes, "in between frames."

\section{Transposing Poetry into Film}

A video runs and a film is projected into its centre, doubling the image.

Cows walk over cows.

Female fingers open the petals of a rose.

A dervish dancer whirls under the gaze of a woman.

The images show clouds, plants, fire or water superimposed over faces, ploughs, and words written on a cave wall.

A curtain opens and a window allows us to look through onto a landscape, while reflecting at the same time the character, as if observing from the other side of the mirror.

These images are part of Hirsch's film Rumi (28 minutes, $16 \mathrm{~mm}$ and video, Argentina, 1999). This work integrates dance as one of the forms of movement of the universe and its creatures. Its metaphors transform time and space into coordinates that are mythological rather than Cartesian. The course drawn by the movements constitutes an eternal present; there is no destiny, no point of arrival, no finishing line. The world turns and turns, in the way the dancer whirls while the landscape (nature at its purest, strongest form) constitutes horizontal lines: a series of peaks of the Andes Mountains, a snowy field, a herd of cows walking in a row. The circular whirling of the eternal present moves against a horizontal timeline, the seasons coming one after another, the sun beginning to fall, the road sustaining the walk of a human. Both directions, the circular and the horizontal, come together on Hirsch's screen. She embroiders poetic images by the heat of the fire that consecrates and consummates the passion.

The film Rumi starts with a scene that reveals the huge scenery of the Andes Mountains. The snowy landscape unravels its power in panoramic views while the words of a poem by Rumi appear on a textured surface. Introducing her films at public screenings, Hirsch offers an analogy with literature, arguing that experimental film is like poetry, while commercial film is like a novel. Deren, a poet before she came to filmmaking, believed like Hirsch that experimental films with their non-linear structure and dream-like transitions could visually transpose the experiential qualities of lyric poems. Hirsch's Rumi is based on a poem by 
Jelaluddin Rumi (Afghanistan, 1207-Turkey, 1273), who left a successful academic career to follow his master Shams e Tabriz to the desert. Meeting Shams caused Rumi's poetry to flow with a mystic eroticism until his death:

See,

this is love.

Whoever is not killed for love is carrion. ${ }^{9}$

In Hirsch's artistic career the encounter with Rumi's poetry was significant and became the culmination of a search she had started as an experimental filmmaker in Buenos Aires in the 1970s. The words of the poem gradually appear in the film written on a textured surface, slowly discovered by a spotlight. The image reminds one of Plato's myth of the cave dwellers, in which reality and the perception we have of it are understood as temporary reflections of eternal ideas. Could it be that for Hirsch, the art of filmmaking is what allows us to unite reality with thought? The original "Allegory of the Cave"10 was intended to demonstrate to Greek philosophical disciples that the real world is not what we see with our eyes, but what we know with our minds. Hirsch, having studied philosophy, revisits the image of the cave to show that what we see and what we know at the end of twentieth century is related through intricate and complex patterns.

Rumi's words are distilled with great deliberation as the film progresses, always lit by the same spotlight and captured by the camera. They delimit, refer to, and anchor the rest of the images that alternate superimposed human bodies, animals and natural elements. All of them are consumed by the passion that is cooked over a low heat.

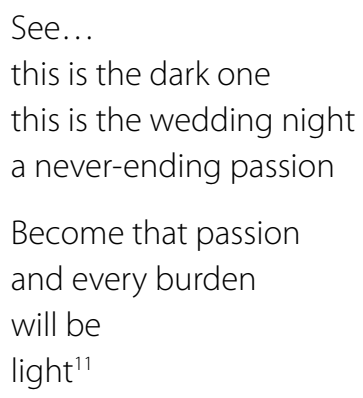

The multiple layers of reality that Hirsch unravels in Rumi remind us of Deren's poetic movement between different states of reality in her films. For Deren, no transition is needed between a place outside (such as a forest, or a park, or the beach) and an interior room. One action can be performed across different physical spaces, as in A Study in Choreography For Camera (1945), and in this way sews together layers of reality, thereby suggesting continuity between different levels of consciousness. Although Hirsch's editing of movement in Rumi tends to favour long shots and repetition rather than the deconstruction and reconstruction of temporal and spatial continuity as in the case of Deren, Hirsch manages to unite the different spaces, interior and exterior, through the gaze of the female character, as she opens curtains and windows, revealing to the spectator both the landscape and her male counterpart.

In Ritual in Transfigured Time (1945/46) Deren uses editing to construct a flow of movement while creating a shared identity between her female protagonists. Hirsch has similarly 
been interested in this sense of doubling, casting multiples of her female characters, for example in Rumi or in Ana, ¿dónde estás?. But Hirsch tends to use a repetition of movement executed by different female figures rather than reconstructing a continuous "real time." For her, movement is an abstract element that finds expression in life and its cycles.

\section{Am A Body, Therefore I Am}

For Hirsch, the body is always both sexual and mythical. And her female gaze strongly colours her films. She was a member of several groups of women who gathered to work out their own concerns, away from the gaze of husbands, bosses and other men. One such group gathered in the seventies around psychologist Susana Balán, who suggested the idea of filming as a means of looking at their own image and talking to themselves. This proposition led eventually to Hirsch's film El mito de Narciso (2005), which will be discussed further below in this essay. Balán was also responsible for introducing Hirsch to the poetry of Rumi. In the film Rumi, Hirsch includes a scene in which a naked male dancer descends a staircase under the gaze of a fully-dressed woman; the fact that she contemplates him appears like a statement by the filmmaker, in which the woman is empowered and actively looking, no longer the object of the male gaze but the subject of her own gaze whilst also gazing at a man's body. ${ }^{12}$

In Testamento y vida interior (Testament and Interior Life, 11 minutes, 8mm, Argentina, 1976) the images of a funeral procession in which four people carry a coffin through the city alternate with images of a woman taking a bath in the middle of a park. The film was shot in the same year that the last Argentinean dictatorship came to power in a coup d'état, and the notion of modesty of the prudish Buenos Aires society of the seventies is profoundly challenged by work such as this. But the film is more than a simple urban provocation. The funeral procession follows its path through the city and out into the fields. The relatives of the deceased move forward through a snowy road, dressed in ponchos, to the sound of flamenco music. The image becomes tinged with red and eventually fades into the light of the sun, swallowing the whole of the procession. Her "actors" - cameo appearances of her colleagues - move naturalistically, but her cinema is very far from naturalism. As Hirsch writes about her own process, there is always a note coming from the unconscious that feeds the narrative: "A film starts from a thought, from an image that emerges, that comes out of its context, becomes independent and sends signals. An image trapped in an instant of opening and estrangement of the world."13

Deren's interest in the unconscious has been evident since her first film, Meshes of the Afternoon (1943). In addition to the link which she establishes between different layers of reality, Deren uses filmic techniques such as slow motion and negative imaging, among other effects, to create a sensation of strangeness or estrangement which the characters also often allude to in their performances. For example, in Ritual in Transfigured Time, we can see Rita Christiani's expression of astonishment from the very moment that she appears in the film, reinforced by the wind that blows her scarf backwards and by the movement of her arms, which she lifts in front of her as if in defence while entering a dangerous space (the room in which she will face her other-being, played by Deren). Hirsch's approach to filmmaking is different in that she uses relatively few in-camera and post-production effects (except occasionally to suggest an acceleration of natural events) and her actors tend to have a neutral 
facial expressions, almost like masks, as for example the figure of Ana in Ana, ¿dónde estás? In this film, two actresses play the part of Ana, and both adopt equally neutral facial expressions. The viewer cannot interpret their emotions, and it is mostly their movements or actions which carry the progression of the narrative. One actress embodies a woman's wild nature; the other conveys her social duties. The first is very physical; she has several scenes where she does acrobatics in a circus tent. The other tends to interact with people and hosts a party at the climax of the film. In this party sequence Hirsch depicts a game of chess, a recurring motif in Deren's At Land (1944). In this film, Deren, in the role of protagonist, intervenes in a chess games she encounters, thus reflecting Deren's own commandment (as artist) of the film's ludic structure. In Ana, Hirsch pits her protagonist against several male opponents, thus implying her strategic negotiation of a gendered game.

In her film A-dios ${ }^{14}$ (22 minutes, 8mm, Argentina, 1982), Hirsch works on the myth of the hero. This film constitutes her explicit tribute to men, to whom she dedicates the film (along with Carl Jung), and in it the naked body, both male and female, receives a sculptural, almost Greek classical treatment. There is something stark in those images of male torsos which include sexual organs but no faces: bodies that are lit, printed in black and white, revealed as if they were made of marble. The artist alternates between these images and other quasi-heroic ones (sportsmen making supreme efforts, warriors entering the sea, nuclear explosions, military parades, Nazi iconography) with the slow advance of a man on crutches, who moves with great difficulty along a path, until he finally reaches a resting place: a pub on the road. In the film Hirsch quotes Simone de Beauvoir, printing text across the filmic image: "Man is in revolt against his carnal state; he sees himself as a fallen god: his curse is to be fallen from a bright and ordered heaven into the chaotic shadows of his mother's womb."15

The hero always has a mission, and the woman-artist shows his failure, his fall, by filming him and accompanying him in his difficult advance on crutches. She looks at that failure with pity but her look gives the warrior, even in his fall, a way to vindicate himself: to get to his resting place by his own means. The warrior always can (and must) vindicate himself. The female gaze is compassionate and admiration is born from this compassion.

This preoccupation with the relationship between women and men is also present in Deren's films. In Meshes of the Afternoon, which is co-directed with her husband Alexander Hammid, the man appears to be an executor of a mandate. In the beginning of the film when Deren's protagonist enters the house, the male figure is absent and his absence is marked by a serious of malfunctioning objects: a knife that falls, a telephone which is disconnected, and an empty bed in the bedroom, with curtains blowing in the wind. Towards the end, just as one of the "Derens" is about to stab the sleeping Deren, she opens her eyes and the male character appears for the first time, facing the camera in a point of view of Deren. He leads Maya upstairs, and on his way puts the telephone handset back into place. Further along, the man enters the house for a second time, this time to witness Deren's character killed by a knife. The co-directors leave any interpretation of the relationship between the woman and the man open, but there is a suggestion that the male figure might be an executor of the woman's intention. In any case, the film suggests that the roles within a couple are not always what they appear.

In Ritual in Transfigured Time, a man is a heroic figure on a plinth, a marble statue seen against the sky. As statue, the man is at the same time an object of desire and of fear, but 
as he jumps off the plinth and comes to life he becomes the connecting element between an ideal world and a real world, just as in A Study in Choreography for Camera, where the movements of a male figure connect an outside space with an interior space. This would have been an unusual casting of a male figure for Deren's time. For Hirsch, who belongs to a generation that lived through the seventies with its Feminism, Free Love and Existentialism (hence her quoting of de Beauvoir), the man who comes to life is also an object of compassion for his historical role of hero and his mandate of success, therefore as victims of his own gender mandate. The anger is faded and there is a possibility to play with the male persona in these films.

\section{Nature Provides}

Another element that is always present in Hirsch's films is nature. Nature as a force, as power, as a signal of the passing of time, and as the signal of humanity's tragic destiny. Hirsch often immerses herself in Patagonia, the icy, deserted and mountainous southern tip of Argentina. For decades she has spent long periods of time in this region, gathering images from the different seasons of the year, images that also remind us of her alpine childhood. Generous framings of snowy fields, mountain ranges and infinite roads are recurrent in her work. She also dwells on details in which matter, almost in an abstract form, invades the whole frame: blue water, rough rocks, flames silhouetted against the night sky. And, over all those images, time embroiders its own course, which Hirsch emphasizes either by means of the acceleration of the cloud motion or the quiet observation of a sunset.

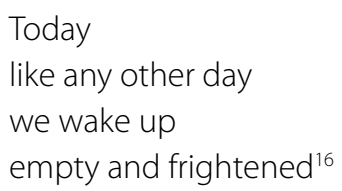

These words, again projected on a surface as if in a cave, give rise to visions of nature and its impressive breadth. We see a woman from behind. She raises a curtain and the movement mediates between our gaze and the landscape in the scene. It is the woman who reveals to the viewer her vision of the landscape. Furthermore, the $16 \mathrm{~mm}$ image, projected into the video image, replays the same scene with a fraction of delay and echoes the woman's gaze looking into the landscape, and by extension, the viewer looking at the woman. From within the landscape, her field of vision, a man moves towards the camera, and towards the audience, carrying his tools.

The film reiterates this discovery, this lifting of the veil between the interior and the exterior, between looking out and looking in. The process is mediated by the hand gesture of a mature woman, of a teenager or of a young girl. It is one woman and many at the same time. At this point the film echoes Deren's Ritual in Transfigured Time, where the female protagonist shares a sense of identity with three different performers: Anais Nin, Rita Christiani, and Deren herself. These three performers perhaps represent a woman at different stages of her life and with different attitudes towards life and society: surprise in the character of Rita, wisdom in Maya and mystery in Anaïs.

In Hirsch's Rumi, each time the woman opens the curtain, we see the landscape which she sees and which is the same, but different. The mountains are the same, but different. 
The fields are the same, but every time they are lit by a new light and seen from a different angle. Or they are superimposed over a previous or a subsequent scene. Time appears to be different under this new, multi-layered gaze. Through the simultaneity of the $16 \mathrm{~mm}$ and the video image, as well as the repetition of gestures, what happened before happens again at the same time as what is happening now. Thereby the viewer never runs out of ways of looking, and of seeing.

For Hirsch, nature is a mirror in which the interior is reflected onto the exterior, much like the close relationship between interior and exterior in Deren's cinema. As Brazilian researcher Joao Luiz Vieira states:

Which is the particular experience that this film, as well as the other dance films made [by Maya Deren], offers to the spectators? Seeing and re-seeing Meshes of the Afternoon, we are continuously surprised by a sequence of images... that seems to continuously express a conflict between the interior and the exterior, or better, the coexistence of both spheres, expressed by means of dream, of imagination and also from some sort of memory of a sexual fantasy that is in conflict with the external reality. Referring not only to Cinema, but also to her desire of Cinema, Deren made clear that she wanted to put into her films "the feeling that a human being experiences in any incident, and not only to register that incident."17

The proximity or perhaps continuity between interior and exterior that Vieira describes is reflected in the fluid relation between dream, imagination, fantasy and reality in Deren's films. This can be mapped onto the work of Hirsch, and Rumi in particular, where the layering of images and the intricate play of a frame within a frame dissolve any clear distinction between seeing and experiencing, watching and being watched, inside and out.

Rumi was originally filmed in $16 \mathrm{~mm}$, but since its premiere it has been projected simultaneously in both film and video, with the $16 \mathrm{~mm}$ image projected as a smaller frame inside the larger video image. It is one of Hirsch's pivotal works of the nineties, during which time she made the difficult transition from film to video. In the seventies Narcisa and her group experimented extensively with projection surfaces, projecting onto water, ice, and smoke in place of the traditional screen. At the occasion of Hirsch's recent retrospective at BAFICI (Buenos Aires International Independent Film) Festival, April 2012, Artistic Director and critic Sergio Wolf described her to be a materialistic filmmaker, working with the material qualities of film. ${ }^{18}$ This is confirmed by Daniela Muttis, filmmaker and assistant to Hirsch, who writes with regards to Hirsch's interest in the relation between technologies and perception:

In these processes of schismogenesis ${ }^{19}$ between the different technological languages Narcisa settles in as an experimental artist, nurturing herself from all the technological variables. Her ideas try to cross-link forms and concepts, to generate a conflict through simultaneous images, to provoke reflection within the space where the actions happen, inside and outside the screen. ${ }^{20}$

The experience of this double projection is particularly touching for the audience and turns the usual movie-theatre experience into one akin to ritual. When both projections run simultaneously, a kind of picture-in-picture effect is generated, but far from the perfect synchronization of digital technology, it causes a degree of mismatch between 
the different qualities of the projected images. Seeing the almost mythical figure of the older filmmaker operating the $16 \mathrm{~mm}$ projector adds a performative aspect to the already poetic images. Meanwhile, listening to the sound of the film move through the projector provides an underlying cushion to the soundtrack and adds another degree of presence to the experience. As this mechanistic soundtrack can be heard beneath that of the video, the combination of both soundtracks and images is experienced as aleatoric. As viewers, we contemplate, or witness these images, which tell us that nothing is concluded, nothing is completely under control, nothing has a definite ending. In Rumi, cows can walk over other cows. As Daniela Muttis argues:

The ritual that Narcisa proposes is the experience of chance, the immersion in the body of the moving image but also in the body of each spectator who traces their own personal journey. The combination of two simultaneous readings that are offset in time. What lies beneath are not the coincidences of the forms, but the possibility of simultaneous thoughts that are superimposed in that search for relationships and conceptual issues, where she proposes to exceed the limits of the languages that technology imposes... The images of her films are part of a mirror that produces the action of their portrait, and the technology is a tool that enables their distortion, by pushing on towards the new, the unpredictable. ${ }^{21}$

This is how the landscape changes, again and again. The harsh winter gives way to spring, the relationship between the woman and the man changes. The transitional moment is marked by images of one of the elements of nature, fire, and the fire is cooking a sacrificial lamb. The next time that the woman opens the curtain, we see the landscape of spring: grass has grown on the land that had been covered by snow. Birds sing over the sound of a flute. The man is harvesting what he had sown, and his image is followed by one verse from Rumi's poetry, superimposed over dark water:

die

of passion

passion $^{22}$

A vase full of flowers of a strong orange color stands in front of a different window: the woman who opens the curtain seems older than the previous one, and a new performer incarnates the man's character, a dancer. The male figure stops being a collector, a hunter. He stops carrying out tasks that are necessary for his survival and appears as a beautiful, naked body walking down a spiral staircase. He sees a woman lying with her back to the camera, fully dressed. She is watching him, which reiterates a leitmotif of the film, the female gaze. As Hirsch has stated: "Rumi is a film about the gaze, about the female gaze."23

The man reiterates a descent, a landing from a distant place in the unconscious carrying of life in his member and in the intensity of his gaze. He allows himself to be watched. The woman, as always situated by a window, which this time around reflects plants as a part of nature that is present and vibrant, is holding a rose in her hands. She touches its petals, deflowering it.

This tactile contact, a process of deflowering, is repeated over and over again across layers of images that blend with each other: reflections of plants, pupils looking at the camera, words travelling over the screen: 
I say:

I burn like a moth in the candle of your face

You say:

Die

Die! ${ }^{24}$

In this moment the man starts dancing and whirls interminably, his skirt circling around his body as the camera pans horizontally, taking him (and the viewer) through new landscapes: a riverside path, a field, flames and mountains. This superimposition adds to the one produced by the double projection technique, multiplying the possible readings. Rumi deals with the passing of time. This theme runs through the work of Hirsch, both generally, with reference to the transitioning of elements of nature, and more particularly, through her treatment of the ageing process of humans, especially women. In El mito de Narciso (The Myth of Narcissus, 20 minutes, $16 \mathrm{~mm}, 8 \mathrm{~mm}$ and video, Argentina, 2005) she explores the issue of "self-image," investigating the possibility or impossibility of knowing oneself. For this purpose, she used interviews that were made at different times with the same women, confronting and talking about her own image. Using a voiceover, Hirsch asks:

Who am I? Am I the one who looks or the one who is looked at? We are always two, that is the dialectic, and between the two of us there is a space. That's why I see myself so strange and so foreign, just as I have always seen myself. And that separation, that distance, would be the no man's land from which utopia could arise. ${ }^{25}$

At the age of 85, Hirsch continues to work and rework her images, bringing new and younger audiences into contact with an Argentinean experimental cinema they never knew existed. For the retrospective that the prestigious festival BAFICl ${ }^{26}$ dedicated to Narcisa Hirsch in April 2012, the filmmaker digitized and re-edited her film Aída (6:41 minutes, 8mm and video, Argentina, 1976-2012) in which the dancer A'da Laib plunges into a frenzied dance that transports her body into an ecstasy of movement. The context is a living room in an apartment, probably the dancer's home. Seen through contemporary eyes it looks somewhat like a pastlife memory, not unlike the experience of watching Study in Choreography for Camera at the moment when the foot of dancer Talley Beatty enters Deren's mid-1940s apartment. The viewer sees the dancer occupy an everyday habitat, but cannot escape the feeling that the body has entered into a different dreamlike time. The viewer's gaze activates the temporal transportations implied by these danced spatial transitions.

In Aida, images of the actual dance alternate with images of Aída's naked body in a foetal position, while the rhythm of the movements is altered through the process of editing. Layers of images are superimposed showing us details at unexpected moments. Aída's dance becomes a dance of the gaze, a ritual in which the audience takes part by simply being there, watching images that address the senses. A strange sense of empathy is provoked, as audiences are invited to feel with the film, despite knowing that they are other. Hirsch says in the voiceover of El mito de Narciso: "Creation in the space, creation in no man's land. It is like love: it is not a fusion; it is separation, distance, to let the other one be."27

One of the common elements between Hirsch and Deren's work is a feminine gaze and the presence of nature in their work, with nature being both the interior and the exterior. In Meshes the interior-Deren's face - is seen through the window as part of an exterior; in 
Rumi the exterior is reflected into the interior. Nature is a possible portal for a flow between the two, and it is also the passing of time. Deren and Hirsch share a view of human movement as a means to enact rituals of passage between different levels of consciousness, an interest that also finds expression in the use of multiplied female characters. But above all, they are both courageous women who challenged prejudices of their era, embracing film as a passport and as a way of shaping the discourses around them.

Some of the filmmakers from Narcisa Hirsch's experimental group still gather today to do screenings in the intimate setting of her home. Hirsch owns several projectors $(8 \mathrm{~mm}$, $16 \mathrm{~mm}$, and video) and enjoys being a hostess for a crowd of filmmakers, musicians and visual artists. Maya Deren, who frequently hosted screenings at her Morton Street apartment, shared with Hirsch a particular connectedness with the materiality of film and its associated apparatuses. In a personal notebook of 1947, Deren wrote: "here, suddenly is the strange fever and excitement. Is it because holding film in one's hand, one holds life in one's hand?" And she continues:

The immediate physical contact with the film, the nearness of the image, the automatic muscular control of its speed - the fact that, as I wound, my impulses and reactions towards the film translated themselves into muscular impulses and so to the film directly, with no machine-buttons, switches, etc.-- between me and the film...This physical contact creates a sense of intimacy. It is not an image independent of me, projected on a wall, of which I am a spectator. It is immediately, directly, uniquely for my eyes. It comes to life out of the energy of my muscles. ${ }^{28}$

\section{Notes}

1. An earlier version of this essay was published in Caldas and Blum, Ensaios Contemporâneos de Videodança.

2. This and other quotations of Narcisa Hirsch were obtained during a series of interviews that the author of this essay had with the artist between September 2011 and December 2012.

3. Torres.

4. Translated from Claudio Caldini's blog: http://eldevenirdelaspiedras.blogspot.com.ar/2012_03_01_archive.html 5. "Salir y mostrar" is the skewed translation of the title of Hirsch's film Comeout in the program of the UNCIPAR festival. It does not translate the real meaning of the title, which is also the title of the music piece by Steve Reich.

6. Taken from an online blog by Claudio Caldini: http://eldevenirdelaspiedras.blogspot.com.ar/2012_03_01_ archive.html

7. Ibid.

8. Torres.

9. Rumi, Jelaluddin. All excerpts from his poetry are quoted by Narcisa Hirsch in her film Rumi.

10. Plato. The Allegory is written as a dialogue narrated by Plato's friend Socrates and Plato's brother Glaucon at the beginning of Book VII, 514a-520a.

11. Rumi, qtd. in Hirsch.

12. See note XXV.

13. $14^{\text {th }}$ BAFICI Festival Catalogue.

14. Translation note: The title A-dios is a word game that translates both as "Good-bye" and "To-God".

15. Translation note: Translated from Spanish from El segundo sexo. Buenos Aires: Sudamericana, 1999.

16. Rumi, qtd. in Hirsch.

17. Vieira (orig. emphasis, my trans.) Deren's original quotation can be found in Writings of Maya Deren. 
18. Sergio Wolf, in his public introduction to the audience at the occasion of Hirsch's recent retrospective at BAFICI Festival, April 2012. See end part of this essay for a comparison with Deren's materialistic and physical relationship to film.

19. Jutoran and Ricardi. As an anthropologist in New Guinea in 1927, studying the latmul tribe, Bateson coined the term "schismogenesis" as "a process of differentiation in the norms of individual behaviour resulting from cumulative interaction between individuals."

20. Muttis.

21. Ibid.

22. Rumi, qtd. in Hirsch.

23. Presentation of Rumi at the Alliance Française de Buenos Aires, August 2011. Discussion with the audience.

24. Rumi, qtd. in Hirsch.

25. Hirsch, voiceover in El mito de Narciso.

26. BAFICI (http://www.bafici.gov.ar/home12/web/es/biographies/show/v/director/810.html)

27. Hirsch, voiceover in El mito de Narciso.

28. Deren, "From The Notebook of Maya Deren," 21.

\section{References}

de Beauvoir, Simone. El segundo sexo. Translated by Juan G. Puente. Sudamericana: Buenos Aires, 1999.

Deren, Maya. "From the Notebook of Maya Deren, 1947." October 14 (Autumn 1980): 21-46.

Jutoran, Sara and Nora Ricardi. "El proceso de las ideas sistémico-cibernéticas." Sistemas familiares 10, no.1 (April 1994).

Marín, Pablo and Andrés Denegri (comp.): Dialética en suspenso: Argentine Experimental Film and Video. Book (English and Spanish) plus 2 DVDs (Film \& Video). Antennae Collection. http://www.antennaecollection.com/ projects.html

Muttis, Daniela. Program notes for the presentation of Rumi in the Video Art and Experimental Cinema Exhibition at the Museum of Modern Art of Buenos Aires (MAMBA) at the Alliance Française de Buenos Aires, August 2011.

Plato. The Republic. Book VII. Translated by Bejamin Jowett. http://classics.mit.edu/Plato/republic.8.vii.html Torres, Alejandra. "Ver(se) mirar a la cámara." In Narcisa Hirsch: Catalogue of Works, edited by Alejandra Torres, 45-60. Buenos Aires: Casa del Bicentenario, 2010.

Vieira, Joao Luiz. "O Visionario Cinema do Fluxo de Maya Deren. "In Ensaios Contemporâneos de Videodança, edited by Paulo Caldas and Leonel Brum, 14-21. Rio de Janeiro: dança em foco, aeroplano editora, 2012.

Festival catalogue. Narcisa Hirsch Retrospective, Buenos Aires International Independent Film Festival, 2012. http://www.bafici.gov.ar/home12/web/es/biographies/show/v/director/810.html

\section{Media}

A-dios (1982). Dir. Narcisa Hirsch. 22:00 min., 8 mm. Argentina.

Aída (1976-2012) Dir. Narcisa Hirsch. 6:41 min., 8mm and video. Argentina.

Ana, ¿dónde estás? (Ana, Where Are You?) (1987). Dir. Narcisa Hirsch. 65:00 min., 16mm. Argentina.

At Land (1944). Dir. Maya Deren. 15:00 min., 16mm. USA.

Bebés (Babies) (1974). Dir. Narcisa Hirsch. 10:37 min., 8mm. Argentina.

Comeout (1971). Dir. Narcisa Hirsch. 10:00 min., 8mm. Argentina.

El mito de Narciso (The Myth of Narcissus) (2005). Dir. Narcisa Hirsch. 20:00 min., 16mm, 8mm and video. Argentina. Marabunta (1967). Dir. Narcisa Hirsch. 7:55 min., 16mm. Argentina.

Meshes OfThe Afternoon (1943). Dir. Maya Deren and Alexander Hammid. 14:00 min., 16mm. Music by Teiji Ito added 1959.

Retrato de una artista como ser humano (Portrait of an Artist as a Human Being) (1968).Dir. Narcisa Hirsch. 5:16 min., $16 \mathrm{~mm}$. Argentina.

Ritual in Transfigured Time (1946). Dir.Maya Deren. 14:00 min. USA.

Rumi (1999). Dir. Narcisa Hirsch. 28:00 min., 16 mm and video. Argentina.

A Study In Choreography For Camera (1945). Dir. Maya Deren. 2:00 min. USA.

Testamento y vida interior (Testament and Interior Life) (1976). Dir. Narcisa Hirsch. 11:00 min., 8 mm. Argentina. 


\title{
INTERVIEW
}

\section{Seeing (Oneself) Looking Into the Camera: An Interview with Narcisa Hirsch}

\author{
Alejandra Torres
}

[This interview was published in 2010 in a catalogue for an exhibition/homage that celebrated Narcisa Hirsch's work as part of the Argentinean Bicentennial, at the recently opened cultural center La Casa del Bicentenario ("The House of The Bicentennial"). The occasion constituted a first celebration of Hirsch's contribution to Argentinian film, as well as a first step in serious academic and social recognition of the '70s Experimental Film Group of which Hirsch was a member. This group of artists had been in the shadows for a long time; since 2010, however, documentary films, retrospective screenings, books, and DVDs, as well as other celebratory initiatives, have taken place. The interview shows the role that Werner Nekes played in bringing Maya Deren's work to Argentina and gives an impression of the debates and tensions in the Argentinian filmmaking community, addressing questions such as the relation between poetry, film, and language, and between self, mobility, and the image.

The interview was done by Alejandra Torres, a writer based in Buenos Aires, and has been translated from the original Spanish by Mariana di Silverio for this issue of The International Journal of Screendance.]

Narcisa Hirsch: Alejandra, before we start I would like to tell you that there are going to be lots of gaps, because when my work started, that is in the '60s and '70s, there did not exist the proper recording of artworks made by curators and critics that there is nowadays.

I was, along with the Experimental Film Group, which appeared later, someone who used to work at the margins of everything. I was like a somnambulist. Therefore it was not so important when, where, or who you worked with; it was all like a game.

Most of our work remains forgotten, except some maybe, thanks to Claudio Caldini. He was, and still is, the most organized person in our group. Thanks to him our work can be partially rescued now. The Experimental Film Group was Marie Louise Alemann, Claudio Caldini, Juan Villola, Horacio Vallereggio, Juan José Mugni, and me.

Alejandra Torres: Since you are talking about the Experimental Film Group, I would like to ask you about the workshop you did with Werner Nekes when he came to Argentina in the '80s. What was that experience like?

NH: Yes, it was at the Goethe Institute. He came along with a sound technician. At that time Nekes was a well-known filmmaker in Germany. He was making good experimental films, very theoretical films. He is a collector of vintage film equipment, projectors, and cameras and has also written a book about cinema, cinema in its purest form. He was a very inspiring 

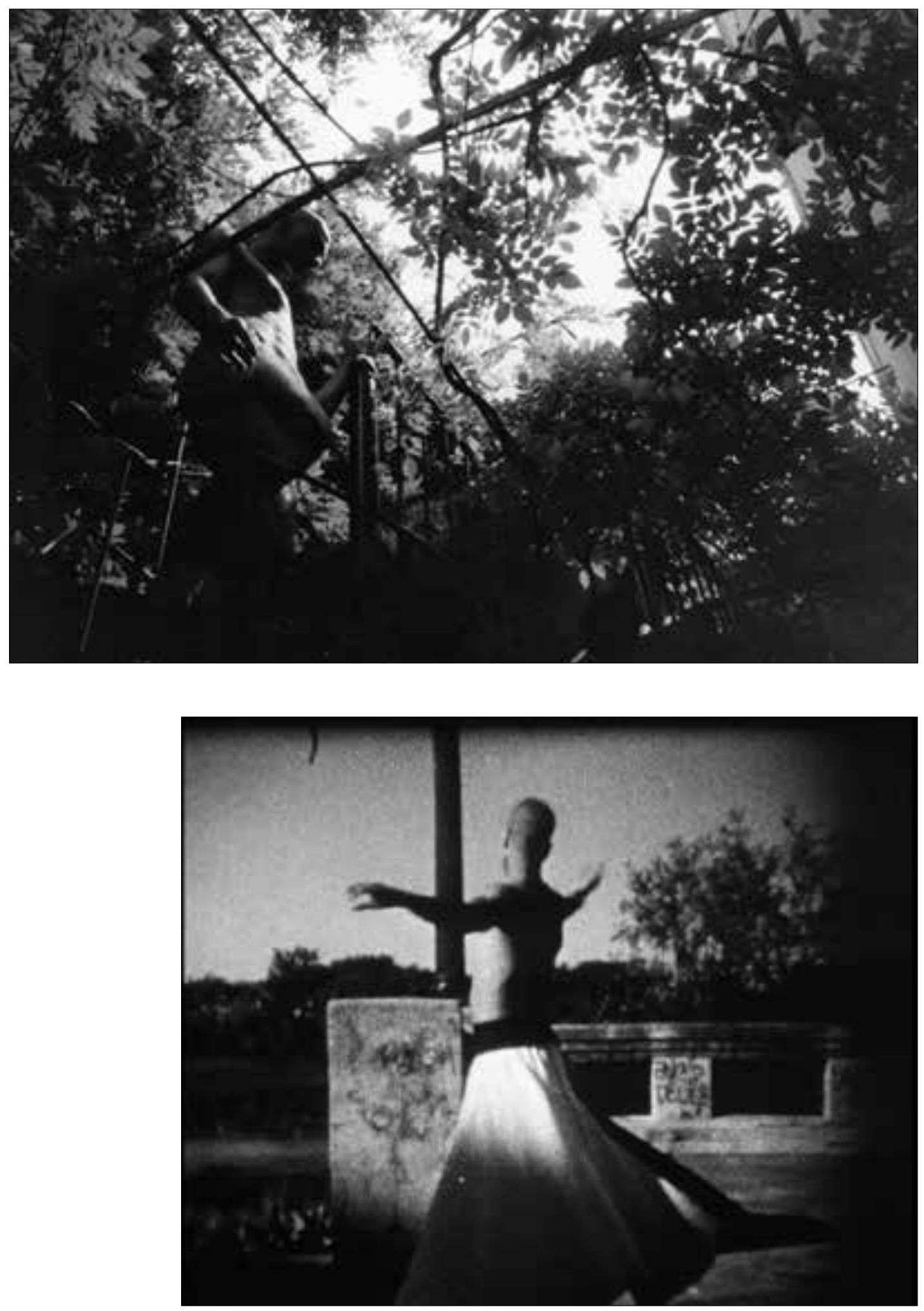


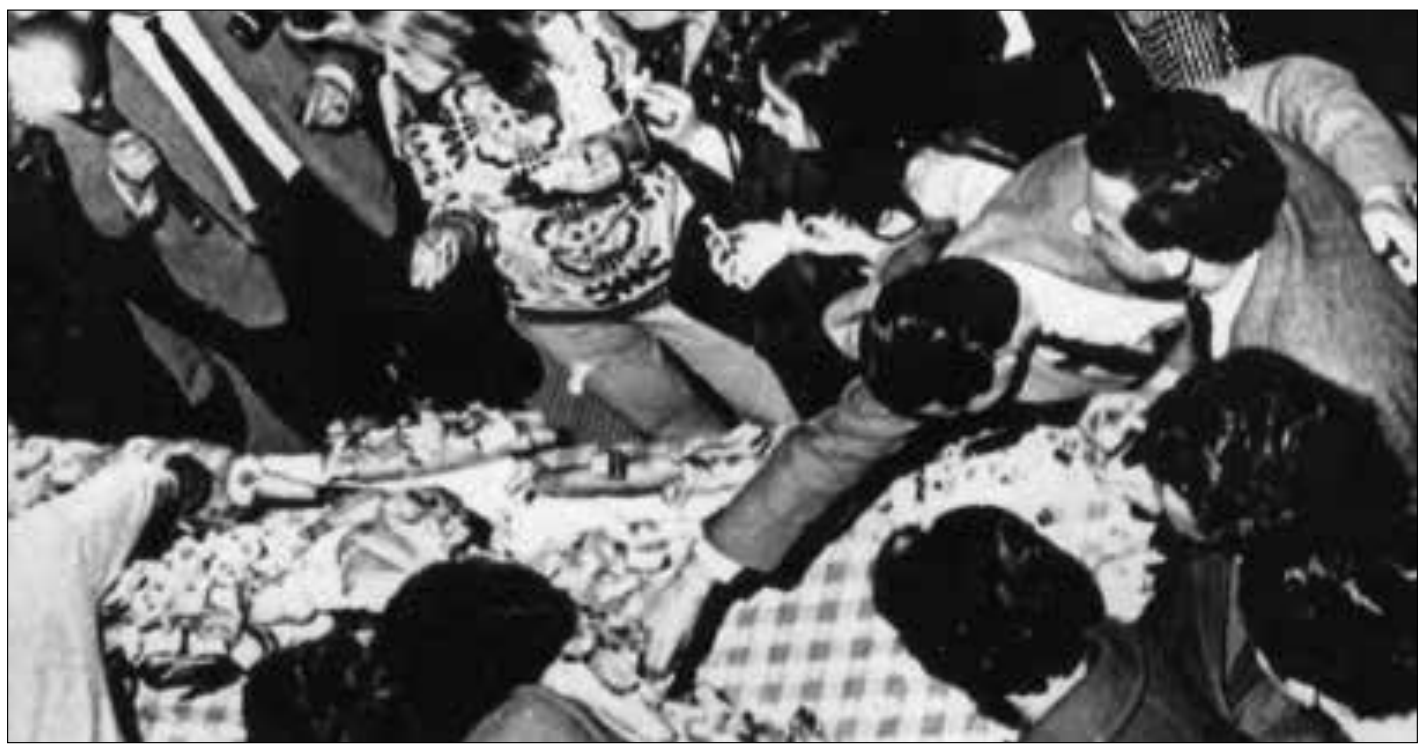

Top and Lower Left: Rumi. 28:00 min., $16 \mathrm{~mm}$ and video, Argentina, 1999. Courtesy of the artist.

Above: Marabunta 7:55 min., $16 \mathrm{~mm}$, Argentina, 1967. Courtesy of the artist.

Below: Aída. 6:41min., $8 \mathrm{~mm}$ and video, Argentina, 1976-2012. Courtesy of the artist.

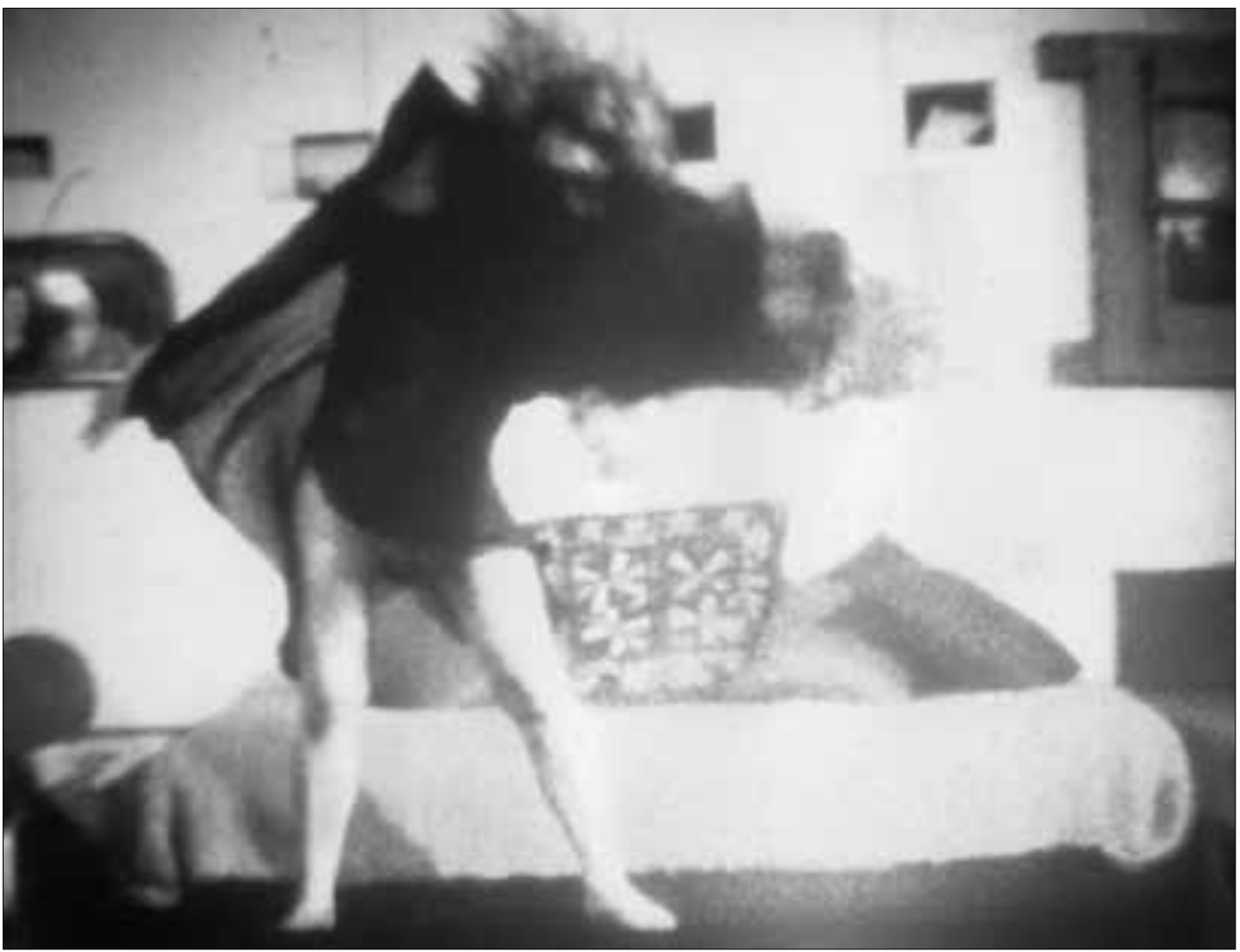


man. His wife Dore $\mathrm{O}$ also made films. We did a workshop with him; we filmed with him. That was all funded by the Goethe Institute. He stayed for about two weeks and then he took all the material away with him. He said he was going to edit it but he never did, so we do not have that material now. Each one of us made a little film in $16 \mathrm{~mm}$ with him. We did filmmaking exercises. It was great because we watched all his films.

AT: Which one of his films did you like the most? Which one had the biggest impact on you?

NH: I cannot remember the names very well. He is a man who works almost scientifically. At that time, his work was very different from what we used to do; we were not so professional. I liked his work, then. I thought it was very original, very interesting. And it showed the trends of the experimental film movement.

AT: Even now, Nekes still considers it very important for young people to be in contact with old technical film equipment, so they can see, in this technological era, what the early beginnings were like...

NH: Yes, I do not know how he got on with video, because when he came to Argentina we were still working on experimental film. In the '80s, video appeared and Super 8 disappeared, physically. When Nekes came he said, "You cannot film in Super 8, you have to film in 16mm, because the medium is too fragile." It seemed like a terrible, unsustainable, underdeveloped medium to him, and he said, "You have to make films, but you have to film in 16mm so you have a negative and you can work in a different way, the sound is different." And in fact, my Super 8 films are in poor condition now, the sound can barely be heard. So he was right, but as a group, we were in a precarious economic situation. Claudio and his friends were young men, they did not have any money, and filming in $16 \mathrm{~mm}$ was not a possibility for us.

AT: Did you organize that workshop?

NH: No. The Goethe Institute did, through Marie Louise Alemann. She was closer to the Institute than me, so she got them to give us a space to show our films. At that time nobody knew about the experimental film movement. There was the so-called American Experimental Cinema, New York's underground film movement, under the leadership of Jonas Mekas. The Di Tella Institute had brought some films of the New American Cinema to Buenos Aires, and that was what we used to watch. Otherwise if you did not go to the USA you did not have the opportunity to watch those films here. And from Germany and Europe there was very little material available, because the experimental film movement was not as strong there as it was in the USA.

AT: In your opinion, what is the difference between underground cinema, experimental cinema, and independent cinema?

NH: Experimental and underground cinema are the same thing. Independent cinema... just to be clear, I am not a theorist at all, contrary to Werner Nekes, I am someone who works deaf and blind, absolutely, do not ask me anything. The theorists who come after my work is done are the ones who find things I have never seen or heard in it before. But, I think that the term independent cinema refers to narrative films, like commercial ones but made on a lower budget, as if they were made by a couple of friends who get together 
and make a film at minimum cost. I think that in the beginning there was a very strong independent film movement in the USA and they used to make that kind of film, but they worked with actors and a screenplay. On the other hand, the underground film movement, experimental cinema, avant-garde films like the ones made by Dalí or Buñuel in Europe, they are not conventional films, they break out of the mold. Those are not the films we are used to watching in the cinema. The term experimental cinema may refer to a wide range of pieces, from the one performed by the American filmmaker Carolee Schneemann, in which she pulled a scroll out of her vagina on stage, to a film loop passing through a light that throws shadows over a wall. These kinds of pieces have very little to do with what we call cinema; when you have to explain to someone, "Well, I make films...", it is impossible.

AT: What is it to be an experimental filmmaker? Silvestre Byrón states that experimental filmmakers identify themselves with poetic intuition, is that true?

NH: Yes, I think it is true. When I want to explain to someone that I make experimental films, I often use a metaphor. The films we make are different from the ones that people watch in the cinema because those ones have a narrative structure like a novel, while the ones we make are more similar to a poem. They do not have a visible narrative like the one in the novel and they do not have a formal rigor like the common films. An experimental film can be one minute long like The Aleph [2005] or twenty-four hours long like Empire State Building [1964] by Andy Warhol.

AT: Nekes states that the rules of grammar determine what we can think, so if our thoughts are influenced by grammar, then the thing is to find another language, a language that allows us to communicate, to go through the platform of perception...

NH: Yes, for example Nietzsche also said the same thing, that we are determined by the rules of grammar. But prior to the rules of grammar - say this, not him-we are determined by language, which is limited, and that is the reason why we have other languages. Photography is another language; cinema is another language, music...But grammar determines us to a large extent. Jalfen, a friend of mine who was a philosopher, said a nice phrase: "If we say, 'Allah is the only god,'that is one thing, but if we say, 'Allah is the only god, in Islam,'the sense of the word entirely changes." So here it is a matter of a comma and it is a matter of grammar.

AT: I go back to Nekes, who takes up Apollinaire again when he says that you have to get used to understanding in a synthetic-ideographic way rather than in an analytic, discursive way. He even talks about Chinese ideograms. You write a lot of haiku poems. This also has a lot to do with experimental cinema.

NH: Nekes used to say something that I think is very characteristic of him: "Things happened frame by frame." It means that things happen in the gap, the adjacent intervals, and for me that is a topos, a place, a very interesting topology. I worked with this in The Myth of Narcissus [2005],the film about women, because the possibility of creating a space between the "I" and oneself, between the image and the self-image, generates a tension. And this is where novel spaces appear, spaces that are not yet colonized by us. It is also strange, because when you divide yourself in two selves, an idea which is not new since psychoanalysis has always talked about the different selves, you do not know "who is the self who asks who," as Derrida writes. 
Rilke says a very nice thing: "Only plants and animals are able to feel that they are in this world, whereas man is always before the world, except for brief instants of love and mystic fusion with God." In that split we have because of our being before the world, which is our ability to think, we also have the possibility of being before ourselves, and at the same time we can observe ourselves watching the world, as if seeing our own backs. This idea of a self that is a witness stretches to infinity, because I can think that I am watching the world and I can think that I am seeing myself watching the world, and then that I am seeing this witness, and then seeing the witness of the witness. It creates a labyrinth of mirrors with no exit. In fact, we are eccentric, because we are both inside and outside the world simultaneously.

AT: What is the riskiest thing you did regarding the technical aspect of experimental film?

NH: Regarding the technical aspect, I used to work with the resources that were available at that time. I had a good Super 8 camera with plenty of bells and whistles but I also had a little camera that was like a box, it was not a reflex camera, you just looked through a hole. I used to carry it in my pocket during my journeys and I filmed, for example, through a cookie, whatever was to hand. I have burnt, drawn, and scratched on the celluloid. I have built filters to put in front of the lens; these were things you could not buy commercially so you had to make them. We projected onto anything, smoke, dry ice, and once we also projected onto a live white rabbit in an art gallery. We also used to debate a lot, because we were always attacked.

AT: Who did you debate with? Did you talk with the people from UNCIPAR?

NH: Yes, we used to discuss things with them. I met Claudio Caldini at UNCIPAR, Unión de Cineastas de Paso Reducido. It was a place where they showed Super 8 films, and the people who attended the screenings were filmmakers who made independent films, but not experimental films. So when we showed our films, the other people were offended, they felt personally attacked. They said, "My five year old son can make something better than this."This was a common attitude in those days. I come from the ' 60 s, the famous ' 60 s that were very polemic. At that time there was an artistic, political, and religious avant-garde, and you had to be on one side or on the other.

AT: Which side were you on?

NH: Of course I was on the side of the avant-garde, because making experimental films was being avant-garde. There were also other artists who made more traditional films. But you had to choose, it was not like nowadays where young people can navigate between everything that is available and can appropriate what they want without having any ideologies. This would have been impossible at that time. Then there were lots of arguments. The people from UNCIPAR were not on the side of the avant-garde; they were emerging filmmakers who wanted to be successful and eventually show their films in big cinemas on Lavalle Street or Corrientes Avenue; that was their goal. So at that time there was a lot of fighting at all levels. The most groundbreaking and remarkable thing then was the Di Tella Institute-how long did it last? Six years, I think. A very short period of time and then it had to close.

AT: What was your relationship with the people from the Di Tella Institute like?

NH: It was hard, because I admired Romero Brest very much. He was an important man at that time, a very intelligent man coming from the field of philosophy, and he did not like 
me, so mine was a frustrated love. I do not know why he did not like me, possibly because of, we could say, functional reasons. His object of desire was primarily Marta Minujin, and then Edgardo Giménez, Dalila Puzzovio, and some other people. This group of young people was patronized and protected by Romero Brest, and the truth is that they were much more committed to this work than me, because I had some kind of double life. I was a lady who was married and had children, living in Vicente Lopez, leading a bourgeois life, and at the same time I had my workshop in the center of Buenos Aires where I used to make my events, the happenings.

AT: Narcisa, did you feel excluded precisely because of this double life you led? Did you feel there was something about you that did not fit in with what they expected from an artist? NH: Actually, I never got to that point; I always felt that I could do whatever I wanted, I never felt excluded. I felt marginalized, but that was what I had chosen.

AT: If Romero Brest did not like you, as you say, did you become a pariah?

NH: I was like off-off Broadway, doubly off. Now I think that the situation has reverted and it is better for me not having been part of the Di Tella Institute because, in a way, all those artists were patronized by the Establishment. Di Tella was a corporation which funded Marta Minujin and Romero Brest, so they were supported by businessmen who liked contemporary art. I did not have anyone. I just had a husband who supported me, that is to say, I did not have to work, so I could film. He used to buy cameras for me, and at the same time he used to criticize me a lot. So it was a strange situation because he felt that my work was not recognized. He was a very cultured man - I want to defend him in that sense-but he came from the fields of music and literature, and not from the visual arts. He was not confident in my work; it looked very suspicious to him.

AT: And, did you get together with other artists who legitimized themselves? What was it like?

NH: Marie Louise's situation was similar to mine; she was married to Ernesto Alemann, a man who was very important in those days. He was the creator of the Pestalozzi Schule. He was a descendant of Swiss journalists who defended the Jewish immigration.

AT: We were talking about your self-legitimization with a group of friends...

NH: Well, it started before the filmmaking. I came from the field of painting, which I had inherited from my father, whose letter you read and thought was nice. But my relationship with painting was not very happy, even though I loved painting and I still love it.

AT: Why? Could it be because of your father?

NH: I do not know, I have never thought about that. Maybe that is because I am a rather visual person, but I certainly picked painting up from my father; it was a way to get close to him, wasn't it? I do not know.

AT: And which materials did you work with, oil painting...?

NH: No, I started drawing and then I worked with different materials such as paste, sand, and cement. I used to make relief paintings. 
AT: And what about watercolor, pastel, Indian ink...?

NH: I worked with Indian ink, but not with watercolor. My father used to work with watercolor and pastel, but I did not use any of those materials.

AT: You got close to him but in a different way...

NH: I always had the feeling that I needed movement, maybe that is the reason why I eventually made the happenings and after that started making films.

AT: Tell me about the happenings.

NH: So-called happenings. The biggest one was Marabunta in 1967. Before that, we distributed apples and baby dolls in the streets. We also made some orange posters with the words "Color, by Narcisa Hirsch" printed on them and we stuck them all over the city. One of us would also beg in the streets disguised as a blind person. We performed lots of actions. I sometimes forget about them. This all happened at the end of the ' 60 s.

AT: Raymundo Gleyzer was the camera operator for Marabunta, did you already know him?

NH: I was a very close friend of Aldo Sessa, who was the owner of Alex Laboratories, and one day I told him, "Well, I am going to make a film and I need a camera operator," and he said, "Ok." So he phoned Raymundo, and then Raymundo came. After that we found out that he was a political activist.

AT: The camera in Marabunta is excellent, how did he do it?

NH: Oh, poor man, he managed to film this huge event with only one camera. He should have worked with several cameras. However he found some way to film it. Then we went to his house. I remember he was a gloomy person. And we edited the material together.

AT: And what about the filmmaker Gerardo Vallejo? He was the camera operator for The Apples ...

NH: Gerardo Vallejo had been in my workshop, and we had been talking. He was a political activist too. I knew that because he had told me. But he had conflicts, not with me personally, I imagine that he liked me, but he was conflicted about the fact that I came from the other side. Because to those who were politically engaged, I was a bourgeois lady who was married to a businessman. And to the businessmen, I was a hippie, a bohemian who hung out with the other side.

AT: When did you film with Vallejo?

NH: The Apples was before Marabunta. He came from Tucumán. He had made a film that I had seen, Viejo Reales' Long Way Journey to Death [1974]. I liked it very much.

AT: Narcisa, what happened to the experimental film movement during the military dictatorship? How did you manage to film? Several studies have been done on this subject...

NH: Experimental films would have been made, and were made, with or without dictatorships all over the world. 
AT: Yes, sure. I am asking because I would like to know what it was like for you...

NH: Young people often ask me this question. At least in my case, I was not making films as a resistance against the military dictatorship, because my work was equally resisted by the right and the left.

Art, when it is art, is subversive, because as [Paul] Klee would say, it makes the invisible visible, and that is what people generally cannot see or do not want to see.'

AT: Let's talk about The Myth of Narcissus. There is a film that predates the autobiography. You started it in 1974 in $16 \mathrm{~mm}$, black and white, and then you continued it in Super 8, color, and after that in video.

NH: Yes, but it was purely a documentary; it was not intended to be a piece of art.

AT: How did you start working on this documentary film with the stories of these women? Were they your friends?

NH: In those days there were lots of women's workshops. I was a close friend of a psychologist called Susana Balán and she organized a workshop for women. At the end of it she said, "Why don't we make a documentary so that we do not lose all the material?_Because we do not have many recordings - You are a filmmaker so you can film the women who have attended the workshop." Then she had the idea of filming the women looking at the camera, almost not speaking, and then projecting the images for the same women and asking them to talk to their own images. That was a very interesting splitting of the personality. They talked to their own images. So this was the first film, in $16 \mathrm{~mm}$, black and white, made in 1974. And after that, five years later, I organized a couple of meetings with some other women, without Susana, and we filmed in Super 8 and color.

AT: Did you film it in video in 2005?

NH: Yes, when I decided to make an autobiographical piece, I said, "Ok, I have two images of my face at different ages; I am going to add a third one which is the image of my face at present." And the autobiography ends with the image of that face.

AT: And in this last film, do you return to the work that started in 1974 ?

NH: No, in the autobiography I return to life and I use all my films, because I have filmed my very life. Everything I filmed was related to my life, to existence; it is an existential selfassertion, as Heidegger would say.

AT: And also it is called The Myth of Narcissus...

NH: Yes, I am just capitalizing on the name; it is a strategy, since my parents gave me such a bad name...

AT: Why do you say they gave you a bad name? Don't you like it?

NH: No, it is a family naming tradition. My mother was named Narcisa, after a Creole lady, who lived in the time of Juan Manuel de Rosas. This lady was called Narcisa Pérez Millán and she was my great-great-grandmother. 
AT: And what do you know about this lady?

NH: This lady... she was a very bad person and she married a German man who came from Hannover. He was a trader, he stayed here in Buenos Aires and he married Narcisa Pérez Millán who was the widow of Rauch. Rauch was also German, Colonel Rauch. Narcisa became a widow when she was very young, she had no children, and then she married this German man named Stegmann, who came from Hannover, and they had ten children. She lived nearby...

AT: Do you mean here in San Telmo?

NH: The house was at 700 Alsina Street, it is not there anymore... So the Narcisas descend from my mother's side, a bunch of Narcisas.

AT: Narcisa, what was your mother like? Because you wrote a Letter to my father but there is no letter to your mother. Why is that?

NH: Because the letters are directed to all men.2

AT: I thought that was very interesting and I would like to ask you...

NH: It started with To God [1989] and then it went down through the ranks.

AT: Did your father make films?

NH: No, he was a painter, and at first the still image was my thing too. Later on, as I am part of a generation in which the image started to move, I guess I jumped on that bus...

AT: Were you interested in photography?

NH: For some time I did quite a lot of photography; I had a darkroom, I developed the photographs myself. I really liked to get my hands dirty. Because in cinema everything was very hands-on.

Everyone, not just me-we used to do everything. We filmed, then we cut the film, and then I hung the pieces on a line, as if they were clothes; then I added the sound, everything in-house, very workmanlike. And the one who had incredible skill for this was, obviously, Claudio Caldini. Besides having a sensibility and a talent for the image, he was a very good craftsman, a very meticulous person.

AT: So you also had a photographic laboratory...

NH: I had a lab for a while, for some years.

AT: So working with the fixed image was not enough for you? Why did you need the moving image?

NH: It is difficult to answer because all this comes from the invisible-invisible concept I mentioned before, a place to which we do not have access, something we call the unconscious. I think that the twentieth century, to which I belong, has a lot to do with movement and I still feel that I need to achieve a certain mobility, I need to unleash certain things. I have never thought about this before, but I think that, actually, it is related to the spirit of a century that unleashed almost everything. The fall of fixed values, truth, reality, all we have been carrying since Modernity in philosophical and metaphysical terms, all this is in ruins now. 
AT: What do you mean by "unleash"...?

NH: During these last years, I have been working on a line of thought that is related to the idea that we all have a hook and we hang our opinions and values on it. This line of thought holds that we, through the mind and reason, and if we make an effort and we search, we read lots of books, we listen to many masters - if we are very cultured, if we understand what we need to understand, and we do what we need to do-then the will is enough. When Nietzsche talks about "the will to power," he says that once it is understood and therefore acquired, the will to power gives us power by through the simple fact of understanding it. But I think that clearly this does not occur. What happens is that we are at the mercy of preverbal and prenatal forces that are completely invisible, and the gurus of justice, education, science, religion, morality, and psychoanalysis expect to control, or at least to interpret, this dimension which is unembraceable. But that is a different thing...

AT: As you said before, you started The Myth of Narcissus, the documentary film, with a gallery of women, your friends. I am interested in the idea of seeing (oneself) looking into the camera. What do you find when you see yourself watching? What happens with the technical mediation? What image does it show you?

NH: When we filmed - it was not video, it was film, so we had to wait until it was developed-once the film was developed, we projected it for these women. They were alone, by themselves; they had a tape recorder and they talked to their own images. And the result was that they were pretty surprised by their own images, all of them saying that they did not recognize themselves. And these were women who supposedly looked at themselves in the mirror every day; they were always looking at their reflections; but they were all very surprised and they talked a lot about the interior - they said they were able to see something internal in the films. I also made a film about men, but men are different. Their speech is different.

\section{AT: In what sense?}

NH: I think that men have a less "fabricated" self-image. Looking at oneself in the mirror is different from looking at oneself filmed. We adapt ourselves to the mirror, the camera is not there, and our eyes are the ones that see. The camera is a different thing. I myself felt like this: my face seemed stranger to me than the other women's faces. The other women's faces looked familiar to me when I saw them filmed, but my face was unrecognizable to me...

AT: There is something monstrous or strange in this; what does the image show you?

NH: I think it is more related to estrangement. I cannot explain it. In my case-we should ask the other women too - the encounter with myself was strange. It is something strange because when you stand in front of a mirror you adapt yourself to an expected reflection, to something you want to see and you do see, while on the contrary, in the filmed image there is a self that appears from that invisibility I mentioned before.

AT: In your films there are lots of female and male naked bodies. This is something new...

NH: Well, the tradition says that, in general, the male artist is the one who looks at the female body. We, the women, do not have a view yet. This is something new, the idea of looking outward, like men do. 
AT: And what does Narcisa see when she looks at men?

NH: For women, I think-I can only speak for myself_eroticism is more focused on the body than on sexuality. We are more interested in the sensuality, in something more inclusive: sounds, textures, smells, colors. The female gaze does not end in the body; it also includes what surrounds the body. I think that sensuality is rather feminine, and when it exists, it is focused on everything. We are pan-erotic.

AT: In one of your books, Aigokeros, which I like very much, you raise the question about perception and the search for a language. I find it very similar to [Clarice] Lispector's viewpoint. I would like to ask you: when you read her books, what impressed you about her writing?

NH: I discovered Clarice Lispector rather late; up until ten years ago I did not even know she existed. One day a friend brought a text by Clarice to our philosophy class and we all liked it a lot, it was a great discovery. Since then I have read her work and actually I like her very much. I think that what I like about her writing is the possibility that thoughts might converge with literature. There is not a conventional narrative; Clarice works with the organic, the animal, the feminine. I think that she represents what you can call not the womanly but the feminine condition. This idea is very clear in her work.

AT: There is also a search for what is inexpressible. In your case, it consists of experimentation with a new language that traverses the technical form. But all your questions are fundamentally about the human condition, and these are questions that Lispector also raised...

NH: Yes, the existential question.

AT: And also the animal question. There is a text called A Breath of Life [2012] by Lispector that is related to this characteristic theme of Lispector, and which is also related to what Nekes says, about this gap in which something imperceptible happens and unleashes the thought. And this also appears in your texts and films.

NH: Yes. Clarice was searching for a language of the invisible-invisible things. The fact that she did not compose music or make films, being a woman who lived in the twentieth century; the fact that she struggled so much against language; it makes one think that she might have wanted to force something there. That is also interesting.

AT: Maybe there is something about language related to the fact that the word has a limit. The limit of the verb, the crisis of the verb we are experiencing takes on a new life and a new force in experimental cinema. I think that is the reason why nowadays it is being rethought and reviewed.

NH: I am surprised because now, young people between twenty and thirty years old are trying to do something about this. When we did it nobody was aware of it, because there were so many things happening with ideologies — I mean, political, artistic, religious, and scientific ideologies, new gurus coming from the East and alternative theologies-so that our activity used to go absolutely unnoticed even though we were on the barricades, but as I already said, they were not the ones that were known. I am surprised that young people are inquiring into that place; maybe this is because nowadays everything is so calm, while 
in the past there was some kind of effervescence and being on the barricades produced adrenaline. Now that the new generation sees it from a distance and the blood is virtual, it looks like an attractive spectacle to them.

AT: Concentrating on the old techniques also helps you to revise issues concerning seeing and producing...

NH: When Super 8 disappeared, physically, like a person who died, we had to film in video or $16 \mathrm{~mm}$, which I did for a while. And video offered so many possibilities; it was so "easy" that in a way that simplicity turned against itself. When we wanted to make video art, it was something completely unknown to me, so I did two things: first I started writing, I wrote a book with Luis Jalfen, who was a philosopher. We wrote The Oblivion of Being [1995] and I wrote by myself Aigokeros, which was a book of essays, mainly written in the south of Argentina. And then I went back to work in $16 \mathrm{~mm}$ and I made some attempts to make narrative films. I worked with a screenplay_Dalmiro Saenz helped me. I worked with professional actors, I became a member of the trade union, and I made what at that time was called independent cinema. That was a different experience, but I felt that it was not my thing. Anyway, it was a good experience because I learned other things and I ended up making RUMI [1999], a film about, and with, the poems by the thirteenth-century Sufi poet. The importance of text emerged, as well as the need to work with text as an image.

AT: In connection to the work of women-artists, I also wanted to ask you about the photographer Sophie Calle. In your case there is a "passion" for recording everything: the body, the everyday events, and I connect this to the recording of Sophie Calle.

NH: Yes, Sophie Calle does it more consciously than me. She is a professional, she focuses her work on that aspect and she is very clear. What I did was never so clear or so defined. Things happened more vaguely. I think that what Sophie Calle does is a very interesting way of capitalizing on experience for the work of art. She says directly and explicitly, something happens to her and from that she makes another thing. When a man leaves her she takes one photograph a day for pain number one, pain number two, and she takes three hundred and sixty-five pain photographs, and one can see that pain number one is more intense than pain number three hundred and sixty-five. Then at the end of the year, the pain is gone and she has a work of art, which is, we could say, more important than the man she lost. It is a transubstantiation. She is the only person I know who does this and I think it is fantastic.

AT: What do you think of feminism?

NH: I have never been a feminist; I have never been keen on any -ism. It is not my thing.

AT: Don't you think that attitude was necessary when the struggles started?

NH: I think it was meant to happen, it was necessary for women to have, in a purely functional aspect, a social protection, as well as the possibility to work on a par with men, having the things that a person needs when she works, when she works as a mother, for example. And that was meant to happen, also because in an overpopulated world, suddenly there was a very vertiginous turn of events. Until a few years ago, the mandate for women was to have as many children as they could. Until the nineteenth century, women had to give birth, and nothing else apart from that, ten, twenty children and suddenly, in the twentieth century, we found ourselves in a 
world that was too populated and we had to reverse that process. And when women started to have fewer children, they were left with empty wombs and longer lives, because suddenly we were all living longer. Then women had an empty space, a new space, and they had to do something about that. And well, we are doing something, we will see what happens.

AT: Among your films, there is one I like very much, and you take it up again in The Myth of Narcissus. This film is the one you made about The King of Patagonia [1983]. How did you start working on this film? What interested you about this story?

NH: It was an idea of Juan Fresan, a friend of mine who died; he was the father of Rodrigo. He was an artist, a very talented painter; he was crazy. He lived just at the time of the Di Tella Institute, in the'60s. Juan would paint and draw. He was also a publicist. Well, at some point Juan decided to make films and he said, "I am going to make a film about 'The King of Patagonia."' He had this idea and then he said, "I am going to go to Paris, because the heir to the 'throne' lives there and I want to make a very domestic film, between experimental and independent." We wanted to make the film together and then he said, "I think I cannot work with women..." and he excluded me from the film. Then he left the film half-finished, he completely forgot about his idea of making a domestic film, he started to work in $35 \mathrm{~mm}$, with professional actors and he had to leave the work halfway through. He never finished it. Then he moved to Venezuela and I lost contact with him. So I said,"I am going to make this film" and I made it with a man from Bariloche who looked like the original king. He was called Eduardo Lauría, he was a friend of mine, and for me it was a way of being in Patagonia, which is my kind of place.

AT: And what exactly interests you about Antoine? In my case, there are several things in the film that attract my attention, the landscapes, the colors...

NH: Yes, it was an attractive theme, then several other people made films on this subject, there are at least two versions of Orly Antoine; there is even a French one.

AT: Yes, but Narcisa's Antoine is related to the love of the land of Patagonia...

NH: I guess it is a sort of identification, when he arrives and he wants to conquer the kingdom, he wanders around not knowing where to go, and he is arrested, they cut his hair and he carries on, he keeps on coming back and failing in his attempt to conquer, walking through the hard and cold grasslands.

AT: In a land with no footprints...

NH: Yes, in the time of Antoine there were no footprints. I have also wandered a lot around Patagonia with no pretensions to be crowned (laughs).

AT: Did the film have any repercussions?

NH: No, nothing at all. Neither is it a film I like very much. I do not think it is a good film. I do not know what happened with that. I refloated it now for the autobiography; in fact the film ends with the scene of the king dancing in Patagonia. So in a way it had an impact on me.

AT: Which one of your films do you like the most?

NH: I think that one has a difficult relationship with your own work; this probably happens to you with your writing. Taste is also related to a time in your life; suddenly you see some 
old work and you say, "Oh, this was pretty good!," or you see some new work and you think it is rubbish, affinities change. I like To God [1989] very much, and maybe The Aleph [2005], but the "box office successes" are Come Out [1971] and Workshop [1975], they are both conceptual films, very different one from the other.

AT: And which is the best one?

NH: People should decide that for themselves.

AT: Narcisa, what are the concerns of Ama-zone [2001]? How did that start? I would like you to tell me something about this work.

NH: It is about the woman who cuts her breast off and in this way she loses her traditional feminine and maternal attributes. In the case of my Amazon, when she cuts her breast off she is naked, then she puts some other clothes on, the clothes a woman has to wear to take the bow and shoot the arrow. She dresses like an Amazon warrior and she becomes that warrior. It is like a striptease that includes the breasts, the most radical nudity.

AT: The image is very strong because there is a mutilation of the body...

NH: We, I mean women, are more organic beings. We produce liquids, tears, menstrual blood, and milk comes out of our breasts. We are more biological than men. We are always aware of that biology. This idea is very nicely expressed by Simone de Beauvoir in the text that appears in The Myth of Narcissus, where she says that man sees himself as a necessary being, completely separated from worldly things, always aspiring to a bright heaven and not fallen into the chaos and darkness of his mother's womb. ${ }^{3}$

AT: I am very impressed by your devotion to and passion for your work, the way you review, rethink, and refloat, in this permanent connection with your whole experience, all these films are fragments of your life...

NH: Yes, I am very focused, but not in the strictly working sense, because I have never worked like those writers who say, "I sit at my desk at nine in the morning and I work until one."

AT: And how do you work?

NH: I work very randomly, in a disorganized way, very impulsively, and with no discipline. Now, belatedly, I have a very good assistant, a talented video maker, Daniela Muttis, who helps me with my work and with my life.

AT: Narcisa, do you still consider yourself a perpetually unknown artist?

NH: No, not now, because there are several people interested in my work now. But for many years I was completely unknown. But that was attractive too. I had total freedom. As I did not have to sell anything, and there were no possibilities of my selling anything, I could film whenever I wanted, at my own rhythm, with no pressures and that was fantastic. At the end of the '70s we had some rooms for exhibitions like the Goethe Institute or the CAYC (Art and Communication Center), but in general when I finished a film, I used to show it in some foul basement or I gathered some people in my studio and showed them my work "straight from the oven."

Once a friend of mine got really angry, and he said, "Why do I come here to see those films that nobody else watches?" 


\section{Selected References}

Beauvoir, Simone. The Second Sex. Translated by H.M. Parshley. New York: Knopf, 1952.

Hirsch, Narcisa and Masanao Kobayashi. Aigokeros, Cuadernos Patagónicos. Buenos Aires: Ediçion del Capricornio, 2003.

Hirsch, Narcisa and Luis Jalfen. El olvido del ser-Conversaciones en la chacra [The Oblivion of Being]. Buenos Aires: Editorial Galerna, 1995.

Klee, Paul. Notebooks, Volume 1: The Thinking Eye. Edited by J. Spiller. London: Lund Humphries, 1961.

Lispector, Clarice. A Breath of Life. Edited by Benjamin Moser. Translated by Johnny Lorenz. New York: New Directions Publishing Corporation, 2012.

\section{Media}

The Aleph (2005). Dir. Narcisa Hirsch. 1:00 min. 16mm. Argentina.

El mito de Narciso [The Myth of Narcissus ] (2005). Dir. Narcisa Hirsch. 20:00 min., 16mm, 8mm and video. Argentina.

Empire State Building, (1964) Dir. Andy Warhol. B\&W, silent, 485:00 min. Raro Video (2004). DVD. Italy.

Manzanas, Apples (1973). Dir. Narcisa Hirsch. 10:00 min., 16 mm. Argentina.

Marabunta (1967). Dir. Narcisa Hirsch. 7:55 min., 16mm. Argentina.

Viejo Reales' Long Way Journey to Death [El camino de la muerte del viejo Reales ] (1974). Dir. Gerardo Vallejo. 90:00 min. 35mm. Argentina.

A Dios, To God (1989). Dir. Narcisa Hirsch. 22:00 min., Super 8mm. Argentina.

Rumi (1999). Dir. Narcisa Hirsch. 28:00 min., 16 mm and video. Argentina.

Orly Antoine, Rey de Patagonia [The King of Patagonia ] (1983). Dir. Narcisa Hirsch. 26:00 min., 16 mm. Argentina.

Comeout (1971). Dir. Narcisa Hirsch. 10:00 min., 8mm. Argentina.

Taller [Workshop ](1975). Dir. Narcisa Hirsch. 11:00 min., 16 mm. Argentina.

Ama-zona (2001). Dir. Narcisa Hirsch. 11:00 min., Super 8mm, Argentina.

Señales de Vida ["Signs of Life"] (1979). Dir. Narcisa Hirsch. 10:00 min., Super 8mm, Argentina.

\section{Notes}

1. See Paul Klee, Notebooks, 76.

2. "letter to my father" is part of a collection of letters addressed to men in a chapter entitled: "Cartas a los hombres" [Letters to the Men], in Narcisa Hirsch, Aigokeros.

3. See Beauvoir, The Second Sex, 710. 


\section{Film as Poetry}

\section{Claudia Kappenberg}

"My film is to other films as poetry is to other forms of literature."1

M aya Deren's body of work builds on poetry and the poetic image as an approach to filmmaking. Not surprisingly, many of the essays and interviews included in this issue of the International Journal of Screendance reference poetry as constituent elements in Deren's films. Andrew James's essay, for example, makes a strong case for the importance of poetry in Deren's transdisciplinary approach, and Sarah Keller complements this through an analysis of the poetic and metaphorical qualities of Deren's films. In addition, the newly translated interview with Austrian-Argentinian filmmaker Narcisa Hirsch pays heed to the kinship between poetic sensibility and film, as do Hirsch's own films such as Rumi (1999), titled after the Persian poet Jelaluddin Rumi (1207-1273). Poetry within cinematic practice permeated the film discourses of the 1940s, '50s and '60s. But what exactly is this relation between poetry and film, this likeness, equivalence or correlation? What does the "poetic"stand for in Deren's work and how come that it can be mapped onto filmmaking? Should we read her work like we might read poetry?

In an essay on Deren's Modernist poetics, Renata Jackson reviews the roots of Deren's interest in poetry, referring to the French Symbolists and the American Imagist school, including Ezra Pound, and to other poets such as T.S. Eliot, whilst identifying poetry's ability "to synthesize emotional content with form" as the central concern. ${ }^{2}$ Furthermore, Jackson points to Pound's definition of an "image" published in 1913 in the journal Poetry, as direct inspiration for Deren. Pound described an image as "that which presents an intellectual and emotional complex in an instant of time,"3 and Deren reformulates this in Anagram as overarching concept for the logic of form: "A work of art is an emotional and intellectual complex whose logic is the whole form." ${ }^{4}$ Pound made numerous attempts at defining the poetic image and the particular formulation referred to by Deren exceeds what the Imagists themselves had articulated. Dating from 1913, Pound's notion suggests that an image actualizes unconscious material and emerges through insight. None of Pound's subsequent attempts seemed to clarify any further what he meant or how exactly he conceived the relation between image and language, although a later statement from his Vorticist phase is intriguing: "The image is itself the speech...the word beyond formulated language." Here the "word" is used metaphorically, to suggest a complex that happens outside of language. On the other hand, Pound always advocated clarity and exactitude, and also effective writing, and it was perhaps a combination of both these aspects that inspired Deren to borrow Pound's "intellectual and emotional complex in an instant of time" for her concept of film. Deren was not at all interested in improvisation or stream of consciousness as an approach to making work; instead, she combined a precision and 
carefully constructed film form with the capacity of the image to directly affect the viewer. As will be discussed further below, Deren's aesthetics builds on a visual poetics and an economy of form, and brings this together with a depersonalization of movement and a stylization of gestures. The constructive elements constitute a basis for a film form that, according to Deren, differentiates itself from documentary on one hand and literary film on the other. This aesthetic also combines with an ethics to provide the artist with the opportunity as well as the obligation to create a reality on screen according to her own vision, a mythical reality that transcends individual experience and the everyday. ${ }^{6}$

In more general terms, the difficulty in defining the poetic image complicates the theorization of the filmic image in that an actual image may correlate with a poetic image that is mainly created through words. This is particularly evident in the case of metaphors, as discussed by Noël Carroll in his essay on visual metaphors. ${ }^{7}$ Carroll argues that there might be some metaphors that could be described as predominantly visual, but that many of them also mobilize linguistic concepts or knowledge which inform the visual material. Equally, metaphors which may appear verbal often activate a personal image repertoire, a communal history of images, or other non-verbal features. He writes: "In expanding the insights offered to us by verbal metaphors we depend upon more than linguistic knowledge. And this is also the case with visual metaphors." ${ }^{\prime \prime}$ Given this fluidity between verbal and visual metaphors, there is an argument that all visual art is metaphorical, but as Carroll argues, this might be stretching the notion of the metaphorical a bit too far. ${ }^{9}$ However, the proximity between the visual and the verbal in metaphorical elements, as well as the capacity of images per se to summon linguistic material, can account for a conceptualization of film as language, and much of film theory builds on this thesis. For example, in an essay entitled "Film and the Radical Aspiration" from 1979 and again in an essay entitled "Poetics and Savage Thought" from 2001, Annette Michelson proposes that film is comparable to language in that it operates like the paradigmatic and the syntagmatic modes in language, following linguist Roman Jakobson's theorization of those terms. ${ }^{10}$ Michelson claims that Deren's notions of horizontal and vertical film form should be read in those terms, as a "cinematic grammar," and this could be a way of understanding Deren's frequent referencing of the poetic."1 This theorization, however, replicates a tension that can already be found in Deren's own writing, in that Deren endeavored to develop and theorize a specific visual logic for film. In view of my following discussion and correlation between Deren and Deleuze, I will propose a different theorization of cinematic form and the poetic, and argue that Deren embraced poetic structures-but not for their likeness to, or interaction with, linguistic material. I will argue that, for Deren, the poetic is instead a means to construct a cinematic visuality, to develop a means of communication that is different from language.

In Magic is New, Deren explains:

I came to understand the difference between contriving an image to illustrate a verbal idea and starting with an image which contains within itself such a complex of ideas that hundred of words would be required to describe it. This is the central problem of thinking in cinematic terms, for our tendency is to think in verbal terms. ${ }^{12}$

To illustrate her point she uses the sentence, "She felt frightened and alone," arguing that a filmic illustration of "fright" and "alone" would never come close to the impact of the verbal 
statement. She then describes an image from At Land, where a small figure stands in the corner of a large room in which the furniture is covered by dust covers, to suggest that this works as a visual statement and that its complexity could not be readily translated into words. ${ }^{13}$ In this passage Deren asserts emphatically that there is a cinematic form in which complexity is built through images and according to a visual logic. She does however fall back on quantity, using the expression "hundreds of words," whilst attempting to formulate something of a qualitative difference between language and image. This expression is a slippage in the context of her argument for a visual logic that is distinct from a verbal logic and suggests a certain struggle in articulating exactly what the cinematic form might be, a point that will be explored in more detail further along. However, this creative logic, Deren argues, should emerge from the actual mechanics and materiality of film, a statement which reflects her interest in securing a specificity of film as a distinct art form. ${ }^{14}$ As Renata Jackson argues in her detailed review of Anagram, Deren systematically explored what film could do that other media could not, searching for a specific "filmic integrity and logic."15 Arguing strongly against a wholesale reproduction in film of other art forms, in particular literary forms and painting, Deren writes:

Just as the verbal logics of a poem are composed of the relationships established through syntax, assonance, rhyme and other such verbal methods, so in film there are processes of filmic relationships which derive from the instrument and the elements of its manipulation. ${ }^{16}$

Technical possibilities afforded by the camera, different lenses, film stock, and the editing, give the filmmaker the means to constitute unique creative possibilities. Deren's pursuit of medium specificity, on the other hand, does not stop her from also endorsing poetic methods; as Jackson remarks, she"is in fact implying, that a filmic adaptation of the methods of poetry is the only proper means of creating film art."17 This suggests that, according to Deren, the poetic is not an operation specific to language but a compositional methodology for visual forms such as cinema.

One particular aspect of the poetic is, for Deren, the "economy of statement," an approach to composition that she also borrows for her cinematic aesthetics. Writing in Anagram about an economy of statement in Cocteau's film Sang d'un Poète (Blood of a Poet), she credits Cocteau for successfully deploying skills he developed as a poet. ${ }^{18}$ With economy of statement Deren means the deployment of a minimal number of elements to greater effect, whereby the final meaning or outcome is different or greater than the sum of its parts. ${ }^{19}$ Besides the economy of statement, Deren deploys a strategy of depersonalization and stylization, both of which are discussed by Erin Brannigan in her book DanceFilm (2011). Brannigan notes that in dance-based films "corporeal performance is one filmic movement amongst many... spreading out across people and things," thereby "releasing figures from the demands of storytelling, allowing them to become part of a transference of movement across bodies and to resonate in moments that are freed in space and time." 20 For Deren, this very particular choreographic strategy stems from her interest in ritual and in the social and political dimension of her art. Rather than exploring individual experience, Deren choreographs the actor or mover as part of a dramatic whole, thus, as Brannigan argues, "sacrificing individuation."21 Discussing this technique through the example of the doubling of Rita Christiani and Maya Deren in Ritual in Transfigured Time, Brannigan proposes that Deren uses dance quintessentially for an "orchestration of sequences 
where a movement phrase or quality moves across frames, edits, cuts, bodies, and spaces, making the body of the film a choreographed whole."22 The dance serves a visual poetics and is a means of organization in time and space. It releases the protagonists from their role in a concrete, narrative thread and allows them to inhabit a situation for its own sake. It also binds different filmic elements together, within an image and across different scenes, to invoke what Deren called a "compelling continuity of duration," a choreographic film form that appears to be informed by Deren's interest in Bergson's notion of an indivisible experience. ${ }^{23}$ The use of stylization in Deren's films serves very much the same purpose as depersonalization: that is, to create a dramatic, formalized whole out of the constituent parts. As Brannigan points out, Deren perceives the movement of film itself as "stylized" and proceeds by treating movement in the same way. ${ }^{24}$ Natural movement is taken from the everyday, formalized, and depersonalized to form a careful choreography of shapes and rhythms.

The significance of the poetic in Deren's oeuvre comes to the fore in her often quoted contribution to the symposium on "Poetry and The Film," which took place at Cinema 16 in New York in 1953. At the symposium, Arthur Miller, Dylan Thomas, Parker Tyler, and Maya Deren discussed, together with Willard Maas, the relation between poetry and film. In the transcript, Deren is given the floor after Taylor and addresses the question, "What is poetry?", in order to help clarify the terms of the debate. She argues that such a definition is useful so that audiences know what to expect when they come to see a film. Deren says: "If you are watching for what happens, you might not get the point of some of the retardations because [the retardations] are concerned with how it happens." 25 The term "retardations" here refers to phases in a film where a dramatic action is interrupted by an exploration of particular aspects of a moment, such as its qualities or emotional content. Deren continues:

Poetry, to my mind, is an approach to experience, in the sense that a poet is looking at the same experience that the dramatist may be looking at. It comes out differently because they are looking at it from a different point of view and because they are concerned with different elements of it. ${ }^{26}$

She explains further, in the often cited passage, that:

the poetic construct arises from the fact, if you will, that it is a "vertical" investigation of a situation, in that it probes the ramifications of the moment, and is concerned with its quality and its depth, so that you have poetry concerned, in a sense, not with what is occurring but with what it feels like or what it means. A poem, to my mind, creates visible or auditory forms of something that is invisible, which is a feeling, or the emotion, or the metaphysical content of the movement. Now it also may include action, but its attack is what I would call the "vertical" attack, and this may be a little bit clearer if you will contrast it to what I would call the "horizontal" attack of the drama, which is concerned with the development, let's say, within a very small situation from feeling to feeling. ${ }^{27}$

Deren elaborates that a horizontal development of a story might be combined with, or interrupted by, a vertical investigation of a particular moment, and emphasizes that all kinds of combinations of these two dynamics are conceivable. She proposes that monologues, establishing shots and dream sequences are all part of the vertical dimension, as are entire short films — such as her own work—and are comparable to lyric poems. As an example 
she cites a film by Willard Maas, Image in the Snow (1952), and describes the visuals as the horizontal drive and the parallel poetic commentary as constituting the vertical element. In other words, the relations between the horizontal and the vertical are complementary and function between images or across image and text.

As is evident from the transcript of the symposium, Deren receives only negative and derisory comments from the other speakers and the discussion contributes little to the ideas or terms that she proposes. One comment from Arthur Miller does warrant attention, however; he comments on Deren's proposition that a dramatic action is interrupted by emotional moments. Arguing against what could appear to be a binary opposition between drama on one side and emotion on the other, Miller insists that emotions are wedded to the action and inseparable from a dramatic structure. ${ }^{28}$

A couple of thoughts emerge from this exchange: Miller's comment subsumes a clear binary, but as Erin Brannigan points out in her discussion of Deren's terminology, the relation between the two modes is much more complex than that, particularly with regard to Deren's own films. ${ }^{29}$ If one scrutinizes the different examples that Deren gives at the symposium, Deren's theory could be read as a way of thinking about the relationship between film and the poetic that is flexible and offers endless possibilities to the filmmaker. She gives the example of a Shakespearean soliloquy which literally disrupts a dramatic plot, alongside the example of Maas's film, in which the horizontal and the vertical concur so that the visual and the sound complement each other. Most importantly, however, Deren says that she is thinking of poetry not so much as a verbal form but "as a way of structuring in any one of a number of mediums, and (I think) that it is also possible to make the dramatic structure in any one, and that it is also possible to combine them." ${ }^{30}$ This comment significantly deviates from her usual emphasis on medium specificity, proposing instead that the poetic can be used in any medium. This sounds much more like a post-medium approach, whereby the vertical and horizontal are conceived as methodologies which are independent of the medium, and constitute two different but complimentary modes of making and perceiving art in general.

It is also worth considering that Arthur Miller's critique of Deren's proposition may have been triggered by the specific terms that Deren deployed to make her point. When she says that a poem or vertical film form gives rise to an emotion, it is difficult to separate this conceptually from narrative or dramatic action, as the emotional is in general considered to be part of narrative, linguistic constructs. This association explains Miller's insistence that the emotional is wedded to action. Deren may, however, have been using the term in a different and less literal way, as something more akin to a register of personal intensity, sensation, and embodied experience- - a register that is generally known as affect in contemporary cultural theory and philosophy and is considered to be a pre-linguistic state. To explore this possibility, it will be useful to expand on the notion of affect, even if it is not possible in the context of this essay to review the various histories and complexities of affect theory in current discourses. A brief detour via Brian Massumi's writing in his essay The Autonomy of Affect may serve to indicate what is explored through this term. In this essay, Massumi argues for a clear differentiation between emotion and affect, or intensity, in that they "follow different logics and pertain to different orders."31 To define emotion, he writes:

An emotion is a subjective content, the socio-linguistic fixing of the quality of an experience which is from that point onward defined as personal. Emotion is 
qualified intensity, the conventional, consensual point of insertion of intensity into semantically and semiotically formed progression, into narrativizable action-reaction circuits, into function and meaning. It is intensity owned and recognized. ${ }^{32}$

By comparison, affect is unqualified and therefore difficult to grasp. Massumi circumscribes affect as an intensity or:

a state of suspense, potentially a disruption. It is like a temporal sink, a hole in time, as we conceive of it and narrativize it. It is not exactly passivity, because it is filled with motion, vibratory motion, resonance. And it is not yet activity, because the motion is not of the kind that can be directed (if only symbolically) towards practical ends in a world of constituted objects and aims (if only on screen). ${ }^{33}$

This description of affect as a suspended state and resonance chimes with Deren's notion of the vertical as a disruption of narrative progression and investigation of a moment. Deren's concept of the vertical also correlates with Massumi's argument that affect is of a different order to language. And even though Massumi writes that language dampens these intensities, he concedes that "linguistic expression can resonate with and amplify intensity," which could conceivably include poetry or the voiceover in a film like Maas' Image in the Snow. ${ }^{34} \mathrm{~A}$ key point is that affect does not support or facilitate linear processes or narratives.

Deren's relatively brief statement at the Symposium, as well as her writings - be they Anagram or her diverse lecture notes and published essays - leave room for speculation as to what exactly she meant with the emotional and whether she considered it as a quality of an experience that is identifiable and recognizable by the spectator, or whether she referred to a more pre-linguistic realm of sensation and intensities, like affect. The fact that she did speak of the emotional and that she did not seek other possible terms does however differentiate her concept of horizontal and vertical film form from Deleuze's film theory of movement-image and time-image, with which it is so often compared. Deleuze develops the notion of the affection image in Cinema 1, and it underpins much of his writing in Cinema 2. However, current literature on Deren does not debate this particular aspect and considers Deren and Deleuze's theories to be similar with equivalent terms. Renata Jackson, for example, argues that Deren and Deleuze make comparable distinctions when they differentiate between "vertical" and "horizontal", or, as in Deleuze's case, between "movement-image" and "time-Image."35 Jackson emphasizes that both theorists work with a binary construct of spatiality and causality on one hand and an emphasis on time and experience on the other. As she points out this structure is derived from a shared interest in the philosophy of Henri Bergson, who argued for a separation of space and time and developed a notion of experience-that-cannot-be-analyzed or compartmentalized (as we would do with space) but is rather indivisible (like time or duration). ${ }^{36}$ As Jackson maintains, Bergson's concept of experience underpins both Deren's and Deleuze's film theories, and both advocate a film form and a spectatorship that is different from that of narrative cinema. Deren, however, struggles to get away from the traditional description of experience as emotion and to push it towards something more specific to visual logic and vertical cinema, as is evident in her statement at the Symposium. One can therefore point to both similarities and differences between Deren's and Deleuze's film theories, though the difference is potentially a difference by degree. Arguably the inconclusive aspect in Deren's work 
is eventually theorized through the notion of an embodied spectatorship, which Deleuze puts forward as part of his writing on the time-image; a review of some of his writing will serve to further elucidate this interlinking between their various concepts.

Deleuze published his writing on film in France in 1985. It divides twentieth-century cinema into two kinds and two historical phases: a classic cinema of movement-images with a narrative structure dominated by action across space and time, and a modern cinema of timeimages in which a continuity of actions and dramatic development has been subordinated to an investigation of time per se. As mentioned above, the first category of movement-images is generally equated with Deren's horizontal film form, while the second category of timeimages is aligned with Deren's the vertical film. Deleuze describes the second category or time-image through fragmentation of linearity, a shattering of causality, and an exploration of disjunctions and extended time frames. According to Deleuze, this modern cinema demonstrates a "whole temporal panorama," the extent of which is tied to a notion of cinema that is independent of language and of traditional narrative. ${ }^{37}$ Deleuze therefore begins Cinema 2 with a review of the historical debate on film as language and aligns himself with those film theorists who critique early twentieth-century cinema for its close association with theatre and narrative and for becoming narrative itself. In this kind of cinema films were little stories and an image was the equivalent of an utterance, a construct by which the visual language was conflated with verbal communication. ${ }^{38}$ Maya Deren expresses a similar view in Anagram when she argues that it might have been better if the film industry had never engaged with writers or with literary scripts, and had continued with the development of silent films which "emphasized visual elements and even sometimes, as in the comedies of Buster Keaton, displayed a remarkable, intuitive grasp of filmic form." ${ }^{\prime 39}$ Interested in freeing film from an assumed affinity with narrative, Deleuze distances himself from semiologists, who want to read cinematic images in linguistic terms. He therefore critiques Christian Metz, who posits that the verbal effectively conditions the visual; Metz contends that narration constitutes the "underlying linguistic determinants from which it flows into the image in the shape of an evident given." ${ }^{\prime \prime}$ In this model the narrative informs the filmic sequences. By contrast Deleuze offers a model by which "narration is only a consequence of the visible [apparent] images themselves and their direct combinations - it is never a given." ${ }^{11}$ Deleuze argues that the image cannot be assimilated to an utterance, or be replaced by utterance, and that film should be considered as "non-language material." ${ }^{2}$ More specifically, Deleuze talks about the movement of the image as that which resists assimilation into narratives and linguistic units, as an excess that defies a linguistic forming of resemblance and representation.

Deleuze argues that due to this attachment to narrative, the movement-image of the early twentieth century is a clichéd representation of objects, in which the viewer perceives what he wants to see. ${ }^{43}$ Drawing again on the writing of philosopher Henri Bergson, Deleuze points out that we never perceive a thing in its entirety, but rather through sensory-motor schemata. A cinema that is based on sensory-motor images is therefore limited in the kind of spectatorship it invites. ${ }^{44}$ In the cinema prevalent in the early 1900s, the spectator would have been entertained and not challenged, indulged with clichés rather than, according to Deleuze, confronted with "real images."45 Again Maya Deren makes a similar point in Anagram, when she reflects on the process of adapting literature to film. She argues that a representation of characters and their feelings leads to "symptom-actions" or a cinematic "shorthand," that supposedly demonstrates such and such a feeling: 
As we watch the screen we continually "understand" this gesture to stand for this state of mind, or that grimace to represent that emotion. Although the emotional impact derives not from what we see, but from the verbal complex that the image represents, the facility with which we bridge the gap and achieve this transcription deceives us, and we imagine that we enjoy a visual experience. ${ }^{46}$

Deren argues that this shorthand does not make use of the real potential of cinema, which resides in the realm of visual experience (as distinct from other art forms such as theatre and literature, which are driven by dramatic, narrative threads). Deleuze proposes that a shift or reversal in the priorities of the film image took place when the classic sensory-motor image was replaced by a pure optical and sound image that subordinated movement to time. Deleuze references René Clair's film Entracte from 1924 as one of the earlier films in this cinematic shift, along with Buñuel's Un Chien Andalou (1929) and some of Buster Keaton's burlesque scenes. According to Deleuze, however, the new time-image is only fully realized in the 1940s in the work of Orson Wells, Fellini, Renoir, Antonioni, Ozu, and others. Deleuze writes of this new image that "the sound as well as the visual elements of the [new] image enter into internal relations which means that the whole image has to be 'read', no less than seen, readable as well as visible." ${ }^{\prime 7}$ Referring to Godard's formula, "It isn't blood, it's some red," he argues that internal elements and relations in the image dominate over any representation of external objects. ${ }^{48}$ This concern with internal relations within the image is also discussed in Cinema 1, where Deleuze first refers to Godard's formula as part of a discussion on colour and its capacity to affect the image itself and all that is within it. ${ }^{49}$ He reflects on the power of color to absorb characters, objects, and entire scenes, describing colour itself as affect, as a "virtual conjunction of all the objects which it picks up."50 The capacity of elements to affect and to bear the impact of other elements extends to the relation between image and spectator. More than, or perhaps instead of, a symbolic value of objects, this kind of image offers a play of affects - a register of changing intensities - and addresses the spectator in the same way, implicating him/her as another resonant body. As formulated in Cinema 2, the new timeimage "brings out the thing in itself, literally, in its excess of horror or beauty, in its radical or justifiable character, because it no longer has to be 'justified."'51

Deleuze's insistence of film as non-language material is significant for a comparison between Deren and Deleuze, and the proximity between their respective theorizations supports a reading of Deren's film form as visual logic and not as "cinematic grammar" as Michelson proposes. Bringing Deleuze into the debate on Deren also shifts her more firmly into a tradition of filmmakers from the early twentieth century who turned to cinema for its possibilities in visual composition. At that time, many visual artists turned to film as a new medium even though it was not yet established as a means to making art. $^{52}$ The DADA artists, for example, saw the particular subversive potential of film as a means to critique a bourgeois modernity which was considered morally corrupt for allowing the unprecedented destructiveness of WW1. ${ }^{53}$ Artist Francis Picabia, who scripted the first ideas for the film Entracte, belonged to this group and shared this attitude, even though he left DADA in 1921 to developed his own Instantanist project. In a review of avant-garde film practices, Chris Townsend argues that the narrative structure of conventional film mirrored too closely the regulated temporality of industrial production and labor, and both Picabia and Clair were fighting against this imposition on the modern subject. ${ }^{54}$ To work against 
these constraints and to allow for a broader spectrum of experience, the artists pushed the medium of film towards something that was relational, in a sense of being part of a live event, despite the inevitable mechanized regularity of film, its linearity, and the relative indifference of attending audiences. Townsend writes: "Like Duchamp, Picabia has a theory of 'kinematics' well before he is involved in the production of a film; indeed it is a theory whose temporal dynamics would largely prohibit realization within a film that functioned as a self-contained work."."55

In 1924, Picabia and the composer Eric Satie were invited to create an evening ballet for the Ballet Suédois, and they asked the filmmaker René Clair to direct a film for the interlude of the performance. Much like the DADA artists, Clair had been very critical of the theatrical, narrative conventions that were popular with the bourgeoisie at the time. He wrote in his Reflections on the Cinema, that "Cinema should not be restricted to representation. It can create... Thanks to... rhythm, the cinema can become a new force which, abandoning the logic of facts and the reality of objects, will engender a series of visions hitherto unknown and unconceivable." ${ }^{\prime 56}$ This statement by Clair gives a sense of what was at stake and explains the fascination for a cinema that exceeded narrative conventions. The film Entracte consists of a fast and confusing collage of images and scenes that are devoid of narrative and intended to touch the audience by audio-visual means. The film takes place across a series of Parisian locations such as rooftops, streets, a fairground, and the countryside, and plays mischievously with the spectator's expectations as well as their moral codes: a number of shots turn into actual shots directed at the viewer executed by a canon or a rifle, while a boxing glove directs a punch at the audience; the film includes a close-up from below on a dancer in a tutu who is later revealed to be a bearded man; a funeral hearse is drawn by a camel; the funeral procession begins in slow motion and turns into a chase. In the first half of the film, the fast editing between seemingly unrelated shots created a sense of dissolution, while the second part emphasizes perpetual motion. In the 1920s this sort of cinematic composition would have suggested freedom-creatively, socially, and politically. Entr'acte was arguably a new vista of what an image could do and what it would consist of in cinematic terms. Conceived in the context of a ballet performance, Entracte combined images much like a choreographer would have composed moving bodies, relying on visuality and rhythm to create an experience for the audience.

This interest in rethinking movement and time was not confined to film, but occurred simultaneously in dance-based practices of the time. In her review of dance of the early twentieth century, Erin Brannigan argues that dance as cultural endeavor and commentator on a technologically advancing society would have been a force that anticipated cinema's dissolution of forms..$^{57} \mathrm{~A}$ wider exchange of ideas and cross-fertilization between dance and film would also have informed a work such as Entr'acte, which was more "open" than what was otherwise seen on screen at the time. In fact, just a few years prior to making Entr'acte, Clair had acted in an avant-garde dance project, Le Lys de la Vie, effectively a choreography for film from 1921 directed by Loïe Fuller.

As Anne Cooper Albright argues in her book on Fuller, Clair's own film and rhythmic composition in Entr'acte can be regarded as part of the legacy of Fuller's experiments with movement and light. ${ }^{58}$ Loïe Fuller, and René Clair, together with Isadora Duncan, Man Ray, Duchamp, and others, must be considered the pioneers of what we now call screendance. They form a timeline for the first half of the twentieth century that leads eventually to 

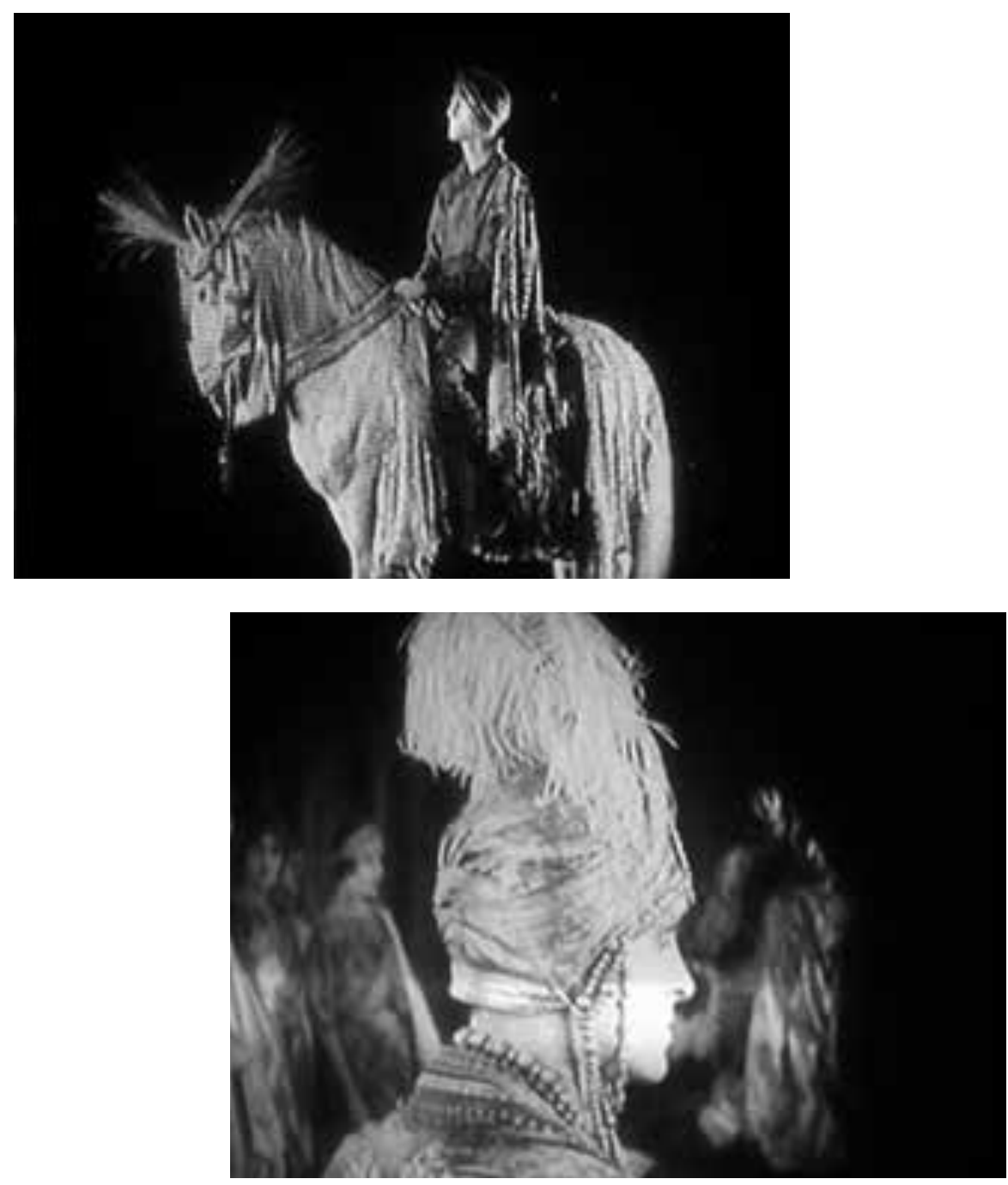

René Clair in the role of the prince, in Le Lys de la Vie (1921). Dir. Loïe Fuller.

Images: permission of the Cinématèque de la Danse (CND), Paris.

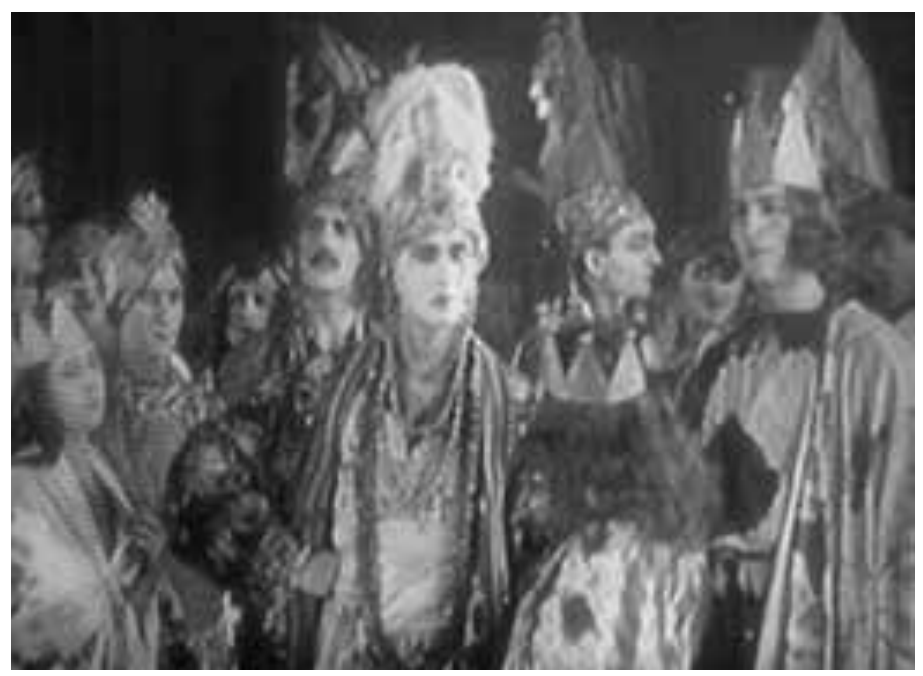



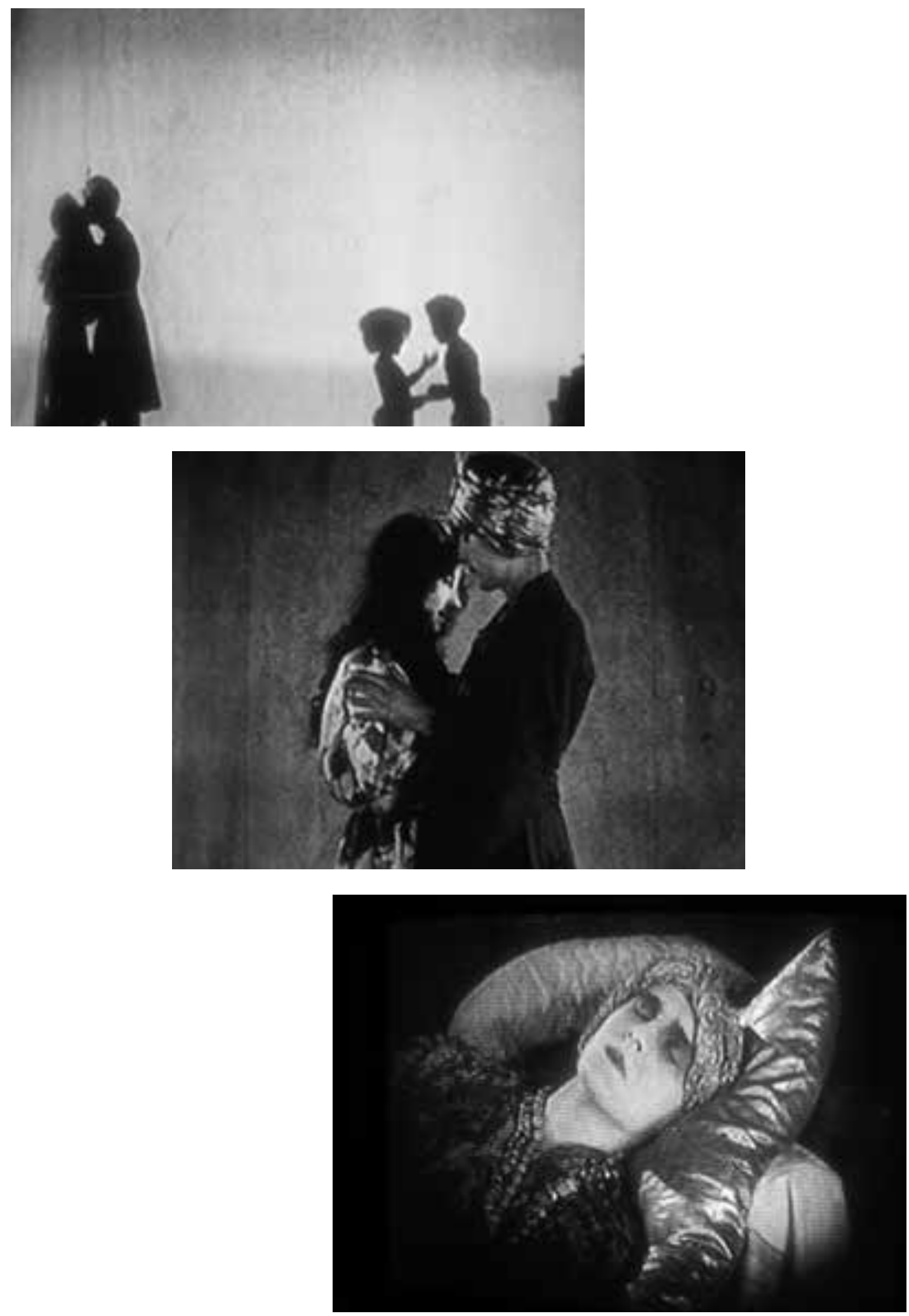
the work of Maya Deren. The timeline traces a shared concern with non-linguistic material which addresses an embodied spectator and works through sensation and visual logic.

Deleuze only commented on very few films of the 1920s avant-garde and never referred to later experimental films such as Deren's, but he made a number of poignant comments on Entr'acte which can be used to build a Deleuzian reading of Deren's work. For example, identifying different kinds of time-images, Deleuze argues that European cinema was generally interested in an "automatic subjectivity," an exploration of phenomena such as hypnosis, hallucination, nightmare, and dreams. ${ }^{59}$ According to Deleuze, Clair's Entr'acte is an example of this kind of work and consists of "unstable [sets] of floating memories, images of a past in general which move past at dizzying speed, as if time were achieving a profound freedom... Dissolves and superimpositions arrive with a vengeance."60 Deleuze describes these images as "malleable sheets of the past," which are part of a circularity in which each image is significant only as part of a chain of images. ${ }^{61}$ In Clair's Entr'acte, each image becomes "actualized" through the following image, which, according to Deleuze, "itself plays the role of virtual image being actualized in a third, and so on to infinity." ${ }^{\prime 2}$ In other words, individual images do not conserve their status or significance and their task is to give way to the next image.

This analysis can be used to describe a dynamic that is at work in Deren's films. The concept of a dream image or "the diffuse condition of a dust of actual sensation," and the "perpetual unhinging which 'looks like' dream, but [takes place] between objects that remain concrete" sounds like Meshes of the Afternoon with its sequences of images in which one gives way to the next. ${ }^{63}$ The party scene in Ritual in Transfigured Time has the quality of one image giving way to the next, enforced by the actual gestures and looks, which underline this ongoing flow across images. At Land also "looks like" a dream, due to the imaginary use of space and time in the film, whilst not containing the narrative one would expect in a classic dream, and I will return to this film further below. A Deleuzian reading of Deren's work speaks to the visuality of her practice and reads it through the actual film form, rather than through other frames of reference. This is worth considering given that Deren argued time and again against the interpretation of her films and those of her contemporaries through, for example, an exploration of the artist's biography or a Freudian supposition of a symbolic value of objects. Deren therefore dismissed any association of her work with the symbolic iconography and methodologies of surrealist work. The association made here between her work and Entr'acte is not to be confused with discourses that invoke surrealist practices; Entr'acte was not a surrealist project, despite its date of production, and Deleuze's reading of Entr'acte further confirms a very different artistic framework. Arguing against many of the ubiquitous critical discourses, Deren writes in New Directions in Film Art: "Unless there is a very good reason why an artist would substitute one thing for another, it might be good to believe that the thing you see, or read, is exactly the thing the artist has intended."64

Deren may have used different terms in her writing compared to those deployed by Deleuze, but the intentions that come across in the writing, as well as in the actual work, are often very close. Deren's work anticipates a Deleuzian insistence on the internal relations within an image and a reading of the image through affect. A depersonalization and stylization of gesture in a film like Ritual in Transfigured Time compares in visual dynamic and purpose to, for example, the use of color in Agnes Varda's films La Pointe Courte and Le Bonheur, where a combination of black and white or a complementary use of colors 
affects and absorbs characters and objects. ${ }^{65}$ This cinema of colors in Varda, Minelli, and Antonioni is what Deleuze terms the affection-image; it does not represent or refer to any particular thing, but constitutes a quality and an affective force. Taking the face as affective surface and as blueprint for what occurs more broadly within and across the image, Deleuze writes: "The affection-image, for its part, is abstracted from the spatio-temporal co-ordinates which would relate it to a state of things, and abstracts the face from the person to which it belongs in a state of things." ${ }^{\prime 66} \mathrm{~A}$ process of abstraction is key to this visual operation, a process which is already evident in Deren's screen choreographies through her treatment of movement and of the moving image.

In her endeavor to advance film as an art form, Deren not only needed to theorize a new aesthetics, but also to educate her audiences and critics how to see these films. In Anagram, Deren addresses the problem of viewing habits, writing that audiences might well expect to understand film in the way they understand theatre: "It would be impossible to understand or appreciate a filmic film if we brought to it all the critical and visual habits which we may have developed, to advantage, in reference to the other art forms." ${ }^{167}$ In addition, she argues, film may appear familiar given that it looks more or less like the world we know. To address viewing habits cinema needed to disrupt this pattern and initiate other modes of affection. Disruptions can, for example, be instigated through a failure of recognition, or a disturbance of memory, a viewing experience which, according to Deleuze, is proper to the pure optical-sound image. Deleuze draws on Bergson in his reflection on the significance of failure, arguing that "attentive recognition informs us to a much greater degree when it fails than when it succeeds."68 Although Deren does not talk about invoking the failure of recognition one could claim that her films break with the logic of time, space, and action in a way that implicates the viewer in an unfamiliar experience. The work demands of the viewer to let go of expected frames of reference and parameters. Offering a reading of one of her own films, Deren writes:

At Land strives for the elimination of literary-dramatic lines and tries to discover, instead, a purely cinematic coherence and integrity. It presents a relativistic universe-one in which the locations change constantly and distances are contracted or extended; in which the individual goes towards something only to discover upon her arrival that it is now something entirely different; and in which the problem of that individual, as the sole continuous element, is to relate herself to a fluid, apparently incoherent universe. It is in a sense a mythological voyage of the twentieth century. ${ }^{69}$

An experience of apparent incoherence may successfully frustrate attempts to relate what is on screen to what is known and familiar. An unexpected flow of images would form an alternative poetics of sensation according to a cinematic coherence, whereby strategies such as an ambivalent use of space and time form a continuity that is neither here nor there, running neither forwards nor backwards.

It is possible to read a film like At Land through Deleuze's time-image as demonstrated here, but this might be taking Deren's ideas further than she had envisaged herself. The description of the film as mythological voyage within the same passage suggests a metaphorical framework that correlates the film with a quest of some sort and which relates to Deren's wider interests in ritual, magic, and topics like the nature of change. Alison Butler 
also notes a tension in At Land between a somewhat "classic quest-narrative" and a more abstracted use of space and time, pointing out how a single moving body provides an overarching continuity across the film's duration, effectively constituting a return towards classic narratives film structures within Deren's body of work. ${ }^{70}$ Butler also comments on this ambivalence with regards to Meshes, arguing that the film allows for a Deleuzian reading of some of its elements even though the protagonist carries a more conventional, dramatic function. She argues that, "In Deleuzian terms, the coexistence of 'incompossible' temporalities in Meshes unleashes the 'powers of the false' and shifts the film into the regime of the time-image."71 The "powers of the false" is a Deleuzian term for the cinematographic power to create in a way that is neither true nor false, but liberated from chronologies and able to create its own logic. ${ }^{72}$ This compares with Deren's interest in the movie camera as instrument for the creation of time, and as a means to visualize intensities. Deren, however, is not categorical in her approach and cinematic logic, sometimes foregrounding the body as physical presence and continuity, and sometimes embracing the metaphorical_as, for example, in the doubling of Rita Christiani and Maya Deren in Ritual in Transfigured Time, whereby the different actresses appear to stand for woman as such. One could cite numerous other examples of metaphorical configurations in Deren's work such as in Study in Choreography for Camera (1945), where a metaphor is created through an alliance between the turning head of the dancer, Talley Beatty, and a sculptural head of the Bodhisattva figure behind him. The metaphorical tenor of Study and Deren's other films is discussed in detail by Sarah Keller in an essay published elsewhere in this issue of the International Journal of Screendance. Referencing earlier writing on Deren by P. Adams Sitney, Keller reads much of Deren's work in metaphorical terms, which makes sense of the cinematic ideas but shifts Deren back into a literary-poetic tradition. ${ }^{73}$ By comparison, Deleuze rejects metaphorical readings of, for example, hallucinatory films and dreams such as Entr'acte, writing: "These are not metaphors, but a becoming which can by right continue to infinity." ${ }^{174}$ As discussed earlier, metaphors tend to combine and mobilize both visual repertoires and verbal concepts, thereby functioning rather differently from the purely visual logic that Deleuze advocates with the notion of the time-image. Deren's work appears to hover somewhere between a poetic literary tradition and a new cinematic logic, using a metaphorical approach but pushing it to explore what a new medium could do for a new age and relativistic universe. Techniques such as depersonalization and stylization demonstrate her intention to produce abstractions and visual intensities, disassociating herself from the logic of narrative cinema; films such as At Land, however, do not go as far as absorbing the character into the image.

Erin Brannigan is concerned with, and tries to dispel, the supposed polarity that Deren is said to have instituted with her two different modes of filmic form. ${ }^{75}$ However, Brannigan's own reading of Entr'acte, in which she only considers the short interludes of the ballerina as the vertical moments within an otherwise horizontal film, enacts a polarity that appears to go against Deren's own intentions. While the scene with the ballerina literally inserts verticality through the camera angle and the performed movement, thereby disrupting a flow of images, Brannigan's reading does not seem to do justice to the complexity of the vertical as invoked by Deren. ${ }^{76}$ Instead, it is possible to attribute large parts of Entr'acte to vertical film structure, in line with Deleuze's reading of Entr'acte in the context of his debate on the time-image. At least the whole of the first part could be considered as an extended vertical 
film form. Given also the interplay between a theory and the material we assign to it this more generous reading of Entr'acte produces a more generous conception of vertical film form that, I would argue, is in line with Deren's own concerns, ambitions, and explorations. The second part of Entr'acte, with its vertiginous race through Parisian streets and dynamic camera angles, is perhaps more ambivalent as to its place within this debate. Clair's own writing points to an association with the visual logic of kinesthetic cinema. Clair was fascinated by the early chase films of Mack Sennet and expressly "wanted to restore film to what it was at the outset.".77 The second part of Entr'acte could therefore be regarded as a homage to the earlier chase films that used the moving image to touch the spectator through visual means, akin to vertical film form. However, the chase could be considered as a relatively coherent montage of images into a dramatic whole, particularly from today's point of view when audiences are very much accustomed to fast paced sequences and cinematic rides through different kinds of spaces. The montage style of editing of the chase could therefore identify the second part as horizontal film form. What Entr'acte also demonstrates is that the vertical and the horizontal mode are not sharply delineated and allow room for interpretation. As Butler argues, the same applies to Deleuze's movement-image and time-image in that the differences are not absolute and constitute "interpenetrating tendencies." 78

This essay has discussed some facets of Deren's and Deleuze's terminologies to ascertain more precisely what the similarities and the differences are between the two. It is apparent that there is a common ground in Bergson's theorization of time and space as well as a shared interest in a radical film form that functions according to its own logic and that does not need a recourse to language. On the other hand, in working with the metaphorical, Deren's own work does not quite let go of linguistic traditions, and her theorization struggles to find an equally new language to match what she is exploring visually in her films. Nevertheless, Deren's writing predates Deleuze's publications on cinema by over thirty years and her films anticipated many subsequent developments. In order to determine more precisely the role that Deren played in the development of experimental film form, one could use the notion of the "recurrence" to say something about the dynamics at play in this timeline. I am drawing here on an argument at the beginning of Cinema 2 where Deleuze writes: "It is never at the beginning that something new, a new art, is able to reveal its essence; what it was from the outset it can reveal only after a detour in its evolution."79 Deleuze writes this with reference to early American and European cinema at the turn of the nineteenth century and the following couple of decades. As he argues, a possibility of pure movement had been noted at the outset of moving image technologies but filmmakers lost track of this discovery in the turn to theatricality. Furthermore, early cinema developed in different directions at the same time and there was no overarching sense of a cinematic specificity. However, during the 1920 s a new interest in pure movement and the actual image became evident within avant-garde projects, as discussed above, and a cinematic specificity was established in the '40s and onwards. It could be argued that Deleuze's hypothesis of a detour in the evolution of a new art form such as film can also be applied to the development of film theory, and explain potential delays in the formation and recognition of new ideas and concepts. Accordingly, his own theory of the movement-image and the time-image could be regarded as a deferred realization of the potential of Maya Deren's horizontal and vertical film form and of its particular visual logic. It will be fitting then to 
end this discussion with Deren's own words, which encapsulate the marvelous promise of cinema as well as the seismic shift from language to image that she dared to undertake:

It was like finally finding the glove that fits. When I was writing poetry, I had, constantly to transcribe my essentially visual images - always movements, incidents, events - into verbal form. In motion picture, I no longer had to do translate. Fortunately, this is the way my mind works, and I could move directly from my imagination onto film..$^{80}$

\section{Notes}

1. Deren, "New Directions in Film Art," 207.

2. Jackson, "The Modernist Poetics of Maya Deren," 60.

3. Harmer, Victory in Limbo, 165.

4. Jackson, "The Modernist Poetics of Maya Deren," 60, and Maya Deren, Anagram, 25.

5. Harmer, Victory in Limbo, 166.

6. Deren, Anagram, 17, 24, 52.

7. Carroll, "Visual Metaphor," 189-218.

8. Ibid., 204.

9. Ibid., 206.

10. Michelson, "Film and the Radical Aspiration," 632. Michelson also explores this subject in her essay "Poetics and Savage Thought," in Maya Deren and the American Avant-Garde, 26. Again she maps the duality of linguistic structure onto film, interpreting Deren's visual poetics as a metaphor in linguistic terms.

11. Michelson, "Poetics and Savage Thought," 22.

12. Deren, "Magic is New," 205.

13. Ibid., 205.

14. For an extensive discussion of the politics involved in establishing a new art form see Jonathan Walley, "Identity Crisis," 23-50.

15. Deren, Anagram, 48.

16. Ibid., 48.

17. Jackson, "The Modernist Poetics of Maya Deren," 64.

18. Deren, Anagram, 51.

19. Ibid., 24, 51.

20. Brannigan, DanceFilm, 113.

21. Ibid., 115.

22. Ibid., 114

23. Deren, "Creative Cutting," 618, 619.

24. Brannigan, Dancefilm, 120.

25. "Poetry and The Film," 173.

26. Ibid., 173, 174.

27. Ibid., 174.

28. Miller, "Poetry and the Film," 186.

29. Brannigan, DanceFilm, 107, 108.

30. Ibid., 185.

31. Massumi, "The Autonomy of Affect," 221.

32. Ibid., 221.

33. Ibid., 220 .

34. Ibid., 219

35. Jackson, "The Modernist Poetics of Maya Deren," 66.

36. Ibid. 
37. Deleuze, Cinema 2, 55.

38. Ibid., 25. See also an interview with David Putnam, the British film producer, who argues that early film escaped language because it was silent. For his discussion of early film see Bragg, The Value of Culture, http:// www.bbc.co.uk/programmes/b01 pmg02.

39. Deren, Anagram, 39.

40. Deleuze, Cinema 2, 26.

41. Ibid., 26.

42. Ibid., 27-29.

43. Ibid., 20.

44. Ibid., 20.

45. Ibid., 21.

46. Deren, Anagram, 40.

47. Deleuze, Cinema 2, 22.

48. Ibid., 22.

49. Deleuze, Cinema 1, 118.

50. Ibid., 118.

51. Deleuze, Cinema 2, 20.

52. As Deleuze points out, the possibility of film to display actual movement did not correspond to the current remit of Art, "since Art seemed to uphold the claims of a higher synthesis of movement, and to remain linked to the poses and forms that science had rejected" (Cinema 1, 6). Film, it seemed, was too realistic, too closely mirroring the flux of the everyday to be considered Art in the traditional sense. Some early film clips by the Lumière brothers and later chase films by Mack Sennett had shown the capacity of cinema to be pure movement, but these films were considered amusement for the proletariat akin to fairground rides and roller coasters, not more.

53. As Malcom Turvey explains in his discussion of avant-garde films, the anarchistic and nihilistic tone was directed against the rationalism of an Enlightenment-style modernity, which appeared to be nothing but a veneer for a derailed society. This notion of a "derailed society" serves not only as metaphor for a historical condition but also suggests a visuality and dynamic which characterizes projects such as Entr'acte. See "DADA, Entr'acte and Paris Qui Dort," 78, 79.

54. Townsend, "The Last Hope of Intuition," 45.

55. Ibid., 45.

56. Clair, Reflections on Cinema, 61.

57. Brannigan, 21.

58. Cooper Albright, Traces of Light, 200.

59. Deleuze, Cinema 2, 55.

60. Ibid., 55 .

61. Ibid., 56. The notion of the dream here is confusing; we conventionally use "dream" in a sense of a dreamy narrative or in terms of a surrealist representation of the unconscious. Malcom Turvey uses the notion of dream in his essay on Entracte in this narrative sense and therefore argues that Entracte is not a dream because it lacks narratives, agents, and goals. He therefore takes issue with Deleuze, but this appears to be caused by a different understanding of the notion of dream. It could be argued that Deleuzian notion of dream describes a hallucinatory and disjunctive episode, which lacks precisely the coherence that Turvey associates with dream.

62. Ibid., 56.

63. Ibid., 56, 58.

64. Deren, "New Directions in Film Art," 209.

65. Deleuze, Cinema 1, 118.

66. Ibid., 97.

67. Deren, Anagram, 42.

68. Deleuze, Cinema 2, 54.

69. Deren,"Magic is New," 205.

70. Butler, "Motor-driven Metaphysics," 10, 11.

71. Ibid., 9 .

72. Deleuze, Cinema 2, 143, 145. 
73. See Sarah Keller, Pas de deux for Dancer and Camera," this issue.

74. Deleuze, Cinema 2, 57.

75. Brannigan, 106, 107.

76. Ibid., 109.

77. Clair, Reflections on Cinema, 60.

78. Butler, "Motor-driven metaphysics," 6 .

79. Deleuze, Cinema 2, 43.

80. "From Poetry to Film", The Legend of Maya Deren, 57

\section{References}

Bragg, Melvyn. The Value of Culture. BBC Radio4. January 3, 2013. http://www.bbc.co.uk/programmes/b01 pmg02. Brannigan, Erin. DanceFilm: Choreography and the Moving Image. Oxford: Oxford University Press, 2011.

Butler, Alison. "'Motor-driven metaphysics': movement, time and action in the films of Maya Deren." Screen 48, no. 1 (Spring 2007): 1-23. http://screen.oxfordjournals.org/content/48/1/1.full.pdf.html

Carroll, Noel. "Visual Metaphor." In Aspects of Metaphor, edited by Jaakko Hintikka, 189-218. AH Dordrecht: Kluwer Academic Publishers, 1994

Clair, René. Reflections on Cinema. London: William Kimber and Co., 1953.

Cooper Albright, Ann. Traces of Light: Absence and Presence in the Work of Loïe Fuller. Middleton, Conn.: Wesleyan University Press, 2007.

Deleuze, Gilles. Cinema 2: The Time-Image. London: The Athlone Press, 1989.

Cinema 1: The Movement-Image. London: Athlone Press, 1992.

Deren, Maya. An Anagram of Ideas on Art, Form, and Film. In Maya Deren and the American Avant-Garde, edited by Bill Nichols, 267-322. Berkeley: Univ. of California Press, 2001.

."Magic is New." In Essential Deren, Collected writings on film by Maya Deren, edited by Bruce R McPherson,

197-206. Kingston, New York: McPherson \& Company 2005.

."New Directions in Film Art. "In Essential Deren, Collected writings on film by Maya Deren, edited by Bruce R McPherson, 207-219. Kingston, New York: McPherson \& Company, 2005.

. "From Poetry to Film." In The Legend of Maya Deren, A Documentary Biography and Collected Works, Vol 1, Part 2, edited by VéVé A. Clark, Millicent Hodson and Catrina Neiman, 57-59. New York City: Anthology Film Archives/ Film Culture, 1988.

. "Creative Cutting." In The Legend of Maya Deren, A Documentary Biography and Collected Works, Vol I, Part 2, edited by VéVé A. Clark, Millicent Hodson and Catrina Neiman, 616-622. New York City: Anthology Film Archives/ Film Culture, 1988.

Harmer, J.B. Victory in Limbo: Imagism 1908-1917. New York: St Martin's Press, 1975.

Jackson, Renata. "The Modernist Poetics of Maya Deren." In Maya Deren and the American Avant-Garde, edited by Bill Nichols, 47-76. Berkeley and Los Angeles: University of California Press, 2001.

Keller, Sarah. "Pas de deux for Dancer and Camera in Maya Deren's Films." International Journal of Screendance 3 (Fall 2013): 53-60.

Massumi, Brian. "The Autonomy of Affect." In Deleuze: A Critical Reader, edited by Paul Patton, 217-239. Oxford: Blackwell Publishers 1996.

Michelson, Annette. "Film and the Radical Aspiration." In Film Theory and Criticism, 2nd ed., edited by Gerald Mast and Marshall Cohen, 617-635. New York: Oxford University Press, 1979.

. "Poetics and Savage Thought." In Maya Deren and the American Avant-Garde, edited by Bill Nichols, 21-45. Berkeley and Los Angeles: University of California Press, 2001.

Turvey, Malcolm. "DADA, Entr'acte and Paris Qui Dort." In The Filming of Modern Life, European Avant-garde film of the 1920s, edited by Malcolm Turvey, 77-104. London and Massachusetts and London, MIT Press, 2011.

Townsend, Chris. "The Last Hope of Intuition: Francis Picabia, Erik Satie and Rene Clair's Intermedial Project Relâche." Nottingham French Studies 50, no. 3 (Autumn 2011): 41-64.

Walley, Jonathan. "Identity Crisis: Experimental Film and Artistic Expansion." October 137 (Summer 2011): 23-50. 


\section{Media}

At Land (1944). Dir. Maya Deren. 15:00 min., 16mm. USA.

A Study In Choreography For Camera (1945). Dir. Maya Deren. 2:00 min. USA.

Entr'acte (1924). Dir. René Clair. 22:00 min. France.

Image in the Snow (1952). Dir. Willard Maas. 29:00 min. US.

Le Bonheur (1965). Dir. Agnes Varda. 94:00 min. France.

Le Lys De La Vie (1921). Dir. Loïe Fuller. 15:00 min., France.

La Pointe Courte (1954). Dir. Agnes Varda. 86:00 min. France.

Meshes OfThe Afternoon (1943). Dir. Maya Deren and Alexander Hammid. 14:00 min., 16mm. Music by Teiji Ito added 1959.

Ritual in Transfigured Time (1946). Dir. Maya Deren. 14:00 min. USA.

Rumi (1999). Dir. Narcisa Hirsch. 28:00 min., 16 mm and video. Argentina.

Un Chien Andalou (1929). Dir. Luis Buñuel. 17:00 min. France. 


\section{INTERVIEW}

\section{Touching Sound: An Interview with Jayne Parker by Aura Satz}

ayne Parker was born in Nottingham in 1957. She studied at Mansfield College of Art,
Canterbury College of Art, and the Slade. She was a visiting lecturer at Goldsmiths College
from 1984 until 1998 and has taught at the Slade School of Fine Art since 1989, where she is now Head of Graduate Fine Art Media. There is a strong element of performance in all of Jayne's work, articulated through the body - the musician, the dancer, the performer. Most of her recent work features the performance of music. Jayne uses the materiality and precision of film to convey a sense of space within the frame, to make connections between seemingly unconnected images and events, and, as she writes, "to try to see and feel what a body can do." Her work has been shown at art venues, on television, and in film festivals internationally. In October 2011, during "Maya Deren: 50 Years On" at the British Film Institute in London," Jayne's films were presented and discussed as part of a season of events exploring the significance of Deren's legacy to contemporary British women's practice.

Artist and writer Aura Satz first encountered Jayne Parker when she was a PhD student at the Slade between 1998-2002. Jayne's work provided many resonances for Aura's later work with sound, musicians, and musical gesture, and both artists have collaborated extensively with cellist Anton Lukoszevieze. In June 2012 Aura included Jayne's work in a curated screening at a pop-up cinema at Christies, South Kensington London, UK as part of Exhibition Road's event "Supersonix."2 The films shared an attention and sensitivity to the materiality of sound and sound-making technologies, devices, and instruments. Alongside her own films, and Jayne's, Aura screened films by Manon de Boer and Luke Fowler.

Jayne's recent Trilogy: Kettles Yard (2008), a series of films featuring Lukoszevieze, are documents of the performances of three compositions for cello. Each composition prescribes an intriguing mediation in the encounter between body and instrument: the tapping of strings with the left hand, the voicing of phonemes, the improvisation of gesture. Set at Kettles Yard, the University of Cambridge gallery house, Trilogy also includes art objects, which open up the metaphorical space and meaning of the compositions. In this interview Jayne reflects on her filmic approach to the performance of sound, the choreography of musical expression and the sculptural quality of the played instrument.

Aura Satz: As this issue of the Journal is focused on the continued relevance of Maya Deren's art and influence, can I begin by asking when you first encountered her films? Like Deren you have collaborated with dance performers, and constructed choreographies for camera; I wonder how her treatment of dance movement on film resonates with your own. 
Jayne Parker: The first Maya Deren film I saw was Meshes of the Afternoon (1943). I can't remember when or where saw it but it was after I had left the Slade. Perhaps it was at the London Film Maker's Co-op or the NFT. I remember liking At Land (1944), especially the part when Deren is climbing the tree bole from the beach to the dining table.

When I think of Maya Deren I always see her as she is in her films: straight back, totally present, striding out, or with a curious knowing expression-and that wonderful hair. I see her as a force of nature, indefatigable, a beacon, whose visionary films endure-memorable, unforgettable-but most of all I am struck by how she articulates filmic space, crossing the boundaries and limitations of our everyday perception.

I value Deren's film presence as a performer and a dancer and the fervour of her relentless drive. I am not a dancer myself but have been drawn to dance. I long to be inside the movement and have access to such physical expression. I particularly like the extreme nature of ballet and its symbolic language, which can be deeply shocking. I approach filming dance in much the same way as other performance subjects. I tend to like action to happen in front of the camera, for the camera to be static, which is challenging when filming dance. I don't have a sense of how to construct choreographed movement but only of how certain movements makes me feel. I structure film very much in response to what I see and feel. This is true for all my work.

AS: Your work has often involved performative acts captured on film, and clearly your work with both dance and music fits within this context. I wonder whether you could provide a brief overview of how you first came to work with musicians? Am I correct in assuming that the first of these was Crystal Aquarium (1995), which featured a drummer?

JP: Music has always been important in my work. The first film I made which featured a musician was Cold Jazz (1993) when I filmed saxophonist Kathy Stobart. The proposal for this film came about in a roundabout way. I was on holiday in France and went to a jazz evening. There was a young saxophonist in the band and she never knew when to come in. She shifted her weight from foot to foot as she counted and the band would circle round until she made it in - then she played perfectly. It reminded me of how I felt when I was making The Pool (1991) and diving into the water-I never knew how to leave the side, how to launch myself into the dive. I was introduced to Kathy through a colleague at work - Kathy was her aunt. Incidentally Debussy referred to the saxophone as "that aquatic instrument" and at the time I thought about the saxophone as being like a metallic eel with the pads opening and closing like gills_-also referring back to imagery in The Pool. All the musicians I have filmed-Kathy Stobart, Michelle Drees, the drummer in Crystal Aquarium (1995), and Katharina Wolpe and Anton Lukoszevieze with whom I have made several films - I have wanted to film because of the quality of their musicianship, their concentration and performance.

AS: Your films reveal an attention to the bodily, choreographic quality of musical performance, and an intense engagement with the materiality of the musical instrument. Can you perhaps explain this specific mode of filmic approach?

JP: I would like to be where the musician is when they are playing-both physically and in their feeling - I want to see and feel what they feel. The question "where is music expressed?" is always there. Is it in the act of playing, the act of touch? Is it in the sound or 
expressed in the face? There is something vicarious about this. Music is a difficult area for me. I nearly did music when I left school but in the end chose art. I always felt I failed at music, that I didn't have a good ear. I had a cello teacher who would become angry when I got something wrong and it made me tentative-I didn't rise to the occasion. So there is a longing for music and a pushing away at the same time. I think of the instrument as standing in for the body, it has a voice and expression - it is the site of music. However, the sense of touch is probably the most important thing.

AS: Some years ago we discussed your film with the eviscerated cello, and I remember you mentioned how much you hated practising. There's a kind of implicit violence in some of the films, whether this be in the destruction of an instrument or, as in one of the films featuring Anton Lukoszevieze, an instrument, which is aggressively scratched, and bears the scars of past performances. What has your relationship to music and your own experience been, and how has this found expression through filmmaking?

JP: I mentioned earlier my relationship to music. I can't remember saying I hated practicing but if I did it would have been because I felt I could never get it right. I certainly never practiced as much as I should have done! I was quick to pick up the basics of playing an instrument and dexterous too, but there comes a point when this isn't enough to carry you through and disciplined practice is required. I always wanted to be better than I was. You are right about the implicit violence in my films. However, in the "music films" it is the score that directs the apparent violence, in that the musician's gestures come about purely through following the composer's notation and this is what fascinates me.

AS: There are a number of musicians who you have worked with on an ongoing basis over several years, such as pianist Katharina Wolpe and the cellist Anton Lukoszevieze. How did those working relationships begin and how did they evolve?

JP: I met Katharina through mutual friends, including the artist Tess Jaray. I knew that I wanted to make a film with Katharina when I heard her give a recital of her father Stefan Wolpe's music at the ICA in the early 1990s_ 1992? The first film we made together, Thinking Twice (1997), was shown at Camden Arts Centre where I met composer Michael Parsons at the opening and he told me about Anton. Anton saw my film and I went to see Anton perform at Kings College and we knew we wanted to work together. Shortly afterwards I was invited to make work for Spacex Gallery, Exeter who co-commissioned the series Foxfire Eins (2000) a series of four films made with Anton, with Film and Video Umbrella. Both Katharina and Anton are important people in my life, great friends and artists, whom I hold in great respect.

AS: Anton features in the trilogy of films you produced for Kettle's Yard, which also engage with sculptural objects in the collection. There is a beautiful sense of poetic resonance between the objects and the musical performance, as well as the parallel camerawork, featuring unusual compositions and unexpected angles. How did you go about devising these works? According to what structuring principles did you choose the artworks and the musical compositions?

JP: The musical compositions featured in Trilogy: Kettle's Yard were pieces that I had wanted to film Anton playing for several years, ever since making Foxfire Eins. Anton was New Music 
Fellow at King's College, Cambridge and Kettle's Yard Gallery from 2005-7, which presented an opportunity for us to film there. Michael Harrison was the Director at this time and he was very supportive and kindly let us film in both the house and the gallery. Originally I had intended to include more objects from the collection but, as often happens, what looks wonderful with the eye doesn't translate through the camera lens, so I only used very few objects whose resonance with the music was apparent. As to the structuring of the films: following the linearity of the score there is already direction, and structure occurs through looking at the form of the music. I try to find ways to approach both the filming and editing that mirrors the sensibility of the musical compositions. Editing Sylvano Bussotti's music, Sensitivo, per arco solo (1959) from the central section of Trilogy: Kettle's Yard, which is a graphic score, proved challenging. I thought at first that I could play a part in determining this indeterminate music through editing, but in the end each take felt complete and I didn't want to interrupt that. So here the takes are long — there is no need to edit. Working with music has changed the frequency of my edits. What in the music or performance is going to indicate a change of view? It could be the meter or the phrasing, but the rhythm of the music doesn't always align with the rhythm of the film.

AS: Your solo exhibition at ROOM in 2009 included sculptures alongside the films. ${ }^{3}$ These included beautiful dismantled and reassembled cello parts which seemed to evoke a darker side to the music. The strings of the bow were loosened to bring back the more animal but also possibly cruel side of musical instrument design. It also recalls the very unusual shape of the curved bow which Anton uses in one of the films, which can play up to four strings at once, producing wonderful chords and harmonics. Again, when at rest it resembles an uncanny horses mane, a relic of sorts, which is both wild and extremely contained. How did these sculptures come about, and how do they relate to your filmmaking?

JP: I think of the sculptures as extending the imagery in the films-I don't experience musical instruments as cruel. I am however interested in the animal in relation to musical instruments, both literally and symbolically. Making objects offers me a chance to explore imagery in a different way and to make explicit connections and references that are often buried in the films. I aim to create objects that are like facetted still moments in that they draw together several things in one image that is actual, physical and tactile. They bring out the physicality of the materials of the instrument and make the instrument more of a body.

AS: Often in your films the choice of music is quite difficult listening, or challenging for the musician. Can you say some more about this stylistic choice, and how you compose the films around such musical compositions and performances?

JP: I choose music that affects me, either aurally or visually, that creates a personal resonance in some way. The pieces of music come about in a variety of ways but most usually through having seen them performed. I like to see music performed; it helps me to hear it_-if I see it I hear it_-seeing and hearing are entwined. I am particularly drawn to the music of Stefan Wolpe. There is something absolute about Wolpe's music, dense and exhilarating and difficult for both performer and listener. It demands concentration. My choice of music is also based on the performative action of the musician-some compositions demand less conventional modes of playing and I am entranced by imagery that comes about through the act of interpreting/translating the score into sound. The cello is a very 

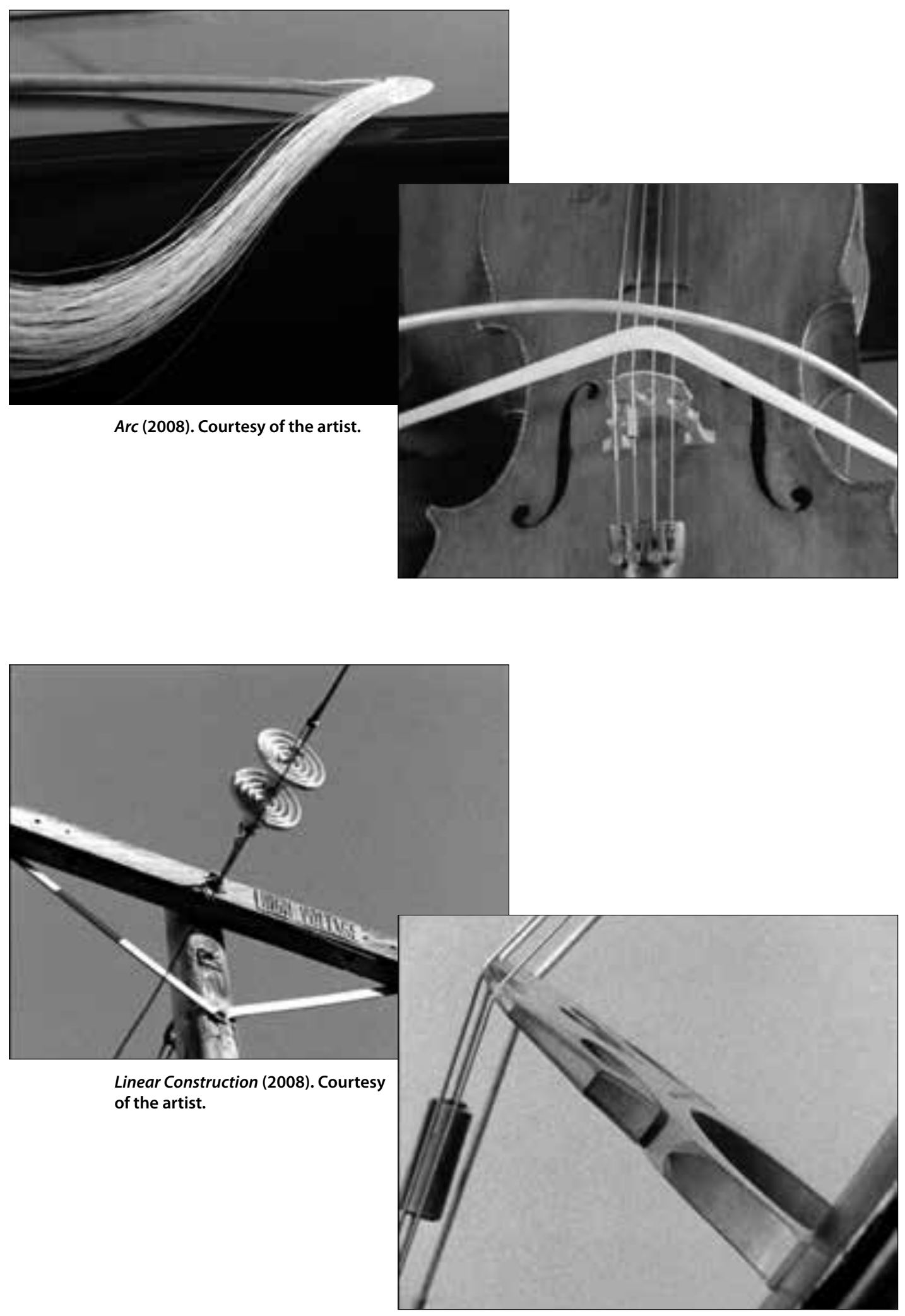


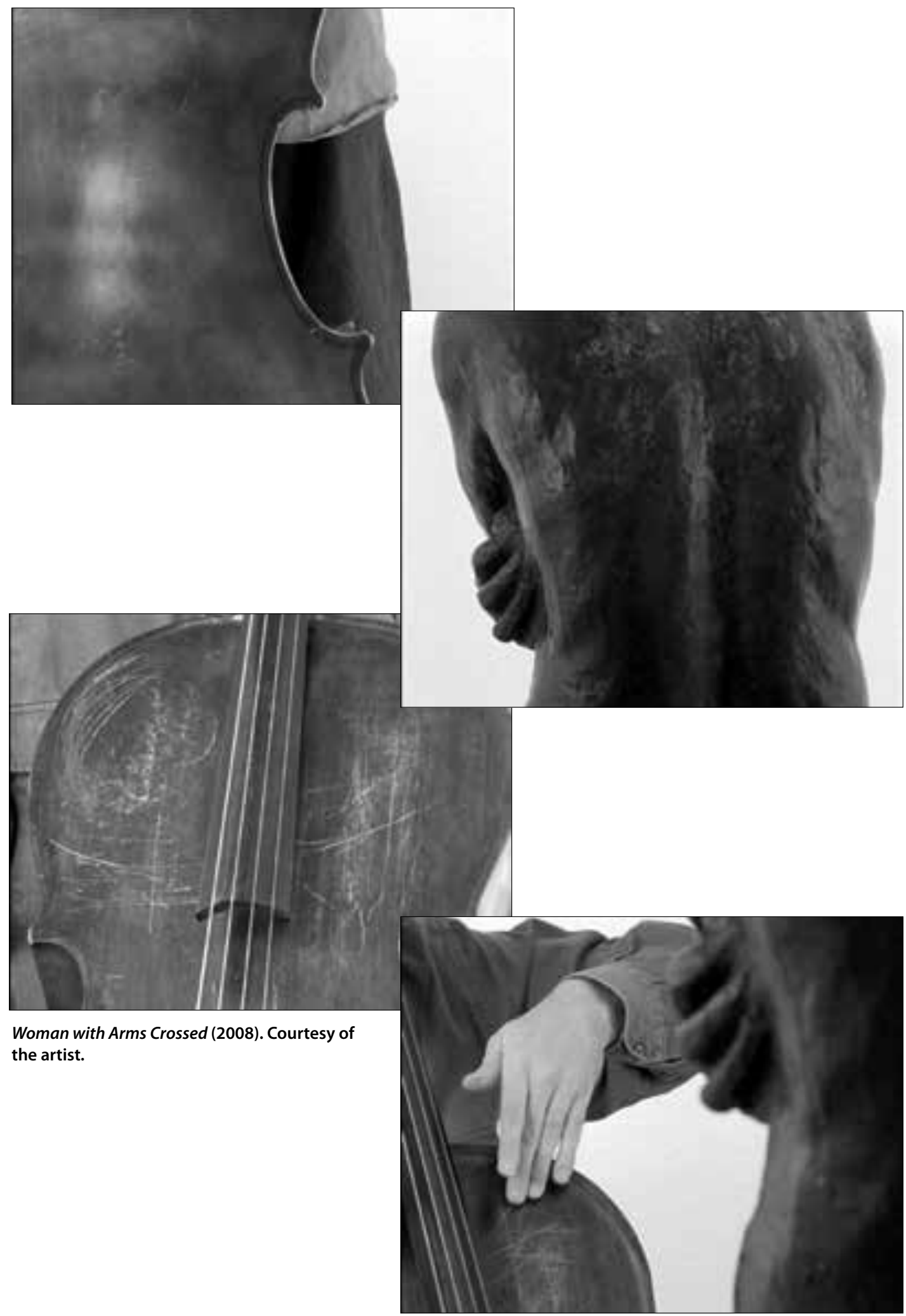


frontally exposed instrument; everything faces outwards with the musician behind. With the piano there is more of an equilibrium - the notes all at rest, settled, like water finding its level - this is how pieces start and end with the piano. With the cello, there is no mechanical interface between the player and the tension of the strings. The action of the piano is internal whilst that of the cello is external. I should say that it is the quality of the performers that is paramount. Both Katharina Wolpe and Anton Lukozsevieze are consummate musicians and the films rest on their very special qualities.

AS: I am always fascinated by the tactile relationship between a musician and his/her instrument, the implied ergonomics of instrument design, and how this prescribes a series of choreographic possibilities, as well as modes of subversion. I find this very interesting from a filmic point of view, as one can guide the viewer to look and, as a result, also hear very differently. How do you structure your camerawork accordingly, and is this something your "score" in advance so to speak?

JP: All the filming is carefully planned to best reflect the music and its structure and catch the nuances of the performer. I only use one camera. From my experience, the second camera always needs to be where the first one is and if you make a mistake you make it twice. It is interesting how consistent musicians can be physically-not just in terms of playing the notes but in how tension and felt experience registers in their bodily movement and expression. I am aware of the structure of the music and keep this in mind in terms of phrasing and my shooting script, where to pick up a shot or end it. I am mindful of how physically demanding performing in a filming situation can be. I aim to make sure everything is covered so I have choice when I am editing, which is where the real structuring takes place.

AS: Can you say something about your relationship to the tactility of $16 \mathrm{~mm}$, and how the medium itself informs the quality of the work?

JP: I can be very pragmatic. I like things to be what they are and film is wonderful for this. It is the materiality and physicality of film is that keeps me working with this analogue medium. It is also what I am used to using. Over the years the medium has shaped how I think, how I see images and how I order material. The 4:3 ratio is ingrained. I like all the stages of filmmaking: loading the camera, framing, shooting, editing. Wanting to film something comes with a sense of urgency — I have to film it. Alongside is anxiety — what if I miss it? With film there is always the possibility of something being more that I could have imagined - it can of course go the other way. It is a transformative process. I like the logic of film, its exacting nature and the precision of the editing process, the depth of space within the frame, filmic space within the frame, the sense of order and all the delineated stages of filmmaking. Film has the stability of a material object. I see a correlation between the grain of the celluloid and the vibration of the sound. I still edit on film and this dictates the decisions and structuring of both the film and my working process.

AS: As an artist, I find myself continually attracted to sound and music as they seem to offer ways of disorienting perception, seeding a sense of doubt as to the source of sound, which is so easily disembodied, and, through film, enabling a potent opportunity to both detach and re-align sound and image, forcing the senses to engage in a closer mode of attention 
and decipherment. What is it about music which draws you in and has made you return to it over and over in so many films?

JP: Music has always been important for its expressive power and its capacity to move us. There was a time when I wanted to make a shift. I felt I was making the same film again and again and I wanted to move the subject away from myself. The films could be seen purely as documents of musical performance but the underlying themes remain the same: the body, inside/outside, felt experience, the body in relation to an object, the object as body, seeking ways to express those things that can't be articulated in any other way, metaphysical yearning.

\section{Media}

Cold Jazz (1993). Dir. Jayne Parker. 16mm, b/w, 17:00 min.

Crystal Aquarium (1995). Dir. Jayne Parker. 16mm, b/w, 33:00 min.

Foxfire Eins (2000). Dir. Jayne Parker. Digibeta from original 16mm, b/w, 10:00 min.

I Dish (1982). Dir. Jayne Parker. 16mm, b/w, 16:00 min.

K(1989). Dir. Jayne Parker. 16mm, b/w, 13:00 min.

The Pool (1991). Dir. Jayne Parker. 16mm, b/w, 10:00 min.

The Reunion (1997). Dir. Jayne Parker. 16mm, colour, 9:00 min, Dance for Camera ACE/BBC.

Stationary Music (2005). Dir. Jayne Parker. Digibeta from original $16 \mathrm{~mm}, \mathrm{~b} / \mathrm{w}, 15: 00 \mathrm{~min}$.

Thinking Twice (1997). Dir. Jayne Parker. 16mm, b/w, 10:00 min.

Trilogy: Kettle's Yard: Linear Construction-Woman with Arms Crossed-Arc (2008). Dir. Jayne Parker. Digibeta from original 16mm, b/w \& colour, 25:00 min.

\section{Notes}

1. Jayne Parker's films I Dish (1982), The Pool (1991), The Reunion (1997), Stationery Music (2005), Arc (2008) and K (1989) were screened at British Film Institute, London Southbank on 7 October 2011 as part of "Maya Deren: 50 Years On."This retrospective was followed by a conversation between the artist and William Fowler, Curator at the BFI National Archive. See http://www.bfi.org.uk/sites/bfi.org.uk/files/downloads/bfi-press-release-bfi-southbankpresents-Maya-deren-50-years-on-2011-08-25.pdf. Jayne Parker's films are distributed by LUX Artists'Moving Image, London, UK. http://www.luxonline.org.uk/artists/jayne_parker/index.html.

2. "Supersonix," a conference and series of events celebrating the art and science of sound, was organised by the Exhibition Road Group, and held in London between 21-23 June 2012. Aura Satz's curated film programme at the Pop Up Cinema, Christie's South Kensington, was screened on 23 June. See http://www.exhibitionroad. com/7416/pop-up-cinema-at-christies-south-kensington-aura-Satz

3. Jayne Parker's solo exhibition at ROOM, an art space on Manchester Street in central London, ran from 15 January - 8 February 2009. Linear Construction, Woman with Arms Crossed, and Arc (collectively Trilogy: Kettles Yard) were presented alongside a small installation of sculptural objects. See http://www.roomartspace.co.uk/ past_detail.php?eventID=133\&eventType=exhibition\&theartist=JAYNE\%20PARKER 


\title{
REVIEW ESSAY
}

\section{About Maya Deren's Sink}

\author{
Eleni Tranouli
}

Maya Deren's Sink (2011). Dir. Barbara Hammer. United States, HD video, 30 minutes, Color/B\&W/sound by Meredith Monk. Film.

This room, housing the flesh, is home for the heart: point of return and point of departure; contains those objects which, the sight fallen or fixed upon, are thresholds for the quick heart's eye. The real thing, caught in the hand, through which the heart takes flight...The breath caught in the early morning because the heart's eye saw something which the hand could never hold...

This is what Maya Deren wrote in her apartment at Morton Street in an article that remained unpublished until her biographers decided to resuscitate the above extract in The Legend of Maya Deren (1988).

Half a century after the death of Deren, who film history remembers as "the Mother of the American Experimental Cinema," another personal belonging of hers emerged from the same apartment. It was her bathroom sink from the 1940s that Barbara Hammer discovered by chance at Anthology Film Archives. This discovery triggered Hammer to undertake her "Grand Tour" in quest of the old residences of the artist in Los Angeles and Greenwich Village. First, Hammer sought to explore the material aspect of these places: the objects, the furniture, the walls. But her vision eventually rose above the physical reality to grasp what the heart's eye saw and which the hand could never hold...

Hammer perceived the sink more as an artifact to be preserved than a home accessory and immediately envisioned it as a projection screen. She placed it in a dark and undefined space and filmed it, at times alone in the darkness, at times illuminated by the exhumed images of Deren, cast by a video projector. This series of projections echoes the performances that Hammer developed in the late 1970s when she projected her films on a weather balloon hanging from the ceiling, attempting in this way to "change the shape of film."2 In Maya Deren's Sink, images of Deren are projected on another curvilinear surface, that of the sink, and become deformed and three-dimensional. Furthermore, Hammer repeated these video-projections in situ in the old apartments of Deren whereby everything became a potential projection screen: the images of Deren's face slip across the walls, dimple on the curtains, pleat between the angles of the floor and the walls. Blending into the bumpy ground of these objects, the images undergo an anamorphosis. They once again animate the interiors as they did six decades ago, when Deren was organizing screenings of her films at her Morton Screen studio. In the absence of a constituted distribution network 
for experimental film practice in the mid '40s in the United States, Deren frequently transformed her home and studio into a private screening room.

The apartments of Deren have become well known. It was at North Kings Road that she filmed with the filmmaker Alexander Hammid, then her husband, the renowned Meshes of the Afternoon (1943), a "home movie," with "home" referring both to the film's independent means of production and the intimate topos of filming. The apartment in Morton Street was later both her home and studio; it also served as set for the films A Study in Choreography for the Camera (1945), The Private Life of a Cat (1945) and Ritual in Transfigured Time (1946). ${ }^{3}$ In a quest for background details, Hammer filmed the interiors by projecting images from Deren's films across the walls. This unexpected juncture of a former space projected back onto its present double produces a strange disorientation.

Today everything seems different and nothing resembles the analog images of Deren in black-and-white. The painting by Paul Klee, Fetische, once hanging in the living room at Morton Street, is now replaced with all kinds of objects and plants. The shelves once filled with shells, stones and primitive objects brought back from Haiti are now empty; the floral wallpaper is painted over. Hammer's imagery plunges the viewer into an anachronism, as if the past were always distorted and redefined by the present.

Maya Deren's Sink joins an expanded practice of recycled images in contemporary cinematic production, but the use of "found footage" is limited. It's through Bekka Lindstrom, an actress who physically resembles Maya Deren that Hammer creates her own iconography —inspired by and quoting the films of Deren_by filming the artist's doppelganger at different angles. She films Lindstrom in Morton Street and at North Kings Road, introducing new images that, superimposed on those familiar images of Deren, blur the real and the non-real, the original and the replica. Furthermore, this quotation goes beyond the visual realm and affects the text when a voiceover repatriates multiple passages from Deren's theoretical writings on film. The writings, dating from the '40s and ' 50 s and elaborating Deren's theories on the poetics of film and film as an artform, correspond to the technological context of the time. Revisiting the material in the age of technological growth and the new media haze, Hammer reanimates Deren's esthetic beliefs by combining them with digital technologies, thereby opening them up to new paths of reading. Thus, in opposition to an overwhelming linearity that would institutionalize the past, Hammer reclaims the extension and contemporaneousness of ideas by projecting them into the present.

Hammer's intention to examine the ways history is written is articulated in her interview with Elisabeth Lebovici for Mousse Magazine, ${ }^{4}$ where she states that in making Maya Deren's Sink she reached into the archives of the everyday to study how Deren kept her diaries, what kind of spaces she lived in, and, by extension, how the everyday life of an artist unfolded at that point in time. Ultimately, Hammer is concerned with how we conceive and build up an archive a posteriori. As an artist and activist Hammer is highly committed to the field of history writing and, in particular, to the erased history of the oppressed which is evident in her films Nitrate Kisses (1992), Tender Fictions (1995), Resisting Paradise (2003), and Lover/Other (2006). Maya Deren's Sink clings to the unseen - the anthropology of domestic life, the routine, the intimate everyday rituals-exploring how these aspects form part of the practice of an artist and her forming of an esthetic. The example of Deren's diaries is illustrative of this concern, and in the film we learn that she kept three simultaneously. ${ }^{5}$ Indeed, the simultaneity with which she kept a record of her thoughts resonates with her 
conception of cinema as a powerful instrument that is capable of making perceptiblereflecting the theories of Einstein - a relativistic universe. Deren's film At Land (1944) is a direct result of this conception. Through the film's creative elements, photography and editing, Deren fabricated the illusion of a tactile simultaneity of an individual traveling across a "20th century-minded time and space" continuum. ${ }^{6}$

In Maya Deren's Sink, Hammer explores the same power of the filmic instrument to transform into image the invisible, the undocumented, and that which was until now undervalued as mere accessory. Curiously, with regard to Deren, few facts seem to have escaped the existing historiography of her life; one thinks of works such as the legendary and ambitious biography The Legend of Maya Deren, A Documentary Biography and Collected Works. This chronicle is a lengthy project; the first two volumes appeared in the 1980s and totaled 1200 pages, and there is still another volume to follow. Facing the hierarchical dilemma inherent in the act of archiving, Deren's biographers seem to have chosen to exclude almost nothing by retracing the life of the artist in its smallest details. In the 1970s, when this edition was being prepared, Hammer was herself playing the archeologist. As she wrote in her own biography, Hammer! Making Movies out of Sex and Life (2010), and due to her interest in the neglected history of women artists, Hammer exhumed at Boston University Library the tapes of many of Deren's lectures which she presented to her students at Binghamton. ${ }^{8}$

With her new "essay documentary," Hammer has sought to revisit the vocabulary introduced by the title of Deren's biography in order to redefine the documentary in her own cinematic terms. ${ }^{9}$ To explain the title, Deren's biographers argue that the word documentary was used to emphasize their commitment to the original materials while the word biography was intended to honor the life. ${ }^{10}$ Hammer herself has often challenged the parameters of the documentary form such as in History Lessons (2000). With Maya Deren's Sink she goes a step further, appropriating the bathroom sink to confirm and reaffirm the term Legend as, in other words, the story of a person converted into myth whose life was distorted and amplified by popular imagination. Accordingly, the images of Deren are deformed when projected on the curvilinear surface of her former sink, just as her memory, like a neverending worksite, is deformed and refracted through the many documents available to readers and researchers who rewrite her history like a palimpsest. Maya Deren's Sink follows this same registry, and its flux of images - soft or sharp, inversed, saturated, superimposed, sometimes psychedelic, out of a thick patina-draws the viewer toward the sensation of a ghostly Deren, more liquid than solid, that metamorphoses in the flow of the;eraclitean dictum: "Into the same river no man can step twice."

Furthermore, the Legend meets its original oral tradition since, in her film, Hammer makes the walls speak. The artist superimposes the speaking portraits of several witnesses onto the frames found hanging in Deren's old apartments, including Carolee Schneemann, Catrina Neiman, Judith Malina and Jerry Tallmer." Through the rising of these collective voices, history is re-articulated, not by Deren's unanimity but through its rich polyphony. Through this vocal montage, the narrators transcend their individuality to become part of a collectivity tied together by the anecdotes of Deren's life. The history Hammer offers is voiced in plural and sculpted sometimes by harmony, sometimes by dissonance. At the end, when the closing credits appear, moments of doubt and hesitation ebb and flow: "The 
rumor that I've heard..., I don't know the story..., I don't remember where l've heard it..., I don't know who told me or how I know it...," etc.

It is by suspending doubt at the end of her film that Hammer destabilizes our trust in the document: what if everything we've heard and witnessed was merely the flit of an unverifiable rumor?

Sink! we hear voices repeat throughout the film at the sight of the bathroom sink. Sink! repeats Hammer and, without a doubt, she hints: Sink! in the abyss like an Atlantis.

\section{Notes}

1. Excerpt from Deren's article "The Home through the Heart's Eye" destined for Flair Magazine. See Clark, Hodson and Neiman, The Legend of Maya Deren, 131. Although Deren's article was never published, it was previewed in the Flair pre-publication issue, 1950, and is going to be reprinted in Ritual, Volume II of The Legend of Maya Deren.

2. Hammer and Lebovici, Mousse Magazine. Back in the late'70s and early'80s, Hammer expanded her artistic practice by a series of performances, making her breakthrough from the movie screen and into the architectural space of projection. Using one or more moving projectors, the artist projected her films around the screening room and on inflated weather balloons, thus challenging in a radical way the film's spatial frame and horizon while, at the same time, stimulating the audience in an active, physical participation. Available Space (1979) was the first of her experiments. Recently, a series of new works have followed, among them: Moving Projector (2009), Balloon Projection (2009), and Changing the Shape of Film (2009). These works are part of Hammer's retrospectives in MOMA, New York (2010), Tate Modern, London (2012), and Jeu de Paume, Paris (2012). See Hammer, Hammer!, 80-84, as well as the artist's personal website: http://barbarahammer.com/multimedia/performances.

3. The home, as the intimate geography of creation, is an important component in Barbara Hammer's own practice as an independent artist and is, as she states, inevitably implicated in the production of her work. Furthermore, this resonates with her initiative to visit and film the interiors of Deren's apartments. The home is for Hammer a place of "creative freedom", where "you can break taboos without being ... arrested. "See Hammer and Earnest, "Time is an Emotional Muscle."

4. Hammer and Lebovici, "The Screen as the Body."

5. Deren kept several diaries and notebooks at different periods throughout her lifetime. More specifically, we know the existence of three diaries dated ca. 1931-36 and a journal she kept before and while in Haiti, dated ca. 1947, preserved at the Howard Gotlieb Archival Research Center at Boston University where the Maya Deren Collection is housed. Furthermore, excerpts of her notebook in Haiti have been published in October journal, 1980. On Deren's notebook, 1947, see Neiman, "An Introduction," 3-15. For a published transcript of Deren's journal see Deren, "From the Notebook," 21-46.

6. Deren, "Program Notes," 2.

7. The Legend, initially conceived as a Maya Deren "Reader," was eventually expanded to become the most extensive collation of documentary biography ever compiled on a woman filmmaker. It is a women's collective project, undertaken in the midst of the second-wave feminist movement in the United States, and part of a wider reevaluation of historiography at Berkeley in the early '70s. This unparalleled biography brings to light exhaustive archival material as well as new, unpublished data on Deren's expanded activity, thus establishing her legend; Clark, Hodson and Neiman, The Legend of Maya Deren, xiv-xvi and 1-4.

8. Hammer, 168.

9. On Hammer's metadocumentary and "essay documentary" practice, see Hammer, 241-45.

10. Clark, Hodson and Neiman, 1984, XV.

11. Those who tell the story of Deren's life in Hammer's film have their own histories; Carolee Scheemann has raised questions about body, sexuality and gender through her pioneer and expanded artistic work in the visual arts. Catrina Neiman, writer and archivist and specialised in artists' writings, is one of the editors of The Legend of Maya Deren. Jerry Tallmer, prolific NYC journalist and critic, is a founder of The Village Voice, where he was an associate editor and drama critic at the time when Deren briefly contributed in the publication in 1960/61. Judith Malina, writer, actress and director, is a founder, together with Julian Beck, of the radical experimental theatre troupe The Living Theatre. It is worth noting that Maya Deren gave, in April 1959, a lecture at the Living Theatre in New York entitled "Moving-Pictures: Motor-Driven Metaphysics." On Deren's lecture, see Butler, "Motordriven metaphysics," 1-23. 


\section{References}

Butler, Alison. "Motor-driven metaphysics: movement, time and action in the films of Maya Deren." Screen 48, no. 1 (Spring 2007): 1-23.

Clark, VeVe, Millicent Hodson and Catrina Neiman. The Legend of Maya Deren: A Documentary Biography and Collected Works: Signatures (1917-42). Volume 1, Part 1. New York: Anthology Film Archives, 1984.

. The Legend of Maya Deren: A Documentary Biography and Collected Works: Chambers (1942-47). Volume 1,

Part 2. New York: Anthology Film Archives, 1988.

Deren, Maya. "Program Notes on three early Films." Film Culture 39 (Winter 1965): 1-2.

"From the Notebook of Maya Deren, 1947." October 14 (Autumn 1980): 21-46.

Hammer, Barbara. Hammer! Making Movies out of Sex and Life. New York: The Feminist Press, 2010.

Hammer, Barbara, and Jarrett Earnest. "Time is an Emotional Muscle." The Brooklyn

Rain. December 2012/January 2013. http://www.brooklynrail.org/2012/12/art/

time-is-an-emotional-musclebarbara-hammer-with-jarrett-earnest

Hammer, Barbara and Élisabeth Lebovici. "The Screen as the Body, Barbara Hammer." Mousse Magazine 32 (February/March 2012). Milano: Mousse Publishing. http://moussemagazine.it/articolo.mm?lang=en\&id=789

Neiman, Catrina. "An Introduction to the Notebook of Maya Deren, 1947." October 14, no. 102 (Autumn 1980): $3-15$.

\section{Media}

At Land (1945). Dir. Maya Deren. United States, 15:00 min., 16mm, B\&W/silent film.

Available Space (1979). Dir. Barbara Hammer. United States, 20:00 min., 16mm film, Color/silent. Performance and film.

History Lessons (2000). Dir. Barbara Hammer. United States, 16mm film, 66 ':00 min., Color/sound. Film.

Lover/Other (2006). Dir. Barbara Hammer. United States, 55:00 min., Video, Color \& B\&W/sound. Film.

Maya Deren's Sink (2011). Dir. Barbara Hammer. United States, 2011, HD video, 30:00 min., Color/B\&W/sound by Meredith Monk. Film.

Meshes of the Afternoon (1943). Dir. Maya Deren. United States, 13:45 min., 16mm, B\&W/silent film. Second version with sound by Teiji Ito (1959).

Nitrate Kisses (1992). Dir. Barbara Hammer. United States, 67:00 min., 16mm film, B\&W/sound. Film.

The Private Life of a Cat (1945). Dir. Maya Deren. United States, 1945, 29:00 min., 16mm, B\&W/silent film.

Resisting Paradise (2003). Dir. Barbara Hammer. United States, 80:00 min., 16mm film, Color/B\&S/sound. Film.

Ritual in Transfigured Time (1945-46). Dir. Maya Deren. United States, 14:30 min., 16mm, B\&W/silent film.

Tender Fictions (1995). Dir. Barbara Hammer. United States, 58:00 min., 16mm film, Color/sound. Film. 


\title{
REVIEW ESSAY
}

\section{Writing on the What Matters \\ Festival, 11-15 April 2012}

\author{
Fiona Wright
}

\section{First Impressions Revisited}

I am making daily experiments now and find I am able to take passing horses at a lively trot square across the line of fire-bits of snow in the air-spokes well defined-some blur on top of wheel but sharp in the main - men walking are no trick-I will send you proofs sometime. I shall show you what can be done from the saddle without ground glass or tripod-please notice when you get the specimens that they were made with the lens wide open and many of the best exposed when my horse was in motion.

\section{- Michael Ondaatje}

The above quote is taken by Michael Ondaatje from an original comment made around 1870-1880 by Western photographer L.A. Huffman, from his book Huffman, Frontier Photographer. The photographer's words, a message from the past, are borrowed to mark the introduction to a poetic portrait of Billy the Kid, itself borrowing from many fragments of fact. It is one of the voices that comes to mind when I sit down to write about two of the artworks I was fortunate to see this year at the What Matters festival. The history of photography and the moving image has always included documents of animals and human figures in motion and from very early it has always included horses. Many of the pieces that were to be found in the festival, so thoughtfully selected and carefully sited at the Siobhan Davies Studio, refer directly or indirectly to the human experience of movement and draw attention to how we experience watching representations of movement. The artworks here also asked questions about the idea of choreography, whether stylized or incidental. And yet, not all the works chosen were intended to make us think about dancing in any particular way and not all of them even contained images of people moving at all.

In my memory of arriving at the festival, the first thing I encounter is entirely made up of the recorded image of the anatomy of horses - The Four Riders (2010) by Chaja Hertog and Nir Nadler. The video installation plays on a loop of almost eight minutes, projected onto four screens in the Research Studio on the first floor. I am immediately drawn into this as a very close movement study with its intense specificity and attention to detail. The deconstruction of the animals is emphasized by the four screens, which are life-size and running simultaneously. The muscles of the chest of each horse seem to become dominant in the image. I find myself thinking that in a sense this would be the part of the horse that is shared with a human body. On the upright stance of a centaur's fantasy body the human 
torso necessarily joins the horse body in this place - the horse's shoulder girdle becoming a sort of second pelvic girdle on the front of the mythical man/horse body. But there are no centaurs in this video installation, and no horsemen, yet the title gives us the idea of the imaginary riders. The powerful chest area is also the part of the animal that would strike you first, fell you to the ground, in that imagined apocalyptic moment.

The artists' own online descriptions of the imagery include "wild and grotesque" and "restrained and elegant." They also cite Muybridge's nineteenth century photography and Durer's fifteenth century woodcut as inspirations. Even without these references an audience could recognize here something ancient or biblical, and perhaps an older, more ordinary relationship to the horse as a working animal. With very few visual clues I can gather, this is indeed filmed with the horses on an actual treadmill and the event of the shoot and the choice-making in the edit is quite present, if in the back of my mind, alongside the immersive feel of the sound and the rich surface of the image. The expanses of flesh do become like landscapes, the skin moves over muscle and although we never see the whole animal we are given enough information to know that these are big animals and are reminded by the scale and sense of power just how huge a horse can be and the size of the passions we project onto these animals even now. Many people still work with and rely on horses. Many of us rarely stand this close to one. What matters here? The encounter between the body of the viewer and the body of the artwork. A fascination with an image that is painterly, cinematic, epic and intimate. The horses are never fully revealed but I seem to get to know them. There is a sense of waiting and potential as the hoof paws at the ground (the floor of the treadmill). The eye fills the screen, returning my look. There is always a question in the act of looking at animals.

Writing and editing several weeks later, I plunge into this attempt to describe the work, revisiting my first impressions and finding a curious link. This installation, The Four Riders, and the very different work of Patrick Keiller's film Robinson in Ruins (2010), were the two pieces I experienced first at What Matters and for me they have become strongly connected. Coming across them both in close proximity in terms of time and space was of course due to the way they were brought together by the creative curation of Lucy Cash and Becky Edmunds. Later I felt as if I saw both on the first evening but now I don't think so. I also thought I'd written several pages of notes about The Four Riders but I hadn't at all. I misremembered, picturing them alongside the notes on Robinson in Ruins in my notebook. The connection I find between the two works is in a particular kind of rigor, a commitment to movement on screen and a patience with the passage of time, even though their form of presentation and duration is completely different. Curiously, both have little or no evidence of actual human figures - the four riders don't ever appear and in Keiller's film it feels like a long way in before we see any people in the long shots of the streets or landscapes. The humans that do feature seem to have the same degree of importance as any other figure in the picture, such as a road sign, or a bee, or a car. Yet I find there is a trace of the human body in the experience of watching each of the works. In both of these pieces something in the approach to the use of camera, the edit and the care for the subject in the frame tells us that we know we are seeing because of the eye of the camera and with the reminder that someone was there behind that camera.

The screening of Patrick Keiller's film, the third in his Robinson series, took place the evening before the actual Private View and the Roof Studio on the top floor became the 
temporary cinema and performance space for the weekend. Before the opening of the other installed and durational works throughout the building, this first evening offered a single screen feature-length film, a chance to tune into the festival in advance, to get a taste of what mattered to the curators in terms of art and artists. Time was set aside for the particular vision of one artist to unfold and begin our thoughts and conversations around the field of practices to be found throughout the coming days. The curators called this a Pre-festival screening and this allowed an artwork to provide an introduction, a kind of foreword, laying out some ideas and concerns as meditations, as provocations.

Robinson in Ruins touches on four kinds of ruins: architectural, personal, ecological and economic. Keiller turns again to the landscape as "an appropriate context in which to examine the tensions between dwelling and displacement." 2 The film works on me as a kind of visual essay, made up of facts narrated through the "wandering" story of a journey pieced together through the abandoned documentation of an invented research projectwhich it so happens resembles the very research project being undertaken by the film's director. The fictional character of the melancholy academic Robinson has a wry humor as he persists in his investigations into social and physical infrastructures and their histories. Keiller uses fictional pretexts to deliver a measured, descriptive style in a survey of selected examples-from industry, sites of scientific interest, defense installations, historical sites and architectural curiosities. The effect is a mass of information, a dense narrative and a sense of the tip-of-the-iceberg in terms of engrossing facts and references that alternately make me think "I know that" or "I can't believe I didn't know that."

Scale seems to matter here. Attention is drawn to the 1940s mapping of the UK's oil pipeline networks and the British Council's mapping of oil fields abroad in relation to potential areas of war. Reference is made to the price of land, the price of wheat, the price of oil. The narration constantly connects back to histories of colonialism, and the politics of land and property ownership in Britain, specifically here, England. Stirring accounts of historical uprisings, including Peterloo in 1819 and the protests against enclosures of common ground at Otmoor in the 1830s, are outlined. But as Keiller himself points out in the publication accompanying the recent The Robinson Institute exhibition at Tate Britain (2012), The Possibility of Life's Survival on the Planet, quoting Robert Wade: "Some caution is in order. There is a recurrent cycle of debate in the wake of financial crises, as an initial outpouring of radical proposals gives way to incremental muddling through, followed by resumption of normal business."

The hum of an industrial estate. A car pulling out of a large edge-of-town supermarket. A yellow lichen is captured, over several years, growing around the honeycomb pattern on the surface of the large green reflective road sign. It is identified precisely as Xanthoria Parietina and you would only notice it if you looked closely and returned later to look again (and again), carefully and closely.

The film's narrator tells us how Robinson "inclined to biophilia, the love of life and living systems." There are long takes of the eye marking on the wing of a butterfly appearing and disappearing as the insect makes its way around the last flowers on a prickly teasel. A white foxglove performs a slow dance, swaying in and out of frame. The screen is often full of extended moments with little apparent action but the image will always reveal a movement within the stillness - of trees and grass in the breeze or the progress of huge farm machinery moving patiently across a field. 


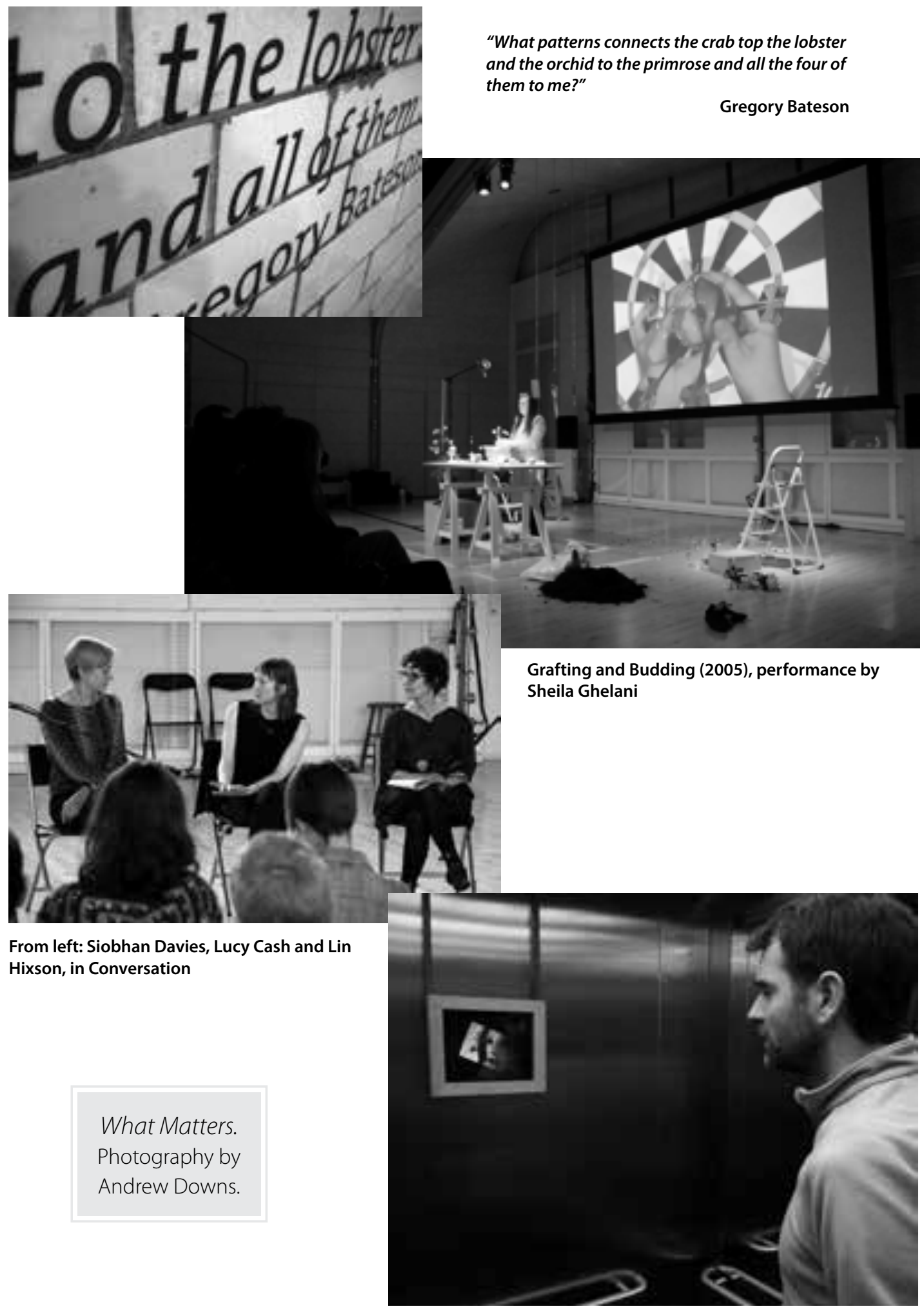

A Self Portrait (2009) 3 mins 39 secs, Dickie Beau 


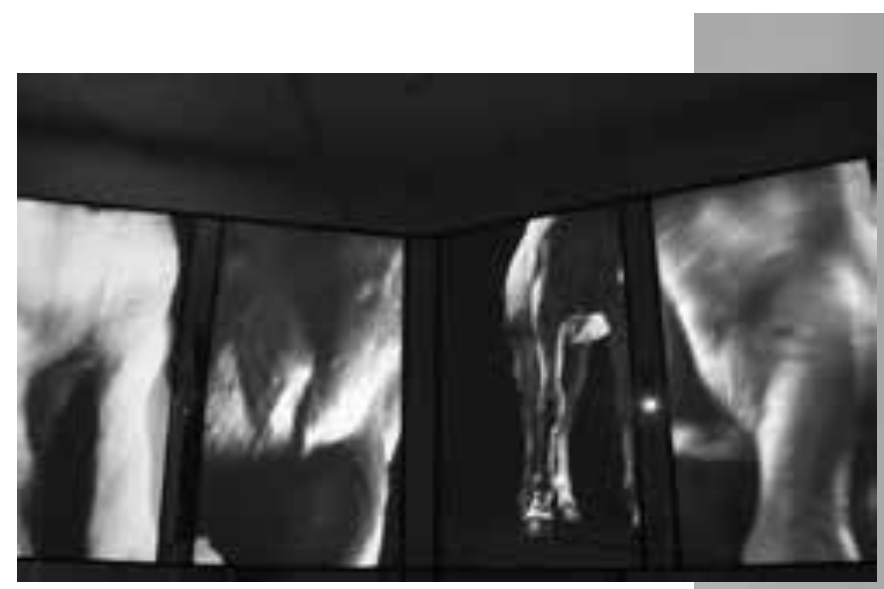

Four Riders (2010), 7 mins 52 secs, Hertog and Nadler

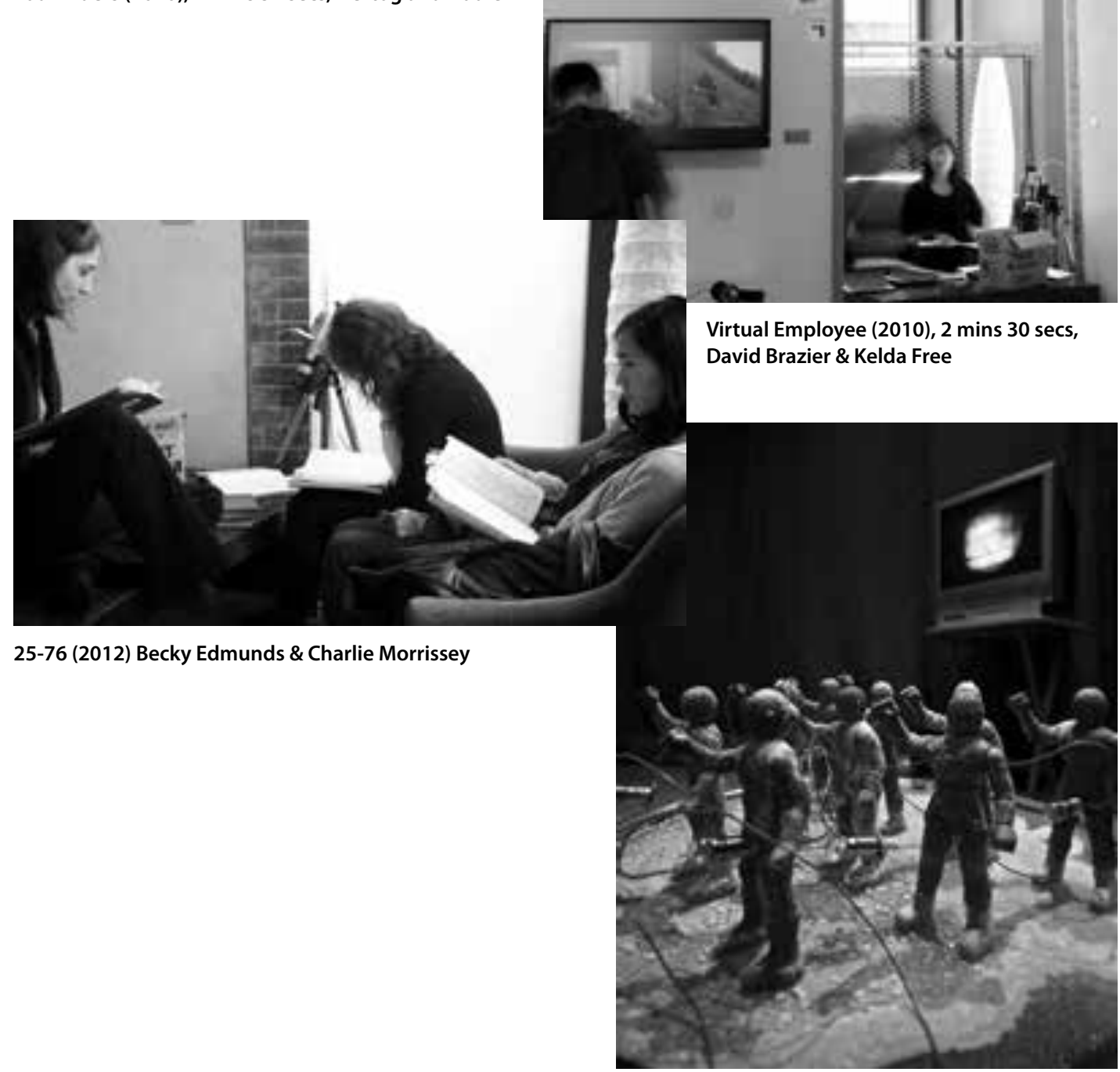

Medearoom (2012) performance/installation, Julia Bardsley with Jacob Alves 
The moon is moving away from the Earth at $3.8 \mathrm{~cm}$ per year, and so has not always appeared to be the same size as the Sun. When it was closer, tidal movements would have been more extreme, and the conditions for life's emergence perhaps even more favourable. ${ }^{4}$

The movement and measurement of time returns on different scales, whether biblical, geological, industrial or agricultural. The film is full of history lessons and reminders of instances of short-term thinking - not least in terms of modern economics and the unplanned ways which familiar environments can become altered. There are no horses here, as far as I can remember, but there are cows and sheep grazing - on common ground, such as the former US Air Force Base at Greenham Common.

"In 1993, the Atomic Weapons Establishment became a 'Government Owned, Contractor Operated' or Go-Co institution [...] The government later sold its BNFL share to the Jacobs Engineering Group, a US company, so that the UK's nuclear weapons production was in two-thirds US ownership."

Quite often something is shown to be covered up, changed, forgotten, abandoned or grown over, left to time and the elements. An image of dilapidation often uncovers the less than shiny aspects of a contemporary capitalist culture. It starts to feel that the wanderer doesn't have to search too hard to find it. It's all around us. But we know he spent some real time, noticing what is there, by the side of the road, and methodically turned the camera towards it, often repeatedly, often over several years.

The film Robinson in Ruins and the video installation The Four Riders both have a sense of ghosts about them. I return again to some of the voices that come to mind as I think about film technology and its fast-moving history of capturing movement that soon followed the first examples of still photography and its early love of portrait and landscape. I think of the voice of the photographer and also the ghostly voice of a fictionalized version of a wild young American cowboy, telling stories of traveling on horseback, at an earlier moment some time ago, in a history of Western expansion and progress:

\author{
MMMMMMMM mm thinking \\ moving across the world on horses \\ body split at the edge of their necks \\ neck sweat eating at my jeans \\ moving across the world on horses \\ so if I had a newsman's brain l'd say \\ well some morals are physical \\ must be clear and open \\ like a diagram of watch or star \\ one must eliminate much \\ that is one turns when the bullet leaves you \\ walk off see none of the thrashing [...]
}

Michael Ondaatje ${ }^{6}$ 


\section{Notes}

1. Ondaatje, Collected Works, 5.

2. Keiller, The Possibility, 12.

3. Ibid. 12.

4. Ibid. 47.

5. Ibid. 38.

6. Ondaatje, Collected Works, 11.

\section{References}

Keiller, Patrick. The Possibility of Life's Survival on the Planet. London: Tate Publishing, 2012.

Ondaatje, Michael. The Collected Works of Billy the Kid. Middlesex, England: Penguin, 1984.

\section{Media}

Robinson in Ruins (2010). Dir. Patrick Keiller. Film. www.tate.org.uk/whats-on/tate-britain/film/robinson-ruins The Four Riders (2010). Dir. Chaja Hertog and Nir Nadler. Video installation. www.hertognadler.com The Robinson Institute. Patick Keiller. 2012. Exhibition. www.tate.org.uk/whats-on/tate-britain/exhibition/ patrick-keiller-robinson-institute 


\section{REVIEW ESSAY}

\section{Beach Party Animal}

Marisa Zanotti

Beach Party Animal (2011). Dir. Liz Aggiss and Joe Murray. Music by Alan Boorman. UK: Commissioned by South East Dance, 20 minutes. Film.

In 2008 Liz Aggiss directed a film entitled Diva, which suggested that her diva persona was being laid to rest in funereal scenes. Two years later, her return to the screen couldn't have been more different from the heightened realities of the screenworks that characterized her work in the early 2000s. Further, from the woman who once said "every dancefilm has a shorter dancefilm inside it screaming to get out," came a 20-minute screenwork, a daring proposition indeed.

In Beach Party Animal, LizAggiss once again collaborates with Joe Murray in a joint directorial role and brings aspects of her recent performance practice to her filmmaking in what she calls a "choreomentary." This film could be also sited in a tradition of poetic subjective documentary where, as Chantal Akerman maintains, the border between fiction and truth is blurred. ${ }^{2}$ Aggiss calls her performers "guerilla performers" and she has explored guerilla tactics in her recent live practice. In filmmaking, guerilla tactics have a history of being associated with low budget work ${ }^{3}$ and can be used to enable a film to be made outside of a studio system, to affect performances in locations and perhaps of locations.

Brighton, the location for this film, is traditionally a place for escape; in the summer, waves of Londoners tumble through the barriers of Brighton station before finally washing up on the seafront. The seafront seems haunted by ghosts of films gone past, from the expressionist 1930s gangsterism of Brighton Rock, ${ }^{4}$ to Quadrophenia's love song, to Mod culture $^{5}$ and Neil Jordan's Mona Lisa, ${ }^{6}$ where on Brighton Pier Bob Hoskins and Cathy Tyson play out a remarkable scene of emotional decimation as the pier carouses around them.

In Beach Party Animal, Aggiss and Murray consider English seafront culture in scenes that are not epic or perhaps even filmic but most definitely screenic; the Brighton seafront becomes a kind of slightly trashy holodeck. This is the seafront as the set for whatever kind of screen moment you want to star in: for "rollerdisco guy" it will always be LA in the 1980s; "a bunch of lads" perform a kind of "Britain's Beachfront Shame" scene of "on the lash" for camera; "virtuosic yoga girl" pretzels herself impossibly; and for the crowds on the beach "fat man in a thong getting covered with ice-cream" is just another tourist, albeit beamed in from the Benny Hill' shows of the 1970s.

The work opens with Parry's Jerusalem; the suffragette's hymn has often functioned as a signifier of Englishness. ${ }^{8}$ Jes Butterworth used it to great effect in the 2009 play of the same name that looks at the English underclass in rural England. Jerusalem is often associated with pastorale; it's an odd choice for a seaside movie, but here Aggiss and Murray play 

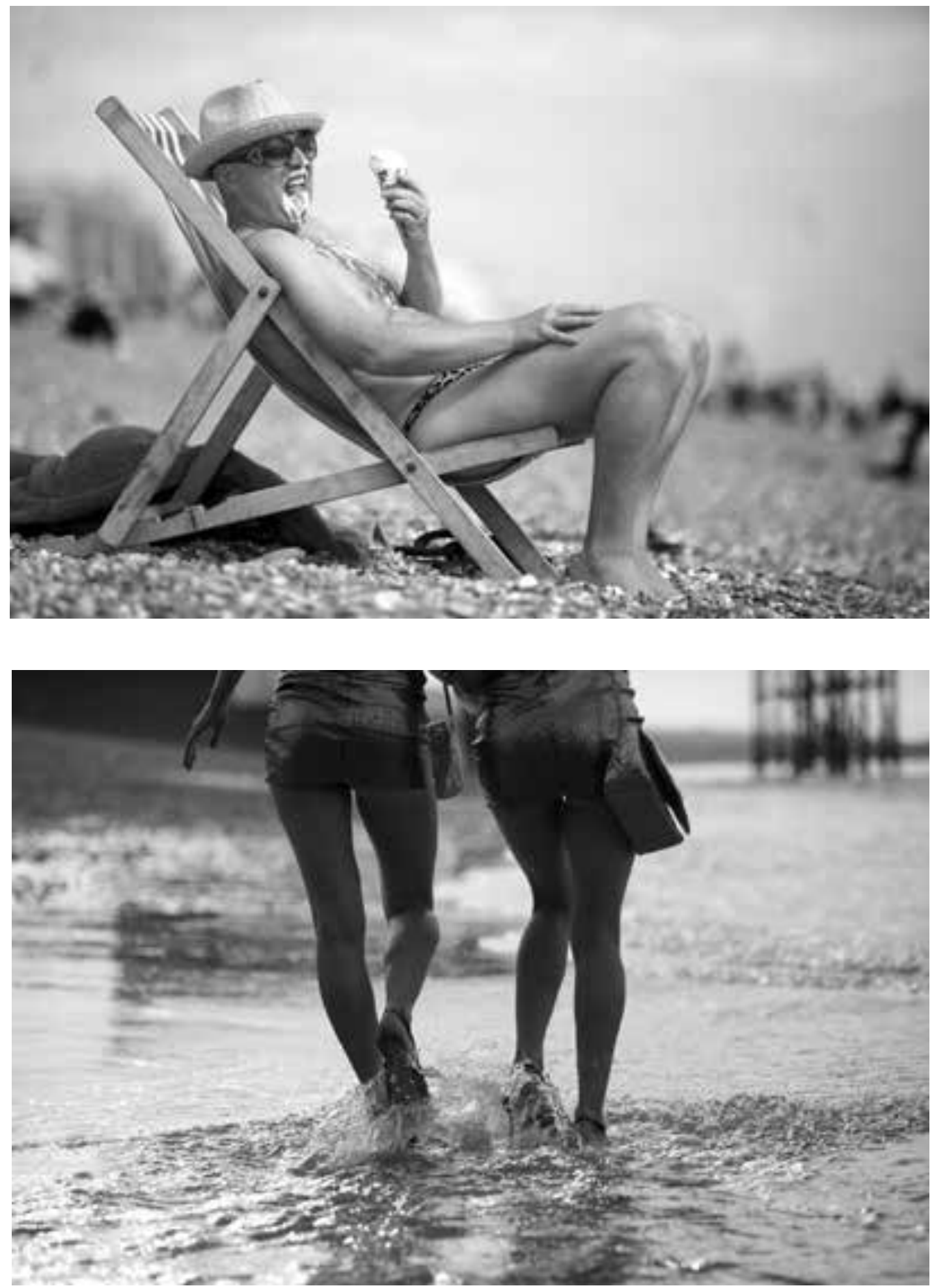

Beach Party Animal (2011). Dir. Liz Aggiss and Joe Murray. UK: Commissioned by South East Dance. Photography by Matthew Andrews. 
on its epic grandeur with a full orchestral choral rendition, contrasted by their depiction of the small activities where people create their heaven. Whilst the sound score frames vignettes as comical, some scenarios seem more barbed: the young mother, so caught up in her own dance under headphones that she is oblivious to the cries of her child, or the nudist in the sea, railing impotently against some imaginary foe. There's a loneliness to these figures who dance like no one's watching in flat brilliant light. Weirdly for Brighton seafront, we don't see a single gay couple; thinking about it, however, it does seem sometimes that heterosexuals never really go beyond the spaces in-between two piers that are map points of reference for Beach Party Animal, and crammed into these spaces, a day in Brighton is pressed out, gathering intensity as the day lengthens. Choices about color and light are key in Aggiss and Murray's language: we see the beach as an early morning lunar landscape, color saturated shots of the nighttime beach, a gold bomber jacket glitters, an intense purple towel against green moss. There is a hyperreality to the grade, particularly in the later shots, that speaks to the hallucinogenic qualities of light.

As the film progresses, the spatial and corporeal grammar of the work finally produces a liminal space, and it is in here that we find the strangest and perhaps most powerful scenes in the film. At the centre of a carousel of dreamy hobby horses there is a man who, like an octopus, seems to survey us with one blinking eye. Later, a mollusk turns into a little girl. At dusk, the air is thick with barbecue smoke. Here is where the film truly begins to create its own image language, through a kind of reverse heat haze that produces, in the neon shimmer mirages of men pissing against the sea wall, the tinkling sound of yacht masts. Most poignantly, two silvery, sheathed, drunk mermaids-one pole dancing in a paddling pool, the other collapsed, arse to the air on the tiles of a Victorian bandstand. This is an extraordinary vision, both beautiful in golden intensity and quite grotesque. There's a melancholy to these good-time girls and we might feel that it is not because they are so extraordinarily drunk, but rather their sadness is that they can't drink anymore; the approaching dawn means the end of a good night and a very good time. What is particularly sweet about this vignette is that there is no hint of judgment of these women and their drinking, which is refreshing in a culture that just loves hysteria about women and drink. What we are seeing is an equivalent of the celebratory male buddy drinking scene as they stagger home arm in arm.

Mitch Rose has written that landscape is "a marker - the material means by which culture appears in time and space." For Aggiss and Murray this holds true: these "material means" are gestures and actions arising from the landscape. Thus movement both acts as a frame for the physical landscape and then by virtue of directorial choices movement becomes the landscape. The behaviors that mark this culture are bodily behaviors; alongside the actions described previously, we see a lot of running and strolling, but sometimes people aren't going anywhere and bodies recline in rest, in sleep, or in surrender to sun or alcohol. There's a unique quality to each image of repose. There's a body that seems to have been turned to a camouflage setting to create the same pale colors as the stones underneath it and of course skin that's been roasted pink. This is an edit which speaks about land and body merging in the changing rhythms of a day to night cycle, and the choice of a 20-minute duration allows for Aggiss and Murray to take time with images when they need it.

By tactically introducing performers to the landscape, Aggiss and Murray's strategy is a gentle disruption, less of an outright insurrection and more a celebration of acceptance 
of otherness. They are interested not in staging dance on the seafront but rather in the performance of the seafront as a gestural site. This a language that renders the seafront as a corporeality and in doing so invites us to consider ideas about landscape, location and performance, culture and behavior.

\section{Notes}

1. Screendance minutes are calculated differently, so Aggiss and Murray's film in screendance terms could be thought of as four hours long.

2. As Akerman said, "Anyway, I don't really believe in the difference between documentary and fiction ("An interview with Chantal Akerman").

3. Although of course the marks of guerilla tactics are often used to add guerilla values to commodified moving image work — for example in advertising or music video_or to delineate a character in a narrative as holding these values.

4. The film was remade in 2010 by Rowan Joffe in a kind of weird mash-up of Quadrophenia where the action of the 1930 s is moved to the Mod era.

5. See Quadrophenia.

6. See Mona Lisa.

7. A mystifyingly (to me) popular English television comedian.

8. Recently, David Cameron, with the ignorance that only a public school education can buy, attempted to claim it as an English sporting anthem; this is excellent news for the rest of us given Blake's sentiments that heaven can be found here on earth outside of church, state and the institutions of government.

9. Rose, "Dreams of presence," n.p.

\section{References}

Dercon, Chris. "An interview with Chantal Akerman about too much and not enough cinema." Contour (2005). http://www.contour2005.be/UK/ca.htm.

Rose, Mitch. "Dreams of presence: a theory of culture and landscape." University of Hull. Book proposal. http:// www.lostgeographer.com/images/pdfs/Dreams_of_presence.pdf

\section{Media}

Beach Party Animal (2011). Dir. Liz Aggiss and Joe Murray. 20:00 min. UK: Commissioned by South East Dance. Film. Brighton Rock (1947). Dir. John Boulting. Prod. Roy Boulting. 92:00 min. UK: Charter Films. Film. Mona Lisa (1986). Dir. Neil Jordan. Prod. Steven Wooley. 104:00 min. UK: Handmade Films. Film. Quadrophenia (1979). Dir. Franc Roddam. Prod. Roy Baird. 117:00 min. UK: The Who Films. Film. 


\title{
REVIEW ESSAY
}

\section{Dancing Bodies, Moving Images: An Exhibition of Installed Works at Summer Dancing, Coventry, UK, June 2012}

\author{
Curators: Andrea Barzey and Polly Hudson
}

7

his review offers an overview of the screendance event Dancing Bodies, Moving Images

(Coventry, 2012) and discusses the major themes that emerged during the curatorial process and from audience responses. It is written from the perspective of the curators, and includes material from interviews and panel discussion with some of the artists whose work was shown. The event was curated in response to an invitation by Decoda, an independent dance organization based in Coventry, UK, who were interested in a Dance Film event as part of the biennial international festival of dance, Summer Dancing.'

We decided to send out an open call for submissions with a remit that aligns specifically with the philosophy of the festival, as well as with our own curatorial interests surrounding dance and the moving image, and somatic practice. We asked questions such as:

- How is the body integrated in dance on screen?

-What are the differences/similarities between choreography for live performance and choreography for camera?

- How can we retain embodiment and somatic sensibilities when creating the artefact that is dance and the moving image?

The ten pieces chosen were gathered from the open call and by invitation. The result was an exhibition of installed works, culminating in a discussion with a number of the artists whose work was being presented, and with ourselves, the curatorial team, joined by Katye Coe, director of Decoda.

There was a very clear vision from us, the curators, for how these works should be presented: installed in a gallery setting that would enable an encompassing kinaesthetic experience for an audience and also support the ethos of the works. Our aim was to create an immersive environment that would allow for a multi-sensory experience and encourage dialogue. The setup allowed the viewer to make choices about how long to witness work, from what angle or position in the room, and to be physically comfortable since we provided cushions, blankets, and a welcoming environment. This seemed to work well, with many audience members staying for long periods of time, sitting or lying down, or moving to see the works from different angles and viewpoints.

It became clear fairly early in the curatorial process that we had selected pieces that fell into two distinct strands, and that these demonstrated differing requirements for how 


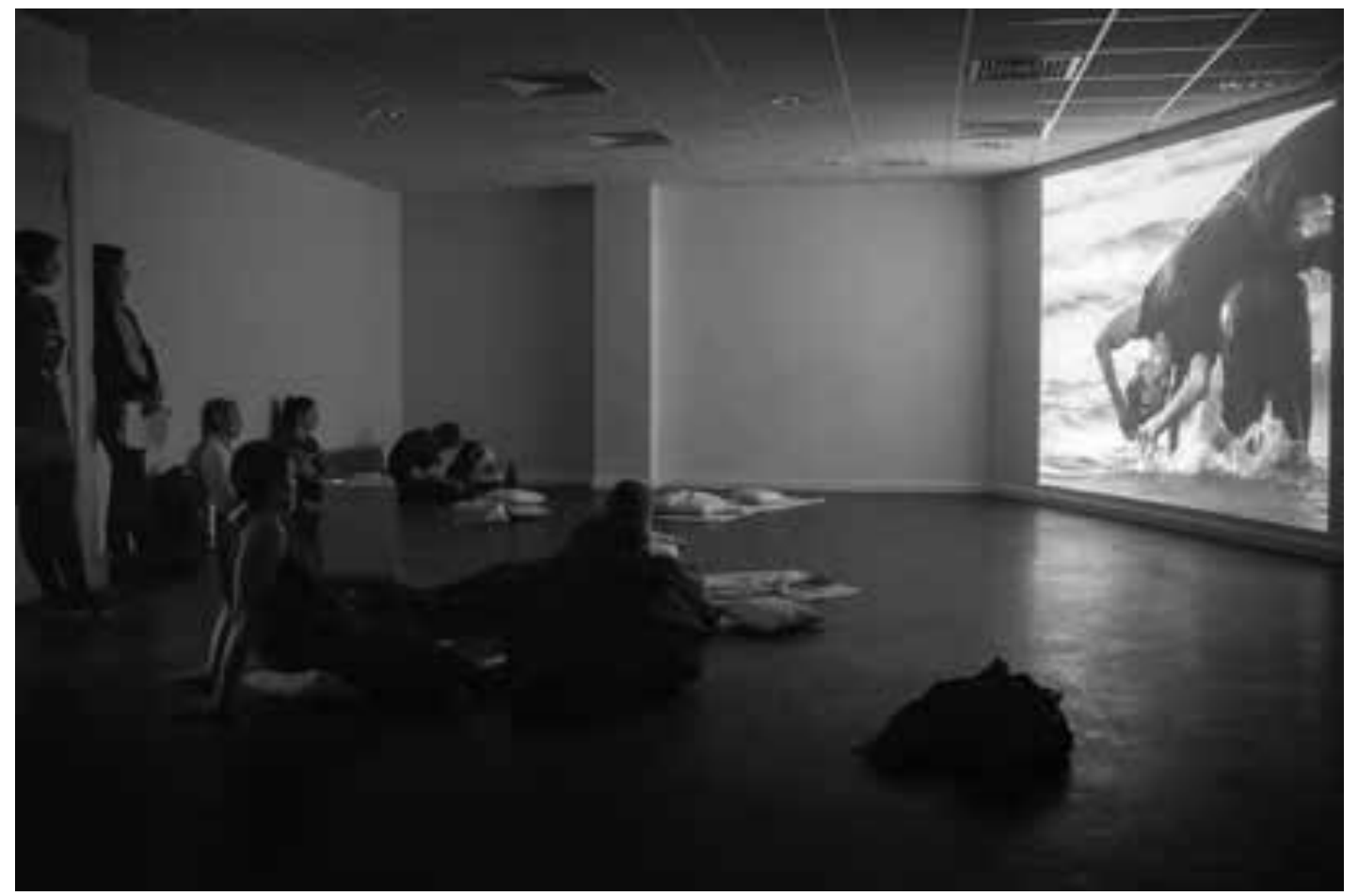

Dancing Bodies. Photograph by Christian Kipp.

the work was to be presented. Some of these differences were also borne out by particular artists' requests. For example, Margerita Zafrilla requested that her piece The Collection (2012) be shown as a small-screen installation as this was her original intention for the work. The final decision for the overall design of the exhibition was therefore to have some of the works projected onto a large screen with surround-sound, and to place a small screen with headphones in the same gallery, but in another part of the space. In the course of the exhibition this spatial arrangement facilitated a somewhat unintended dialogic relationship between the works as some viewers were witnessing the large-screen works with the headphone sound of the small screen.

The large screen featured works by Mattias Malmivaara (Finland), Tara Rutter (UK), Johan Planefeldt (Sweden), Wilkie Branson (UK), Rachel Sweeney (Ireland). The small screen showed works by Rahel Vonmoos (Switzerland/UK), Susan Sentler (USA/UK), Dolphin Dance Project (USA), Karen De Silva (UK), Margerita Zafrilla (Spain). ${ }^{2}$

A scheduled panel discussion took place once the exhibition had concluded, led by both curators and open to all film artists and Decoda participants, where a number of key issues were raised by artists, audiences and the curators. Curator Polly Hudson noted:

...something that came up for us in the curating of these works is that there are two overriding themes happening at the moment in dance film-one type of film is being made in nature, particularly drawn to water, snow, rocks, woodland, and we were wondering about why that is...the other takes place in interior spaces with "no site" that focuses on the body in a different way. ${ }^{3}$ 


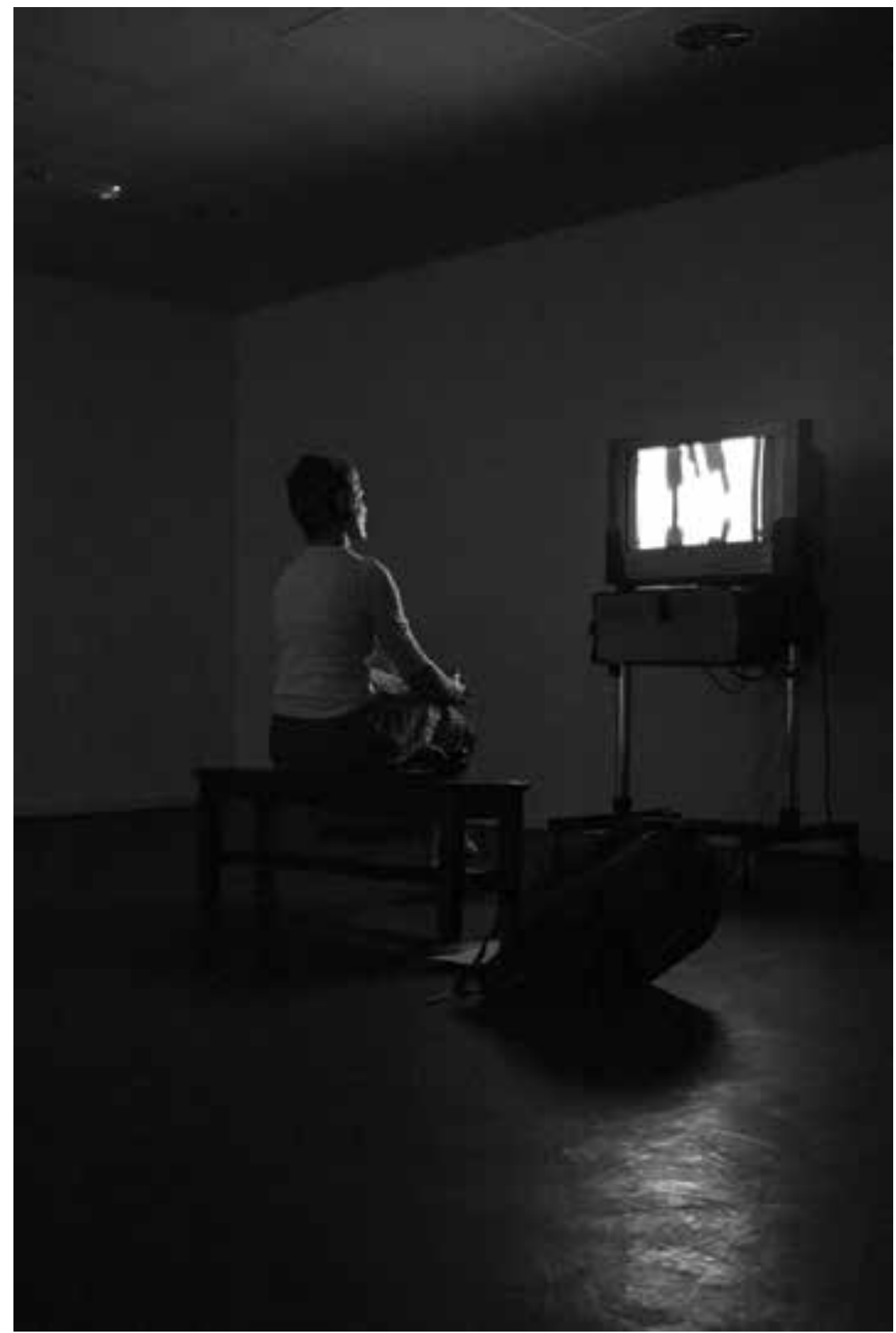

Dancing Bodies. Photograph by Christian Kipp. 
Artist Rachel Sweeney responded, with regards to her work Driftlines, flooded memories (2011):

... this piece is the very beginning of an experiment. I was trying to think of it as three stages: one is the receptive site that is an immersive environment and involved with itself, which raises the question of navigation, crossing terrain and the translation of body across site, and then there is the relational context which for me I am starting to question. The question is how does the camera force these kinds of communication processes out? Having deliberately not known where the camera is faced (and I am trying to not use the term "framed")...I suppose there is something about perspective, fluidity and immersion that relates to that somatic quality really clearly. You can then see if the camera uses that somatic quality or whether the camera cheats and changes it.

There is a delicacy about this kind of choice of setting for dance film, and in the images and works that emerge. It becomes an immersion of the body in landscape. Besides Rachel Sweeney, artist Tara Rutter also pursued an investigation of the site, and her movement practice includes an ongoing commitment to work within the landscape as demonstrated in Meeting Cliff Tops (2011).

There were other works concerned with landscape, but they slightly differ from those by Rutter and Sweeney, such as Mattias Malmivaara's Release (2012). A female dancer is moving in snow in the Finnish mountains in a way that allows the viewer to see the landscape as backdrop as well as the body within it, leading to a rich cinematography. It depicts the somatic body within site, presenting work with movement material that could however be translated from one site to another, a subtly alternative view from Rutter and Sweeney's work in which the site is integral to both movement and body.

Wilkie Branson's piece Big Wide World (2011) is different again. What is notable about this work is the impressive, sophisticated production quality; the use of steady, long follow shots; the highly honed framing; and the clarity that is brought to the work by the artist's understanding of his media. Branson also demonstrates an eye for colour, and an empathetic approach to landscape and to the moving body within it.

A piece that sparked some interesting discussions around sexuality and the portrayal of the female body in dance film was Johan Planefeldt's In Touch (2012). Filmed at the In Touch Journey festival in Goa, this work could be deemed controversial, as was noted by a number of audience members, with regards to the representation of gender on screen, as it depicts semi-naked women on beaches and in water alongside men, who are generally shown as more active and in some instances are fully clothed; drawing on sexual imagery akin to soft porn, the work is reminiscent of the exploitation of the female body on screen. Conversely, this depiction could be read as the sensuality of Somatics, and in an interview with Hudson in September 2012, both Planefeldt and the director of the In Touch Journey festival, Volker Eschmann, who commissioned the piece, responded to questions around these issues.

Polly Hudson: "The work has brought up strong feelings for some people in terms of its portrayal of gender. I'm interested to know what your thoughts are about that?"

Volker Eschmann: "I wanted, originally, a film about moving from the centre, but time constraint made that not possible. So I said to Johan, who's an experienced filmmaker, and is also newly involved in the work, just to capture what was going on at the festival." 
Johan Planefeldt: "It's an interesting topic —I've been facing it a lot in my movies. I'm happy that these discussions come up. Re. the gender perspective-I of course have a male gaze, I wasn't consciously trying to remove it. On the other hand, most of the participants were women, in bikinis, in a state of bliss; when you work like this people become more photogenic - in a state of love and presentness. Beauty from the heart. And maybe people confuse that with the kind of beauty that is in H\&M adverts for example, famous for being sexist, having scantily clad women in their winter publicity." [We break off to discuss this kind of advertising campaign and the images contained within it.] "There are questions about this already in the Contact Improvisation community; the most interesting part is that this film does not say at any point that it is Cl."

Polly Hudson: "What would you call it?"

Johan Planefeldt: "A documentation of the In Touch Journey: trying to capture the essence of the festival. A cinematic ritual. This is a running theme, the main focus of my work."

Polly Hudson: "There is however a juxtaposition between the semi-clad people and the clothed men dancing."

Johan Planefeldt: "That's also one of the main criticisms - of the passive woman and the active man."

Polly Hudson: "What do you feel about that?"

Johan Planefeldt: "It's a bit of a shame, but that's what happened. I wasn't even planning on making this movie — I shot some stuff_l made something out of it_-documenting some stuff... And in all my movies I work with peak experiences."

Volker Eschmann: "The idea is that the film has a similar effect to the ritual itself." [Eschmann refers to the ritualistic movement practises at the In Touch festival] "By being in a meditative state whilst watching this video-people said [on Vimeo] that it changed their day."

Despite its possible challenging readings, the curators felt that the piece had a place within this collection of works, because of the cinematic depiction of Contact Improv that has been a key underpinning practice in Summer Dancing. It was also included because of its representation of Somatics in motion that gives the viewer an opportunity for kinaesthetic empathy, as illuminated by Planefeldt and Eschmann's comments.

The works on the small screen in the gallery had slightly different foci and sensibilities as far as landscape and setting were concerned. Most were set in interior locations, with the exception of Karen De Silva's Abigail Hurly's 7.47 (2010). Reflecting on locations for dance film, De Silva echoed the curators' earlier observations:

... I always work in site because I work with lived experience and lived imagination so the place has to be real for me... but I really see the increasing engagement of working with nature and I am wondering if it has something to do with the emergence of somatic practices...there seem to be various strands of working with the body in nature, where we see the body impacting on nature, the body being impacted on by nature, and the sensuality of the experience of the body in nature.

Susan Sentler, whose piece Exposed (2012) is located in a dance studio, said in relation to her own decisions:

...the site needed to be ambiguous and an open enough canvas so that the viewer could get a sense of interior, which could have been that of the protagonist 
or from a past life, like a canvas... Film lends itself to time/images being sliced and cut together and they can exist together.

Rahel Vonmoos's piece but - at least (2010-2012) appears to combine both documentary and dance film, which sparked an interesting debate in the curatorial team during the selection process and was highlighted by the curator Andrea Barzey during the discussion:

What came up for Polly and I, with reference to teaching dance film to undergrads, is referring to dance and the moving image as a separate entity to documentary. Rahel's piece blew this theory out of the water... there is an overlap in the film that is really interesting.

In response to Barzey's comment, Vonmoos explained her process, pointing out that she began recording a video diary that she kept over three years whilst working on a piece that used projections, therefore gathering many video images or spaces:

That's all I had so I re-filmed things and re-projected it, using the projections to make textures and other sounds... using sounds from another space, another time... I was really interested in the rehearsal videos. I really enjoy watching rehearsal videos, but don't enjoy watching performance videos of myself because it has this heightened "thing," a form. When there is a rehearsal there is just nothing. There's just me and I am putting on the camera... nothing becomes something, because that's all I have to make something... Blending in is very much about how my life is... I am trying to layer and then scrape away. You just see the body and I am interested in just this physicality of the body and in the emotional impact.

Vonmoos's work is a different type of film, which does not sit either within dance film or documentary and which could perhaps be classified as Somatic Documentary. Katye Coe, director of Decoda, suggested that when watching Vonmoos's film, she can easily identify with the piece as she understands "herself, alone in the studio, as a female, with objects." Some other members of the audience felt this was due to the rawness and vulnerability that Vonmoos exposes of herself and which is different to works which have high technical production values and polished choreographies, potentially creating a barrier between the work and its viewer.

Hudson noted that: "In a lot of other cinematic arenas, low production values would be unacceptable because the work is not 'high tech' enough, whereas such work can, conversely, provide a kinaesthetic and empathetic experience."

De Silva argued that Vonmoos's film is still highly technical given the projections, editing and lighting that were used to build up the layers. Vonmoos used these elements as a tool with which to choreograph the piece, as in "traditional dance film."

As ever, when engaging in a creative process, unexpected results emerged in the process of curating this exhibition. Sometimes a conceptual point of departure is just that: a place to begin. New ideas arose during the event, surprising both curators and audiences. The notion of Somatic Documentary was proposed, and perhaps this is a new development in dance filmmaking and offers something different to the field of screendance.

The individual works did, however, answer some of the questions posed by the curators, retaining somatic sensibilities on screen, underlining the importance of a deep 
understanding of the body in motion when making such works, as well as the benefit of a commitment to investigation. As a collection of works, they posed new questions about the choices artists make about settings and working with site, which became the overriding topic of the show, and the ensuing discussions.

\section{Notes}

1. The Artistic Director for Decoda is Katye Coe. Decoda is based in Coventry, UK, and is the organization that has grown from the Summer Dancing festivals whose collaborating host partner is Coventry University. See http:// www.decoda-uk.org/.

2. Many of the works in Dancing Bodies, Moving Images can be viewed online via the Decoda website, at http:// www.decoda-uk.org/summer-dancing/dancing-bodies-moving-images

3. This and the following responses were part of an open conversation between curators Andrea Barzey and Polly Hudson and artists featured in the screendance installation, Summer Dancing, $28^{\text {th }}$ June 2012, UK.

\section{Media}

Abigail Hurly's 7.47 (2010). Dir. Karen De Silva. UK. 5:30 min., video, color/sound.

Big Wide World (2012). Dir. Wilkie Branson. UK. 3:57 min., 16mm film, color/sound.

but -at least (2010-2012). Dir. Rahel Vonmoos. UK. 10:08 min., video, color/sound.

The Collection (2012). Dir. Margerita Zafrilla. UK. 3:28 min., video, color/sound.

Driftlines, flooded memories (2011). Dir. Rachel Sweeney. Ireland. 4:07 min., 16mm film, color/sound.

Exposed (2012). Dir. Susan Sentler. UK. 9:01 min., video, color/sound.

In Touch (2012). Dir. Johan Planefeldt. Sweden. 11:48 min., 16mm film, color/sound.

Meeting Cliff Tops (2011). Dir. Tara Rutter. UK. 10:00 min., video, color/sound.

Release (2012). Dir. Mattias Malmivaara. Finland. 7:39 min., $16 \mathrm{~mm}$ film, color/sound. 


\section{REVIEW ESSAY}

\section{Screendance: Yes, And...}

Karen Pearlman

Rosenberg, Douglas. Screendance: Inscribing the Ephemeral Image. Oxford University Press. 232 pp. $\$ 29.95$.

"Yes, and..." is a warm up game played in improvisation classes. In it, one is required to say "yes" to every offer and build from it." This game is not commonly played in academic circles or as part of the development of theory mostly because it is, by definition, uncritical, but also, in part, because academia is not that kind of game. It is necessary to block other arguments in order to win promotion or job security, critical authority or authorization as a spokesperson. I have never played "yes, and" with Douglas Rosenberg though (full disclosure) I do know him and have gone a few rounds of "yes, but" with him over the years. So I would like to propose a brief game of "yes, and" herein. Yes, Rosenberg has written a richly researched and considered book. Yes, he has explored a vein of historical and theoretical contextualization of screendance that urgently needed such attention. Yes. And there are other veins that also need to be explored before we can come to a comprehensive theoretical understanding of screendance. As long as Rosenberg's book is understood as one of a number of theoretical streams in this "polyvocal" discourse, it is a useful, energetic and informative call to action.

The 2006 "Screendance, State of the Art" conference convened by Douglas Rosenberg engaged in a robust discussion of names and sub-genres of screendance, which produced "a diagram of 3 overlapping disciplines: dance, cinema, and visual art. Unlike the typical result of these models, it was determined that the 'ideal' screendance production was not necessarily a mix of all 3. Rather, each approach and each overlap provided a way of comprehending a given work."2 Rosenberg, who is a professor of art and who is trained in performance art and video art, champions this polyvocality in the consideration of screendance, but also seems, at some turns, to curtail it. His particular voice in the mix is one that speaks from the perspective of visual art discourses. He brings a visual art theory perspective to the tasks of: distinguishing between "media as a method for archiving and ... a site for art making" in Chapter One; choosing which "dancing bodies on screen" to contextualize within "significant esthetic and cultural movements" (9) in the art world in Chapter Two; and the choice of metaphor for describing his understanding of mediated dance in Chapter Five. It is also the underlying frame of reference for the general project of the book of locating screendance "within the larger frame of the visual arts" (13). The only issue to be taken with this perspective is when claims are made to "signify the richness and diversity of the history and practice of screendance" (13), to seek a hybrid theory arising from all three forms (cinema, dance and visual art). Any such claims are overwhelmed in Screendance: 
Inscribing the Ephemeral Image by Rosenberg's focus on visual art as the frame through which he will theorize the work.

Given that frame, there are many aspects of Rosenberg's argument in Screendance: Inscribing the Ephemeral Image to which one can simply say "yes," others to which it seems important to declare "no." Ultimately, though, it is possible to affirm and endorse the underlying project of the book: to "initiate a theory that defines screendance, to open screendance up to further theorization" (13), and at the same time to note some of the key areas requiring this further theoretical exploration so that the understanding of screendance by academics, curators, practitioners, and audiences can develop the connoisseurship that Rosenberg champions.

\section{"Yes"}

Yes, "organizers, presenters, institutions and the academy must necessarily be activists, informed and informing consumers and disseminators of cultural product" (152). This statement refers to one of the strongest chapters of the book, Chapter Seven: "Curating the Practice/the Practice of Curating," on which I have scribbled "Yes!" in the margins on page after page. Chapter Seven offers a clear, concise, relevant, and important understanding of curatorial practice and its role and responsibilities to screendance at this moment in history. Chapter Eight follows this up with an argument for connoisseurship, which Rosenberg proposes relies on activist curating, and both of these-active curating and connoisseurship-require coherent theoretical frameworks on which to build expertise, perspective, and creativity. The project of all the preceding chapters is to create that coherent theoretical framework, or at least to incite discussion of it. If Screendance: Inscribing the Ephemeral Image does nothing more than catalyze a much-needed revolution in curatorial practice to create connoisseurship-whether by agreement or by opposition to the theoretical framework it proposes - it will have had a seminal influence on the art form, its ongoing development and practice, and its context, culture and ideas.

Screendance: Inscribing the Ephemeral Image will, of course, do more than this. It will position Rosenberg as the "site" of theory that engaged practitioners will have to either consciously embrace or refute through their own practices and theories. Even, or perhaps especially, practitioners who don't read the book will be judged and affected by Rosenberg's declared and undeclared frames of reference. The book will be a catalyzing force for arguments for years to come, and alternative theories of screendance will have to position themselves in argument with Rosenberg's. Perhaps this is just what screendance makers and theorists need - an argument to give focus to counter arguments. As such, I salute this project. I pay all due respect to the tremendous effort, erudition and body of knowledge Rosenberg's book represents. And thus I begin my arguments with it.

Many of my arguments with Screendance: Inscribing the Ephemeral Image are the result of not sharing a frame of reference with Rosenberg-his is steeped in the discourse of visual art and mine is steeped in the discourses of film and experience of the embodied theory of dance. One consequence of this clash is a reaction to Rosenberg's specific vocabulary, which I have to translate into terms that I would use in order to recognize the gist of his arguments. Chapter Six, "Excavating Genres," is an excellent example. Here Rosenberg describes a series of considerations a curator or critic could apply to analysis of a work (160). 
These include consideration of: qualities of the work; contingencies that tether the work to the screen; "histories and theories that belong to the work in the process"; formal qualities of the rendering and the choreographic language; intent of the work; and content. While I have no major argument ${ }^{3}$ with this useful and coherent list of considerations, I struggle with Rosenberg's use of the term genre. Most of the things he calls "genres", e.g. movies, visual art, dance, dance for television, etc. (115), I would either call forms or apparatuses. I am much more comfortable, therefore, with the statement that "Screendance is a master category with numerous genres and sub-genres flowing from it" (117).

Similarly, following as I do cognitive film theory as articulated by David Bordwell, among others, my understanding is that a "narrative" is comprised of a series of events in a cause and effect chain. ${ }^{4}$ So most of what Rosenberg calls narrative I would call juxtaposition. These juxtapositions may provoke associations in the viewer's mind, but the associations described on pages 123-124 do not seem to be intended as a causal chain and therefore are not what I would call narratives.

For the most part these clashes of vocabulary can be overcome, with careful consideration of Rosenberg's intent, but not always.

\section{"No"}

As Rosenberg writes, "Critical discourse relies on language" (15). The rhetoric used when engaging in critical discourse is, therefore, significant. Screendance: Inscribing the Ephemeral Image is written with a recurring rhetorical device of using metaphor inside assertions. This use of metaphor diverts attention from assertions that cannot be substantiated, possibly making them poetic, but more likely simply making them inaccurate. Rosenberg makes liberal use of slippage into metaphor to ascribe psychology, even agency, to forms or objects that are not, in themselves sentient beings. Can screendance as a form "exhibit a desire" (152)? Curators, audiences, practitioners, and other sentient beings can desire and exhibit desires. Screendance, as a concept or a form, cannot. Rosenberg has a stated interest in positioning screendance inside the history and theory of visual art, and this rhetorical style may be common to visual art theory, but it obfuscates more than it reveals and excuses generalizations that would not otherwise be given credence. This slippage seems to occur most often when Rosenberg is tacitly passing judgment on an aesthetic or approach that falls outside of his own visual art driven interests. For example: "choreography tends to capitulate to the desires of cinema, to the desire to be narrative" (124). But cinema doesn't desire. Screendance makers desire. A desire to make use of narrative strategies (or even to make use of associative juxtapositions, which, as described above, Rosenberg conflates with narrative) is an informed choice, not a capitulation to a desire that is only metaphorically possessed by a material object. But the slippage of the possession of desire from sentient beings, making critically informed choices, to the metaphor that the material or concept of film itself "desires," allows Rosenberg to class people who work with narrative as capitulating, implying lack of informed creative judgment or artistic intent, without directly saying so, thus asserting something which cannot be substantiated but equally cannot be addressed in critical argument because its terms are slippery.

Similarly, film editors do not "hack," "jettison," or even "trash" recorded images. Ascribing such actions to the process of editing and shaping the flow of movement reads as an 
accusation of violence and abuse that would, if understood as literal actions, be a source of distress to those practicing the creative art of filmmaking.

Perhaps the most dangerous of these slippages can be found, among other places, at the end of Chapter Nine when Rosenberg states somewhat self-contradictorily that "the camera is a carnivore" (170). This slippage makes an inanimate object bestial. Given that Chapter Nine is a culminating chapter, outlining Rosenberg's proposed theoretical framework and the chapters that have contributed arguments to its structure, it is worth responding to in some detail, particularly as my margin notes, which are scrawled on almost every page of my dog-eared review copy, alternate more rapidly between dispute and affirmation here than perhaps any other chapter.

\section{"Yes, No, Yes, No"}

Yes, screendance is simultaneously "conformative and performative" (155).

Yes, it moves beyond the "simple migration of dance from the stage" (155).

No, this is not necessarily, or even "often," "at odds with choreographic logic" (155), given that choreography may be conceptualized in any number of logics, including fragmented, mediated, or non-linear logics.

Yes to the theories of Noël Carroll, Sally Banes, and Arthur Danto and Rosenberg's application of them; his useful critiques of dance theory; and his brief statement about the uses of naming conventions in visual art (156-157).

No, screendance is not necessarily "equal parts moving image production and dance" (158). It may be extremely unequal for all kinds of reasons relating to intention and production circumstances.

Yes, screendance is "often" seen as "a product of dance" (158), particularly in the film or visual art contexts, though it is also often seen as a product of film or visual art when being discussed by dance makers, dance producers, or dance funding bodies, and hence actually occupies a tenuous position that needs strengthening in all three forms and their theoretical frames.

No, Richard James Allen and I do not propose that "screendance can be defined as 'stories told by the body'" (158). "Stories told by the body" is the descriptor we use for our work and our company, The Physical TV Company. It is a phrase that refers to some of the provenance, genre and intentions of our own work. As a descriptor it could be applied elsewhere, if useful, but only makes sense when applied to dancefilms ${ }^{5}$ that intentionally explore narrative form.

Yes, "it is the screendance director's central challenge to grasp Merleau Ponty's ideas about kinesthetic sensation and Martin's metakinesis" (160).

No, I don't see how Rosenberg can possibly have been in enough screendance making scenarios other than his own to substantiate the claim that "the act of making a screendance often becomes ritualistic." Perhaps he means his process of making screendance often becomes ritualistic? The series of claims qualified by "often" on pages 160 and 161 perhaps also warrant wider research data.

Yes, the camera may be "a prosthetic for seeing" (162), though Rosenberg could acknowledge his debt to Dziga Vertov's notion of the Kino-Eye for this thought, thus situating his own theories in closer dialogue with film and film theory. ${ }^{6}$ 
No, to say that a work of screendance "perpetuates Mulvey's notion of the male gaze in its often-sexualized depictions of women" (164) is to misunderstand the point that film theorist Laura Mulvey makes in her controversial 1975 paper. Mulvey's argument, as quoted by Rosenberg, is that in Hollywood narrative films, women's "visual presence tends to work against the development of a storyline, to freeze the flow of action in moments of erotic contemplation" (163). However, it is important to note that screendance does not necessarily use the formal devices of Hollywood storytelling to which Mulvey refers. In fact, screendance is often not narrative and even when it is, it is rarely primarily so-it more often favors moments of contemplation (erotic or otherwise) of the body or image in motion, rather than the development of a causal chain of a narrative, as its primary meaning making experience?. Thus Mulvey's concern about contemplation "working against the development of a storyline" is irrelevant, even contradictory to the form.

No, to say that screendance "perpetuates the notion of the male-gaze even in films made by women" (163) is not simply incorrect, it is wrong. Yes, women filmmakers may frame women, and men, and water, and mud, and so on and so on erotically, but that does not make their gaze, or that of their female audiences, "male."

Finally, no, "the camera is not a carnivore" (170), it is a recording device or even a prosthetic for seeing. To assert that it is categorically a carnivore denies the potential of Rosenberg's own proposition that screendance is, or could be, "a site for a kind of liberated body" (169). If a screendance will necessarily involve a camera and if the carnivorous camera consumes the body, well, how then can the body be liberated? The proposition that screendance may be a site for a liberated body is more useful to the development of creative practice and connoisseurship than the slipped metaphor which suggests that it cannot be.

\section{"Yes. And..."}

As noted above, Douglas Rosenberg's stated intention is to locate screendance within the "larger frame of visual arts"(13). Yes. And... there is an equally rich vein of creativity and theorizing in cinema that would strengthen this book's claim for an inclusive theory of screendance. By repeatedly characterizing cinema as "spectacle" and "entertainment" and aligning this characterization with Yvonne Rainer's puritanical manifesto against spectacle (143), Rosenberg limits the potential of his critical discourse on screendance to advance connoisseurship. Equating cinema as a whole with spectacle or entertainment is like equating art as a whole with prettiness or decoration. Where is this framework's reference to the cinema movements that have been so influential both on art and on screendance? Where is the discussion of the influence of Soviet Montage ${ }^{8}$ on kinesthetic filmmaking; of German Expressionism on fantastical spaces and bodies; of Italian Neorealism on the long take, the use of non-professionals and real places; of the poetic, associative and philosophical filmmaking of the French "Left Bank"; of Cinéma vérité and the act of observation; of reflexive documentary and documentary hybrids that would have a fascinating intersection with Marcel Duchamp's notion of the "readymade" (95); of the cinematic images of memory, time and space created by artists such as Ingmar Bergman, Federico Fellini, Alain Resnais, and Marguerite Duras; of the contemporary developments in "subjective realism" that radically challenge cinematic form; ${ }^{9}$ and so on? 
Given these absences, perhaps what is needed is another book, an "and" to Screendance: Inscribing the Ephemeral Image. Rosenberg provides a useful resource for understanding, analyzing, and extending the creative practice of screendance, one that has its provenance in visual art or overlaps with the concerns of visual art more so than with the concerns of cinema. As such, this book is an outstanding contribution to theorizing the form. Each chapter provides some "forensic evidence" (47) of the overlapping frameworks of selected screendance works and the visual arts. In the end, Rosenberg "maps out a new territory for pedagogy inclusive of the histories of the visual arts" (11) and, though he does not do the same for cinema driven screendance, ${ }^{10}$ he succeeds for visual art driven screendance in providing a resource for academics, practitioners, and curators to "blend the legacies of the historical and contemporary practice of screendance into the cannons of both dance and visual arts" (180).

\section{Notes}

1. See Johnstone, Impro for Storytellers.

2. See Pearlman, "A dance of definitions." See also: http://www.dancefilm.co.uk/about/about-screendance and http://movetheframe.wordpress.com/2009/05/20/creating-a-lexicon-for-screendance/ among other citations for this taxonomy.

3. Though I would add "intended affect on audience" under intent, as this is a key determinant in film, of genre, and of formal qualities.

4. See Bordwell and Thompson, "Narrative as a Formal System."

5. "Dancefilm" is the preferred designation for the sub-genre of screendance that draws its lineage from film practices rather than visual art practices, and notably as a designation it is absent from the entire book. This is also notable given that it is used in one of the key existing texts in screendance theory: Dancefilm: Choreography and the Moving Image, by Erin Brannigan.

6. See Vertov, Kino-Eye.

7. Further, screendance is not definitively "voyeuristic" cinema, which is the subject of Mulvey's paper. For a discussion of the difference between voyeuristic and exhibitionist cinema and the different ways in which these two types position the spectator's "gaze" see Pearlman, "If a dancer falls."

8. There is a reference to Sergei Eisenstein on page 59 that attributes Eisenstein's extraordinarily prolific insights on the nature of film and cinema to the influence of Cubism, which was influential, but not formatively so, unlike, among other things, Eisenstein's work with the theories of physical theatre practitioner Vsevolod Meyerhold.

9. See Campora, Subjective Realist Multiform Cinema.

10. Chapter Two, "Mediated Bodies: From Photography to Cine-dance," is Rosenberg's most substantial nod to cinema and it confines itself to early cinema and Charlie Chaplin before claiming the Surrealists and Maya Deren as visual artists and moving on to video art. 


\section{References}

Berry-Fint, Sarah. "Genre." In A Companion to Film Theory, edited by Toby Miller and Robert Stam, 25-44. Malden, MA: Blackwell Publishing, 2004.

Bordwell, David and Kristin Thompson. "Narrative as a Formal System." In Film Art, An Introduction, $10^{\text {th }}$ Edition, 89-108. New York: McGraw Hill, 2012.

Brannigan, Erin. Dancefilm: Choreography and the Moving Image, New York: Oxford University Press, 2011.

Campora, Matthew. Subjective Realist Multiform Cinema. New Milford, CT: Berghahn, 2013.

Cook, Pam and Mieke Bernink, eds. "New Hollywood, Art Cinema, East Asian Cinema, Avant-Garde and Counter Cinema." In The Cinema Book, 98-120. London: BFI, 2007.

Fisher, Lucy. "Film Editing." In A Companion to Film Theory, edited by Toby Miller and Robert Stam, 64-83. Malden, MA: Blackwell Publishing, 2004

Johnstone, Keith. Impro for Storytellers, New York: Routledge, 1999.

Pearlman, Karen. "If a dancer falls in the forest and nobody sees her..." Participations 7, no. 2 (November 2010). http://www.participations.org/Volume\%207/Issue\%202/special/pearlman.htm.

. "A dance of definitions." RealTime 74 (Aug-Sept. 2006). http://www.realtimearts.net/article/issue74/8164.

Stam, Robert. "Alternative Aesthetics." In A Companion to Film Theory, edited by Toby Miller and Robert Stam, 257-264. Malden, MA: Blackwell Publishing, 2000.

Vertov, Dziga. Kino-Eye, The Writings of Dziga Vertov. Edited by Annette Michelson. Berkeley: University of California Press, 1984. 



\title{
Epilogue: After Deren
}

\author{
Elinor Cleghorn
}

M

y eyes are locked with his, but around the edges, the iris of my vision, there is a circle of dancing movement. There is, encircling us, also, a cylinder of song and deep beats. And there is a third unseen, unheard circle about us, too ... a tension, a watching ... And we two, dancing in the center. I dance as I have never danced before. It is not more violent, nor more expertly, cleverly achieved. It is simply correct in a very final sense, in the fact that there is neither decision nor triumph, but only the immaculate execution of an inevitability. Yet, I feel as if a transparent level of consciousness were superimposed upon this reality; that there is something about these movements which is still my own; in the shorter length of my limbs, in the longer drop of my hair, in some attitude of my fingers which articulates my own singular history of ecstasy and pain.'

Maya Deren wrote this passage, or something close to it, in her diary in 1947, while in Haiti on the first of her several trips to observe, film, record, and participate in the rituals of Voudoun. The passage describes her inauguration into the rhythms of possession: induced by dance, compelled by drum and song. She published a very personal account of this "first contact with Voudoun,"2 based on these diary notes, in December 1948 in the important yet short-lived art and literature magazine The Tiger's Eye. Titled "The Artist as God in Haiti," Deren's contribution was included with others by Max Ernst, Joan Miro, Georges Bataille, Robert Motherwell, and Mark Rothko, to name only a few. Barnett Newman acted as the magazine's art director for its second and third issue, and his renowned essay "The Sublime is Now" was originally published alongside Deren's piece. The Tiger's Eye was named after William Blake's 1794 poem "The Tyger." It focussed on artists' own reflections on their processes, imposed no particular editorial framework, and sought to foster a sympathetic yet critical readership. The inclusion of Deren's diary-based account as exemplary of such a journalistic metier goes some way towards countering the claims of P. Adams Sitney and Stan Brakhage that her fascination with Voudoun "essentially ... destroyed her as an artist."3 The editors of The Tiger's Eye, painter John Stephan and his wife Ruth, provided a context for Deren's meditations on Voudoun that was attuned to the significance she afforded to her participatory involvement with ritual activity. For Deren, possession was process. It enabled her to inhabit the modes of intense expression that she sought to "convert," to borrow Stephen Heath's term, into her cinema. ${ }^{4}$ With her Bolex in hand and her eye behind its lens, she indeed dared, as William Blake imagined, "to frame" ritual's "fearful symmetry."

In her lifetime Deren published methodological and theoretical essays, statements on filmic form, and comments on her own films across a variety of other journals and magazines, including New Directions, Daedalus, and Mademoiselle. The year after her death, the New York-based journal Filmwise dedicated an issue to memories of Maya. The impact of her loss reverberates through the celebratory, anecdotal, and poetic eulogies by Brakhage, Rudolph 
Arnheim, Willard Maas, Parker Tyler, Charles Boultenhouse, and Jerry Tallmer, amongst others. This 1962 publication is a poignant commemoration of Deren by the community of artists and writers with whom she was not only professionally but also personally connected. At the same time, it documents a very particular moment in time, when the journal served as the ideal format for the galvanisation of collective energies circulating around the production and presentation of independent and experimental cinema.

This issue of The International Journal of Screendance is dedicated to Deren some fifty years after the New York filmic avant-garde memorialised her as their peer, agent, mobiliser and "mother." Our title, "After Deren," exemplifies the extent to which, at this particular moment in time and within the ever-expanding context of screendance's own galvanic energies, Deren's legacy continues to reverberate. It seems fitting, therefore, to reflect in epilogue upon the way that the journal, a conversational format, a gathering of voices, so appositely enables a retracing of the contours, as Claudia Kappenberg puts it, of the "multifaceted crystalline figure we call Deren."

I dance opposite one woman, then a man, then a girl, then another. They seem to wish to mirror with me, and there is a curious graciousness in my accepting and permitting this with one then another, for these are the preliminaries in some act which, in its accomplishment, will bless all those who have partaken of it ... suddenly our mirroring movements slip into the accord of complete unity. Meaning takes flight from mile post to mile post. The cadence of the singing is sharper and sharper... My left foot seems rooted and I try not to fall but when I do it is without fear. People hold me up. I feel my shoes being removed. Then I am stood up again like a doll set on its own feet ... My reaching arms meet a voice and cling to it and that which has been travelling up my leg reaches my mind and obliterates it. ${ }^{6}$

At the time of writing 'The Artist as God in Haiti' Deren had advanced her "choreocinema" from the elliptical, solo male dance of A Study in Choreography for Camera, to the mythological dance-drama Ritual in Transfigured Time (1945/46) and the dualistic, parabolic Meditation on Violence (1948). Deren came to filmmaking with a lifelong love for dance, and a closely held academic interest in ritual dance forms. As the editors of The Legend of Maya Deren emphasise, the favourable response to Study by dance critics such as Walter Terry, as well as John Martin, whose public enthusiasm for Deren's innovations bore the term "choreocinema," significantly expanded her audiences, and compelled her to further pursue the possibilities for the radical enmeshment of dance and film. At the time of its release, Study provoked generative debates within the spheres of dance and film criticism. While Study was neither the first example of dance in cinema, nor the inauguration of filmmaking as a choreographic practice, it was nonetheless an exceptionally provocative catalyst for the opening up of conversations across disciplines about the "potentialities of the dance in motion pictures." In Dance Observer magazine in 1946 the sculptor Richard Lippold exalted Study as the "first conscientious and consistent effort" to use the technological specificities of the filmic apparatus to free the dancing body from the "earth bound" limitations of space, time and physicality. In Film News earlier that year, writer and producer Newton Melzer celebrated Deren's evolution of "a new choreographic concept, one that stems from the camera's mobility and versatility and her own editing principles." The journalist Louise Levitas, also in 1946, found in the floating leaps and "strange, spiral turns" of Study a "kind of magic," and marvelled at the ways Deren's camera movements embodied those of her dancer..$^{10}$ These and other responses appeared in various journals 
and magazines in the months preceding Deren's first public solo screening at New York's Provincetown Playhouse.

Taken together, these writings emblematise the ways that Deren's emancipation of the strictures of theatrical dance through the capacities of cinema instantiated "choreocinema," "filmic dance," and "dance film" as subjects of discourse. This issue of The International Journal of Screendance is testament to the continuing capacity of Deren's cinema to further the parameters of a mode of discourse that her specific approach, at that very particular time, undeniably mobilised. Furthermore, the essays, interviews and reviews in "After Deren" reflect the ways that Deren's treatment of film as dance has yielded, and will continue to yield, multiconversational, inter-disciplinary, ever-moving formulations of screendance as discourse.

"After Deren" is, in many ways, the continuation of a series of conversations: of those unfolding between artists, academics and audiences at the BFI season Maya Deren: 50 Years On; of those which heralded Deren as the proponent of a "virtually new medium" in 1946; of those opened up by the contributions to Maya Deren and the American Avant-Garde; and of those instantiated by the inclusion of Deren's writings in journals and magazines across disciplines during and after her life. Most importantly, this issue focuses on Deren in order to continue the conversations happening right here, within The International Journal of Screendance, "a living space for serious, lively, on-going debate about the art form."11 Deren might not be the "mother" of screendance, but she is undoubtedly one of the art form's most illuminating cynosures. In the orbit of this issue she guides a constellation of satellites. Sophie Mayer and Lucy Reynolds extend their conversations from the BFI symposium Maya Deren: New Reflections; Silvina Szperling and Narcisa Hirsch speak to us from Buenos Aires; Sarah Keller and Barbara Hammer from New York; Aura Satz and Jayne Parker from London; Andrew James from Plymouth; Eleni Tranouli from Paris; Harmony Bench from Ohio; Douglas Rosenberg from Madison, Wisconsin; and Claudia Kappenberg from Brighton.

By offering these rich, original, insightful and reflective interpretations of Deren's resounding relevance in The International Journal of Screendance, we are by no means enclosing her legacy within any pre-determined parameters, which might be imposed to dogmatically define "screendance." Rather, as editors Douglas Rosenberg and Claudia Kappenberg elucidated in their editorial comment for Volume 1, "we have chosen to use the term screendance to broadly describe a field, while noting that there are no hard and fast criteria for a definition of screendance." Within this open, thoughtful, yet critically rigorous context, readings and analyses of Deren's filmmaking methodologies, theoretical and personal writings, ethnographic practices, advocacy of cinema as art, and activism for independent practice contribute to the furthering of "screendance as a form of research," precisely because neither Deren's cinema, nor screendance, is limited to the constitution of dancing bodies as cinematic entities. "After Deren" exemplifies the journal's ambitions to explore screendance as a locus for the examination of "the interrelationships of composition, choreographic language, and meanings of body, movement, space, and time ... in the context of contemporary cultural debates about artistic agency, practice as theory, and interdisciplinarity." ${ }^{12}$ It has been a privilege to have a hand in the choreography of this special issue-for the process of planning, editing and compiling a journal, particularly one for which movement is the medium, is akin to a choreographic act. From its roots in the Ancient Greek word khoreia meaning both the dance itself and the circular enclosure in which it takes place, choreography resounds in chorus. The choreographic intention of 
"After Deren" is not to encircle but to circulate Maya Deren, through the scholarly re-visions, theoretical examinations, artists' interviews and reviews, all of which, we hope, will resonate. Thank you to all our contributors for your generosity of thought and time. We look forward to continuing the conversation.

The form is complete. In the tiny room neither of us is ourselves. He, knowing, and I, learning through a tuning stretched tight to the most subtle expectation, realize in collaboration a complete, a perfect mythology. To achieve the impersonal perfectly is a personal triumph...13

\section{Notes}

1. Deren, "The Artist as God in Haiti," 118, 119.

2. Ibid.

3. Brakhage, Film at Wit's End, 111. See also P. Adams Sitney, Visionary Film, 40. Sitney purports that Deren's art "diminished" when she moved from "the powerful element of psycho-drama" towards the embodiment of ritualistic principles in Meditation on Violence (1948) and The Very Eye of Night (1955), her final two films made in the midst of her participatory thrall to Voudoun.

4. Heath, Questions of Cinema, 179.

5. The final stanza of Blake's "The Tyger": "Tyger! Tyger! burning bright/ In the forests of the night/ What immortal hand or eye/ Dare frame thy fearful symmetry?" See Blake 51.

6. Deren, "The Artist as God in Haiti," 119.

7. Leaf, "Loose Leaves from a Dance Notebook," 285.

8. Lippold, “Dance and Film," 59.

9. Melzer, "Three Abandoned Films," 390.

10. Levitas, "How to Make Your Own Movies on a Shoestring," 16.

11. Editorial comment, The International Journal of Screendance, 3-4.

12. Ibid., 1.

13. Deren," The Artist as God in Haiti," 123

\section{References}

Blake, William. "The Tyger" (1794). In Songs of Innocence and Songs of Experience, edited by David Price. London: R. Brimley Johnson, 1901.

Brakhage, Stan. Film at Wit's End. New York: Documentext/McPherson and Company, 1989.

Clark, VèVè, Millicent Hodson, and Catrina Neiman. The Legend of Maya Deren:Documentary Biography and Collected Works. Vol. 1, Part 2, "Chambers" (1942-47). New York: Anthology Film Archives, 1984.

Deren, Maya. "The Artist as God in Haiti." The Tiger's Eye 1, no. 6 (December 1948): 115-24.

Heath, Stephen. Questions of Cinema. London: Macmillan, 1981.

Kappenberg, Claudia and Douglas Rosenberg. "Editorial Comment: Screendance: Practice in Print." The International Journal of Screendance 1 (Summer 2010): 1-4.

Leaf, Earl. "Loose Leaves from a Dance Notebook." Dance Magazine (July 1945). In The Legend of Maya Deren: Documentary Biography and Collected Works. Vol. 1, Part 2, "Chambers" (1942-1947), edited by Clark et. al., 285. New York: Anthology Film Archives, 1984

Levitas, Louise. "How to Make Your Own Movies on a Shoestring." P.M. (Tuesday, March 19, 1946): 16.

Lippold, Richard. "Dance and Film: A Review in the Form of a Reflection." Dance Observer (May 1946): 58-60.

Melzer, Newton E. "Three Abandoned Films." In The Legend of Maya Deren: Documentary Biography and Collected Works, Vol. 1, Part 2, "Chambers", edited by Clark et. al., 389-391. New York: Anthology Film Archives, 1984.

Sitney, P. Adams. Visionary Film: The American Avant-Garde, 1943-2000. Third edition. Oxford: Oxford University Press, 2002. 


\section{Contributors}

Andrea Barzey is Associate Head of Performing Arts and Senior Lecturer in Dance at Coventry University, and is engaged in research into the dancing body on screen. Her films have been shown throughout the UK and Europe. She is currently involved in digital pedagogical research, which includes D-TRACES. Website: http://dancetraces.wordpress.com/.

Harmony Bench is Assistant Professor of history and theory in the Dance Department at The Ohio State University, where she teaches in the areas of Dance, Media, and Performance Studies. She completed her PhD in Culture and Performance at UCLA, and holds additional degrees in Performance Studies, Women's Studies, and Ballet. Harmony researches the impact of media technologies on movement, gesture, choreography, and cultural belonging in dance onscreen. Her writing can be found in Dance Research Journal, The International Journal of Performance Arts and Digital Media, Participations, The International Journal of Screendance, and a number of forthcoming edited volumes. In addition to publishing essays on net.art, viral videos, flash mobs, mobile media, dance on television, and dance video games, she is working on a book manuscript that addresses dance in digital cultures after the social turn.

Elinor Cleghorn is a writer, lecturer and film curator. She recently completed her PhD at the London Consortium, Birkbeck College, UK with a thesis exploring the embodied uses of technology in the choreographic cinema of Maya Deren, Lotte Reiniger, and Loïe Fuller. Elinor curated the British Film Institute season Maya Deren: 50 Years On, and has given talks on Deren's films and writings at Camden Arts Centre, Nottingham Contemporary, and the Moves festival at Manchester Metropolitan. She has participated in a variety of international research events and symposia, and has been invited to speak on panels at BFI, ICA London, and Tate Modern. Elinor lectures on visual art and performance at the University of Brighton, critical studies at Central St. Martins, and has contributed to The International Journal of Screendance and The Moving Image Review and Art Journal.

Barbara Hammer is a visual artist primarily working in film and video. She was recently honored with retrospectives at the Museum of Modern Art in New York City (2011), Tate Modern, London (2012), and the Jeu de Paume, Paris (2012). Her work reveals and celebrates marginalized peoples whose stories have not been told, and it engages an audience viscerally and intellectually with the goal of activating them to make social change.Her trilogy of documentary film essays on lesbian and gay history (Nitrate Kisses [1992], Tender Fictions [1995], History Lessons [2000]) has received numerous awards. More recently, her films A Horse Is Not A Metaphor (2009), Generations (2010), and Maya Deren's Sink (2011) were awarded Teddy Awards for Best Short Film at the Berlin International Film Festival. HAMMER! Making Movies Out of Sex and Life, a book of memoirs and personal film theory, was published by The Feminist Press, City University of New York, and Fearless Frames: The 
Films of Barbara Hammer at The Tate Modern will be released by Mousse Publishing, Milan, Italy in 2013.

Born in Berlin, Germany, in 1928, Narcisa Hirsch has been living in Argentina since her childhood. A pioneer of Argentinian experimental cinema, she expanded her activities in the '60s and'70s into installation art, objects, performances, graffiti, and urban intervention. In her work, Hirsch explores themes such as love, birth, and death, and interrogates the female condition through an intimate visual language and through personal audio-visual poetry. She has made more than 30 films to date in super $8 \mathrm{~mm}$ and $16 \mathrm{~mm}$, including Come Out, A-Dios, Ama-zona, Bebes, Mujeres, Homecoming, Pioneros, Ana Donde Estas, La Pasión, Testamento y Vida Interior, Rumi, El Mito de Narciso, and Aleph. Her work was featured in the Viennale, Vienna International Film Festival 2012.

Polly Hudson is Co-Course Director for Dance and Senior Lecturer at Coventry University, specializing in improvisation and in dance and the moving image. Her performance and dance film works have been shown in the UK, United States, and Europe. She is a certified teacher of the Skinner Releasing Technique, and is book review editor of the Journal of Dance and Somatic Practices.

Andy James is an artist working with film, installation, and performance. He graduated from the London College of Printing (now LCC) with a BA (Hons) Film, Video and Photography, and subsequently trained in performance. He has over 20 years of experience as a freelance artist and filmmaker working both in the UK and internationally, and currently teaches on the BA Film at Plymouth College of Art in the UK. His research focuses on transdisciplinary strategies in experimental film.

Claudia Kappenberg is a performance and visual artist and principal lecturer in the School of Art, Design and Media at the University of Brighton, UK. Claudia leads the international AHRC Screendance Network and is co-founder and editor of The International Journal of Screendance. She co-curated the What If Festival, London in 2010. Her writing has been published in The International Journal of Performance Arts and Digital Media and Anarchic Dance (Routledge, 2006), among other places. Her performance projects comprise single screen work as well as screen-based installations and live site-specific events and have been shown across Europe, the United States, and the Middle East. Website: www.ckappenberg.info and http://www.whitemarket.de/

Sarah Keller is Assistant Professor of English and Cinema Studies at Colby College in Maine, USA. With Jason Paul, she co-edited Jean Epstein: Critical Essays and New Translations (Amsterdam University Press, 2012), and her current book project, Incomplete Control: Maya Deren's Unfinished Business, studies the role of incompletion in Maya Deren's work.

Sophie Mayer is the author of The Cinema of Sally Potter: A Politics of Love, and co-editor of There She Goes: Feminist Filmmaking and Beyond (with Corinn Columpar) and The Personal is Political: Feminist Documentary (with Elena Oroz). A regular contributor to Sight \& Sound, she also writes about film for The F-Word, and recently co-edited Catechism: Poems for Pussy Riot. Website: www.sophiemayer.net. 
Jayne Parker is an artist and filmmaker living and working in London. Her work has been widely shown, both nationally and internationally, in major art institutions, on television, and in film and music festivals. In 2003 she was the recipient of the 1871 Fellowship, researching the relationship between music and film, hosted by the Ruskin School of Drawing, Oxford and the San Francisco Art Institute. Much of her recent work features the performance of music. In 2008, a DVD compilation of her film works was released by the British Film Institute in their British Artists' Film series. Her films are distributed by LUX (www.lux.org.uk) and she teaches at the Slade School of Fine Art, University College London, where she is Head of Graduate Fine Art Media.

Dr. Karen Pearlman is currently Head of Screen Studies at AFTRS, Australia's national screen arts and broadcast school. She is the author of Cutting Rhythms, Shaping the Film Edit (Focal Press) and co-artistic director, with Richard James Allen, of the multi awardwinning dancefilm production company Physical TV (www.physicaltv.com.au). In addition to being a film editor and former dancer (Bill T.Jones/Arnie Zane Company) Karen has edited a number of issues of Lumina, the Australian Journal of Screen Arts and Business, and has written about screen, dance, and screendance for various publications and academic journals. She is currently directing and editing a new form choreographed documentary: "The Dancer from the Dance."

Lucy Reynolds is an artist, film lecturer and curator. Her articles on artists' moving image have appeared in journals such as Afterall, Millenium Film Journal and Tate Etc, and she has curated film programmes for museums and galleries such as Tate Modern and Mukha, Antwerp. She teaches the history and theory of cinema and artists'moving image at Central St. Martins, Kingston University, and Goldsmiths College, London. Her own films, performances, and installations have been shown at the National Film Theatre and galleries in London and Europe.

Douglas Rosenberg is Professor of Art at the University of Wisconsin-Madison and the editor of the forthcoming Oxford Handbook of Screendance Studies (Oxford University Press). Professor Rosenberg has helped to shape the discourse of the field of screendance through his published writing, the organization of conferences, the founding of a longstanding international screendance festival, and as the co-editor of The International Journal of Screendance. He is the author of the recent book, Screendance: Inscribing the Ephemeral Image (Oxford), which situates screendance in the wider discourse of the visual arts, performance, and film studies. His screendance work has been recently exhibited at the Lincoln Center, NY; Kennedy Center, Washington, DC; Manipur, India; Findhorn, Scotland; Sao Paulo, Brazil; London, England; Buenos Aires, Argentina; Kowloon, Hong Kong; Guangzhou, China; and Kowloon, Hong Kong.

Aura Satz has performed, exhibited, and screened her work nationally and internationally, including at the Rotterdam film festival (Rotterdam); the Zentrum Paul Klee (Switzerland); Färgfabriken (Stockholm); Wundergrund Festival (Copenhagen); Frieze Art Fair NY (New York); Tatton Park Biennial (Cheshire); AV festival (Newcastle); Arnolfini (Bristol); Ikon gallery (Birmingham); FACT (Liverpool); Site Gallery (Sheffield); Galleria Civica di Arte Contemporanea di Trento (Italy); De La Warr Pavilion (Bexhill-on-Sea); BFI Southbank, Whitechapel Gallery, the Victoria \& Albert Museum, Barbican Art Gallery, ICA, Jerwood 
Space, Tate Britain, Beaconsfield Gallery, Artprojx Space, the Wellcome Collection and the Tate Tanks (London). During 2009-2010 she was artist-in-residence at the Ear Institute, UCL. In 2012 she was shortlisted for the Samsung Art award and the Jarman award. Forthcoming exhibitions include a solo show at the Hayward project Space (London), at Paradise Row gallery (London), and "Curiosity: Art and the Pleasures of Knowing," as part of the Hayward Touring exhibition. Her projects can be seen online at www.iamanagram.com.

Born in Buenos Aires, Argentina, Silvina Szperling has choreographed since the' 80 s, both for the stage and site-specific pieces. In 1993 she made her first videodance, Temblor, which received the "Best Editing" Prize in Argentina and which is held at the New York Public Library's Dance Collection. In 1995 she founded the International Festival VideoDanzaBA, and is founding member of Latin American Forum of Videodance. She currently teaches at the Arts Criticism Department at IUNA (Instituto Universitario Nacional del Arte). Silvina contributed to Envisioning dance on Film and Video (Routledge, NY-London), is co-editor of Terpsícore en ceros y unos. Ensayos de Videodanza (Guadalquivir, Buenos Aires, 2010) and has written for Página/12 (Buenos Aires), La Opinión (Los Angeles), and Dance Magazine. Her videodance, Chámame (2008), was awarded First Prize at "La mujer y el cine" contest, Third Prize at "La noche del cortometraje" (Buenos Aires), Best Performance Prize at festival Tápias (Rio de Janeiro), and First Prize in its category at "Cinedans/IMZ" (Amsterdam).

Eleni Tranouli is a postgraduate student in film studies at the University of Sorbonne Nouvelle-Paris 3. A graduate of the School of Architecture at the Aristotle University of Thessaloniki in 2009, Tranouli has also received training in painting, photography, and theater. She has participated in numerous exhibitions in Greece and has collaborated with the experimental group "Living Theater." She is currently pursuing research under the direction of Nicole Brenez, on the theoretical body of work of Maya Deren, which she is translating into French. For the purposes of her MA thesis she also studied the filmmaker's papers at Howard Gotlieb Archival Research Center and the Anthology Film Archives.

Fiona Wright is an independent artist who has been making performances since the late 1980s, working through choreography, writing, and installation. Solo work includes a series of close-up and 'one-to-one' performances, several performance lectures, a practice-based PhD project (2005). Ongoing collaborations include a duet with Caroline Bowditch as girl jonah, and the History Dances projects with video artist Becky Edmunds. Fiona is training to teach the Feldenkrais Method and has long experience teaching in higher education. She is now working in a freelance capacity, including being invited as visiting artist in Performance at the School of the Art Institute of Chicago (2007). She has also worked with Simone Aughterlony (Zurich/Berlin) as dramaturge and performer and was a performer in Entitled, a theatre piece by Quarantine (UK). Website: fionawright.org.

Marisa Zanotti is an award winning artist who creates moving image work. Recent projects include the first choreographic smartphone app with Ben Wright, and the documentary Edits Film with Lea Anderson and The Featherstonehaughs. She is currently working with Charlie Morrissey on Plans of the 10th Floor, a moving image installation in a Luton Van. Marisa is on the faculty at University of Chichester where she teaches choreography, screendance, and improvisation. Website: www.marisazanotti.com. 


\section{UW-Madison Dance Department}

Innovators in the field of dance, a world class faculty, state-of-the art facilities, developing well-rounded artists for the global \& technological community. Located near Wisconsin's state capitol \& downtown Madison. BS and BFA tracks in Dance and Choreography/Performance. Offering students options to pursue double majors or engage more deeply in dance studies.

www.dance.wisc.edu | 608.262.1691

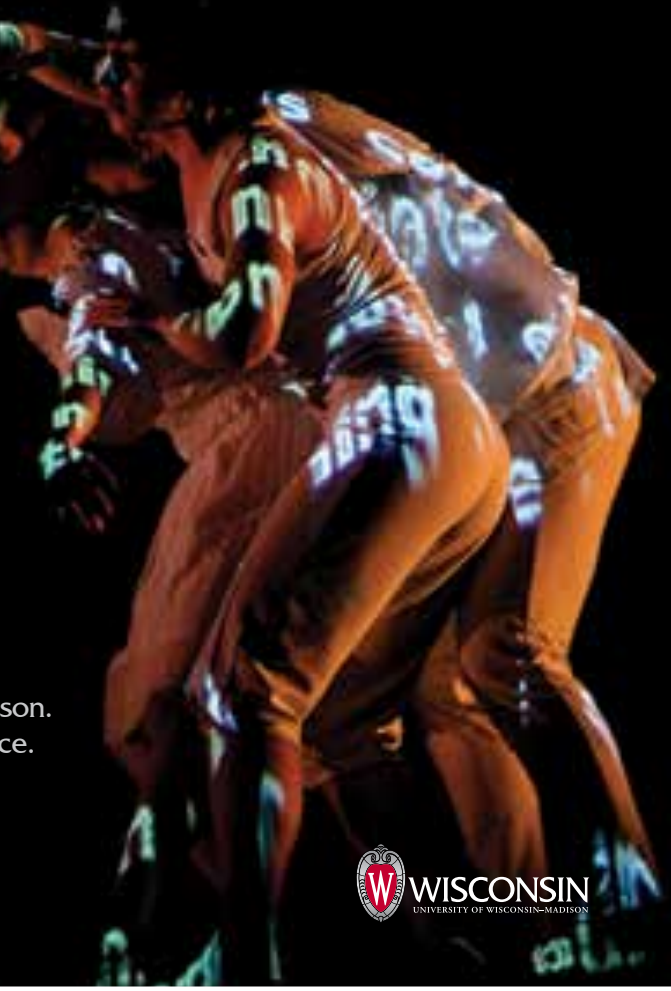

次

\section{University of Brighton}

Faculty of Arts

\section{Performance and Visual Practices MA}

Based in the heart of one of Europe's most vibrant and creative cities, Performance and Visual Practices MA is a unique interdisciplinary programme that facilitates practical and theoretical research across a wide spectrum of performance and the visual arts, such as live sitespecific performance, screendance, sound art and installation. Study full- or part-time on this innovative UK masters degree.

Find out more

samadmissions@brighton.ac.uk www.brighton.ac.uk/arts arts.brighton.ac.uk/screendance

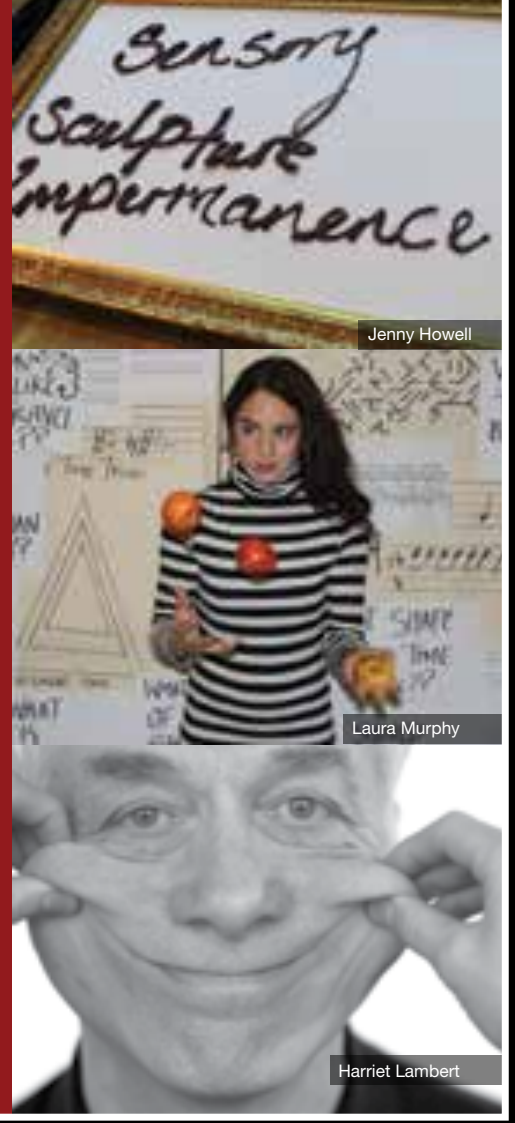

